UNIVERSIDADE DE SÃO PAULO

ESCOLA DE ENGENHARIA DE SÃO CARLOS

DEPARTAMENTO DE ENGENHARIA DE ESTRUTURAS

TOMAZ GURGEL DALL’ ACQUA

Estudo teórico e experimental de ligações parafusadas em chapas onduladas de silos cilíndricos metálicos

São Carlos 
TOMAZ GURGEL DALL' ACQUA

\title{
Estudo teórico e experimental de ligações parafusadas em chapas onduladas de
} silos cilíndricos metálicos

\author{
Versão Corrigida \\ A versão original encontra-se na Escola de Engenharia de São Carlos
}

Dissertação apresentada à Escola de Engenharia de São Carlos da Universidade de São Paulo, para obtenção do título de Mestre em Engenharia Civil (Estruturas)

Orientador: Prof. Titular Carlito Calil Junior

São Carlos 
Autorizo a reprodução e divulgação total ou parcial deste trabalho, por qualquer meio convencional ou eletrônico, para fins de estudo e pesquisa, desde que citada a fonte.

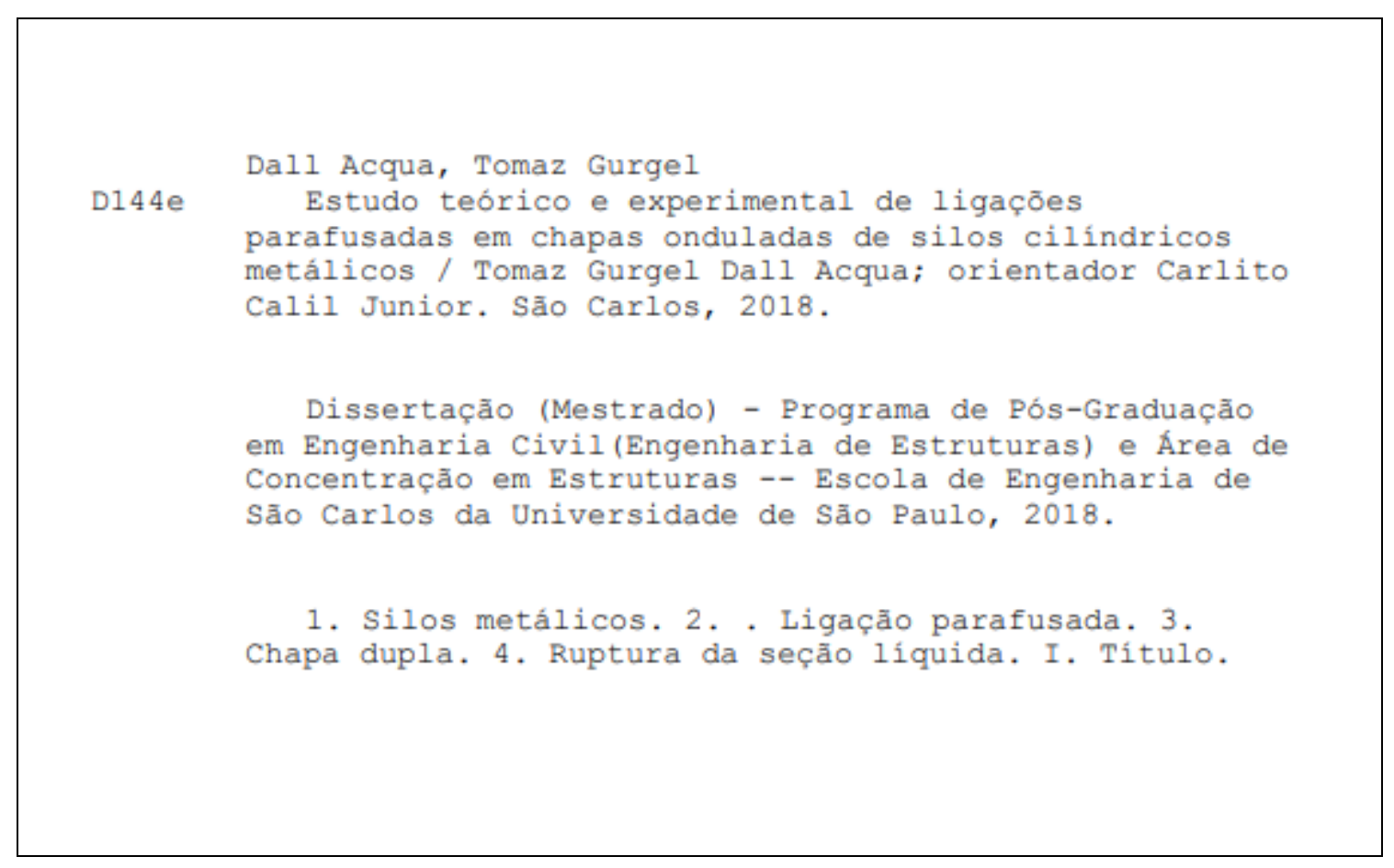




\section{FOLHA DE JULGAMENTO}

Candidato: Engenheiro TOMAZ GURGEL. DALL'ACQUA.

Título da dissertação: "Estudo teórico e exṕerimental de ligações parafusadas em chapas onduladas de silos cilíndricos metálicos".

Data da defesa: 29/03/2018

Comissão Julgadora:

Resultado:

Prof. Titular Carlito Call Junior (Orientador)

APRovisDO

(Escola de Engenharia de São Carlos/EESC)

Prof. Dr. Andrés Batista Cheung

APrQUADQ

(Universidade Federal de Mato Grosso do Sul/UFMS)

Prof. Dr. José Wallace Barbosa do Nascimento

Appouned

(Universidade Federal de Campina Grande/UFCG)

Coordenador do Programa de Pós-Graduação em Engenharia Civil

(Engenharia de Estruturas):

Prof. Titular Humberto Breves Coda

Presidente da Comissão de Pós-Graduação:

Prof. Associado Luis Fernando Costa Alberto 


\section{AGRADECIMENTOS}

Ao prof. Tit. Carlito Calil Junior, pela excelente orientação, encorajamento e profundo saber que nortearam a condução deste trabalho.

À Escola de Engenharia de São Carlos, por todos os recursos de apoio à pesquisa.

Ao Conselho Nacional de Desenvolvimento Científico e Tecnológico, pelo suporte financeiro.

À Kepler Weber Industrial, especialmente ao eng. Marcelo J., pela orientação prática e cooperação com os ensaios experimentais.

Ao Departamento de Engenharia de Estruturas e seus colaboradores, pela formação e por viabilizar este trabalho.

Aos colegas de departamento, pela convivência, especialmente ao Pastori, amigo de todas as horas.

À Iara, minha companheira na alegria e nos momentos difíceis.

À minha família, Beatriz, Nelson e Yara, minha base. 


\section{RESUMO}

\section{DALL ACQUA, T. G. Estudo teórico e experimental de ligações parafusadas em chapas}

onduladas de silos cilíndricos metálicos. 2018. 113 p. Dissertação (Mestrado em Engenharia Civil (Estruturas)) - Escola de Engenharia de São Carlos, Universidade de São Paulo, São Carlos, 2018.

Este trabalho realiza estudo teórico e experimental de ligações parafusadas em chapas finas onduladas, com aço de alta resistência, submetidas a esforços de tração em situação de cisalhamento simples. A aplicação deste tipo de ligação ocorre em paredes de silos cilíndricos metálicos. Também foi avaliada a utilização de montagem com chapas duplas, utilizadas na prática para aumentar a espessura total da parede, devido a demanda por silos cada vez maiores. O programa experimental compreendeu 137 ensaios, nos quais foram variados parâmetros de interesse com aplicações práticas, resultando em dois modos de falha distintos, ruptura da chapa na seção líquida e esmagamento do aço na parede do furo. Foram propostas novas equações para o cálculo da resistência deste tipo de ligação. Os resultados experimentais obtidos mostraram que em ligações com falha por ruptura na seção líquida, reduzir a área líquida à uma área efetiva por meio de um coeficiente redutor resulta em valores conservadores para a resistência deste tipo de ligação. As ligações com chapas duplas apresentaram resistência elevada, superior à condição de chapa simples.

Palavras-chaves: Silos metálicos. Ligação parafusada. Chapa dupla. Ruptura da seção líquida. 


\begin{abstract}
DALL ACQUA, T. G. Theoretical and experimental study of bolted connections in corrugated sheets of cylindrical steel silo. 2018. 113 p. Dissertation (M. Sc. in Civil Engineering (Structures)) - São Carlos School of Engineering, University of São Paulo, São Carlos, 2018.

This work presents a theoretical and experimental study of bolted connections with thin, corrugated, high strength steel sheets, subjected to tension in simple shear condition. This type of connection is applicable in walls of cylindrical steel silos. It also was evaluated the case of double sheet assemblage, that is used in practice to increase the total wall thickness, due to the demand for bigger silos. The experimental program comprised 137 tests, in which it were varied chosen parameters of practical interest, providing failure by net section tension rupture and bearing of the sheet. New equations were proposed for the strength calculation of this type of connection. The experimental results indicated that in connections subject net section rupture, to reduce the net section area to an effective area through a reduction coefficient returns conservative values of resistance for this type of connection. The connections with double sheet exhibited high values of resistance, which resulted bigger than for simple sheet cases
\end{abstract} Keywords: Steel silos. Bolted connection. Double sheet. Net section rupture. 


\section{LISTA DE FIGURAS}

Figura 1 - Componentes de um silo cilíndrico metálico de fundo plano.................................. 18

Figura 2 - Processo de perfilação da chapa corrugada …..........................................................20

Figura 3 - Processo de calandragem da chapa corrugada ...................................................20

Figura 4 - Efeitos do trabalho e frio e do envelhecimento no aço..........................................21

Figura 5 - Chapa corrugada típica utilizada em silos ........................................................22

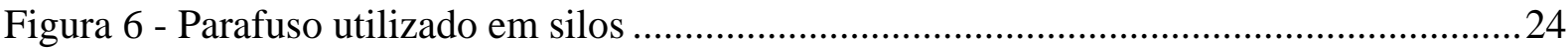

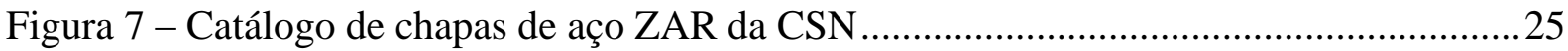

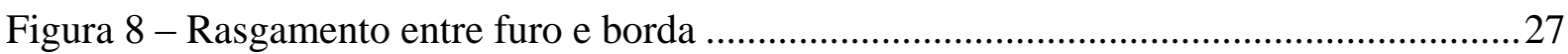

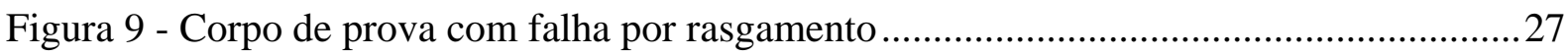

Figura 10 - Esmagamento da chapa junto ao parafuso ......................................................28

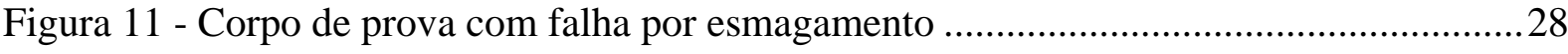

Figura 12 - Esmagamento com deslocamento fora do plano e fratura ..................................29

Figura 13 - Falha por esmagamento com deslocamento fora do plano e fratura.....................29

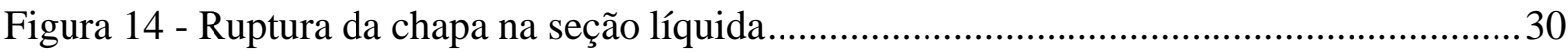

Figura 15 - Corpo de prova com falha por ruptura da seção líquida ...................................... 30

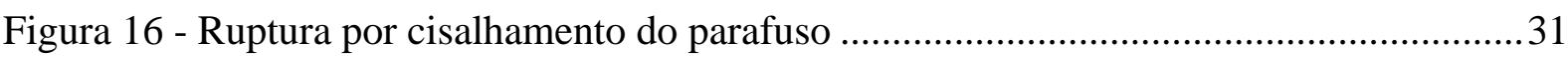

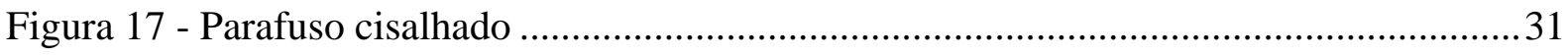

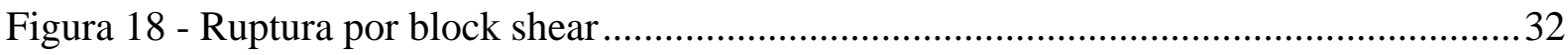

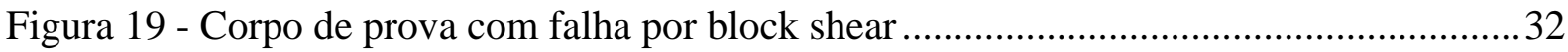

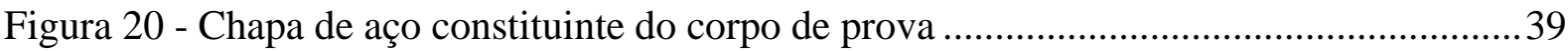

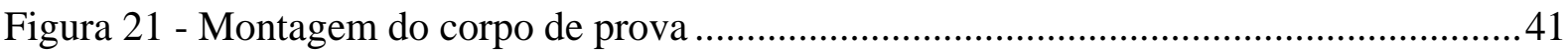

Figura 22 - Corpo de prova com chapa dupla e furação defasada...........................................41

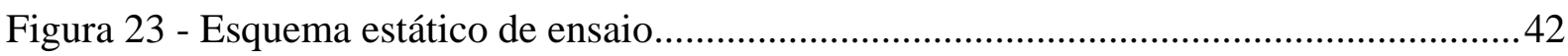

Figura 24 - Exemplo de identificação de corpo de prova ......................................................43

Figura 25 - Parâmetros variáveis nos ensaios de (ESTEVES JR, 1990) ..................................43

Figura 26 - Corpos de prova ensaiados por (ESTEVES JR, 1990) com (a) uma, (b) duas e (c) três linhas de parafusos na direção perpendicular à solicitação ............................44

Figura 27 - Parâmetros variáveis nos ensaios do LE-EESC-USP em maio de 2015 ...............45

Figura 28 - Corpos de prova ensaiados no LE-EESC-USP em maio de 2015 com (a) duas e (b) três linhas de parafusos na direção perpendicular à solicitação

Figura 29 - Parâmetros variáveis nos ensaios do LE-EESC-USP em outubro de 2015 
Figura 30 - Corpos de prova ensaiados no LE-EESC-USP em outubro de 2015 variando (L, C) em (a) $(5,2),(b)(5,3),(c)(4,3),(d)(3,3),(e)(4,4)$ e (f) $(3,4)$ 47

Figura 31 - Parâmetros variáveis nos ensaios do LE-EESC-USP em junho de 2017 ............. 48

Figura 32 - Corpos de prova ensaiados no LE-EESC-USP em junho de 2017 com (a) três e (b) duas linhas de parafusos na direção perpendicular à solicitação ......................... 49

Figura 33 - Lotes de corpos de prova antes do ensaio ...................................................... 50

Figura 34 - Corpo de prova (a) em montagem e (b) prontos para o ensaio ............................ 50

Figura 35 - Corpos de prova com chapa tipo (a) corrugada, (b) plana e (c) montagem em composição dupla..................................................................................... 51

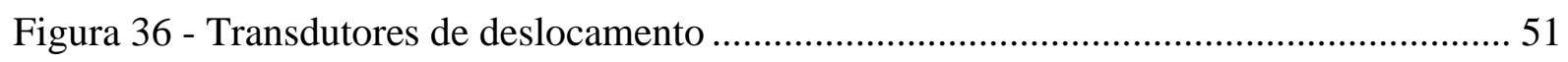

Figura 37 - Corpo de prova para caracterização mecânica do aço ......................................... 52

Figura 38 - Representação da a) prensa, b) extensômetro e c) corpo de prova rompido referentes à caracterização do aço...................................................................... 53

Figura 39 - Máquina de ensaio e sistema de aquisição de dados ........................................... 54

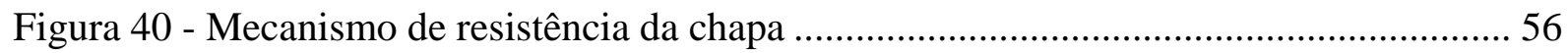

Figura 41 - Corpo de prova com ruptura da seção líquida (a) montado e (b) desmontado..... 57

Figura 42 -Modelo da norma AISI S100-16 e resultados experimentais de ruptura da seção líquida com valores (a) amostrais e (b) em média e desvio padrão ....................... 59

Figura 43 - Corpos de prova variando (L, C) em (a) $(3,4),(b)(4,3),(c)(5,3)$ e (d) $(5,3) \ldots 60$

Figura 44 - Modelo da norma AS/NZS 4600:2005 e resultados experimentais de ruptura da seção líquida com valores (a) amostrais e b) em média e desvio padrão. 64

Figura 45 - Modelo da norma NBR 14762:2010 e resultados experimentais de ruptura da seção líquida com valores (a) amostrais e (b) em média e desvio padrão 68

Figura 46 - Modelo da norma EN 1993-1-3:2006 e resultados experimentais de ruptura da seção líquida com valores (a) amostrais e (b) em média e desvio padrão ............. 72

Figura 47 - Falha por esmagamento da parede do furo ........................................................ 74

Figura 48 - Modelo da norma AISI S100-16 e resultados experimentais de esmagamento com valores (a) amostrais e (b) em média e desvio padrão 76

Figura 49 - Modelo da norma AISI S100-16 e resultados experimentais de esmagamento com valores (a) amostrais e (b) em média e desvio padrão 79

Figura 50 - Modelo da norma NBR 14762:2010 e resultados experimentais de esmagamento valores (a) amostrais e (b) em média e desvio padrão 81

Figura 51 - Modelo da norma EN 1993-1-3:2006 e resultados experimentais de esmagamento com valores (a) amostrais e (b) em média e desvio padrão 83 
Figura 52 - Análise dos ensaios em corpos de prova com chapa de espessura (a) 0,95 mm, (b)

$$
1,25 \mathrm{~mm} \text {, (c) } 1,55 \mathrm{~mm} \text { e (d) } 1,95 \mathrm{~mm} \text {. }
$$

Figura 53 - Efeito da furação coincidente e defasada em corpos de prova com chapas de espessura total (a) 3,10 $\mathrm{mm}$ e (b) 3,90 $\mathrm{mm}$. 


\section{LISTA DE TABELAS}

Tabela 1 - Parafusos de aço com qualificação estrutural segundo NBR 14762:2010 ..............25

Tabela 2 - Intervalos para ruptura da seção líquida pela norma AISI S100-16.......................58

Tabela 3 - Intervalos para ruptura da seção líquida pela norma AS/NZS 4600:2005 .............62

Tabela 4 - Intervalos para ruptura da seção líquida pela norma NBR 14762:2010.................66

Tabela 5 - Intervalos para ruptura da seção líquida pela norma EN 1993-1-3:2006................70

Tabela 6 - Configurações dos ensaios de (ESTEVES JR, 1990)...........................................93

Tabela 7 - Configurações dos ensaios realizados no LE-EESC-USP em maio de 2015 ..........96

Tabela 8 - Configurações dos ensaios realizados no LE-EESC-USP em outubro de 2015 com chapas corrugadas em montagem simples

Tabela 9 - Configurações dos ensaios realizados no LE-EESC-USP em outubro de 2015 com chapas planas em montagem simples 98

Tabela 10 - Configurações dos ensaios realizados no LE-EESC-USP em outubro de 2015 com chapas corrugadas em montagem dupla 98

Tabela 11 - Configurações dos ensaios realizados no LE-EESC-USP em junho de 2017 com chapas corrugadas em montagem dupla

Tabela 12 - Resultados experimentais dos ensaios de (ESTEVES JR, 1990) 100

Tabela 13 - Resultados experimentais dos ensaios realizados no LE-EESC-USP em maio de 2015 103

Tabela 14 - Resultados experimentais dos ensaios realizados no LE-EESC-USP em outubro de 2015 com chapas onduladas em composição simples 104

Tabela 15 - Resultados experimentais dos ensaios realizados no LE-EESC-USP em outubro de 2015 com chapas planas em composição simples

Tabela 16 - Resultados experimentais dos ensaios realizados no LE-EESC-USP em outubro de 2015 com chapas onduladas em composição dupla.

Tabela 17 - Resultados experimentais dos ensaios realizados no LE-EESC-USP em junho de 2017 106

Tabela 18 - Falha por ruptura da seção líquida nos ensaios de (ESTEVES JR, 1990) 107

Tabela 19 - Falha por ruptura da seção líquida nos ensaios realizados no LE-EESC-USP em maio de 2015.

Tabela 20 - Falha por ruptura da seção líquida nos ensaios realizados no LE-EESC-USP em outubro de 2015 com chapa onduladas em composição simples 
Tabela 21 - Falha por ruptura da seção líquida nos ensaios realizados no LE-EESC-USP em outubro de 2015 com chapa planas em composição simples 111

Tabela 22 - Falha por ruptura da seção líquida nos ensaios realizados no LE-EESC-USP em outubro de 2015 com chapa onduladas em composição dupla ..... 111

Tabela 23 - Falha por ruptura da seção líquida nos ensaios realizados no LE-EESC-USP em junho de 2017 112

Tabela 24 - Falha por esmagamento nos ensaios realizados por (ESTEVES JR, 1990) 113

Tabela 25 - Falha por esmagamento nos ensaios realizados no LE-EESC-USP em maio de 2015 


\section{LISTA DE ABREVIATURAS E SIGLAS}

$\begin{array}{ll}\text { ABNT } & \text { Associação Brasileira de Normas Técnicas } \\ \text { ASTM } & \text { American Society for Testing and Materials } \\ \text { BLS } & \text { Block shear } \\ \text { CEN } & \text { European Committee for Standardization } \\ \text { CSN } & \text { Companhia Siderúrgica Nacional } \\ \text { EESC } & \text { Escola de Engenharia de São Carlos } \\ \text { ESM } & \text { Esmagamento da parede do furo } \\ \text { EUA } & \text { Estados Unidos da América } \\ \text { ISO } & \text { International Organization for Standardization } \\ \text { LE } & \text { Laboratório de Estruturas da EESC } \\ \text { NBR } & \text { Norma Brasileira aprovada pela ABNT } \\ \text { RAS } & \text { Rasgamento entre furo e borda } \\ \text { RSL } & \text { Ruptura da seção líquida } \\ \text { USP } & \text { Universidade de São Paulo } \\ \text { ZAR } & \text { Zincada de alta resistência }\end{array}$




\title{
LISTA DE SÍMBOLOS
}

\author{
d Diâmetro nominal do parafuso \\ $f_{u b} \quad$ Resistência à tração do parafuso \\ $F_{R} \quad$ Força resistente nominal \\ $t \quad$ Espessura nominal da chapa \\ $e \quad$ Distância do centro do furo à borda mais próxima do furo adjacente ou da chapa, \\ na direção paralela à solicitação \\ $f_{u} \quad$ Tensão de ruptura do aço \\ $\alpha_{e} \quad$ Fator referente ao esmagamento definido pela NBR \\ $d_{b} \quad$ Diâmetro nominal do parafuso \\ $C_{t} \quad$ Coeficiente de redução da área líquida \\ $A_{n} \quad$ Área líquida da seção transversal na região da ligação \\ $A_{g v} \quad$ Área bruta sujeita ao cisalhamento da parte suscetível ao block shear \\ $f_{y} \quad$ Tensão de escoamento do aço \\ $A_{n t} \quad$ Área líquida sujeita à tração da parte suscetível ao block shear \\ $A_{n v} \quad$ Área líquida sujeita ao cisalhamento da parte suscetível ao block shear \\ $g$ Maior distância, na direção perpendicular à solicitação, entre furos ou entre os \\ dois furos de extremidade e respectivas bordas \\ C Fator referente ao esmagamento definido pela AISI \\ $m_{f} \quad$ Fator de modificação referente ao esmagamento definido pela AISI \\ $A_{e} \quad$ Área efetiva da seção transversal na região da ligação \\ $n \quad$ Número de parafusos na seção crítica da ligação \\ $e_{n} \quad$ Distância da borda do furo à borda mais próxima do furo adjacente ou da chapa, \\ na direção paralela à solicitação \\ $U_{s l} \quad$ Fator de shear lag definido pela AISI \\ $S$ \\ Largura da chapa dividida pelo número de parafusos na seção em análise \\ $\alpha \quad$ Fator de modificação referente ao esmagamento definido pela AS/NZS \\ C Fator referente ao esmagamento definido pela AS/NZS \\ $\alpha_{b} \quad$ Fator referente ao esmagamento definido pelo Eurocode 3 \\ $k_{t} \quad$ Coeficiente referente ao esmagamento definido pelo Eurocode 3
}


Número de parafusos na seção crítica divido pelo número total de parafusos na ligação

$d_{o} \quad$ Diâmetro nominal do furo

$u$

Menor distância, na direção perpendicular à solicitação, entre furos ou entre os dois furos de extremidade e respectivas bordas

$e_{1} \quad$ Distância entre centro do furo e borda adjacente, na direção paralela à solicitação

$e_{2}$ Distância entre centro do furo e borda adjacente, na direção perpendicular à solicitação

$p_{2} \quad$ Distância entre furos na direção perpendicular à solicitação

$l_{c} \quad$ Comprimento planificado da chapa na direção perpendicular à solicitação

$x_{1} \quad$ Distância entre centro do furo e borda adjacente, na direção paralela à solicitação

$x_{2} \quad$ Distância entre furos na direção paralela à solicitação

$y_{1} \quad$ Distância entre centro do furo e borda adjacente, na direção perpendicular à solicitação

$y_{2} \quad$ Distância entre furos na direção perpendicular à solicitação

$L \quad$ Linha de parafusos paralela à solicitação

C L L inha de parafusos perpendicular à solicitação

$d_{f} \quad$ Diâmetro nominal do furo

$C_{\text {red }} \quad$ Coeficiente redutor da área líquida

Fult Força máxima de resistência obtida experimentalmente

$S_{f} \quad$ Espaçamento entre parafusos na direção perpendicular à solicitação

$C_{e s m} \quad$ Coeficiente relativo ao esmagamento da parede do furo

$d_{f f p} \quad$ Distância entre furos adjacentes na direção perpendicular à solicitação

$d_{b f p} \quad$ Distância entre furo e borda da chapa na direção perpendicular à solicitação

$d_{f f l} \quad$ Distância entre furos adjacentes na direção paralela à solicitação

$d_{b f l} \quad$ Distância entre furo e borda da chapa na direção paralela à solicitação 


\section{SUMÁRIO}

1 INTRODUÇÃO ...............................................................................................17

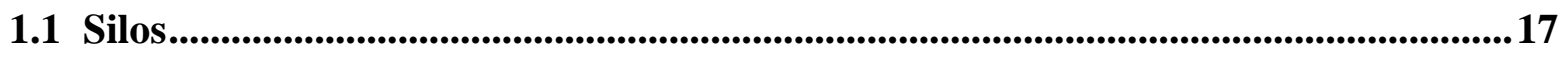

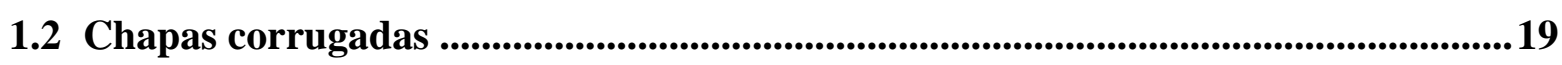

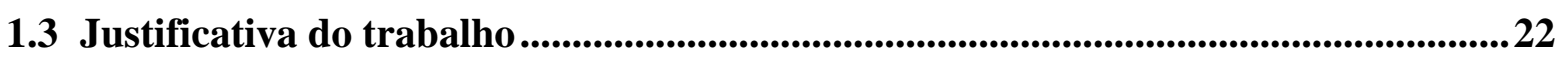

1.4 Objetivos da trabalho ..............................................................................................................23

2 LIGAÇÕES PARAFUSADAS EM CHAPAS FINAS ..................................................24

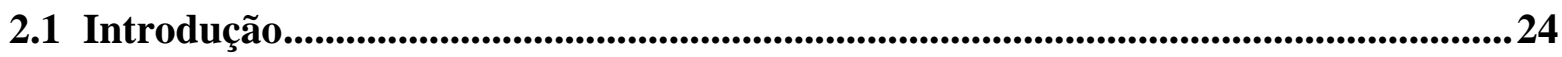

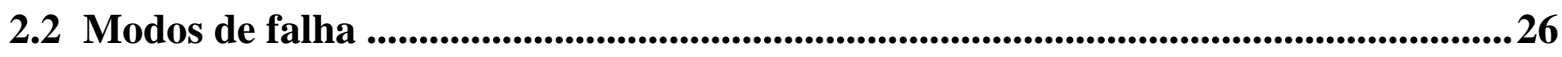

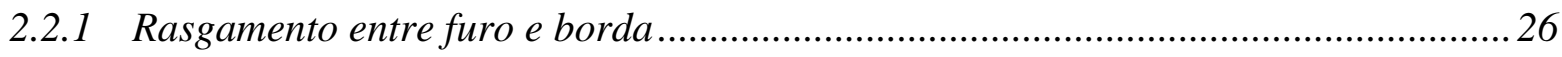

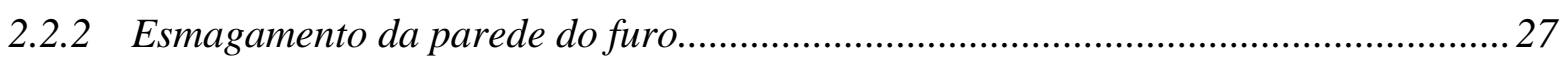

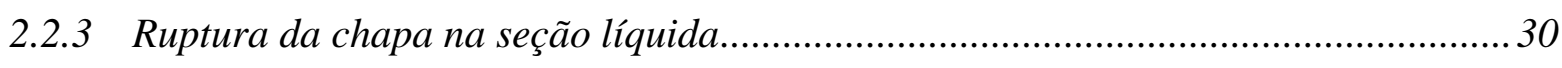

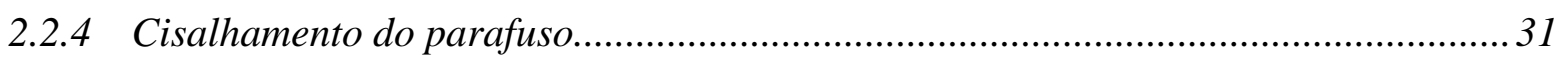

2.2.5 Destacamento do bloco de ligação .......................................................................... 32

2.3 Resistência teórica das ligações parafusadas ......................................................33

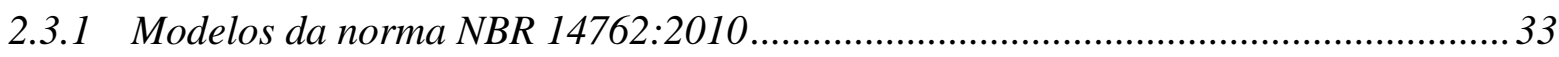

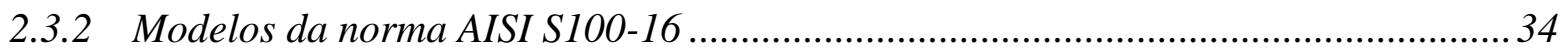

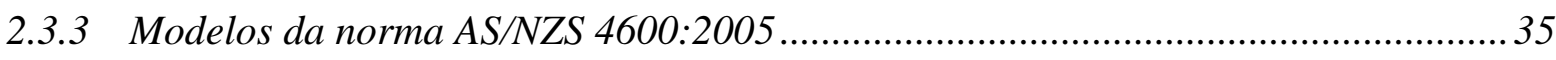

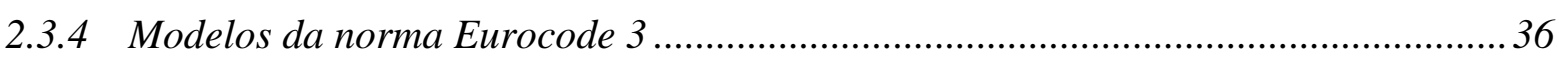

3 PROCEDIMENTO EXPERIMENTAL .....................................................................38

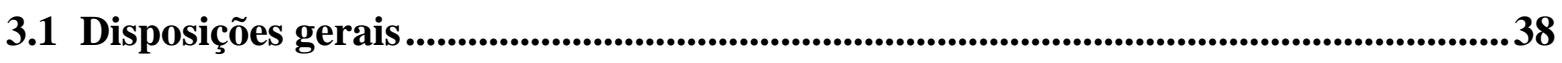

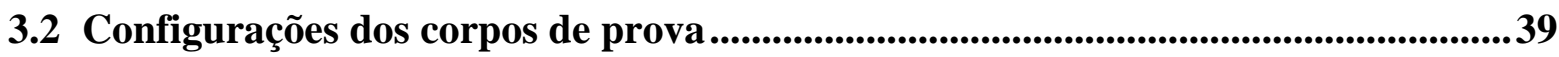

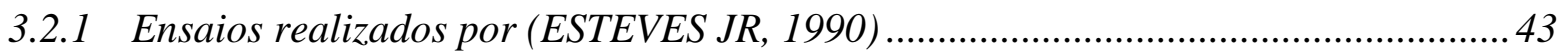

3.2.2 Ensaios realizados no LE-EESC-USP em maio de 2015 .......................................... 45

3.2.3 Ensaios realizados no LE-EESC-USP em outubro de 2015 ........................................ 46

3.2.4 Ensaios realizados no LE-EESC-USP em junho de 2017 ....................................... 48

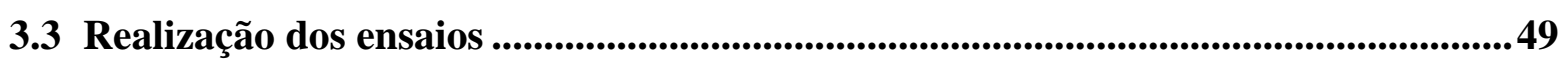

3.3.1 Montagem e instrumentação dos corpos de prova .................................................. 49

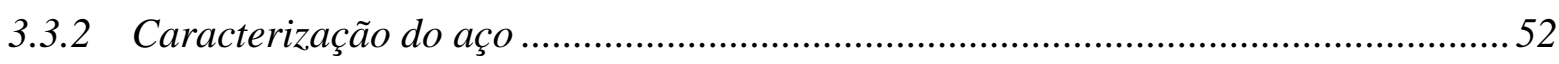




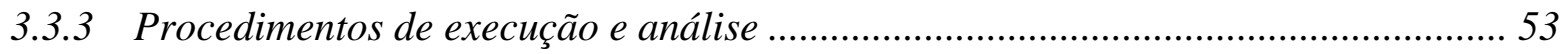

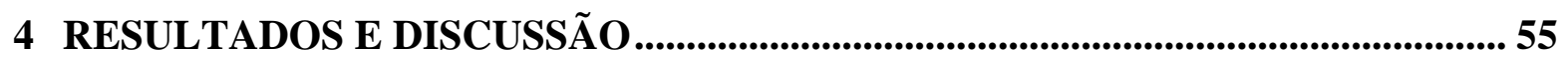

4.1 Ruptura da chapa na seção líquida............................................................................ 56

4.1.1 Ruptura da seção líquida pela norma AISI S100-16 .............................................. 58

4.1.2 Ruptura da seção líquida pela norma AS/NZS 4600:2005 ....................................... 62

4.1.3 Ruptura da seção líquida pela norma NBR 14762:2010 ........................................ 66

4.1.4 Ruptura da seção líquida pela norma EN 1993-1-3:2006 ..................................... 70

4.2 Esmagamento da parede do furo ................................................................................................ 74

4.2.1 Esmagamento da parede pela norma AISI S100-16 …........................................... 75

4.2.2 Esmagamento da parede pela norma AS/NZS 4600:2005 ...................................... 78

4.2.3 Esmagamento da parede pela norma NBR 14762:2010 ........................................ 80

4.2.4 Esmagamento da parede pela norma EN 1993-1-3:2006 ..................................... 82

4.3 Considerações finais ................................................................................................................. 84

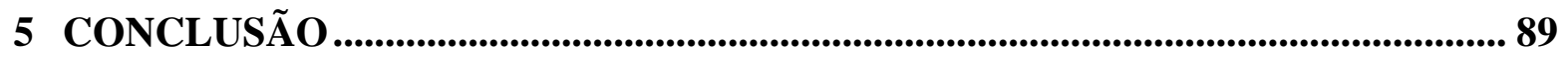

REFERÊNCIAS BIBLIOGRÁFICAS ........................................................................... 91

APÊNDICE A - CONFIGURAÇÕES DOS CORPOS DE PROVA ................................ 93

APÊNDICE B - RESULTADOS DOS ENSAIOS........................................................... 100

APÊNDICE C - RESULTADOS TEÓRICOS E EXPERIMENTAIS........................... 107 


\section{INTRODUÇÃO}

\subsection{Silos}

A palavra silo tem sua origem grega e significa lugar escuro, cavernoso. Nos dias atuais, seu sentido está relacionado ao armazenamento de produtos granulares ou pulverulentos (CALIL JR; CHEUNG, 2007). Os silos são estruturas que desempenham uma função específica e possuem uma importância econômica relevante, pois as operações de armazenagem e manipulação são essenciais a um grande número de atividades industriais e agrícolas. Segundo Arnold e Roberts (1985), os custos destas etapas são substanciais em relação aos custos totais de produção em que estão envolvidas.

O projeto de um silo deve atender a critérios aceitáveis de segurança e economia, pois seu desempenho estrutural influencia a cadeia produtiva em que está inserido. Trahair (1985) destaca que os silos devem proporcionar uma maneira de estocar os produtos armazenados em ambiente protegido, de modo que o descarregamento possa ser feito de forma rápida e fácil, majoritariamente por ação da gravidade. Calil Jr (2007) apresenta as seguintes vantagens de uma unidade armazenadora tecnicamente projetada e bem conduzida:

a) Obtenção de um produto bem conservado, longe do ataque de pragas;

b) Eliminação de impurezas e do excesso de água pela secagem, diminuindo custos de transporte;

c) Estocagem segura e racional, dando a seu proprietário poder de negociação frente às flutuações dos preços do produto e do transporte.

O silo é um tipo de estrutura com características técnicas particulares e, em muitos casos, complexas. Os efeitos do fluxo e da pressão exercidos pelo produto armazenado, especialmente em situações dinâmicas de descarregamento, a consideração correta das demais ações, uma análise estrutural condizente com a geometria e material de construção empregados e uma avaliação correta dos modos de falha susceptíveis de ocorrerem são os principais fatores complicadores. 
A geometria de um silo é determinada principalmente por seus requisitos de funcionalidades, tais quais volume de armazenamento, vazão de descarga e tipo de produto armazenado. As possibilidades de materiais de construção são diversas e de acordo com Calil Jr (2007) pode ser empregados aço, concreto armado e protendido, madeira, argamassa armada, entre outros. Entretanto, a predominância no Brasil é a utilização de silos cilíndricos metálicos, com parede em chapa corrugada, de baixa espessura, zincada de alta resistência. O silo metálico serve a qualquer tipo de produto e possui as vantagens próprias de seu sistema construtivo, como reduzido peso próprio e componentes estruturais industrializados, resultando em maior controle de qualidade e rapidez na montagem da estrutura. A Figura 1 mostra a representação de um silo cilíndrico metálico de fundo plano.

Figura 1 - Componentes de um silo cilíndrico metálico de fundo plano

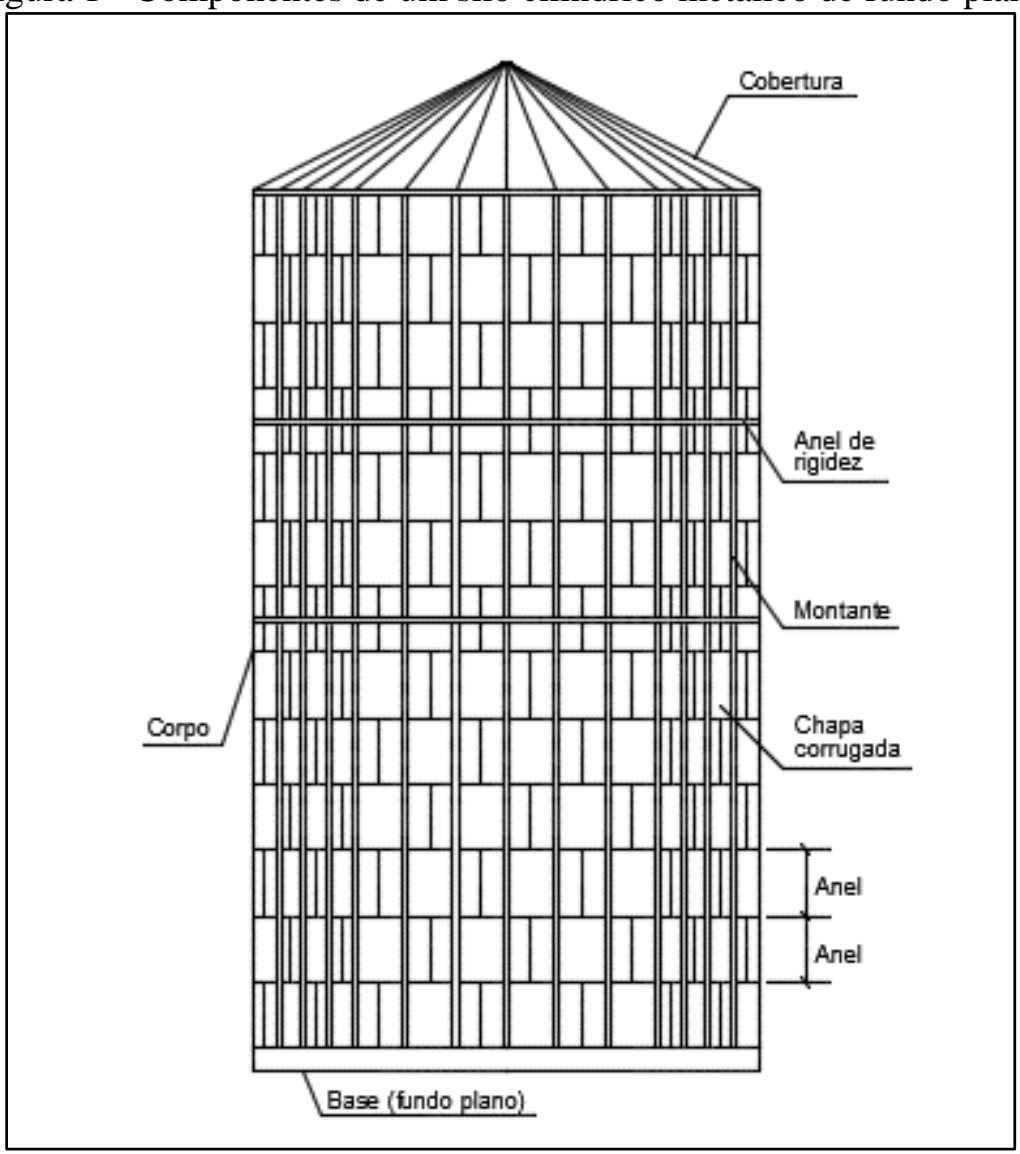

Fonte: o autor

A estrutura de um silo cilíndrico metálico de fundo plano é dividida em cobertura, corpo, por vezes chamado de costado, e base. O corpo do silo é composto por chapas finas de aço com corrugações horizontais, enrijecidas verticalmente por montantes e horizontalmente por anéis de rigidez. Seu sistema estrutural é concebido de forma que os montantes estejam solicitados majoritariamente à compressão e as chapas de parede à tração. Os anéis de rigidez são elementos que impedem a ovalização (perda de estabilidade) das paredes do silo pela ação do 
vento, principalmente quando o silo está vazio. A ligação entre os elementos estruturais do silo é geralmente feita por meio de parafusos de alta resistência. O corpo de um silo cilíndrico metálico constitui-se de uma estrutura em casca bastante eficiente por possuir peso muito inferior ao do produto armazenado. Segundo Rotter (1985a) as cascas de baixa espessura suportam a maioria dos carregamentos por meio de um estado plano de tensões, em que apenas tensões de membrana são mobilizadas, desprezando-se os efeitos de flexão.

A estrutura do corpo do silo é segmentada verticalmente por anéis, conforme mostrado na Figura 1, sendo este o parâmetro para a mudança de resistência dos elementos do costado. A altura de um anel corresponde ao comprimento em projeção da porção da chapa corrugada que não está superposta com a chapa do anel subsequente. O principal carregamento sobre um silo operando em condições normais são as pressões exercidas pelo produto armazenado, que são maiores nos níveis mais próximos à base. Desta maneira, em anéis desta região é comum haver chapas com maior espessura, montantes com maior rigidez, ligações com mais parafusos e emprego de aço com maior resistência. A linha vertical de ligação entre chapas de um mesmo anel deve ser desencontrada em relação ao mesmo tipo de ligação do anel consecutivo, para evitar o prolongamento da descontinuidade que esta ligação representa. A ligação entre chapa e montante constitui uma linha vertical da base ao topo do costado e também não deve coincidir com a linha vertical de ligação entre chapas de parede.

\subsection{Chapas corrugadas}

As chapas de paredes dos silos cilíndricos metálicos são constituídas por aço estrutural dobrado a frio, de baixa espessura, do tipo ZAR. As chapas são revestidas em ambas as faces por uma camada de zinco que protege o aço da corrosão atmosférica. O mecanismo de proteção pode ocorrer por duas formas, proteção por barreira, exercida pela camada de revestimento, ou proteção galvânica, em casos de pequenas descontinuidades do revestimento em que haja exposição simultânea do par aço-zinco. No trabalho a frio a que é submetida, a chapa inicialmente passa por um processo contínuo de perfilação através de deslocamento longitudinal sobre roletes que conferem gradativamente a forma definitiva à chapa, conforme mostrado na Figura 2. Posteriormente a chapa é cortada no comprimento previsto em projeto e calandrada, para adquirir a curvatura do corpo cilíndrico do silo, como ilustrado na Figura 3. 
Figura 2 - Processo de perfilação da chapa corrugada

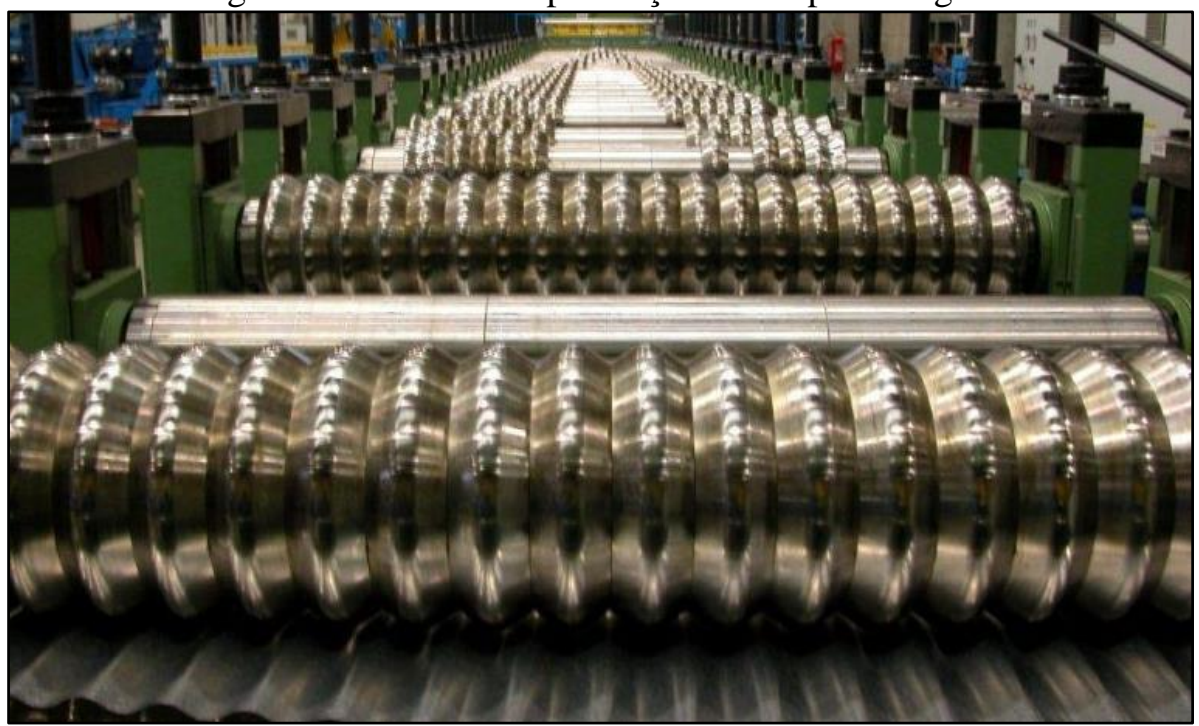

Fonte: http://www.stam.it/wp-content/uploads/2015/05/cat_3_1277814973.jpg Acesso em: 06 mar. 2017

Figura 3 - Processo de calandragem da chapa corrugada

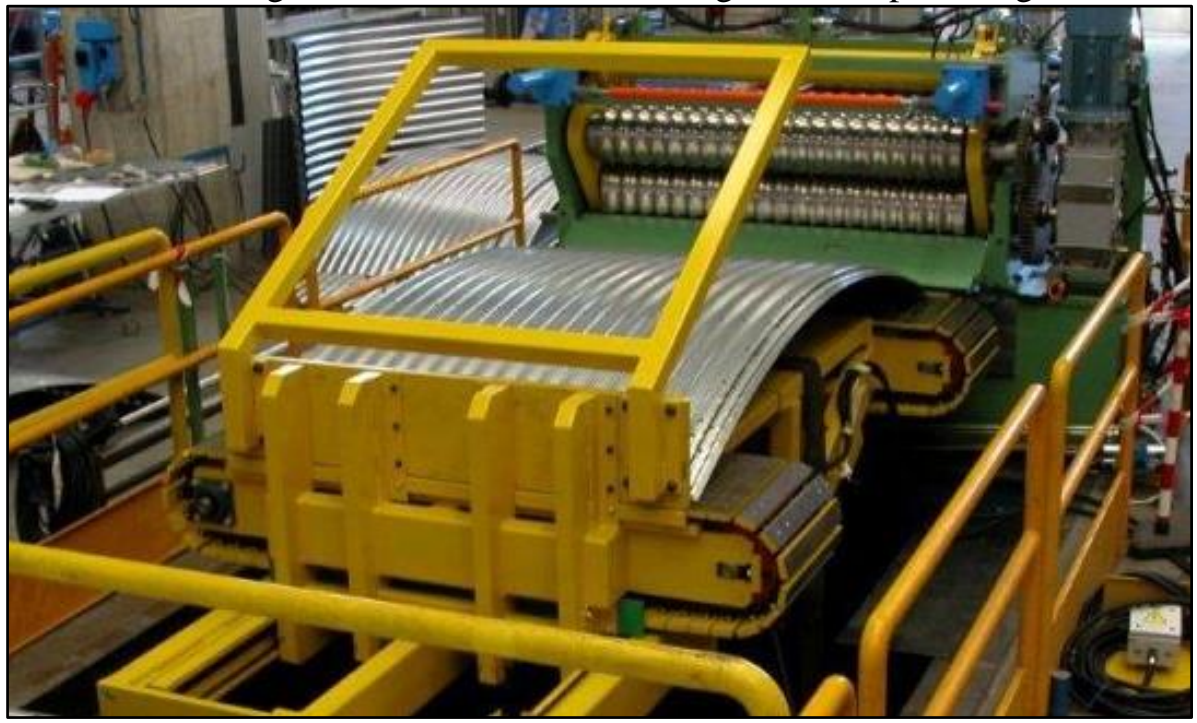

Fonte: http://www.stam.it/wp-content/uploads/2015/05/cat_4_1277814987.jpg Acesso em: 06 mar. 2017

O trabalho a frio na chapa provoca envelhecimento e estricção do aço na região da dobra. As variações nas dimensões da seção decorrentes da estricção podem ser desconsideradas para efeito de dimensionamento. O envelhecimento corresponde ao fenômeno de carregamento até a zona plástica, descarregamento, e posterior carregamento, porém não imediato. Com isso ocorre aumento da resistência ao escoamento e à ruptura do aço, com consequente redução de ductilidade, isto é, o diagrama tensão-deformação sofre uma elevação na direção das resistências-limites, mas acompanhado de um estreitamento no patamar de escoamento. Para o processo contínuo esse acréscimo de resistência atinge todas as regiões da chapa, pois na linha de perfilação toda a parte do perfil entre roletes está sob tensão (SILVA; PIERIN; SILVA, 
2014). A redução da ductilidade significa uma menor capacidade de o material se deformar. Segundo Yu (2000), ductilidade é a capacidade de um material resistir à deformação plástica sem que haja ruptura e é uma propriedade importante no processo de redistribuição de tensões na região de ligações.

A Figura 4 representa as mudanças de propriedade no aço devido ao trabalho a frio e ao envelhecimento. A curva A descreve o diagrama tensão-deformação do aço virgem, a curva B mostra o descarregamento após o trabalho a frio, a curva $\mathrm{C}$ representa o caso de um carregamento imediatamente após B e a curva D representa o fenômeno do envelhecimento, onde o carregamento ocorre não imediatamente após B.

Figura 4 - Efeitos do trabalho e frio e do envelhecimento no aço

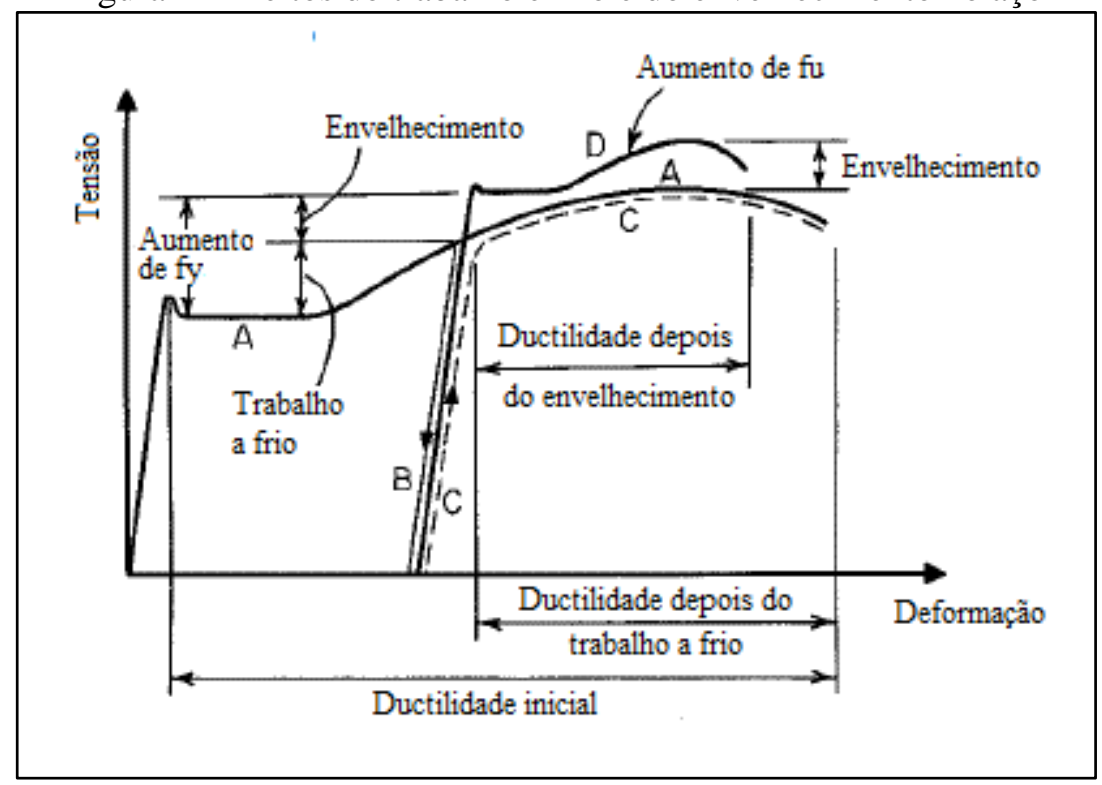

Fonte: adaptado de (YU, 2000)

As chapas corrugadas destinadas a construção de silos são previamente esquadrejadas e perfuradas, e podem ser perfiladas com diferentes ondulações, sendo mais comum aquelas com comprimento de onda de 104,4 mm e altura $12 \mathrm{~mm}$. Na prática, é comum a utilização de chapas com largura planificada de a $1000 \mathrm{~mm}$, resultando em altura útil do anel de $914,4 \mathrm{~mm}$. As espessuras comerciais de chapa normalmente empregadas são de 0,$95 ; 1,25 ; 1,55 ; 1,95 ; 2,30$; 2,70 e 3,00 mm. Devido à demanda por silos cada vez maiores tem-se empregado chapas com montagem em composição dupla, ou seja, a sobreposição de duas chapas para se obter o dobro de espessura final na parede. A Figura 5 mostra a configuração típica de uma chapa corrugada empregada em silos cilíndricos metálicos. 
Figura 5 - Chapa corrugada típica utilizada em silos

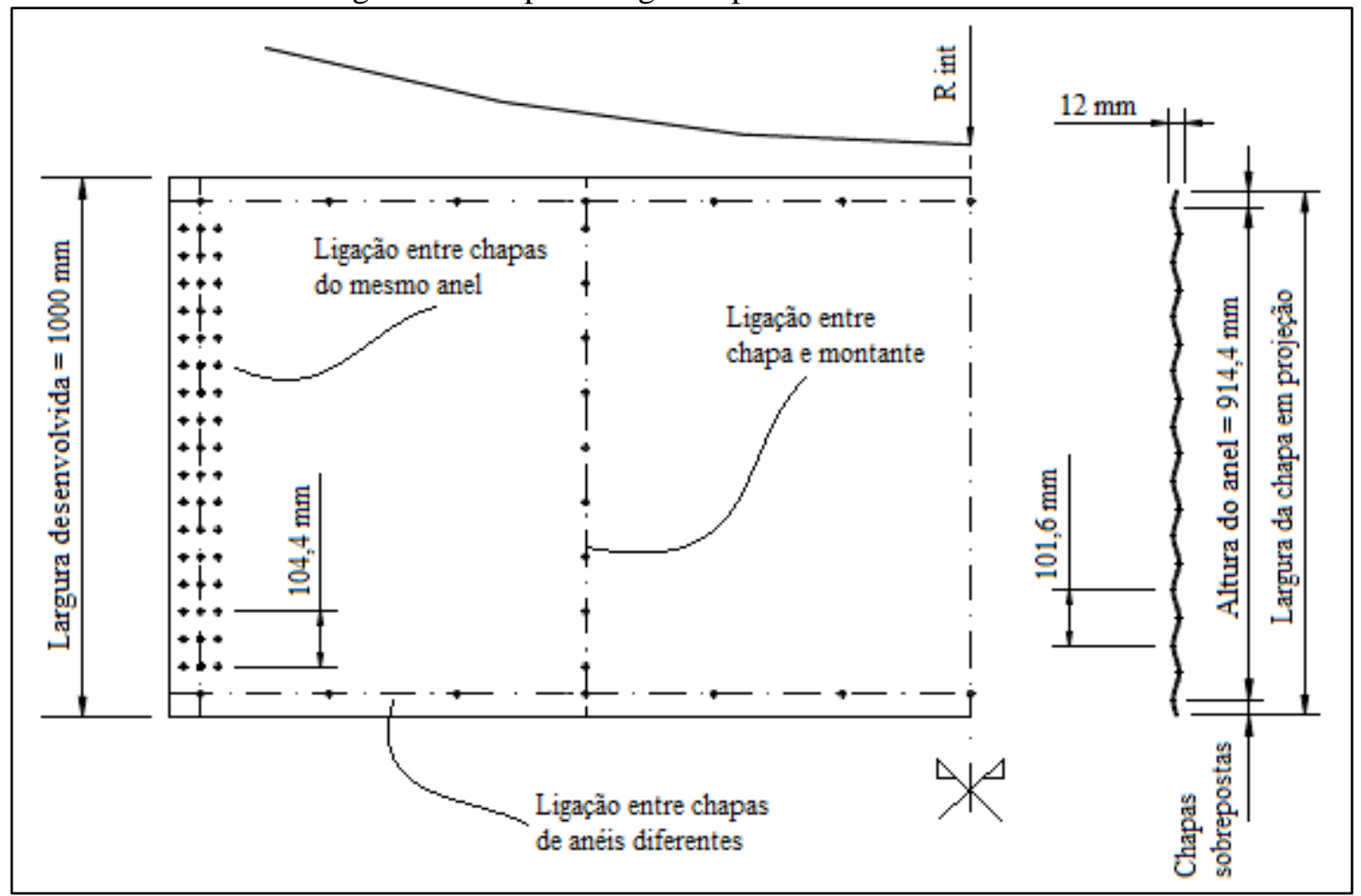

Fonte: o autor

A tensão de ruptura do aço empregado na fabricação destas chapas pode ultrapassar 500 MPa. O revestimento de zinco geralmente é feito no padrão $450 \mathrm{~g} / \mathrm{m}^{2}$, que corresponde a uma espessura de 0,064 mm considerando ambas as faces, e cujo valor não é descontado no valor nominal da espessura da chapa. Para efeito de dimensionamento, no cálculo da área da seção transversal da chapa, considera-se o comprimento desenvolvido e a espessura sem a camada de zinco. Para fins construtivos, o parâmetro de interesse é a altura útil do anel.

\subsection{Justificativa do trabalho}

A ocorrência de colapsos em silos, historicamente, tem sido bastante superior comparada com outros tipos de estruturas. Por serem estruturas complexas, maiores responsabilidades são depositadas sobre seu projetista e há uma demanda crescente por documentação acerca de sua segurança estrutural (BROWN; NIELSEN, 1998). Nesse contexto se insere o estudo teórico e experimental de ligações parafusadas em chapas onduladas de silos cilíndricos metálicos, matéria deste trabalho. Maiola (2004) afirma que as ligações podem ser consideradas como a parte mais importante de uma estrutura metálica, tanto em relação ao custo de produção quanto ao comportamento estrutural, pois constituem descontinuidades cujo comportamento deve ser analisado de forma mais precisa possível. 
Os resultados experimentais deste trabalho constituem uma valiosa base de dados acerca das ligações parafusadas empregadas em chapas de parede de silos cilíndricos metálicos. Segundo Davies (2000), o estudo experimental tem sido historicamente mais presente em estruturas compostas por aço formado a frio do que nos outros tipos. A análise comparativa com modelos teóricos de normas de dimensionamento estrutural forneceu um panorama de sua aplicabilidade a este tipo de ligação. Rogers e Hancock (2000) afirmam que no desenvolvimento de equações para uso em normas de projeto estrutural é imperativo que resultados experimentais estejam disponíveis para comparação com a formulação proposta.

\subsection{Objetivos da trabalho}

O objetivo deste trabalho é a avaliação do comportamento estrutural de ligações parafusadas com aplicação em silos cilíndricos metálicos e a comparação dos resultados com as prescrições de normas de dimensionamento vigentes no Brasil, EUA, Austrália e Europa. Estas normas são veiculadas pelos órgãos ABNT, AISI, AS/NZS e CEN, respectivamente e são indicadas a seguir:

a) NBR 14762:2010 - Dimensionamento de estruturas de aço constituídas por perfis formados a frio;

b) AISI S100-16 - North American Specification for the Design of Cold-Formed Steel Structural Members;

c) AS/NZS 4600:2005 - Cold-formed steel structures;

d) EN 1993-1-3 (2006) - Eurocode 3: Design of steel structures - Part 1-3: General rules - Supplementary rules for cold-formed members and sheeting;

e) EN 1993-1-8 (2005) - Eurocode 3: Design of steel structures - Part 1-8: Design of joints. 


\section{LIGAÇÕES PARAFUSADAS EM CHAPAS FINAS}

\subsection{Introdução}

A ligação de uma estrutura metálica promove a união entre suas partes e é um item delicado do ponto de vista estrutural, pois caracteriza uma região de descontinuidade e concentração de tensões. De acordo com Esteves Jr (1990) as ligações dos elementos estruturais de silos são preferencialmente parafusadas para facilitar sua fabricação, transporte, montagem e desmontagem. Os parafusos utilizados são de alta resistência e têm uma arruela estampada para fixação do neoprene de vedação, como mostrado na Figura 6.

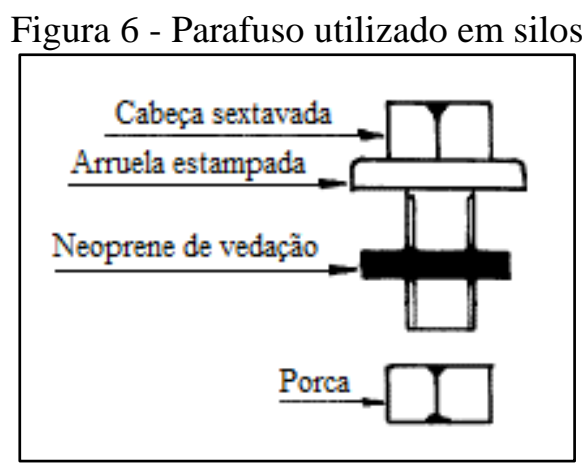

Fonte: (ESTEVES JR, 1990)

A Tabela 1 a seguir mostra as especificações dos parafusos de aço com qualificação estrutural previstos pela NBR 14762:2010 e suas características. A Figura 7 mostra as propriedades de chapas em aço ZAR comercialmente disponível, com fabricação nacional pela CSN. Na prática corrente é comum o emprego de chapas com tensão de ruptura da ordem de $500 \mathrm{MPa}$, parafusos classe 8.8 ou 10.9, quando necessário, sem o uso de uma segunda arruela junto à porca. 
Tabela 1 - Parafusos de aço com qualificação estrutural segundo NBR 14762:2010

\begin{tabular}{|c|c|c|c|c|}
\hline \multirow{2}{*}{ Especificação } & \multirow{2}{*}{ Classe } & \multicolumn{2}{|c|}{ Diâmetro nominal $(\mathbf{d})$} & $\boldsymbol{f}_{\boldsymbol{u b}}$ \\
\cline { 3 - 5 } & & $(\boldsymbol{m m})$ & $(\boldsymbol{i n})$ & $(\boldsymbol{M P a})$ \\
\hline \multirow{2}{*}{ ASTM A307-07b } & \multirow{2}{*}{ Comum } & - & $1 / 4 \leq \mathrm{d}<1 / 2$ & 370 \\
\cline { 3 - 5 } & & \multirow{2}{*}{ Alta resistência } & $1 / 2 \leq \mathrm{d} \leq 4$ & 415 \\
\cline { 3 - 5 } & & $24<\mathrm{d} \leq 36$ & $1<\mathrm{d} \leq 11 / 2$ & 725 \\
\hline \multirow{2}{*}{ ASTM A325M } & Alta resistência & - & $1 / 4 \leq \mathrm{d}<1 / 2$ & 930 \\
\hline ASTM A354 (grau BD) & Comum & - & $1 / 2 \leq \mathrm{d} \leq 1$ & 510 \\
\hline ASTMA394 (tipo 0) & Alta resistência & - & $1 / 2 \leq \mathrm{d} \leq 1$ & 825 \\
\hline ASTM A394 (tipos 1, 2 e 3) & Alta resistência & - & $1 / 4 \leq \mathrm{d}<1 / 2$ & 745 \\
\hline ASTM A449 & Alta resistência & $16 \leq \mathrm{d} \leq 36$ & $1 / 2 \leq \mathrm{d} \leq 11 / 2$ & 1035 \\
\hline ASTM A490 & Comum & $6 \leq \mathrm{d} \leq 36$ & - & 400 \\
\hline ISO 898-1 classe 4.6 & Alta resistência & $6 \leq \mathrm{d} \leq 36$ & - & 800 \\
\hline ISO 4016 - classe 8.8 & Alta resistência & $6 \leq \mathrm{d} \leq 36$ & - & 1000 \\
\hline ISO 4016 - classe 10.9 & Alta & \multicolumn{3}{|c}{} \\
\hline
\end{tabular}

Fonte: NBR 14762:2010

Figura 7 - Catálogo de chapas de aço ZAR da CSN

\begin{tabular}{|c|c|c|c|c|c|c|c|c|c|}
\hline \multirow[b]{3}{*}{ Norma Técnica } & \multirow[b]{3}{*}{ Grau } & \multirow{3}{*}{$\begin{array}{l}\text { Espessura } \\
\text { (mm) }\end{array}$} & \multicolumn{3}{|c|}{$\begin{array}{l}\text { Composipes Orimica } \\
\text { (th mexima) }\end{array}$} & \multicolumn{4}{|c|}{ Propriedades Mecãnicas } \\
\hline & & & \multirow[b]{2}{*}{ c } & \multirow[b]{2}{*}{$P$} & \multirow[b]{2}{*}{5} & \multirow[b]{2}{*}{$\begin{array}{l}\text { limite de } \\
\text { Escosmento } \\
\text { min. } \\
\text { (MPa) }\end{array}$} & \multirow[b]{2}{*}{$\begin{array}{l}\text { limite de } \\
\text { Resistêncis } \\
\text { min. } \\
\text { (MPa) }\end{array}$} & \multicolumn{2}{|c|}{ Alongamento } \\
\hline & & & & & & & & $\begin{array}{l}\text { Base de } \\
\text { Medidla } \\
\text { (mm) }\end{array}$ & $\begin{array}{l}\text { Valor min. } \\
\qquad \text { [क }\end{array}$ \\
\hline \multirow{6}{*}{ NBR 7008} & ZAR - 230 & $0,30-3,00$ & 0,20 & 0,04 & 0,04 & 230 & 310 & - & 22 \\
\hline & ZAR - 250 & $0,35-3,00$ & 0,20 & 0,10 & 0,04 & 250 & 360 & 50 & 18 \\
\hline & ZAR - 280 & $0,45-3,00$ & 0,20 & 0,10 & 0,04 & 280 & 390 & - & 16 \\
\hline & ZAR - 345 & $0,55-3,00$ & 0,20 & 0,20 & 0,04 & 345 & 430 & 50 & 12 \\
\hline & ZAR - 400 & $0,71-1,60$ & 0,20 & 0,20 & 0,04 & 400 & 450 & 50 & 10 \\
\hline & ZAR - $550^{\text {(1) }}$ & (D) & 0,20 & 0,04 & 0,04 & 550 & 570 & - & - \\
\hline \multirow{9}{*}{ ASTM A653 } & SS33 (ou 230) & $0,30-3,00$ & 0,20 & 0,04 & 0,04 & 230 & 310 & - & 20 \\
\hline & S537 (ou 255) & $0,50-3,00$ & 0,20 & 0,10 & 0,04 & 255 & 360 & 50 & 18 \\
\hline & 5540 (ou 275) & $0,42-3,00$ & 0,25 & 0,10 & 0,04 & 275 & 380 & - & 16 \\
\hline & SS50 (340) Class 1 & $0,55-3,00$ & 0,40 & 0,20 & 0,04 & 340 & 450 & 50 & 12 \\
\hline & SS50 (340) Class 2 & $0,55-3,00$ & 0,40 & 0,20 & 0,04 & 340 & - & 50 & 12 \\
\hline & SS50 (340) Class 3 & $0,55-3,00$ & 0,50 & 0,04 & 0,04 & 340 & 490 & 50 & 12 \\
\hline & SS50 (340) Class 4 & $0,55-3,00$ & 0,40 & 0,20 & 0,04 & 340 & 414 & 50 & 12 \\
\hline & SS80 (550) Class 1 (1) & (d) & 0,20 & 0,04 & 0,04 & 550 & 570 & - & - \\
\hline & SSeo $(550)$ Class 2 (1) & (D) & 0,02 & 0,05 & 0,02 & 550 & 570 & - & - \\
\hline
\end{tabular}

Fonte: http://www.prada.com.br/conteudo_pti.asp?idioma=0\&conta=45\&tipo=59673

Acesso em: 17 mar. 2017

Para fins de dimensionamento estrutural, é permitida a plastificação do aço na região da ligação, de modo que a verificação de sua resistência é feita com base na tensão de ruptura do aço. Entretanto, Yu (2000) descreve que a pequena espessura das partes conectadas e a proximidade entre os valores de tensão de escoamento e ruptura do aço das chapas são 
características que afetam o comportamento deste tipo de ligação parafusada. Segundo Maiola (2004) esta ligação é mais suscetível a efeitos localizados e concentração de tensões na região dos furos e interface entre chapa e parafuso. Para reduzir os efeitos negativos da concentração de tensões, é necessário que a chapa de aço tenha uma capacidade suficiente de deformação (ROGERS; HANCOCK, 1999).

Os principais parâmetros que afetam o comportamento estrutural das ligações parafusadas em chapas finas são:
a) Diâmetro do parafuso;
b) Dimensão do furo;
c) Espaçamento dos parafusos nas direções paralela e perpendicular à solicitação;
d) Distância entre furo e borda nas direções paralela e perpendicular à solicitação;
e) Espessura da chapa;
f) Resistência ao escoamento e à ruptura do aço;
g) Número de parafusos;
h) Relações entre os parâmetros anteriores.

\subsection{Modos de falha}

Winter (1956) em seus estudos sobre ligações parafusadas em chapas finas identificou primeiramente quatro modos de falha: rasgamento entre furo e borda, esmagamento da chapa junto ao parafuso, ruptura da chapa na seção líquida e cisalhamento do parafuso. Além destes, aponta-se a ruína por destacamento do bloco de ligação - block shear e a possibilidade da ocorrência de um modo combinado. Estes modos de falha são caracterizados em sequência.

\subsubsection{Rasgamento entre furo e borda}

A falha por rasgamento entre furo e borda é mais susceptível em ligações que apresentam elevada pressão de contato na parede dos furos e pequena distância entre o furo e a borda da chapa ou borda do furo adjacente, na direção paralela à solicitação. A ruína é caracterizada por rasgamento da chapa em frente ao parafuso até a borda, a partir de duas linhas paralelas à direção da solicitação. Devido à pequena extensão de chapa, ocorre esmagamento 
do aço em frente ao parafuso e o rasgamento se prolonga até alcançar a borda, o que caracteriza este modo de falha. A Figura 8 e a Figura 9 mostram estas características.

Figura 8 - Rasgamento entre furo e borda

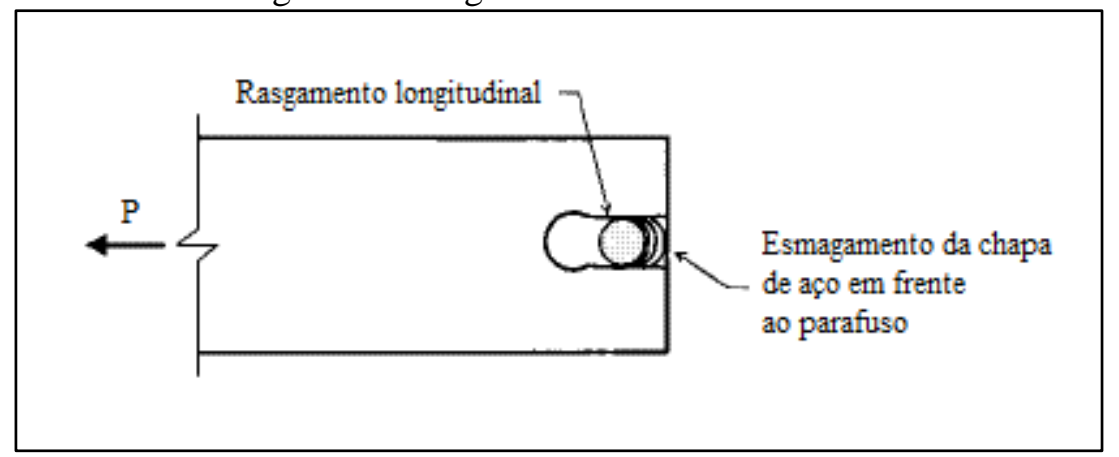

Fonte: adaptado de (ROGERS; HANCOCK, 2000)

Figura 9 - Corpo de prova com falha por rasgamento

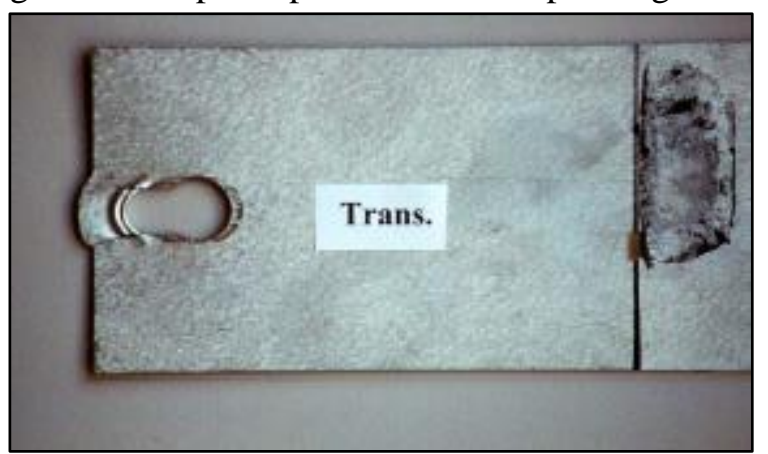

Fonte: (ROGERS; HANCOCK, 1997)

\subsubsection{Esmagamento da parede do furo}

A falha por esmagamento da parede do furo está mais sujeita a ocorrer em ligações que apresentam elevada pressão de contato na parede dos furos e elevada distância entre o furo e a borda da chapa ou borda do furo adjacente, na direção paralela à solicitação. Nesse tipo de ruptura ocorre um princípio de rasgamento na direção da solicitação, que se estabiliza e resulta no esmagamento da chapa em frente ao parafuso, como mostrado na Figura 10 e na Figura 11. 
Figura 10 - Esmagamento da chapa junto ao parafuso

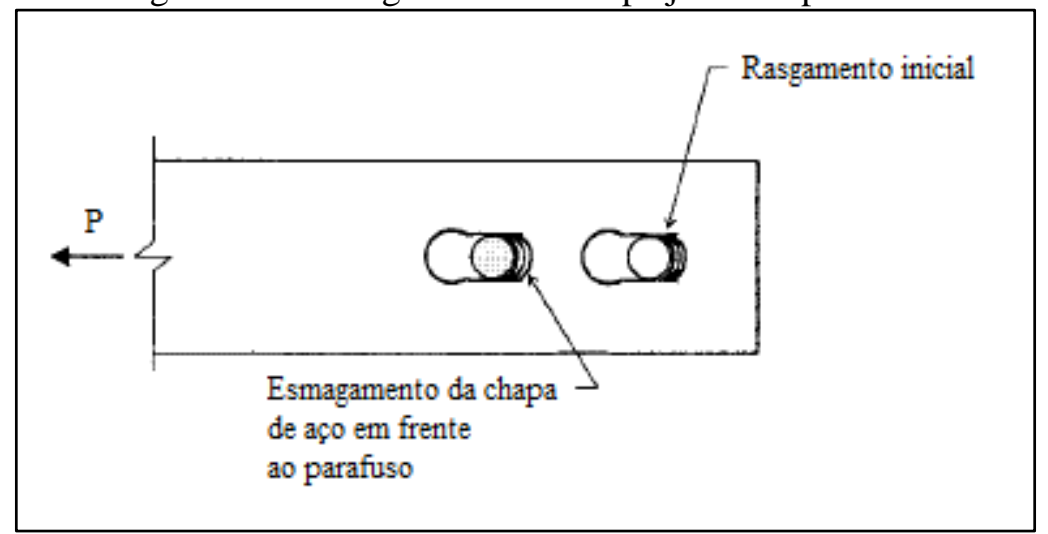

Fonte: adaptado de (ROGERS; HANCOCK, 2000)

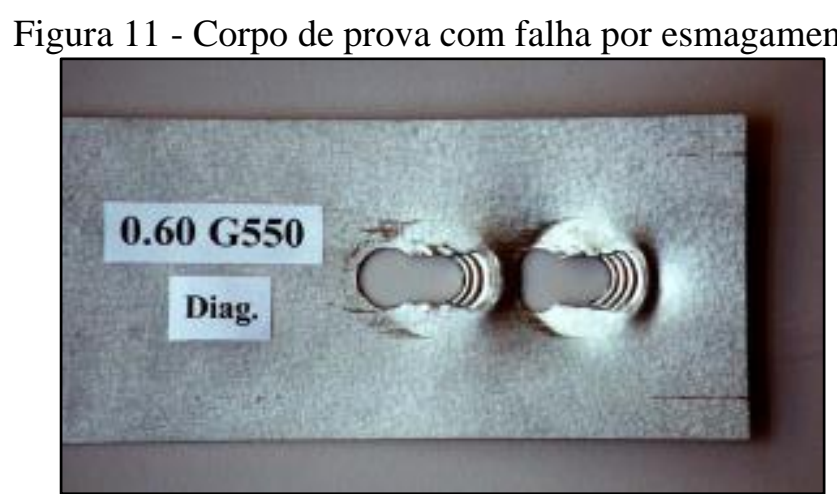

Fonte: (ROGERS; HANCOCK, 1997)

Segundo Rogers e Hancock (2000), caso haja impedimento ao deslocamento fora do plano na extremidade da chapa, este pode ocorrer juntamente com o deslocamento no plano, em furos afastados desta região. Com isso, desenvolve-se um estado de tensão com componentes normal e de cisalhamento nas proximidades dos furos. Devido à concentração de tensão na parede do furo e ao estado de tensão desenvolvido, podem ocorrer pequenas fraturas na borda dos furos, com direção perpendicular à solicitação. Estas linhas de ruptura se originam na região que sofreu esmagamento, fora da linha da furação original, como mostrado nas Figura 12 e Figura 13. 
Figura 12 - Esmagamento com deslocamento fora do plano e fratura

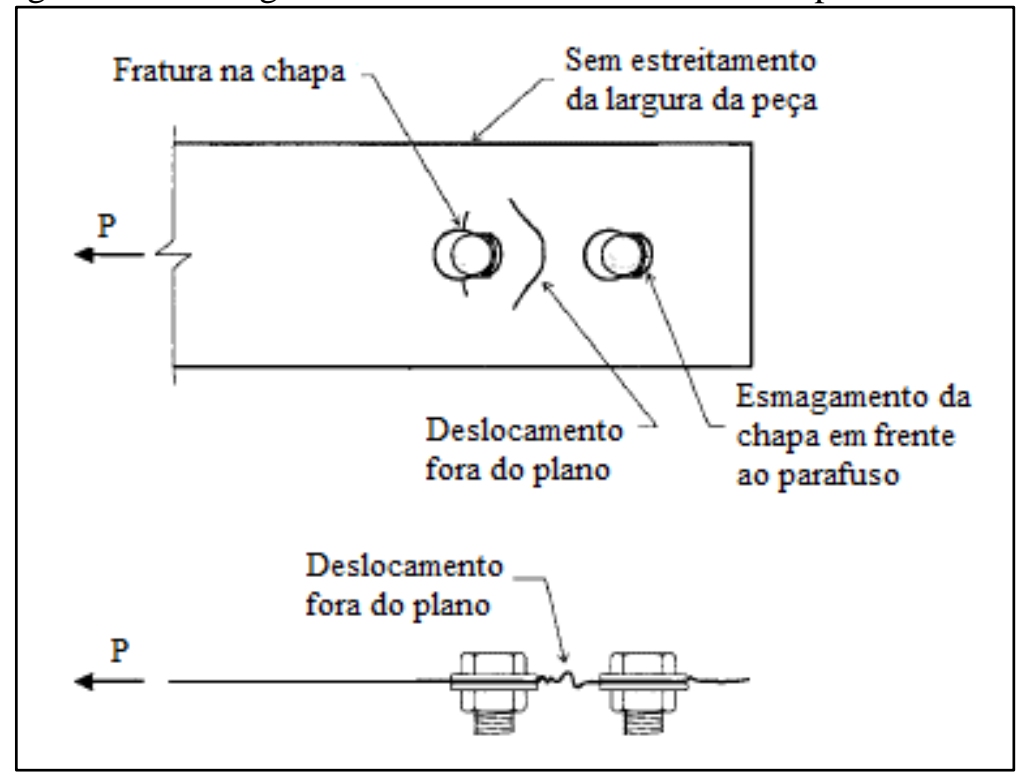

Fonte: adaptado de (ROGERS; HANCOCK, 2000)

Figura 13 - Falha por esmagamento com deslocamento fora do plano e fratura

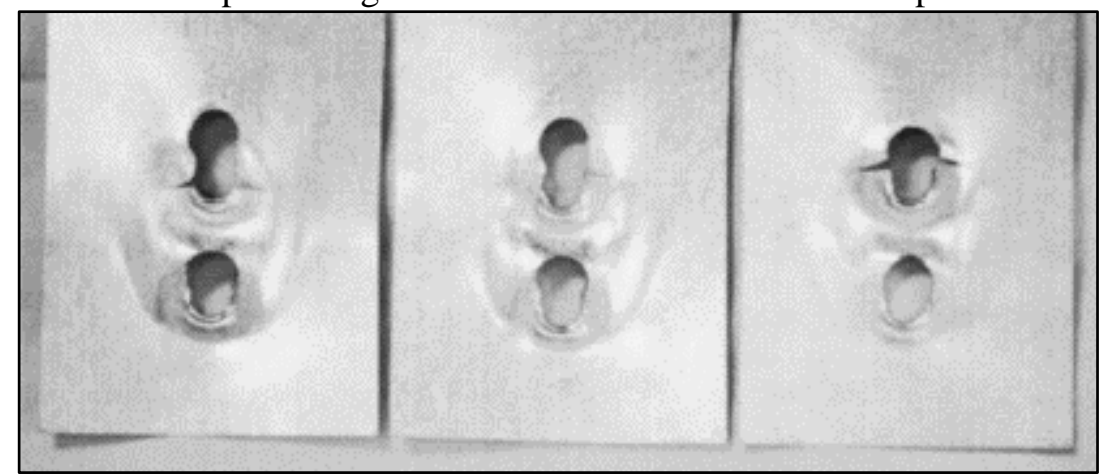

Fonte: (ROGERS; HANCOCK, 2000)

A ocorrência de fraturas nessas circunstâncias geralmente ocorre após a carga crítica ser atingida e, portanto, não influencia a resistência última da ligação. São características do modo de falha por esmagamento da parede do furo que auxiliam na identificação correta de sua ocorrência:

a) Ocorre esmagamento expressivo da chapa nas paredes dos furos em contato com os parafusos;

b) Não há estreitamento nem da largura e nem da espessura da chapa;

c) Pode haver deslocamento fora do plano se este não estiver impedido;

d) Pode ocorrer fraturas com direção de propagação perpendicular à solicitação, originadas fora do eixo da furação original. 


\subsubsection{Ruptura da chapa na seção líquida}

A falha por ruptura da chapa na seção líquida é causada por insuficiência de área efetiva na seção crítica da ligação para suportar a força solicitante de tração. Os efeitos locais de rasgamento e esmagamento da chapa não são acentuados. Neste tipo de ruína, o esgotamento da capacidade resistente da seção transversal ocasiona a ruptura da chapa na borda de um furo da seção crítica, coincidente com a linha de furação original. Esta ruptura se propaga na direção perpendicular à solicitação até a borda dos demais furos ou da chapa, ocasionando estreitamento de sua largura e espessura. Para chapas finas, um fator agravante é a concentração de tensões, devido a presença de furos e ao contato entre chapa e parafuso. O uso de múltiplos parafusos na direção paralela à solicitação causa um alívio deste último efeito, pois a força é dividida entre mais parafusos. A Figura 14 e a Figura 15 mostram esse tipo de ruptura.

Figura 14 - Ruptura da chapa na seção líquida

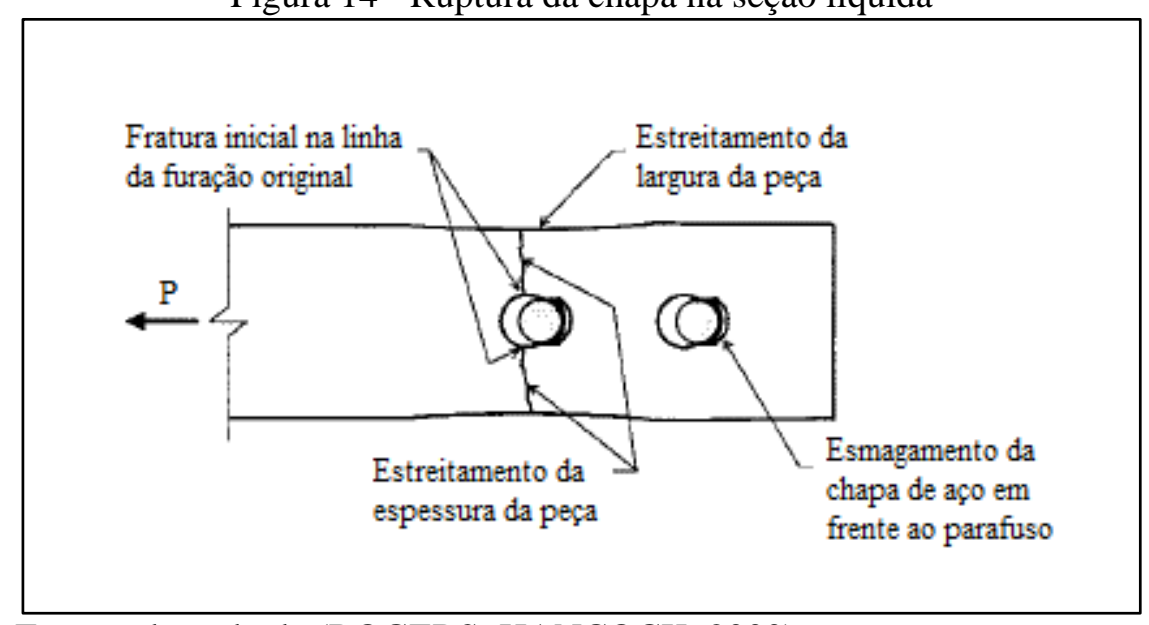

Fonte: adaptado de (ROGERS; HANCOCK, 2000)

Figura 15 - Corpo de prova com falha por ruptura da seção líquida

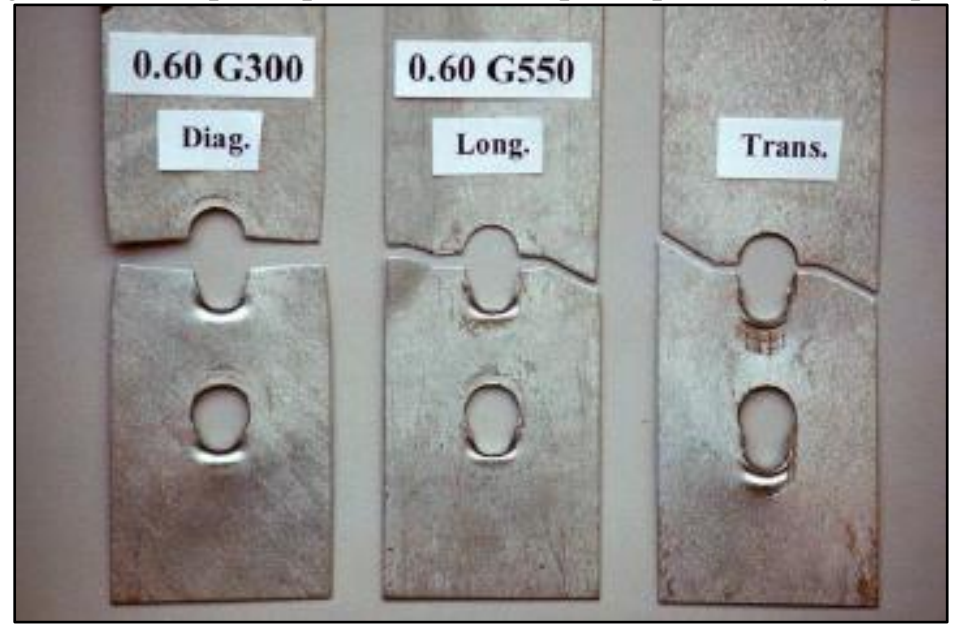

Fonte: (ROGERS; HANCOCK, 1997) 
São características do modo de falha por ruptura da chapa na seção líquida que auxiliam na identificação correta de sua ocorrência:

a) Estreitamento na largura e espessura da chapa;

b) Linha de ruptura coincidente com a de furação original;

c) Não há deslocamento fora do plano;

d) A deformação dos furos é reduzida.

\subsubsection{Cisalhamento do parafuso}

A falha por cisalhamento do parafuso ocorre em situações que a resistência do grupo de parafusos ao cisalhamento é inferior à resistência da chapa à tração. Na situação de ruína os parafusos encontram-se sobrecarregados e rompem por cisalhamento, como mostrado na Figura 16 e na Figura 17.

Figura 16 - Ruptura por cisalhamento do parafuso

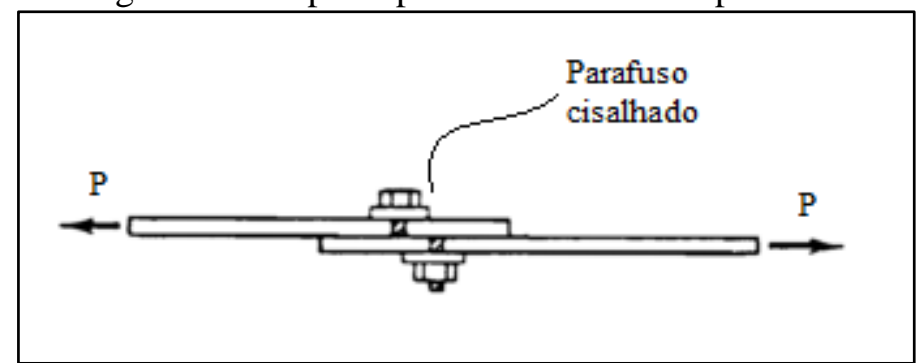

Fonte: adaptado de (LABOUBE; CARRIL; YU, 1994)

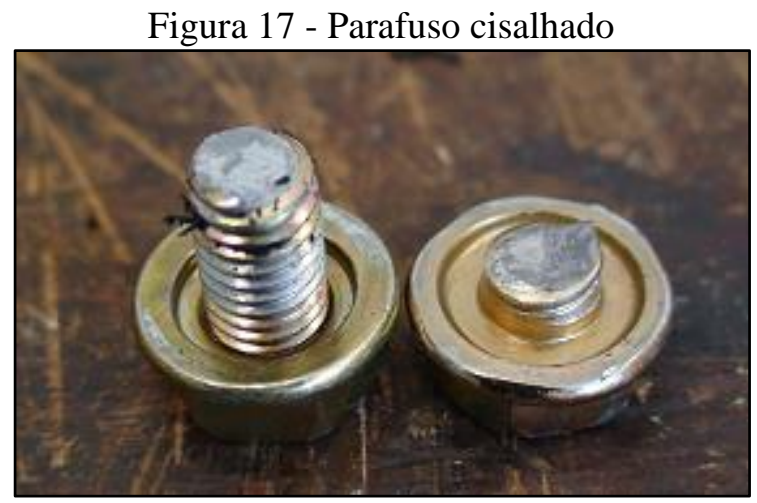

Fonte: o autor 


\subsubsection{Destacamento do bloco de ligação}

A falha por block shear é causada pelo destacamento de um pedaço do elemento conectado pela ligação. Este tipo de ruína ocorre através de uma combinação de tensão normal e de cisalhamento no contorno do elemento destacado, em linhas perpendiculares entre si, de forma a delimitar a região da falha. Ocorre cisalhamento da chapa na direção paralela à solicitação e ruptura ou escoamento na direção perpendicular. A Figura 18 e a Figura 19 mostram este modo de falha.

Figura 18 - Ruptura por block shear

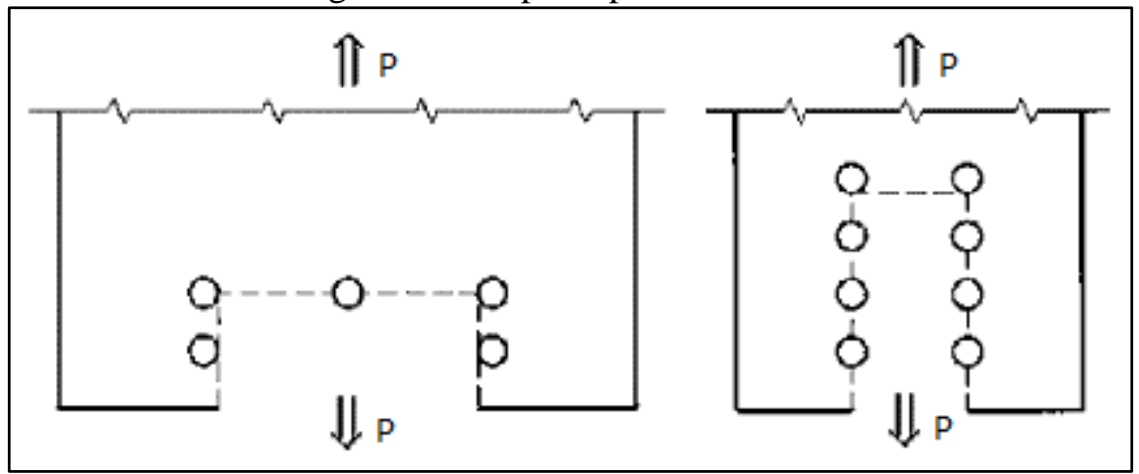

Fonte: (GREGORY; THOMAS; DUANE, 2001)

Figura 19 - Corpo de prova com falha por block shear

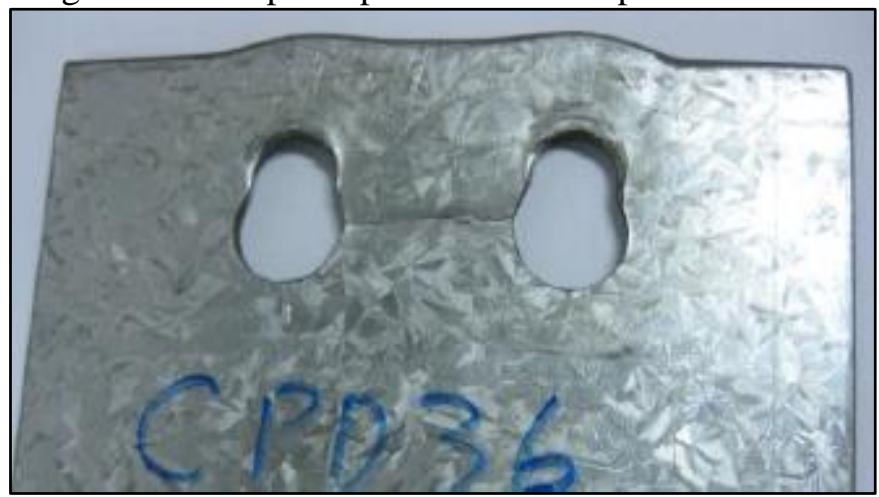

Fonte: (TEH; CLEMENTS, 2012)

É conservador calcular a resistência ao destacamento do bloco de ligação utilizando os valores integrais da tensão de escoamento e tensão de ruptura do aço em planos perpendiculares descritos pelas linhas de ruptura. Portanto, dois casos devem ser analisados, com a ponderação desses valores. As possibilidades são considerar a tensão de ruptura na área líquida submetida a tração e a tensão de escoamento na área bruta submetida ao cisalhamento ou considerar a tensão de escoamento na área bruta submetida à tração e tensão de ruptura na área líquida submetida ao cisalhamento (GREGORY; THOMAS; DUANE, 2001). 


\subsection{Resistência teórica das ligações parafusadas}

A seguir são apresentados os modelos teóricos para a resistência de ligações parafusadas, referente aos modos de falha descritos anteriormente, segundo as normas de dimensionamento estrutural consideradas. Observa-se que, nos casos de rasgamento e esmagamento, as expressões de cálculo se referem a um único parafuso na ligação, de modo que a análise deve ser estendida à todos para a consideração da resistência total da ligação.

\subsubsection{Modelos da norma NBR 14762:2010}

A seguir apresenta-se as equações de resistência da ligação parafusada para os seguintes modos de falha: rasgamento entre furo e borda (RAS), esmagamento da chapa junto ao parafuso (ESM), ruptura da chapa na seção líquida (RSL) e block shear (BLS).

$$
\begin{array}{cc}
\text { RAS - } & F_{R}=t \cdot e \cdot f_{u} \\
\text { ESM - } & F_{R}=\alpha_{e} \cdot d_{b} \cdot t \cdot f_{u} \\
\text { RSL - } & F_{R}=C_{t} \cdot A_{n} \cdot f_{u} \\
\text { BLS - } & F_{R}=\operatorname{menor}\left\{0,6 \cdot A_{g v} \cdot f_{y}+A_{n t} \cdot f_{u} ; 0,6 \cdot A_{n v} \cdot f_{u}+A_{n t} \cdot f_{u}\right\}
\end{array}
$$

Sendo:

$t$ : Espessura nominal da chapa;

$e$ : Distância do centro do furo à borda mais próxima do furo adjacente ou da chapa, na direção paralela à solicitação;

$f_{u}$ : Tensão de ruptura do aço;

$f_{y}$ : Tensão de escoamento do aço;

$\alpha_{e}$ : Fator referente ao esmagamento definido pela NBR;

$d_{b}$ : Diâmetro nominal do parafuso;

$C_{t}$ : Coeficiente de redução da área líquida;

$A_{n}$ : Área líquida da seção transversal na região da ligação;

$A_{g v}$ : Área bruta sujeita ao cisalhamento da parte suscetível ao block shear;

$A_{n t}$ : Área líquida sujeita à tração da parte suscetível ao block shear;

$A_{n v}$ : Área líquida sujeita ao cisalhamento da parte suscetível ao block shear;

$g$ : Maior distância, na direção perpendicular à solicitação, entre furos ou entre os dois furos de extremidade e respectivas bordas; 
Na Equação 2, considerando $t$ em mm:

$$
\alpha_{e}=0,183 \cdot t+1,53
$$

$\mathrm{Na}$ Equação 3, para todos os parafusos da ligação contidos em uma única seção transversal:

$$
C_{t}=2,5 \cdot d_{b} / g \leq 1,0
$$

Para dois parafusos na direção da solicitação:

$$
C_{t}=0,5+1,25 \cdot d_{b} / g \leq 1,0
$$

Para três parafusos na direção da solicitação:

$$
C_{t}=0,67+0,83 \cdot d_{b} / g \leq 1,0
$$

Para quatro ou mais parafusos na direção da solicitação:

$$
C_{t}=0,75+0,625 \cdot d_{b} / g \leq 1,0
$$

\subsubsection{Modelos da norma AISI S100-16}

A seguir apresenta-se as equações de resistência da ligação parafusada para os seguintes modos de falha: rasgamento entre furo e borda (RAS), esmagamento da chapa junto ao parafuso (ESM), ruptura da chapa na seção líquida (RSL) e block shear (BLS).

$$
\begin{array}{ccc}
\text { RAS - } & F_{R}=0,6 \cdot f_{u} \cdot A_{n v} \\
\text { ESM - } & F_{R}=C \cdot m_{f} \cdot d_{b} \cdot t \cdot f_{u} \\
\text { RSL - } & F_{R}=f_{u} \cdot A_{e} \\
\text { BLS - } & F_{R}=\operatorname{menor}\left\{0,6 \cdot f_{y} \cdot A_{g v}+f_{u} \cdot A_{n t} ; 0,6 \cdot f_{u} \cdot A_{n v}+f_{u} \cdot A_{n t}\right\}
\end{array}
$$

Sendo:

$t$ : Espessura nominal da chapa;

$n$ : Número de parafusos na seção crítica da ligação;

$e_{n}$ : Distância da borda do furo à borda mais próxima do furo adjacente ou da chapa, na direção paralela à solicitação;

$f_{u}$ : Tensão de ruptura do aço;

$f_{y}$ : Tensão de escoamento do aço;

$C$ : Fator referente ao esmagamento definido pela AISI;

$m_{f}$ : Fator de modificação referente ao esmagamento definido pela AISI;

$d_{b}$ : Diâmetro nominal do parafuso;

$A_{e}$ : Área efetiva da seção transversal na região da ligação; 
$U_{s l}:$ Fator de shear lag definido pela AISI;

$s$ : Largura da chapa dividida pelo número de parafusos na seção em análise;

$A_{g v}:$ Área bruta sujeita ao cisalhamento;

$A_{n t}:$ Área líquida sujeita à tração;

$A_{n v}$ : Área líquida sujeita ao cisalhamento.

Na Equação 10:

$$
A_{n v}=2 n \cdot t \cdot e_{n}
$$

Na Equação 11:

$$
\begin{gathered}
\text { se } d_{b} / t<10 \rightarrow C=3,0 \\
\text { se } 10 \leq d_{b} / t \leq 22 \rightarrow C=4-0,1 \cdot d_{b} / t \\
2 \text { arruelas por parafuso } \rightarrow m_{f}=1,00 \\
1 \text { arruela por parafuso } \rightarrow m_{f}=0,75
\end{gathered}
$$

Na Equação 12:

$$
\begin{gathered}
A_{e}=U_{s l} \cdot A_{n t} \\
U_{s l}=0,9+0,1 \cdot d_{b} / s
\end{gathered}
$$

\subsubsection{Modelos da norma AS/NZS 4600:2005}

A seguir apresenta-se as equações de resistência da ligação parafusada para os seguintes modos de falha: rasgamento entre furo e borda (RAS), esmagamento da chapa junto ao parafuso (ESM), ruptura da chapa na seção líquida (RSL) e block shear (BLS).

$$
\begin{array}{cc}
\text { RAS - } & F_{R}=t \cdot e \cdot f_{u} \\
\text { ESM - } & F_{R}=\alpha \cdot C \cdot d_{b} \cdot t \cdot f_{u} \\
\text { RSL - } & F_{R}=A_{n} \cdot f_{u} \\
\text { BLS - } & F_{R}=\operatorname{menor}\left\{0,6 \cdot f_{y} \cdot A_{g v}+f_{u} \cdot A_{n t} ; 0,6 \cdot f_{u} \cdot A_{n v}+f_{y} \cdot A_{g t}\right\}
\end{array}
$$

Sendo:

$t$ : Espessura nominal da chapa;

$e$ : Distância do centro do furo à borda mais próxima do furo adjacente ou da chapa, na direção paralela à solicitação;

$f_{u}$ : Tensão de ruptura do aço;

$f_{y}$ : Tensão de escoamento do aço;

$C$ : Fator referente ao esmagamento definido pela AS/NZS;

$\alpha$ : Fator de modificação referente ao esmagamento definido pela AS/NZS;

$d_{b}$ : Diâmetro nominal do parafuso; 
$A_{n}$ : Área líquida da seção transversal na região da ligação;

$A_{g t}:$ Área bruta sujeita à tração;

$A_{g v}:$ Área bruta sujeita ao cisalhamento;

$A_{n t}:$ Área líquida sujeita à tração;

$A_{n v}$ : Área líquida sujeita ao cisalhamento.

Na Equação 22:

$$
\begin{gathered}
\text { se } d_{b} / t<10 \rightarrow C=3,0 \\
\text { se } 10 \leq d_{b} / t \leq 22 \rightarrow C=4-0,1 \cdot d_{b} / t \\
2 \text { arruelas por parafuso } \rightarrow \alpha=1,00 \\
1 \text { arruela por parafuso } \rightarrow \alpha=0,75
\end{gathered}
$$

\subsubsection{Modelos da norma Eurocode 3}

A seguir apresenta-se as equações de resistência da ligação parafusada para os seguintes modos de falha: rasgamento entre furo e borda (RAS), esmagamento da chapa junto ao parafuso (ESM), ruptura da chapa na seção líquida (RSL) e block shear (BLS).

$$
\begin{array}{cc}
\text { RAS - } & F_{R}=t \cdot e \cdot f_{u} \\
\text { ESM - } & F_{R}=2,5 \cdot \alpha_{b} \cdot k_{t} \cdot d_{b} \cdot t \cdot f_{u} \\
\text { RSL - } & F_{R}=\left[1+3 r \cdot\left(d_{o} / u-0,3\right)\right] \cdot A_{n} \cdot f_{u} \leq A_{n} \cdot f_{u} \\
\text { BLS - } & F_{R}=f_{u} \cdot A_{n t}+1 / \sqrt{3} \cdot f_{y} \cdot A_{n v}
\end{array}
$$

Sendo:

$t$ : Espessura nominal da chapa;

$e$ : Distância do centro do furo à borda mais próxima do furo adjacente ou da chapa, na direção paralela à solicitação;

$f_{u}$ : Tensão de ruptura do aço;

$f_{y}$ : Tensão de escoamento do aço;

$\alpha_{b}$ : Fator referente ao esmagamento definido pelo Eurocode 3;

$e_{1}$ : Distância entre centro do furo e borda adjacente, na direção paralela à solicitação;

$k_{t}$ : Coeficiente referente ao esmagamento definido pelo Eurocode 3;

$r$ : Número de parafusos na seção crítica divido pelo número total de parafusos na ligação;

$d_{o}$ : Diâmetro nominal do furo;

$u$ : Menor distância, na direção perpendicular à solicitação, entre furos ou entre os dois furos de extremidade e respectivas bordas; 
$e_{2}$ : Distância entre centro do furo e borda adjacente, na direção perpendicular à solicitação;

$p_{2}$ : Distância entre furos na direção perpendicular à solicitação;

$A_{n}$ : Área líquida da seção transversal na região da ligação;

$d_{b}$ : Diâmetro nominal do parafuso;

$A_{n t}$ : Área líquida sujeita à tração;

$A_{n v}$ : Área líquida sujeita ao cisalhamento.

Na Equação 30, considerando os parâmetros em mm:

$$
\begin{gathered}
\alpha_{b}=e_{1} / 3 d \leq 1,0 \\
k_{t}=\frac{0,8 \cdot t+1,5}{2,5} \leq 1,0
\end{gathered}
$$

Na Equação 31:

$$
u=2 \cdot e_{2} \leq p_{2}
$$




\section{PROCEDIMENTO EXPERIMENTAL}

A norma NBR 14762:2010 determina como condições para execução de ensaios e validade dos resultados experimentais que os testes sejam realizados por laboratórios idôneos, adequadamente equipados e por profissionais com comprovada experiência. Adicionalmente, que a definição dos protótipos e a montagem do aparato de ensaio, envolvendo a vinculação do protótipo, o carregamento e a maneira de se aplicar o carregamento sejam coerentes com as condições de serviço da estrutura.

\subsection{Disposições gerais}

O programa experimental deste trabalho consistiu no ensaio de ligações parafusadas em corpos de prova formados por chapas finas de aço, submetidos a cisalhamento simples, por meio da aplicação de força normal de tração. A configuração dos corpos de prova e a metodologia dos ensaios reproduziram de forma precisa a situação prática de ligações parafusadas em chapas de parede de silos cilíndricos metálicos.

Todos os ensaios, a menos dos referentes ao trabalho de Esteves Jr (1990), foram realizados no LE-EESC-USP, onde foi utilizada uma máquina servo-hidráulica de ensaio, modelo INSTRON 8506, com capacidade estática de $3000 \mathrm{kN}$, juntamente com um sistema automático de aquisição de dados. Foram confeccionados dispositivos especiais, com geometria concordante à dos corpos de prova em uma extremidade e chapa plana na outra, para possibilitar o encaixe com as garras da máquina. Os dados coletados durante os ensaios foram: força aplicada pelo atuador, deslocamento do pistão e deslocamento na região da ligação, medidos por transdutores posicionados manualmente.

As configurações dos corpos de prova foram definidas de modo a abranger variações com significado prático para silos cilíndricos metálicos, variando os seguintes parâmetros:

a) Espessura das chapas;

b) Diâmetro dos furos e parafusos; 
c) Número de furos e espaçamento entre eles;

d) Tensões de escoamento e de ruptura do aço das chapas (valores medidos);

e) Afixação do parafuso com arruela simples ou dupla;

f) Tipo da chapa: lisa ou corrugada;

g) Montagem do corpo de prova: em composição simples ou dupla;

h) Para chapa dupla: furação coincidente ou defasada.

A descrição completa de todos os corpos de prova analisados encontra-se no Apêndice A - Configurações dos corpos de prova. Os resultados experimentais de todos os ensaios são apresentados no Apêndice B - Resultados dos ensaios.

\subsection{Configurações dos corpos de prova}

Um exemplo genérico da chapa de aço utilizada na confecção dos corpos de prova é mostrada na Figura 20.

Figura 20 - Chapa de aço constituinte do corpo de prova

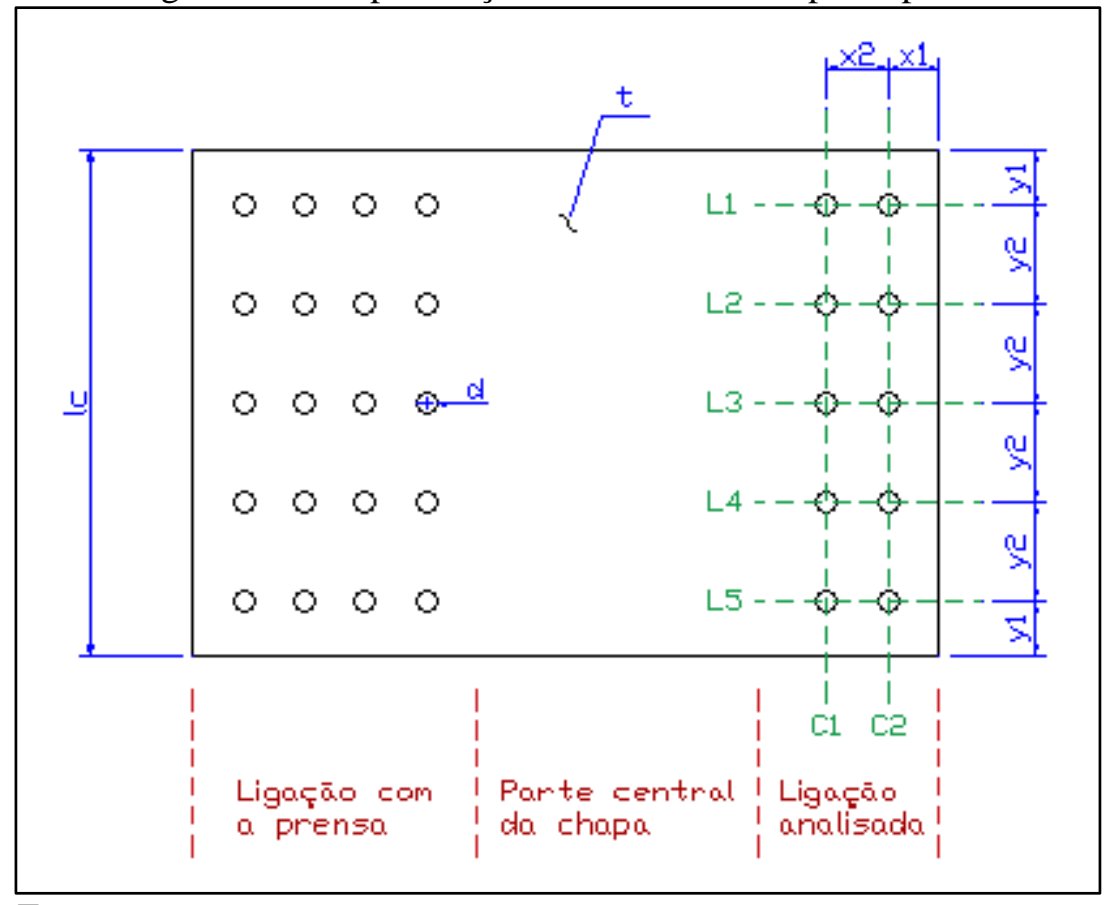

Fonte: o autor.

A chapa possui ligações parafusadas nas duas extremidades e uma parte central. A ligação da chapa com a prensa tem unicamente as funções de restringir o deslocamento ou transmitir a força aplicada, se relativa à extremidade estática ou dinâmica da máquina de ensaio, respectivamente. Esta ligação não foi objeto de estudo, portanto foi mais reforçada para prevenir que a ruptura nela ocorresse. A parte central da chapa simulou a parede de um silo 
cilíndrico metálico, com a função de transmitir tensão normal de forma homogênea à ligação em análise. Segundo Rogers e Hancock (2006), este comprimento não é um parâmetro de influência no estudo de ligações, deve apenas ser suficientemente longo para que haja redistribuição das tensões. A ligação analisada representou a ligação entre chapas de parede de silos cilíndricos metálicos.

A Figura 20 apresenta os parâmetros das ligações analisadas que foram variados nos ensaios, com dimensões planificadas, listados a seguir:

a) Espessura das chapas;

b) Diâmetro dos furos e dos parafusos;

c) Número de linhas e colunas de parafusos;

d) Distâncias entre furos e entre furo e borda, na direção paralela à solicitação;

e) Distâncias entre furos e entre furo e borda, na direção perpendicular à solicitação;

f) Tensão de escoamento e de ruptura do aço, valores obtidos por caracterização do material.

Além destes parâmetros, também variou-se o tipo da chapa e a montagem do corpo de prova. As chapas utilizadas foram do tipo plana ou corrugada, sendo que, para efeito de cálculo, foram consideradas as dimensões desenvolvidas nos casos de chapa corrugada. A montagem do corpo de prova foi feita em composição simples ou dupla, neste último caso, sobrepondo-se duas chapas com a finalidade de aumentar a espessura total. A Figura 21 mostra a confecção de um corpo de prova completo. As chapas foram posicionadas de maneira espelhada e o corpo de prova foi montado parafusando-se a ligação central, resultando numa condição de cisalhamento simples. As extremidades do corpo de prova foram então parafusadas aos dispositivos de ligação que, por sua vez, possuíam um acabamento em chapa plana para possibilitar o encaixe com a garra da máquina de ensaio. 
Figura 21 - Montagem do corpo de prova

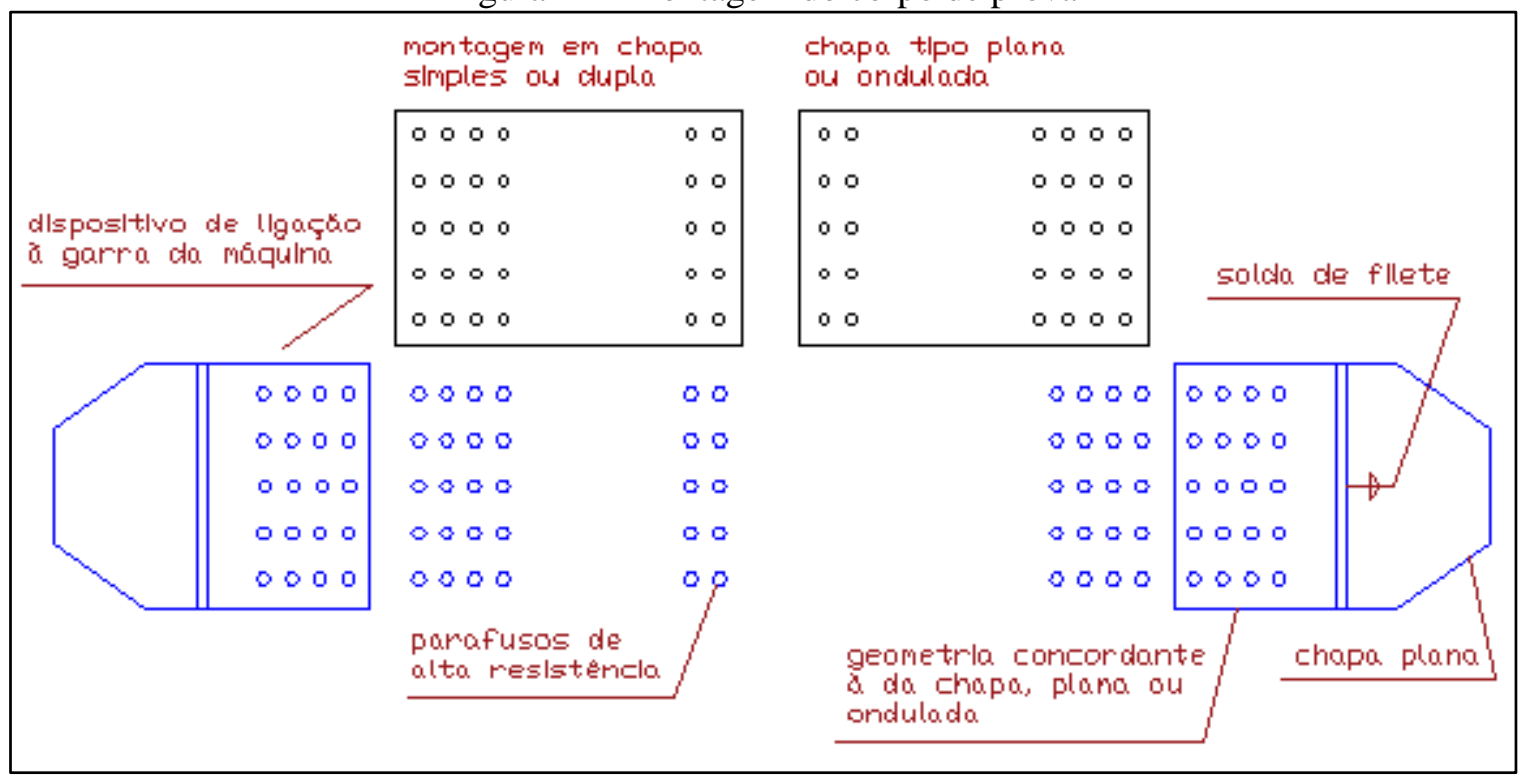

Fonte: o autor.

Para montagem em composição dupla, foi adotada furação coincidente ou defasada nas chapas sobrepostas. A furação defasada reproduz a situação prática de um silo com chapa dupla de parede, pois as chapas são fabricadas com as mesmas dimensões e o raio de montagem ligeiramente superior da chapa externa causa um desencontro dos furos na ligação de silos construídos. A Figura 22 mostra um corpo de prova com montagem em composição dupla e furação defasada. $\mathrm{O}$ valor adotado para o desencontro de centro de furos foi de 1,0 $\mathrm{mm}$, que corresponde à folga entre os diâmetros do furo e do parafuso, para possibilitar a montagem deste tipo de corpo de prova.

Figura 22 - Corpo de prova com chapa dupla e furação defasada

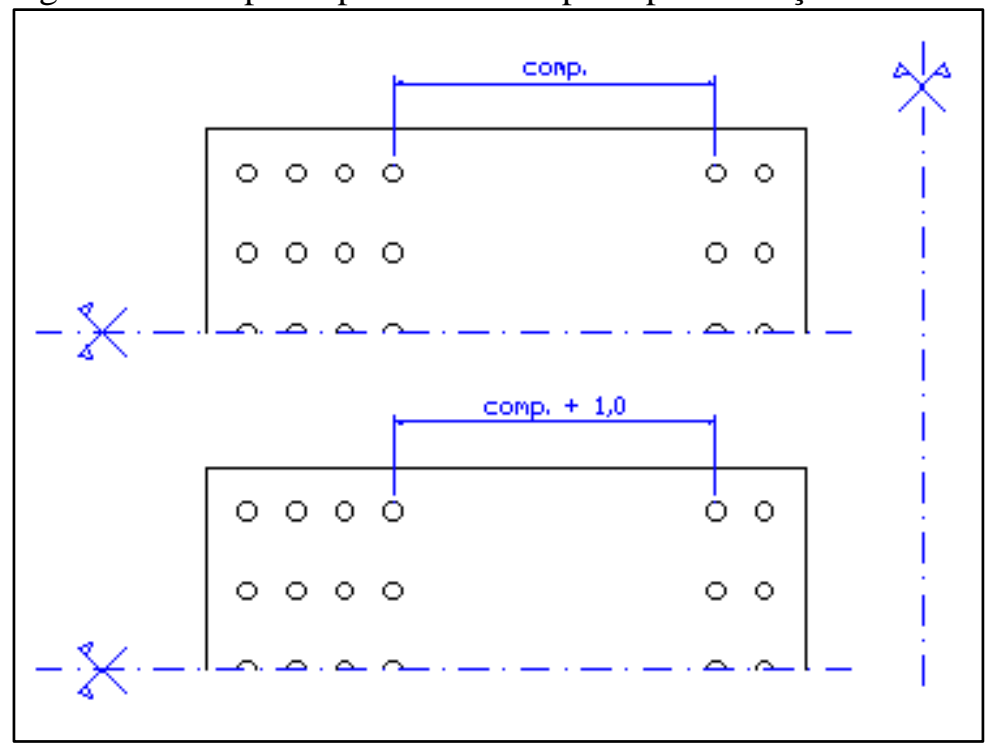

Fonte: o autor. 
O esquema estático dos ensaios é mostrado na Figura 23, em que uma extremidade do corpo de prova permanece fixa e a outra é solicitada por força normal, com controle de deslocamento do pistão, a uma taxa de $2,0 \mathrm{~mm} / \mathrm{min}$. A máquina de ensaio registra, através de um sistema automático de aquisição de dados, a força e o deslocamento do pistão. Além desses valores, também foram medidos os deslocamentos na região da ligação, por meio de transdutores posicionados manualmente.

Figura 23 - Esquema estático de ensaio

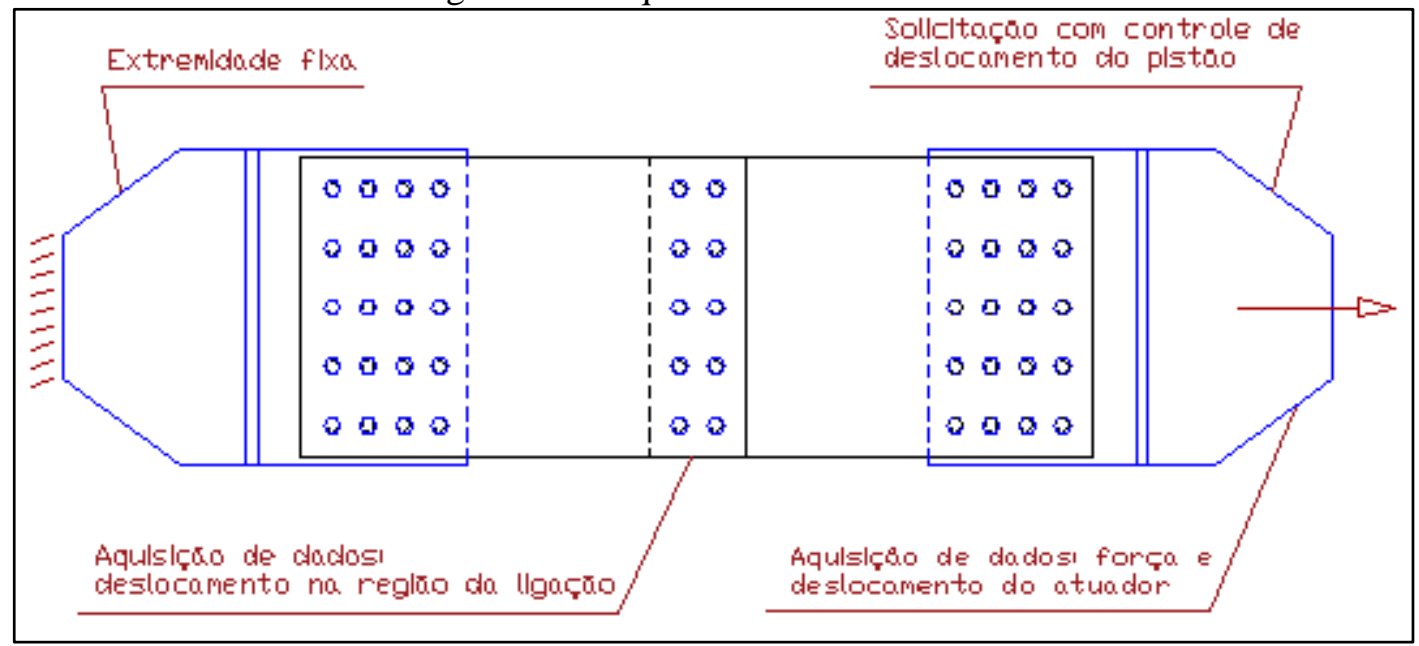

Fonte: o autor.

As chapas utilizadas possuem revestimento de zinco no padrão $450 \mathrm{~g} / \mathrm{m}^{2}$, que corresponde a uma espessura de 0,064 mm considerando ambas as faces, e cujo valor não é descontado na espessura nominal da chapa. Para efeitos de cálculo, a espessura de zinco foi descontada da espessura nominal.

Foram obtidos 137 resultados experimentais, sendo 60 relativos ao estudo de Esteves Jr (1990) e 77 provenientes de ensaios realizados no LE-EESC-USP. Destes últimos, 58 advém de trabalhos independentes realizados pelo laboratório em maio e outubro de 2015, e 19 foram executados no âmbito desta dissertação de mestrado, em junho de 2017. Para cada um destes grupos diferentes de ensaio, alguns parâmetros se mantiveram constantes e outros foram variados. A identificação dos corpos de prova foi feita de acordo com o grupo de ensaio e os parâmetros variáveis, suprimindo-se os que se mantiveram constantes, por simplificação. Por exemplo, o segundo ensaio de um corpo de prova com chapa de 1,25 $\mathrm{mm}$ de espessura nominal, parafuso com diâmetro de 10,0 mm, 5 linhas de parafuso paralelas à solicitação e 3 linhas perpendiculares (colunas) foi identificado conforme mostrado na Figura 24. As demais características deste corpo de prova não variaram dentro de seu grupo de ensaio e podem ser obtidas por meio desta referência. 
Figura 24 - Exemplo de identificação de corpo de prova

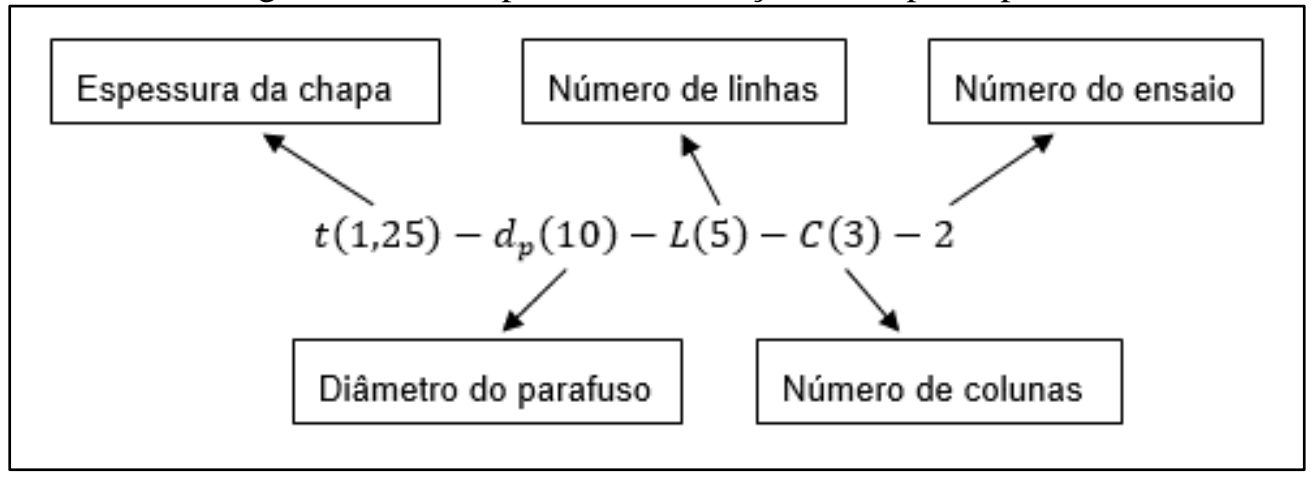

Fonte: o autor.

A seguir são mostradas as características de cada grupo de ensaio. A descrição completa de cada corpo de prova é apresentada no Apêndice A - Configurações dos corpos de prova.

\subsubsection{Ensaios realizados por (ESTEVES JR, 1990)}

A Figura 25 mostra os parâmetros que foram variados na série de ensaios realizados por Esteves Jr (1990).

Figura 25 - Parâmetros variáveis nos ensaios de (ESTEVES JR, 1990)

$$
t\left(\begin{array}{l}
0,96 \\
1,26 \\
1,56 \\
1,90
\end{array}\right)-d_{p}\left(\begin{array}{l}
08 \\
10
\end{array}\right)-L(4)-C\left(\begin{array}{l}
1 \\
2 \\
3
\end{array}\right)-\left(\begin{array}{l}
1 \\
2 \\
3 \\
4
\end{array}\right)
$$

Fonte: o autor

Os parâmetros que foram mantidos constantes são descritos a seguir:

a) Tipo da chapa: corrugada;

b) Montagem do corpo de prova: composição simples;

c) Tensão de escoamento e de ruptura do aço:

$$
\begin{aligned}
& -t=0,96 \mathrm{~mm} \rightarrow f_{y}=323 \mathrm{MPa}, f_{u}=375 \mathrm{MPa} \\
& -\quad t=1,26 \mathrm{~mm} \rightarrow f_{y}=295 \mathrm{MPa}, f_{u}=366 \mathrm{MPa} \\
& -\quad t=1,56 \mathrm{~mm} \rightarrow f_{y}=274 \mathrm{MPa}, f_{u}=360 \mathrm{MPa} \\
& -\quad t=1,90 \mathrm{~mm} \rightarrow f_{y}=297 \mathrm{MPa}, f_{u}=375 \mathrm{MPa}
\end{aligned}
$$

d) Diâmetro dos furos:

$$
-d_{b}=8,0 \mathrm{~mm} \rightarrow d_{f}=9,5 \mathrm{~mm}
$$




$$
-d_{b}=10,0 \mathrm{~mm} \rightarrow d_{f}=11,5 \mathrm{~mm}
$$

e) Distância entre borda e furo na direção longitudinal: $x_{1}=30,0 \mathrm{~mm}$

f) Distância entre furos na direção longitudinal: $x_{2}=30,0 \mathrm{~mm}$

g) Distância entre borda e furo na direção perpendicular: variável, pois o processo manual de corte das chapas, neste caso, não resultou em um valor padrão para esta dimensão. Consultar Apêndice A - Configurações dos corpos de prova;

h) Distância entre furos na direção perpendicular: $y_{2}=52,2 \mathrm{~mm}$

i) Arruelas duplas.

A Figura 26 mostra os corpos de prova ensaiados por (ESTEVES JR, 1990).

Figura 26 - Corpos de prova ensaiados por (ESTEVES JR, 1990) com (a) uma, (b) duas e (c) três linhas de parafusos na direção perpendicular à solicitação

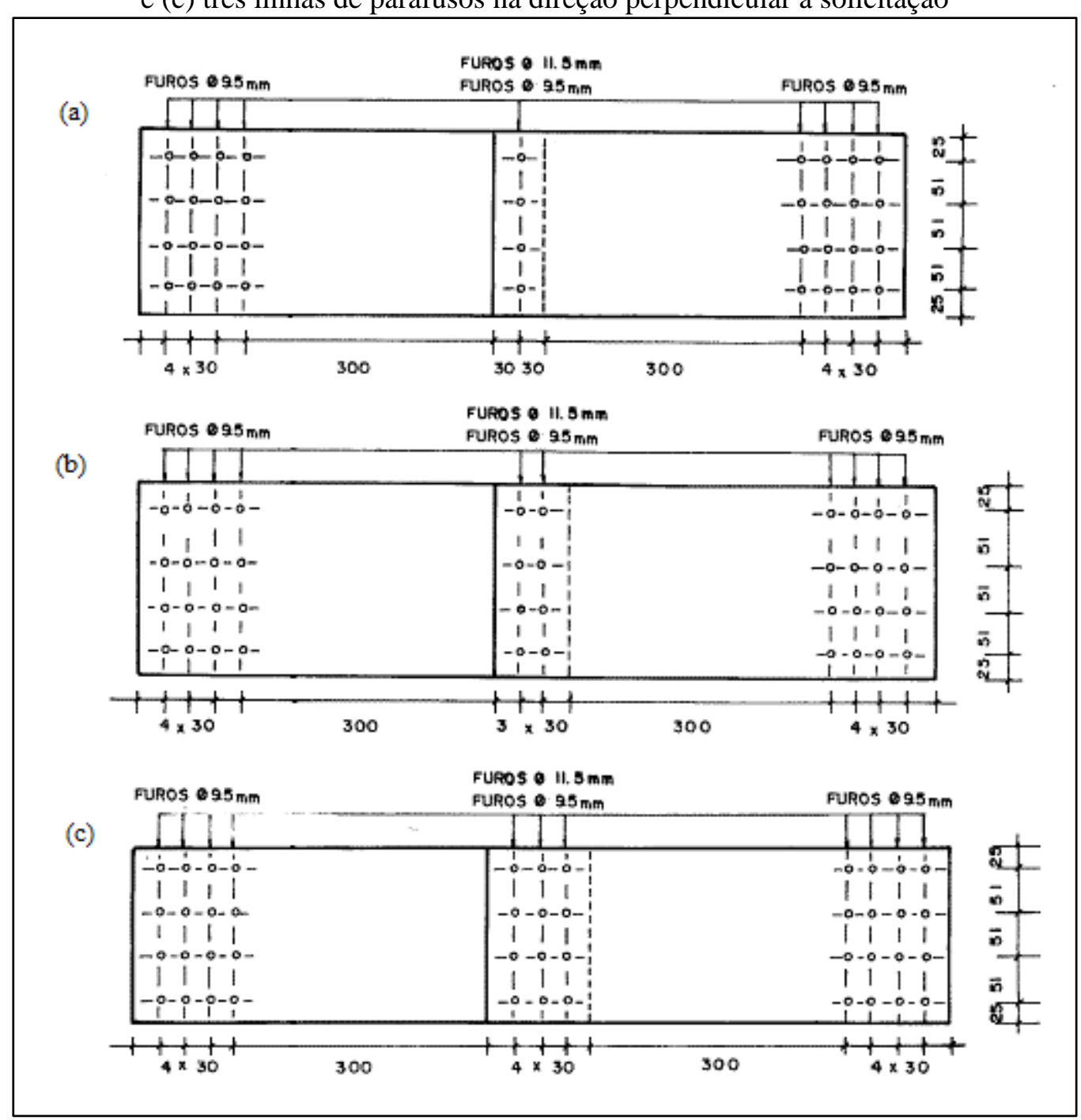

Fonte: adaptado de (ESTEVES JR, 1990) 


\subsubsection{Ensaios realizados no LE-EESC-USP em maio de 2015}

A Figura 27 mostra os parâmetros que foram variados na série de ensaios realizados no LE-EESC-USP em maio de 2015.

Figura 27 - Parâmetros variáveis nos ensaios do

LE-EESC-USP em maio de 2015

$$
t\left(\begin{array}{l}
0,95 \\
1,25 \\
1,55 \\
1,95
\end{array}\right)-d_{p}(10)-L(5)-C\left(\begin{array}{l}
2 \\
3
\end{array}\right)-\left(\begin{array}{l}
1 \\
2 \\
3
\end{array}\right)
$$

Fonte: o autor

Os parâmetros que foram mantidos constantes são descritos a seguir:

a) Tipo da chapa: corrugada;

b) Montagem do corpo de prova: composição simples;

c) Tensão de escoamento e de ruptura do aço:

$-\quad t=0,95 \mathrm{~mm} \rightarrow f_{y}=431 \mathrm{MPa}, f_{u}=484 \mathrm{MPa}$

- $t=1,25 \mathrm{~mm} \rightarrow f_{y}=662 \mathrm{MPa}, f_{u}=674 \mathrm{MPa}$

- $t=1,55 \mathrm{~mm} \rightarrow f_{y}=604 \mathrm{MPa}, f_{u}=630 \mathrm{MPa}$

$-\quad t=1,95 \mathrm{~mm} \rightarrow f_{y}=573 \mathrm{MPa}, f_{u}=608 \mathrm{MPa}$

d) Diâmetro dos furos: $d_{f}=11 \mathrm{~mm}$

e) Distância entre borda e furo na direção longitudinal: $x_{1}=27,2 \mathrm{~mm}$

f) Distância entre furos na direção longitudinal: $x_{2}=31,9 \mathrm{~mm}$

g) Distância entre borda e furo na direção perpendicular: $y_{1}=28,4 \mathrm{~mm}$

h) Distância entre furos na direção perpendicular: $y_{2}=52,2 \mathrm{~mm}$

i) Arruela simples. 
A Figura 28 mostra os corpos de prova ensaiados no LE-EESC-USP em maio de 2015.

Figura 28 - Corpos de prova ensaiados no LE-EESC-USP em maio de 2015 com (a) duas e (b) três linhas de parafusos na direção perpendicular à solicitação

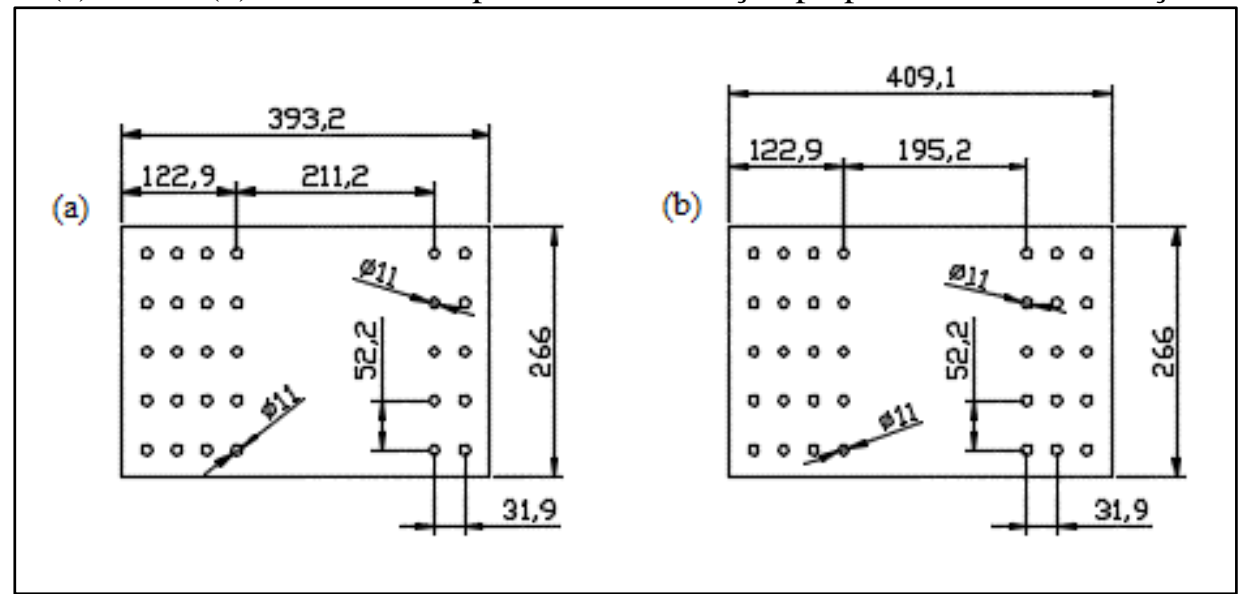

Fonte: o autor.

\subsubsection{Ensaios realizados no LE-EESC-USP em outubro de 2015}

A Figura 29 mostra os parâmetros que foram variados na série de ensaios realizados no LE-EESC-USP em outubro de 2015.

Figura 29 - Parâmetros variáveis nos ensaios do LE-EESC-USP em outubro de 2015

$$
t\left(\begin{array}{l}
1,55 \\
2,70
\end{array}\right)-d_{p}\left(\begin{array}{l}
10 \\
12
\end{array}\right)-L\left(\begin{array}{l}
3 \\
4 \\
5
\end{array}\right)-C\left(\begin{array}{l}
2 \\
3 \\
4
\end{array}\right)-\left(\begin{array}{l}
1 \\
2 \\
3
\end{array}\right)
$$

Fonte: o autor.

Os parâmetros que foram mantidos constantes são descritos a seguir.

a) Tipo da chapa: corrugada ou plana;

b) Montagem do corpo de prova: composição simples e dupla;

c) Furação: coincidente;

d) Tensão de escoamento e de ruptura do aço:

$$
\begin{aligned}
& -t=1,55 \mathrm{~mm} \rightarrow f_{y}=551 \mathrm{MPa}, f_{u}=576 \mathrm{MPa} \\
& -\quad t=2,70 \mathrm{~mm} \rightarrow f_{y}=490 \mathrm{MPa}, f_{u}=523 \mathrm{MPa}
\end{aligned}
$$

e) Diâmetro dos furos:

$$
\begin{aligned}
& -d_{b}=10,0 \mathrm{~mm} \rightarrow d_{f}=11,0 \mathrm{~mm} \\
& -\quad d_{b}=12,0 \mathrm{~mm} \rightarrow d_{f}=14,0 \mathrm{~mm}
\end{aligned}
$$

f) Distância entre borda e furo na direção longitudinal: $x_{1}=27,2 \mathrm{~mm}$ 
g) Distância entre furos na direção longitudinal: $x_{2}=31,9 \mathrm{~mm}$

h) Distância entre borda e furo na direção perpendicular: $y_{1}=28,4 \mathrm{~mm}$

i) Distância entre furos na direção perpendicular:
a. $L=5 \rightarrow y_{2}=52,2$
b. $L=3$ ou $L=4 \rightarrow y_{2}=104,4$

j) Arruela simples.

A Figura 30 mostra os corpos de prova ensaiados no LE-EESC-USP em outubro de 2015.

Figura 30 - Corpos de prova ensaiados no LE-EESC-USP em outubro de 2015 variando (L, C) em (a) $(5,2),($ b) $(5,3),(c)(4,3),(d)(3,3),(e)(4,4)$ e (f) $(3,4)$

(a)

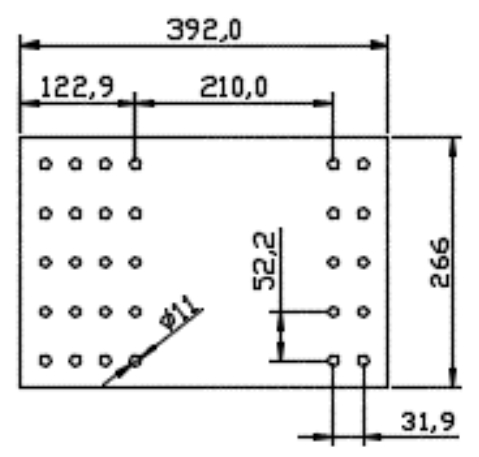

(c)

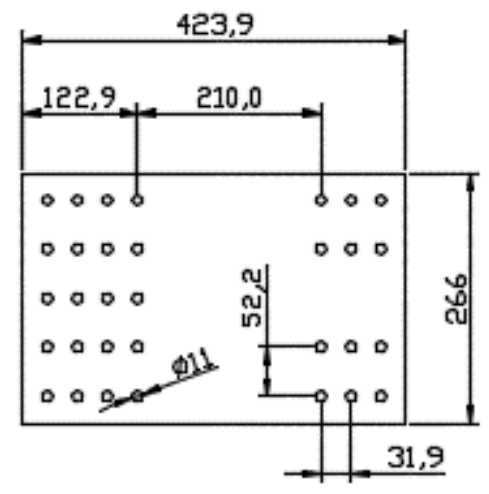

(e)

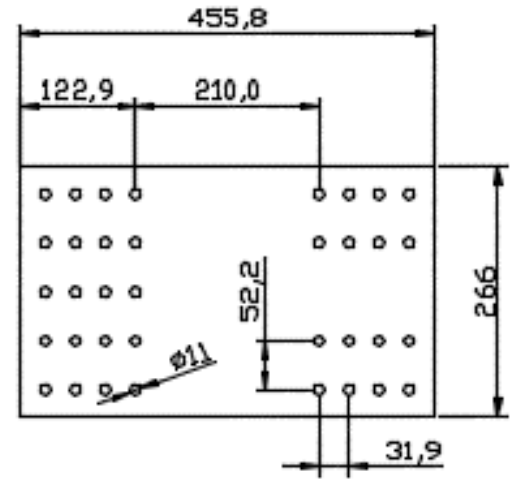

(b)

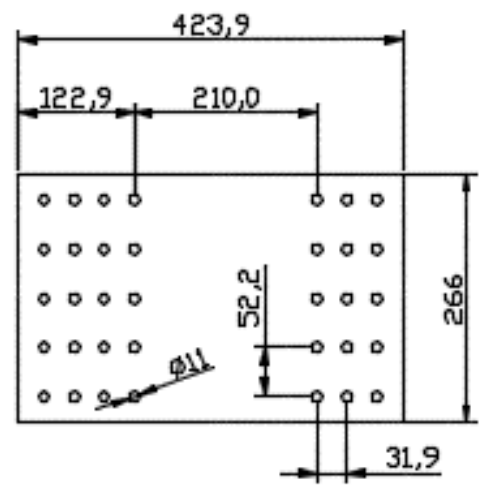

(d)

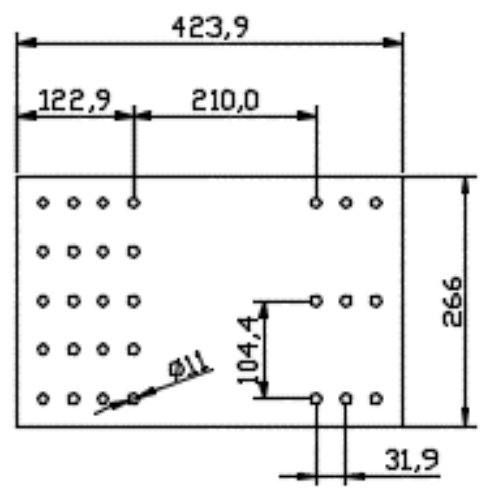

(f)

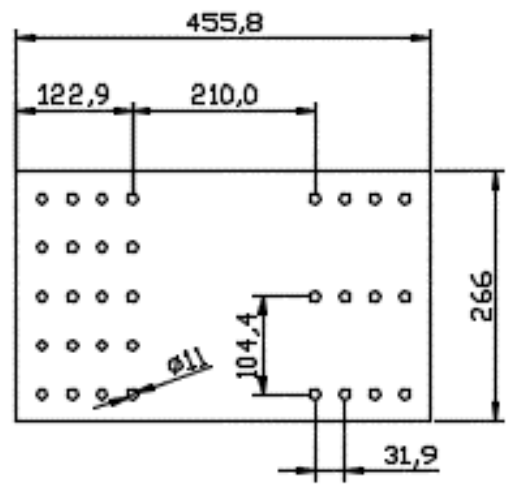

Fonte: o autor. 
A Figura 31 mostra os parâmetros que foram variados na série de ensaios realizados no LE-EESC-USP em junho de 2017.

Figura 31 - Parâmetros variáveis nos ensaios do LE-EESC-USP em junho de 2017

$$
t\left(\begin{array}{l}
3,10 \\
3,90
\end{array}\right)-d_{p}\left(\begin{array}{l}
10 \\
12
\end{array}\right)-L(5)-C\left(\begin{array}{l}
2 \\
3
\end{array}\right)-\left(\begin{array}{l}
1 \\
2
\end{array}\right)
$$

Fonte: o autor.

Os parâmetros que foram mantidos constantes são descritos a seguir.

a) Tipo da chapa: corrugada;

b) Montagem do corpo de prova: composição dupla;

c) Furação: defasada ou coincidente;

d) Tensão de escoamento e de ruptura do aço:

$-t=3,10 \mathrm{~mm} \rightarrow f_{y}=447 \mathrm{MPa}, f_{u}=526 \mathrm{MPa}$

$-t=3,90 \mathrm{~mm} \rightarrow f_{y}=421 \mathrm{MPa}, f_{u}=518 \mathrm{MPa}$

e) Diâmetro dos furos:

- $d_{b}=10,0 \mathrm{~mm} \rightarrow d_{f}=11,0 \mathrm{~mm}$

$-d_{b}=12,0 \mathrm{~mm} \rightarrow d_{f}=14,0 \mathrm{~mm}$

f) Distância entre borda e furo na direção longitudinal: $x_{1}=27,2 \mathrm{~mm}$

g) Distância entre furos na direção longitudinal: $x_{2}=31,9 \mathrm{~mm}$

h) Distância entre borda e furo na direção perpendicular: $y_{1}=28,4 \mathrm{~mm}$

i) Distância entre furos na direção perpendicular: $y_{2}=52,2 \mathrm{~mm}$

j) Arruela simples. 
A Figura 32 mostra os corpos de prova ensaiados no LE-EESC-USP em junho de 2017.

Figura 32 - Corpos de prova ensaiados no LE-EESC-USP em junho de 2017 com (a) três e (b) duas linhas de parafusos na direção perpendicular à solicitação

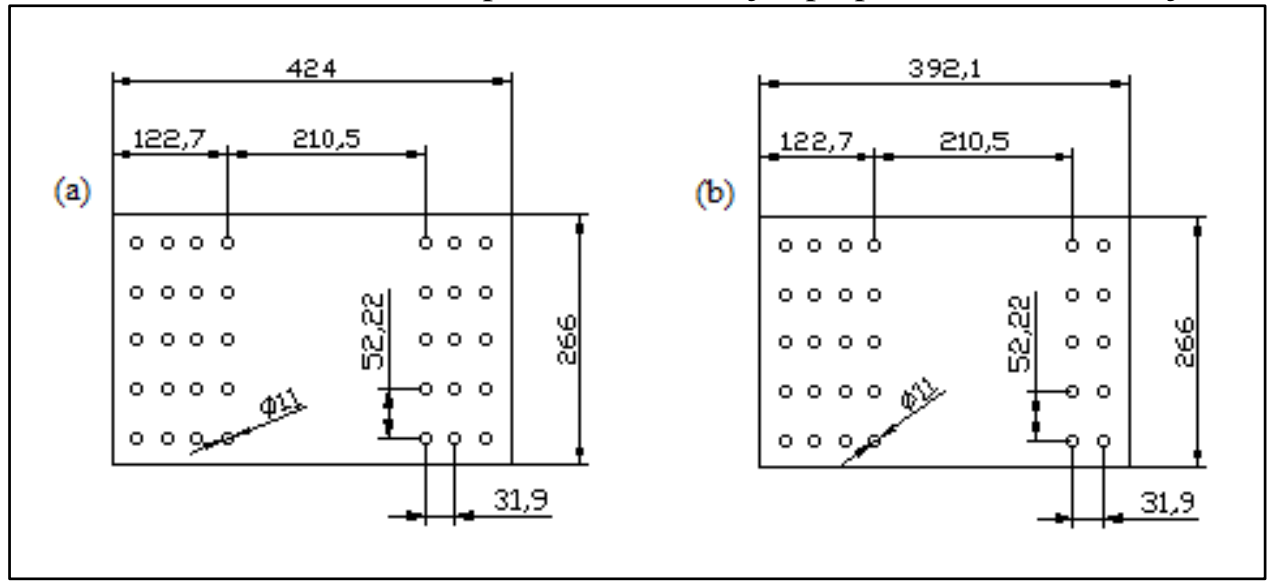

Fonte: o autor.

\subsection{Realização dos ensaios}

Este item se refere aos procedimentos de montagem, instrumentação, execução e análise dos resultados referentes ao ensaios realizados no LE-EESC-USP. As mesmas informações, relativas aos ensaios realizados por Esteves Jr (1990), encontram-se em sua dissertação de mestrado, referenciada neste trabalho.

\subsubsection{Montagem e instrumentação dos corpos de prova}

Visando reproduzir a prática corrente de projeto e montagem de silos cilíndricos metálicos, os corpos de prova foram confeccionados com arruela simples e parafusos de alta resistência. A arruela simples corresponde à estampada na cabeça do parafuso, não havendo arruela junto à porca do lado oposto. Os parafusos utilizados foram de alta resistência, com qualificação estrutural, especificação ISO 4016 - classe 8.8 .

De posse dos componentes constituintes dos corpos de prova, a montagem foi iniciada unindo-se as chapas de cada lado pela ligação intermediária. Nesta etapa não foram utilizadas ferramentas de torque, apenas o posicionamento manual dos parafusos e porcas. Os lotes foram posicionados em ordem e local convenientes para ensaio, conforme Figura 33, e um a um foram preparados, conforme descrito em sequência. 
Figura 33 - Lotes de corpos de prova antes do ensaio

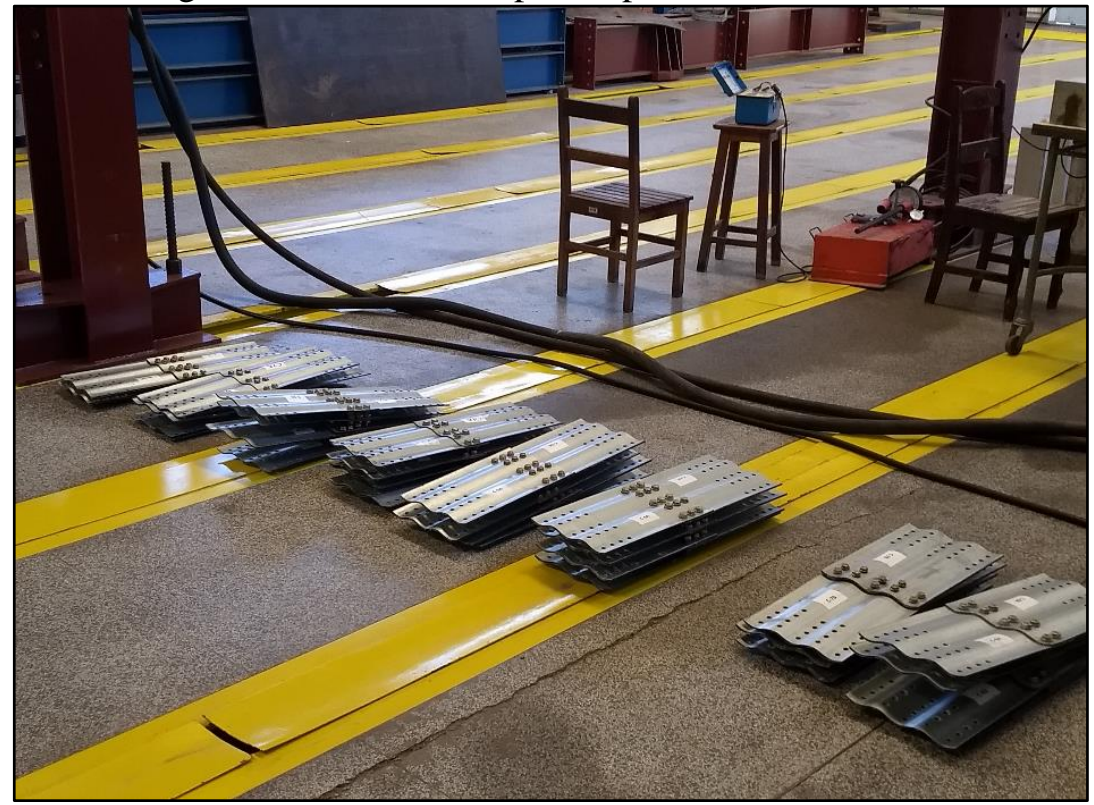

Fonte: o autor

Para a realização do ensaio, as ligações de extremidade do corpo de prova foram parafusadas aos dispositivos de compatibilização, confeccionados sob medida, com uso de parafusadeira elétrica. Estes dispositivos possuíam geometria concordante à dos corpos de prova de um lado, ligados por solda de filete a uma chapa plana do outro, para possibilitar o encaixe com as garras da máquina de ensaio, conforme Figura 34a. Por último foi utilizada a máquina parafusadeira no aperto da ligação intermediária, para evitar que um manuseio posterior causasse perda de torque nesses parafusos. A Figura $34 \mathrm{~b}$ mostra um corpo de prova pronto para ser posicionado na máquina de ensaio.

Figura 34 - Corpo de prova (a) em montagem e (b) prontos para o ensaio

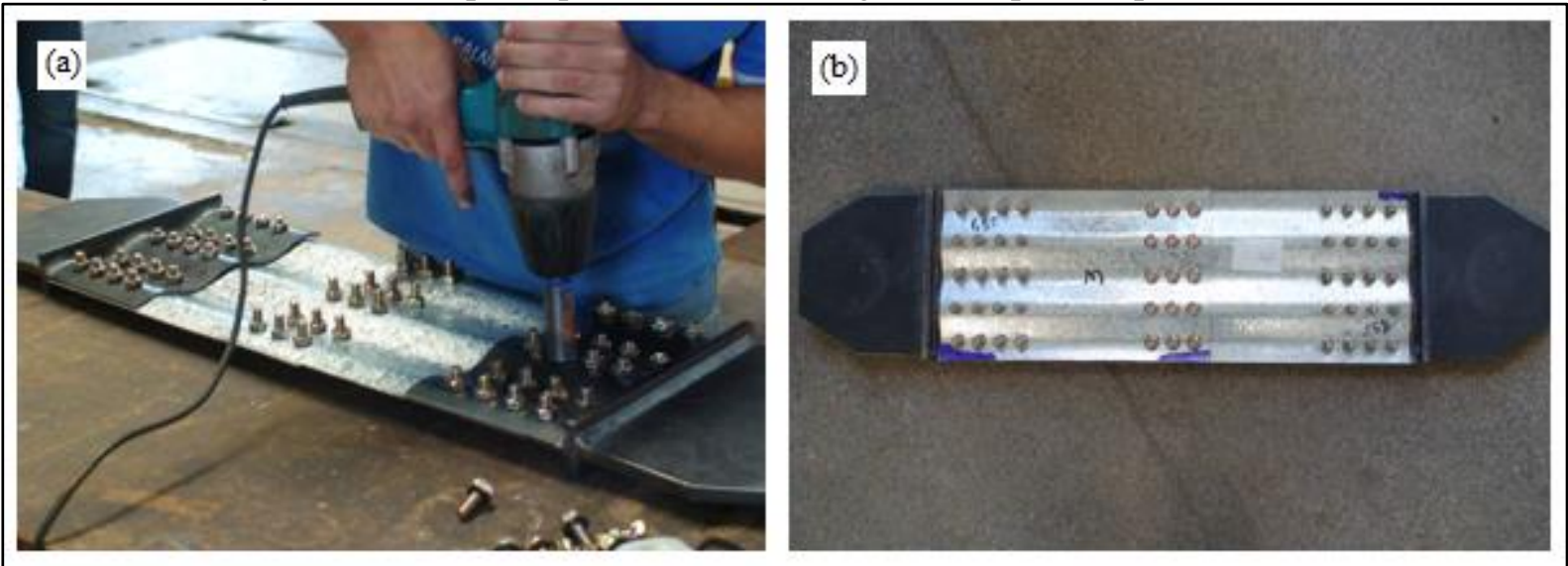

Fonte: o autor.

Após a montagem, o corpo de prova foi posicionado na máquina de ensaio, com seu eixo longitudinal na direção vertical. A Figura 35 mostra esta etapa, em a) com um corpo de prova de chapa corrugada e em b) de chapa plana. A Figura 35c mostra o detalhe de uma 
montagem em composição dupla. A parte de baixo do corpo de prova foi mantida indeslocável e à parte de cima foi aplicada a força, com controle de deslocamento do pistão.

Figura 35 - Corpos de prova com chapa tipo (a) corrugada, (b) plana e (c) montagem em composição dupla

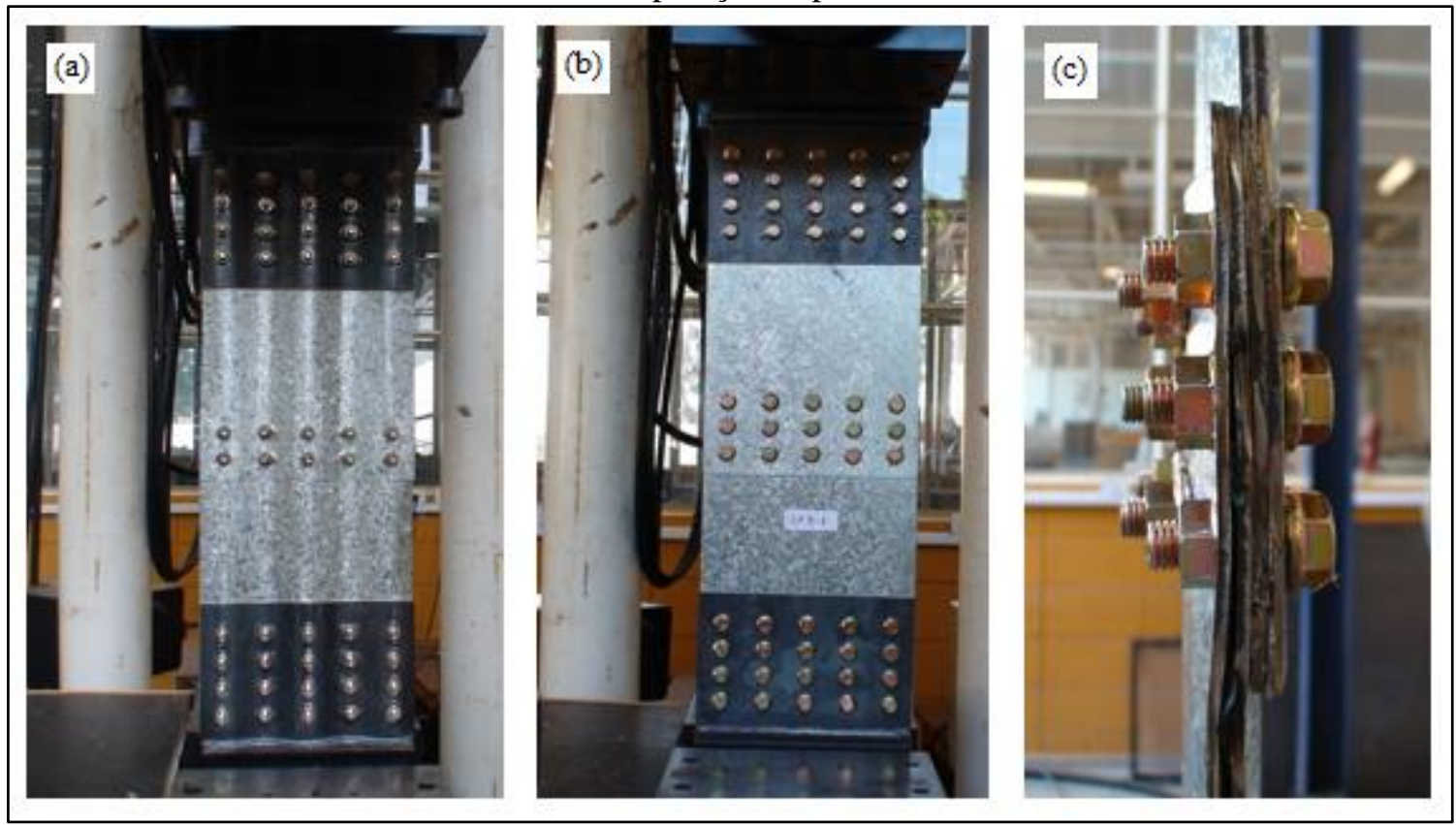

Fonte: o autor.

A máquina de ensaio utilizada registrou automaticamente a força aplicada e o deslocamento equivalente, via um sistema de aquisição de dados. Adicionalmente foram posicionados manualmente dois transdutores de deslocamento na região central do corpo de prova, para medir o deslocamento da ligação durante o ensaio. Os transdutores foram dispostos na direção longitudinal, um na linha de eixo e outro na extremidade do corpo de prova, conforme Figura 36.

Figura 36 - Transdutores de deslocamento

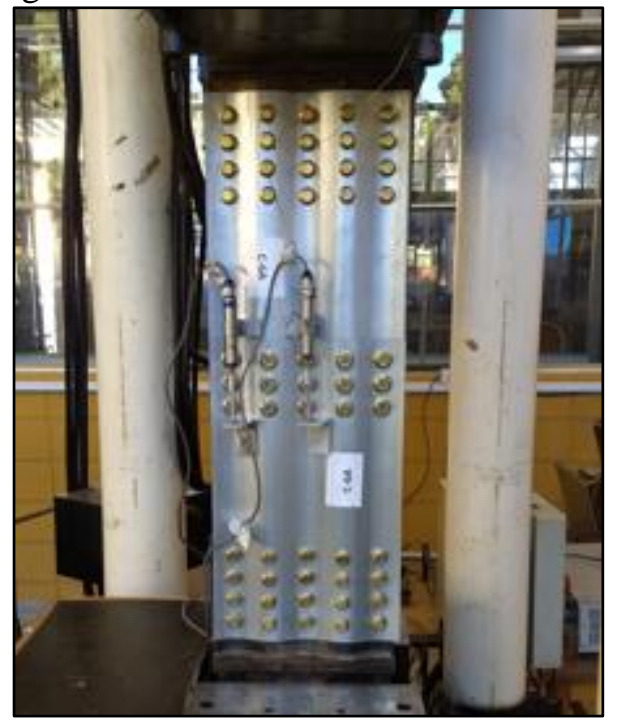

Fonte: o autor. 
Nesta etapa, todos os procedimentos necessários à realização do ensaio já foram efetuados. Posteriormente à realização do teste, os dispositivos de extremidade e transdutores foram removidos e reaproveitados no corpo de prova subsequente, seguindo o mesmo procedimento.

\subsubsection{Caracterização do aço}

Foi feita a caracterização mecânica do aço empregado nas chapas utilizadas nos ensaios, para cada valor de espessura, em cada lote diferente. Foram determinados os valores da tensão de escoamento e de ruptura do aço, por teste de tração simples. A Figura 37 mostra a geometria do corpo de prova utilizado.

Figura 37 - Corpo de prova para caracterização mecânica do aço

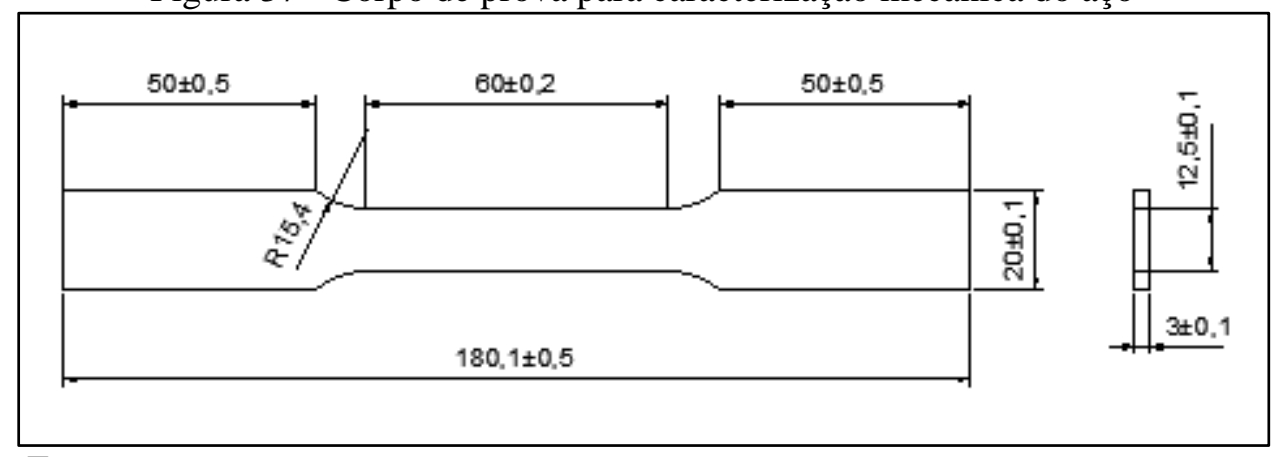

Fonte: o autor.

Os ensaios de caracterização foram realizados nas instalações do Departamento de Engenharia de Materiais da EESC-USP, em virtude do equipamento utilizado ser de pequeno porte, como mostrado na Figura 38a. As extremidades do corpo de prova foram presas às prensas da máquina de ensaio e a porção intermediária, de menor largura, onde ocorreu a falha por tração, foi instrumentada com um extensômetro, conforme Figura 38b. Um sistema de aquisição automática de dados gravou os dados da força aplicada pela máquina e da deformação medida pelo extensômetro ao longo do ensaio. A tensão de escoamento do aço foi obtida pelo patamar de escoamento no gráfico de tensão versus deformação do ensaio, e a tensão de ruptura foi determinada pelo máximo valor suportado pelo corpo de prova, todos os valores sendo em tensões e deformações de engenharia. A Figura 38c mostra um corpo de prova após a realização do ensaio. 
Figura 38 - Representação da a) prensa, b) extensômetro e c) corpo de prova rompido referentes à caracterização do aço

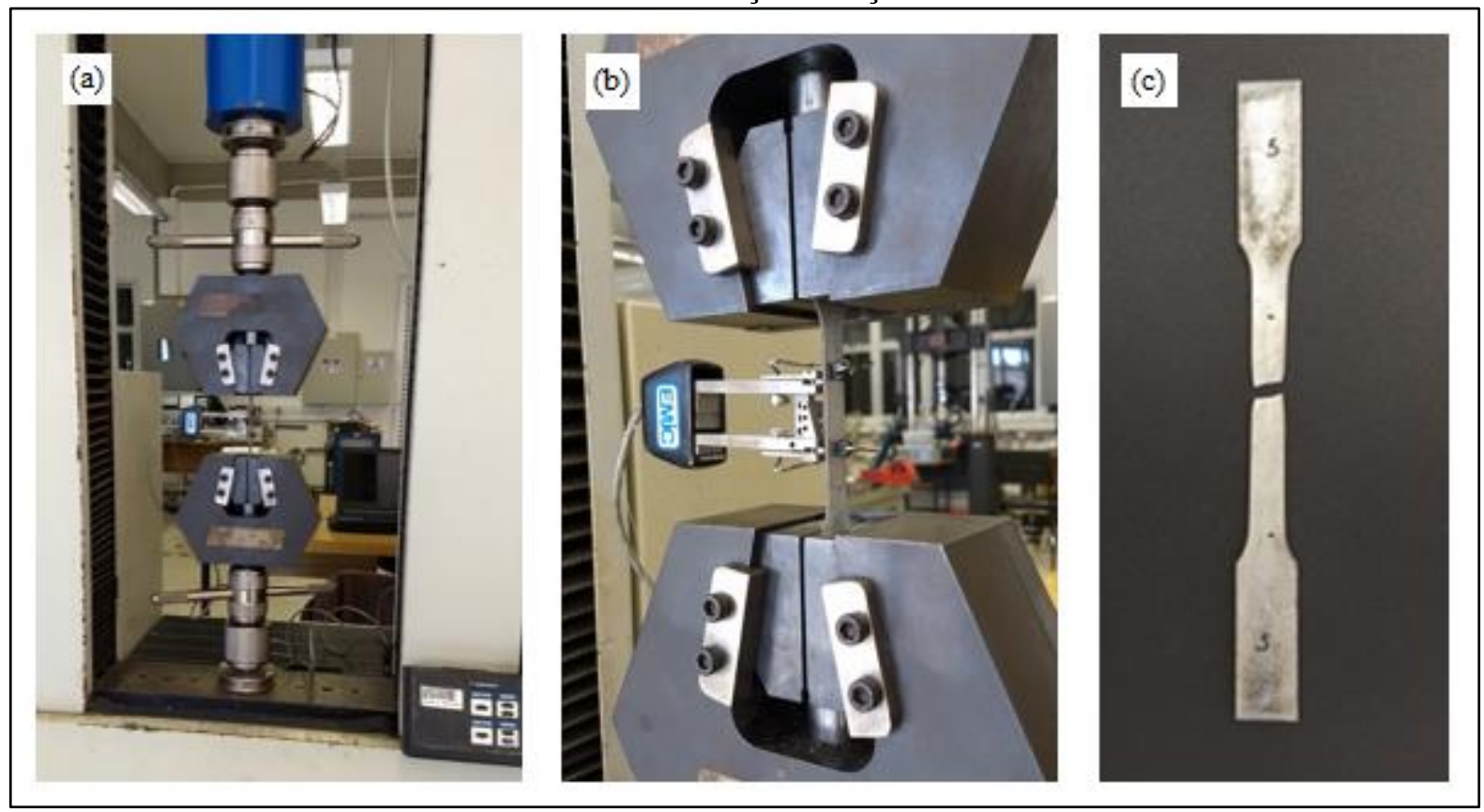

Fonte: o autor.

\subsubsection{Procedimentos de execução e análise}

Os corpos de prova foram ensaiados na máquina servo-hidráulica modelo INSTRON 8506, do LE-EESC-USP, mostrada na Figura 39. A força de tração foi aplicada com controle de deslocamento do pistão a uma taxa de $2,0 \mathrm{~mm} / \mathrm{min}$ com intervalo de aquisição de dados de $1 \mathrm{~s}$. Os ensaios foram realizados sem restrições quanto ao deslocamento máximo, uma vez que a acomodação inicial, referente à folga entre os diâmetros dos furos e dos parafusos, por si só, já causaram um deslocamento considerável. Nesse sentido, Rogers e Hancock (1998) afirmam que um ensaio com limite de deslocamento pode não levar o corpo de prova à ruína. 
Figura 39 - Máquina de ensaio e sistema de aquisição de dados

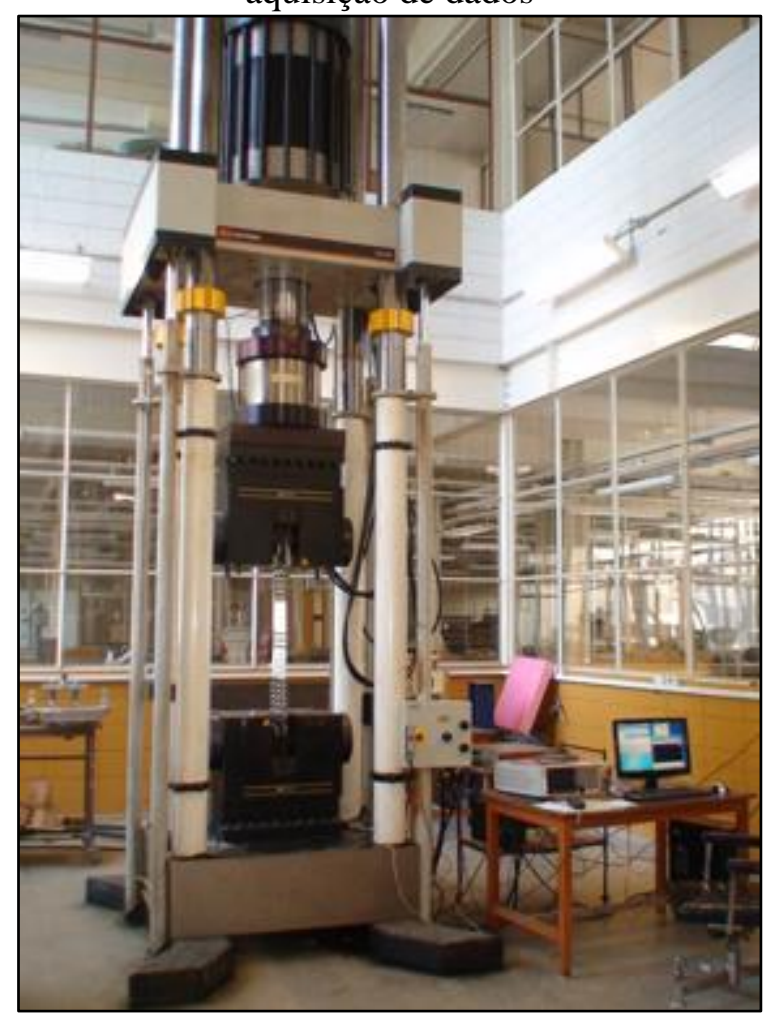

Fonte: o autor

Os resultados primários da investigação experimental deste trabalho são a resistência da ligação ensaiada e seu respectivo modo de falha. A resistência experimental foi considerada como a força máxima registrada durante o ensaio e seu modo de falha correspondente foi atribuído por inspeção visual. São estes os resultados que foram comparados com modelos teóricos de normas de dimensionamento estrutural. Também foi feito um registro fotográfico de todos os corpos de prova, íntegros e rompidos. Estes dados, juntamente com os provenientes da instrumentação, forneceram subsídio à interpretação dos resultados. 


\section{RESULTADOS E DISCUSSÃO}

Neste capítulo apresenta-se os resultados da análise experimental realizada e sua comparação com os valores teóricos obtidos pelas normas de dimensionamento de perfis formados a frio vigentes no Brasil, EUA, Austrália e Europa.

Nos ensaios realizados foi observada ocorrência de dois modos de falha distintos, o esmagamento da parede do furo e a ruptura da chapa na seção líquida. Para as configurações de corpos de prova ensaiadas, que abrangem variações de interesse com aplicação prática em chapas de parede de silos cilíndricos metálicos, os demais modos de falha não constituíram casos críticos. Os resultados completos de todos os ensaios, contendo informações de força última experimental, modo de falha verificado e valores teóricos correspondentes, referentes às normas utilizadas, encontram-se no Apêndice B - Resultados dos ensaios e no Apêndice C Resultados teóricos e experimentais.

O modelo estrutural considerado na análise da solicitação e resistência da ligação parafusada é mostrado na Figura 40. Considerou-se que todos os parafusos são solicitados com a mesma intensidade. Em um estágio inicial de carregamento esta hipótese pode não ser precisa devido a excentricidades de montagem inerentes aos procedimentos experimentais, mas à medida que ocorre a plastificação do aço, há redistribuição de esforços e tendência de uniformizar o carregamento por parafuso. A tensão normal solicitante na chapa foi adotado constante na seção transversal e proporcional ao número relativo de parafusos na seção correspondente e anteriores. Deste modelo, depreende-se que a falha por esmagamento se torna crítica em situações de número insuficiente de parafusos, os quais solicitam excessivamente a chapa na borda dos furos. Quando o número de parafusos não é limitante, a resistência da ligação fica condicionada à capacidade resistente da área líquida da chapa. Em ambos os casos, a ruína ocorre na seção crítica, correspondente à última linha de parafusos na direção perpendicular à solicitação, onde a força normal é máxima. 
Figura 40 - Mecanismo de resistência da chapa

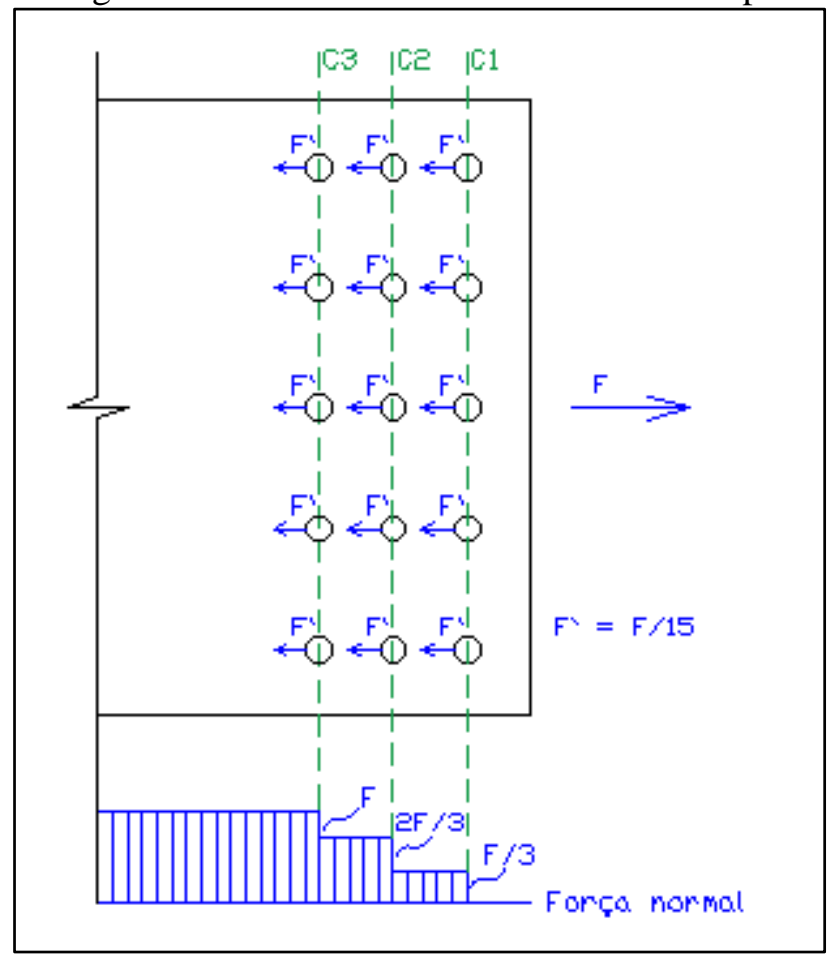

Fonte: o autor.

Na comparação entre os valores experimentais de resistência das ligações ensaiadas com a dos modelos teóricos das normas consideradas, adotou-se o procedimento da norma NBR 14762:2010 para a análise de resultados experimentais. Segundo essa especificação, o valor médio obtido em ensaio deve ser tomado como o valor nominal do esforço resistente. Esta determinação é idêntica à da norma AISI S100-16.

\subsection{Ruptura da chapa na seção líquida}

A falha da ligação por ruptura na seção líquida caracterizou-se pelo esgotamento da capacidade resistente da chapa na seção crítica, conforme mostrado na Figura 41. Neste modo de falha ocorreu a plastificação do aço na região da ligação sem que houvesse, contudo, grandes deformações na região dos furos. Este processo prosseguiu até a ruptura do aço, ocasionando fratura de material junto à borda de algum furo pertencente à seção crítica, a qual propagou-se em sequência na direção perpendicular à solicitação até a borda de um furo adjacente ou à borda da chapa. Nas condições de realização dos ensaios, com controle de deslocamento do pistão, a ocorrência da fratura causou uma queda abrupta na força solicitante, caracterizando o fim do teste. Foi verificada estricção da chapa na seção crítica nas duas dimensões da seção transversal. Não houve deslocamento fora do plano na chapa e nem esmagamento pronunciado da parede 
do furo, o que resultou em uma linha de ruptura bem definida, coincidente com a linha da furação original.

Figura 41 - Corpo de prova com ruptura da seção líquida (a) montado e (b) desmontado

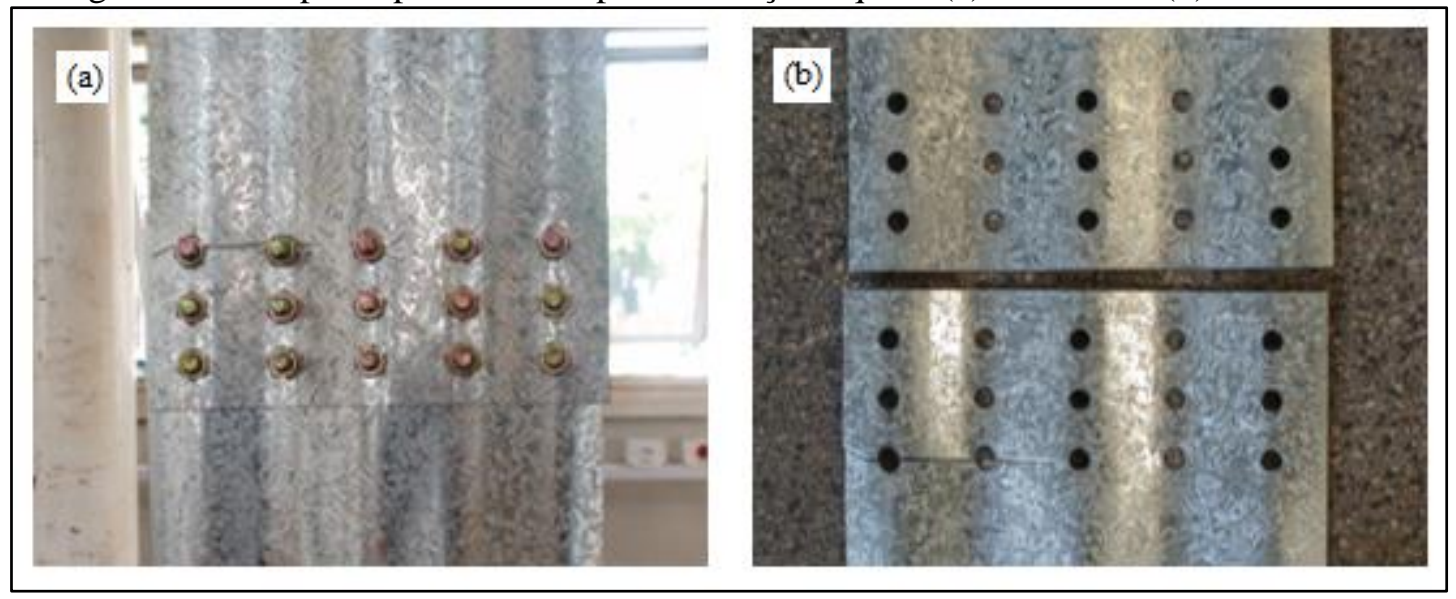

Fonte: o autor.

O modelo de cálculo da resistência à ruptura da seção líquida neste tipo de ligação parafusada diverge entre as normas de dimensionamento estrutural quanto à adoção ou não e à formulação de um coeficiente redutor da área líquida. O produto deste coeficiente pela área líquida da seção transversal resulta em uma área efetiva, que multiplicada pela tensão de ruptura do aço fornece a resistência de uma dada seção transversal da ligação, conforme Equação 36.

$$
F_{R}=C_{\text {red }} A_{n} f_{u}
$$

No caso de não se considerar o coeficiente redutor, ou considerá-lo unitário, assume-se que a seção transversal líquida é capaz, em sua totalidade, de mobilizar uma tensão igual à tensão de ruptura do aço. No caso deste coeficiente ser menor do que a unidade, considera-se que apenas uma porção efetiva da seção transversal líquida é capaz de atingir a tensão de ruptura. A formulação deste coeficiente é empírica e depende de fatores como diâmetro do parafuso e disposição dos furos.

A análise dos corpos de prova que apresentaram este modo de falha foi feita em termos do coeficiente redutor da área líquida, experimental para os testes realizados, e teórico para os modelos das normas consideradas. O coeficiente redutor da área líquida experimental foi definido como a razão $F_{u l t} / A_{n} f_{u}$ e o teórico conforme equação do modelo. Os resultados são apresentados a seguir de forma individual para cada norma. 


\subsubsection{Ruptura da seção líquida pela norma AISI S100-16}

No modelo de cálculo da resistência de uma ligação parafusada à falha por ruptura da seção líquida, a norma AISI S100-16 estabelece um coeficiente redutor conforme a Equação 37 a seguir.

$$
U_{s l}=0,9+0,1 \cdot d_{b} / s
$$

O uso desta norma previu corretamente $97 \%$ das ocorrências onde a ruína se deu por ruptura da seção líquida. Para estes casos, a Figura 42 mostra graficamente o coeficiente redutor da área líquida teórico, como função do parâmetro $d_{b} / s$, e o coeficiente experimental, em função do mesmo parâmetro, com seus valores amostrais em a) e representados pela média e desvio padrão em intervalos bem definidos em b). A distribuição dos ensaios nestes intervalos, com relação ao parâmetro $d_{b} / s$, é explicada na Tabela 2 .

Tabela 2 - Intervalos para ruptura da seção líquida pela norma AISI S100-16

\begin{tabular}{|c|c|c|c|c|c|}
\hline Intervalo & $l_{c}(\mathrm{~mm})$ & $N L$ & $s(\mathrm{~mm})$ & $d_{b}(\mathrm{~mm})$ & $d_{b} / s$ \\
\hline a) & 266 & 3 & 88,7 & 10,0 & 0,113 \\
\hline \multirow{2}{*}{$\mathrm{b})$} & $215^{*}$ & 4 & 53,8 & 8,0 & 0,149 \\
\cline { 2 - 6 } & 266 & 4 & 66,5 & 10,0 & 0,150 \\
\hline \multirow{2}{*}{$\mathrm{c})$} & $215^{*}$ & 4 & 53,8 & 10,0 & 0,186 \\
\cline { 2 - 6 } & 266 & 5 & 53,2 & 10,0 & 0,188 \\
\hline d) & 266 & 5 & 53,2 & 12,0 & 0,226 \\
\hline
\end{tabular}

*Ensaios realizados por (ESTEVES JR, 1990), em que o comprimento de corte das chapas não foi idêntico para em todos os casos. Vide Apêndice A.

Fonte: o autor. 
Figura 42 -Modelo da norma AISI S100-16 e resultados experimentais de ruptura da seção líquida com valores (a) amostrais e (b) em média e desvio padrão

(a)

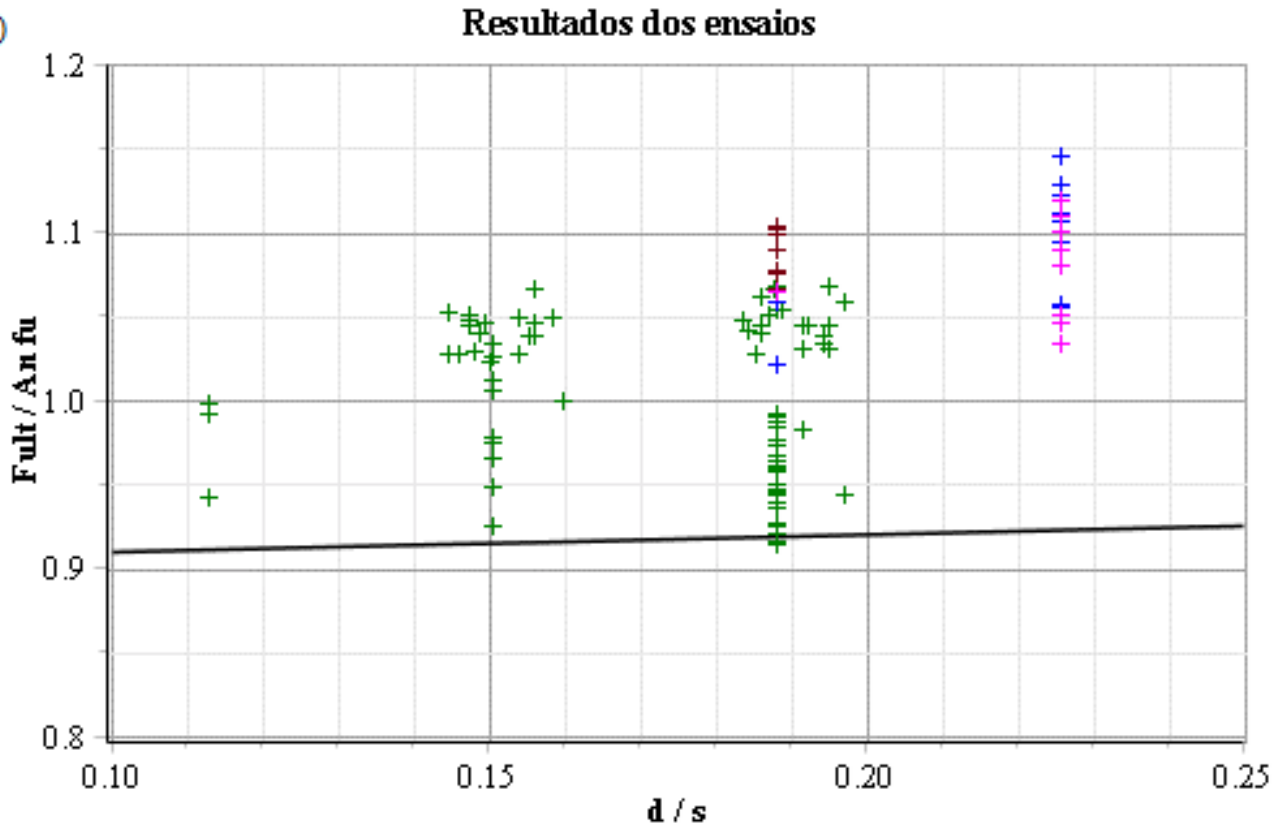

(b)

Média e desvio padrão

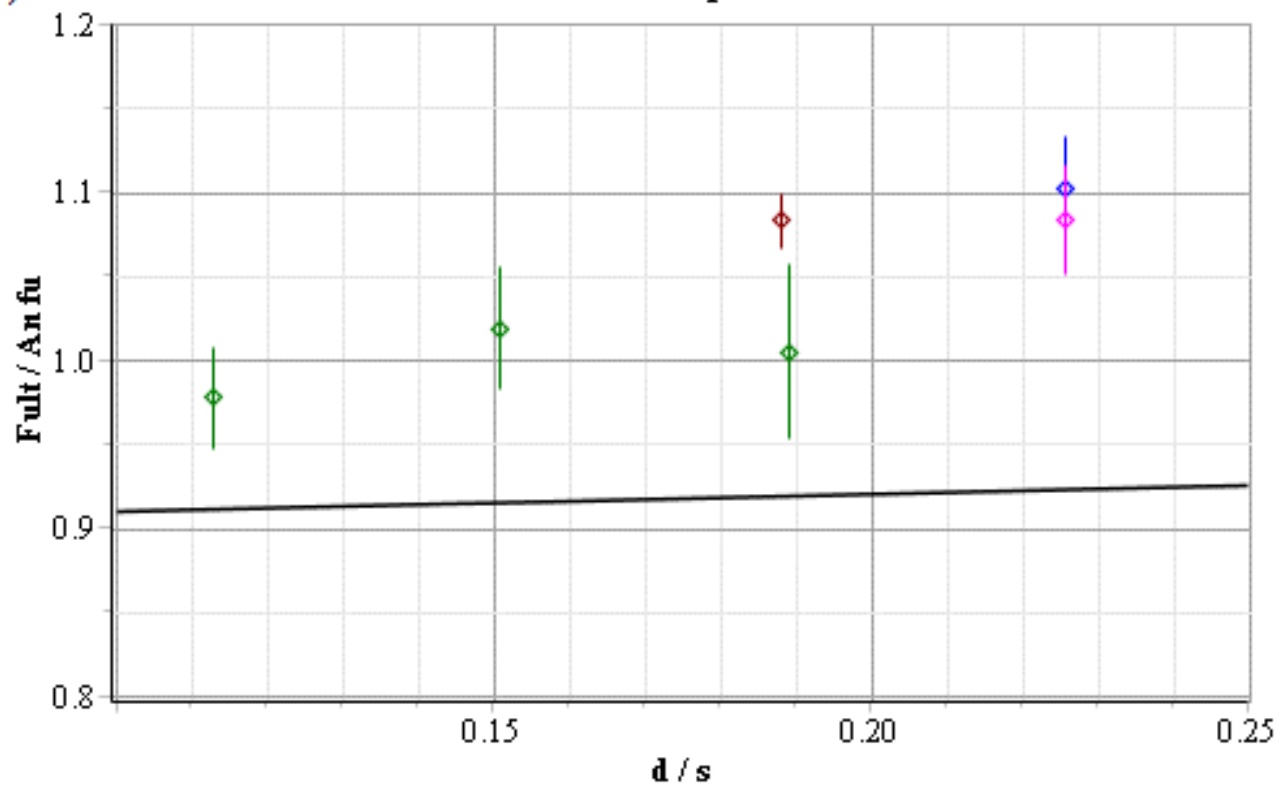

$+\quad$ Ch. simples corrugada

$+\quad$ Ch. simples plana

+ Ch. dupla corrugada fur. coincidente

$+\quad$ Ch. dupla corrugada fur. defasada AISI S100-16

$\diamond \quad$ Ch. simples corrugada

- Ch. simples plana

- Ch. dupla corrugada fur. coincidente

- Ch. dupla corrugada fur. defasada AISI S100-16

Fonte: o autor. 
As diferentes configurações de corpos de prova que resultaram nos intervalos de análise são mostradas na Figura 43. O intervalo a) corresponde aos corpos de prova com furos em cristas alternadas da chapa corrugada, resultando em 3 parafusos de diâmetro nominal $10 \mathrm{~mm}$ por seção. O intervalo b) compreende as configurações com uma crista intermediária sem furo, entre os 4 parafusos de diâmetro nominal $10 \mathrm{~mm}$ existentes por seção, e também as que empregaram parafuso com diâmetro nominal de $8,0 \mathrm{~mm}$. Os ensaios do intervalo c) possuíam corpos de prova com furos em todas as cristas, perfazendo 5 parafusos de diâmetro nominal 10 mm em cada seção. Por fim, para as configurações do intervalo d), foram usados parafusos de diâmetro nominal $12 \mathrm{~mm}$ nos 5 furos de cada seção. Observa-se que, neste último caso, o aumento do diâmetro do parafuso foi uma necessidade para evitar sua ruína por cisalhamento, pois todas as configurações deste intervalo possuíam montagem em composição dupla, com consequente aumento da força última de ensaio.

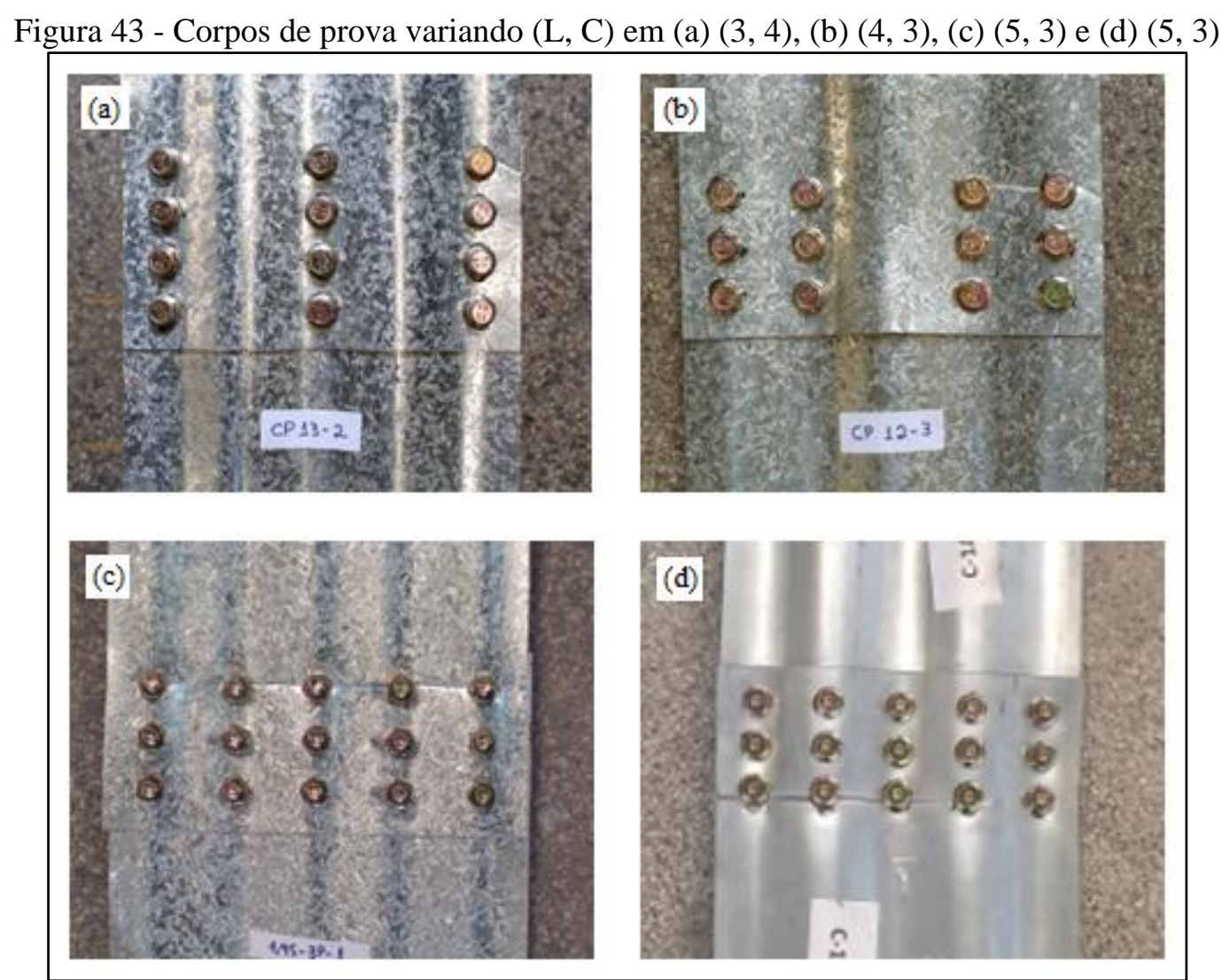

Fonte: o autor.

Nos ensaios realizados por Esteves Jr (1990), o processo de corte das chapas causou variação na dimensão perpendicular à direção da solicitação $\left(l_{c}\right)$ entre os corpos de prova, vide Apêndice A, resultando em valores amostrais com abscissas variáveis, conforme Figura 42a. Para todos os casos anteriores, houve variação de parâmetros dentro de cada intervalo, tais quais espessura da chapa, resistência do aço, número total de parafusos, entre outros, que não foram 
considerados diretamente no coeficiente redutor da área líquida teórico, mas que têm influência na resistência última da ligação.

O coeficiente redutor da área líquida teórico proposto pela norma AISI S100-16, representado pela Equação 37, possui valores compreendidos entre 0,90 e 0,95 para configurações usuais de ligações parafusadas empregadas em chapas de parede de silos cilíndrico metálicos, a depender do parâmetro adimensional $d_{b} / s$. Não há distinção em caso de chapa corrugada ou plana e montagem em composição simples ou dupla. Os resultados obtidos mostram que existe diferença e que, para todos os casos, o modelo é conservador.

A maior parte dos corpos de prova ensaiados possuía chapa corrugada com montagem em composição simples. Para estas configurações, apenas os corpos de prova do intervalo a) resultaram em coeficiente redutor da área líquida experimental menor do que a unidade, com valor médio de 0,98. Nestes casos, devido ao número reduzido de parafusos, houve maior concentração de tensão na borda dos furos, ocasionando uma fratura prematura. Nos demais casos obteve-se valores médios experimentais para o coeficiente de 1,02 e 1,01 para os intervalos b) e c), respectivamente.

Os corpos de prova com chapas planas empregaram montagem em composição simples em todos os casos e constituíram um menor número de ensaios, representados apenas no intervalo c), conforme Figura 42. A resistência da ligação para este caso resultou superior comparada às configurações com chapa corrugada do mesmo intervalo, resultando em coeficiente redutor da área líquida experimental com valor médio de 1,09. A implicação imediata deste resultado é que ensaios empregando chapas planas não caracterizam corretamente casos com chapas corrugadas.

Os ensaios dos corpos de prova com montagem em composição dupla representam o intervalo d), conforme Figura 42, em função do uso de parafuso com diâmetro nominal 12,0 mm. Em comparação com as configurações que empregaram montagem em composição simples, a resistência da ligação resultou sistematicamente elevada, com valor médio do coeficiente redutor da área líquida experimental de 1,11 e 1,08 para os casos de furação coincidente e defasada, respectivamente. Este tipo de montagem permite uma redistribuição de esforços entre as chapas durante o ensaio, de modo que a tensão em ambas se mantém equilibrada até a ruptura do corpo de prova. Consequentemente, os corpos de prova com furação defasada possuem menor capacidade de prover redistribuição de esforços, pois a folga entre a borda do furo e o parafuso em uma das chapas é menor do que na outra. Dessa forma, após a 
acomodação da ligação, uma das chapas se encontra com maiores níveis de solicitação e nela ocorre a ruptura.

A aplicação da norma AISI S100-16 no cálculo da resistência de ligações parafusadas de paredes de silos cilíndricos metálicos sujeitas a falha por ruptura da seção líquida resulta em valores conservadores. Os resultados indicam que um coeficiente redutor da área líquida teórico unitário representa de forma mais simples e adequada os resultados experimentais obtidos, em termos de valores médios. Para o mecanismo de resistência da ligação considerado, não há sentido físico em um coeficiente superior a 1,0. Desta maneira, os casos práticos de montagem em composição dupla ainda estariam a favor da segurança.

\subsubsection{Ruptura da seção líquida pela norma AS/NZS 4600:2005}

A norma AS/NZS 4600:2005 não reduz a área líquida da ligação parafusada a uma área efetiva, no cálculo de sua resistência à falha por ruptura da seção líquida, quando há múltiplos parafusos na linha paralela à solicitação. Isto é equivalente a um coeficiente redutor da área líquida teórico de valor unitário. O uso desta norma previu corretamente $97 \%$ das ocorrências onde a ruína se deu por ruptura da seção líquida. A Figura 44 apresenta os resultados gráficos para o coeficiente redutor da área líquida teórico e experimental. Os ensaios também foram distribuídos em intervalos distintos, conforme o parâmetro $d_{b} / s_{f}$. A constituição destes intervalos é descrita na Tabela 3 e difere da definição da norma americana.

Tabela 3 - Intervalos para ruptura da seção líquida pela norma AS/NZS 4600:2005

\begin{tabular}{|c|c|c|c|c|}
\hline Intervalo & $N L$ & $S_{f}(\mathrm{~mm})$ & $d_{b}(\mathrm{~mm})$ & $d_{b} / s$ \\
\hline \multirow{2}{*}{ a) } & 3 & 104,4 & 10,0 & 0,096 \\
\cline { 2 - 5 } & 4 & 104,4 & 10,0 & 0,096 \\
\hline \multirow{2}{*}{ b) } & 4 & 52,2 & 8,0 & 0,153 \\
\hline \multirow{2}{*}{ c) } & 4 & 52,2 & 10,0 & 0,192 \\
\cline { 2 - 5 } & 5 & 52,2 & 10,0 & 0,192 \\
\hline d) & 5 & 52,2 & 12,0 & 0,230 \\
\hline
\end{tabular}

Fonte: o autor.

Pela definição da norma AS/NZS 4600:2005, o intervalo a) de ensaios abrange todas as configurações com uma ou duas cristas sem furos por seção e parafusos de diâmetro nominal 10,0 mm, conforme Figura 43a e Figura 43b. O intervalo b) compreende todos os ensaios em que foram utilizados parafusos de 8,0 $\mathrm{mm}$ de diâmetro. O intervalo c) engloba o restante das configurações com parafusos de diâmetro $10,0 \mathrm{~mm}$ em que há furos em todas as cristas, como 
mostrado na Figura 43c. O intervalo d) é composto por todos os corpos de prova que empregaram parafusos de 12,0 $\mathrm{mm}$ tal qual indicado na Figura $43 \mathrm{~d}$. $\mathrm{O}$ fato do processo de corte das chapas em (ESTEVES JR, 1990) ter causado variação de dimensões entre os corpos de prova, vide Apêndice A, não resultou em valores amostrais com abscissas variáveis, conforme Figura 44a, pois a distância perpendicular entre os furos se manteve constante. Neste caso, não há influência do comprimento de corte da chapa, apenas da distância planificada entre os furos, referente ao processo de fabricação da chapa. Assim como na análise da norma americana, no item anterior, houve variação de parâmetros dentro de cada intervalo, tais quais espessura da chapa, resistência do aço, número total de parafusos, entre outros, que não foram considerados diretamente no coeficiente redutor da área líquida teórico, mas que têm influência na resistência última da ligação. 
Figura 44 - Modelo da norma AS/NZS 4600:2005 e resultados experimentais de ruptura da seção líquida com valores (a) amostrais e b) em média e desvio padrão

(a)

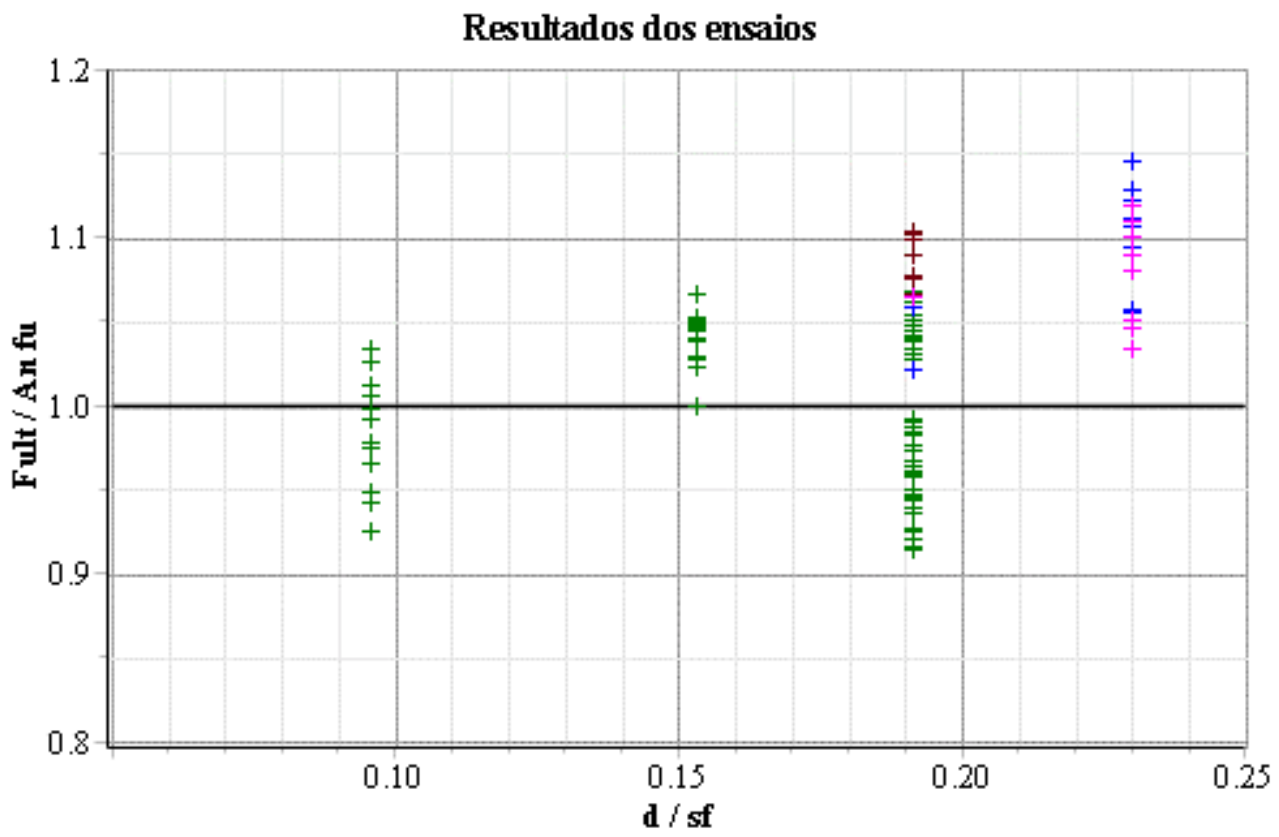

(b)

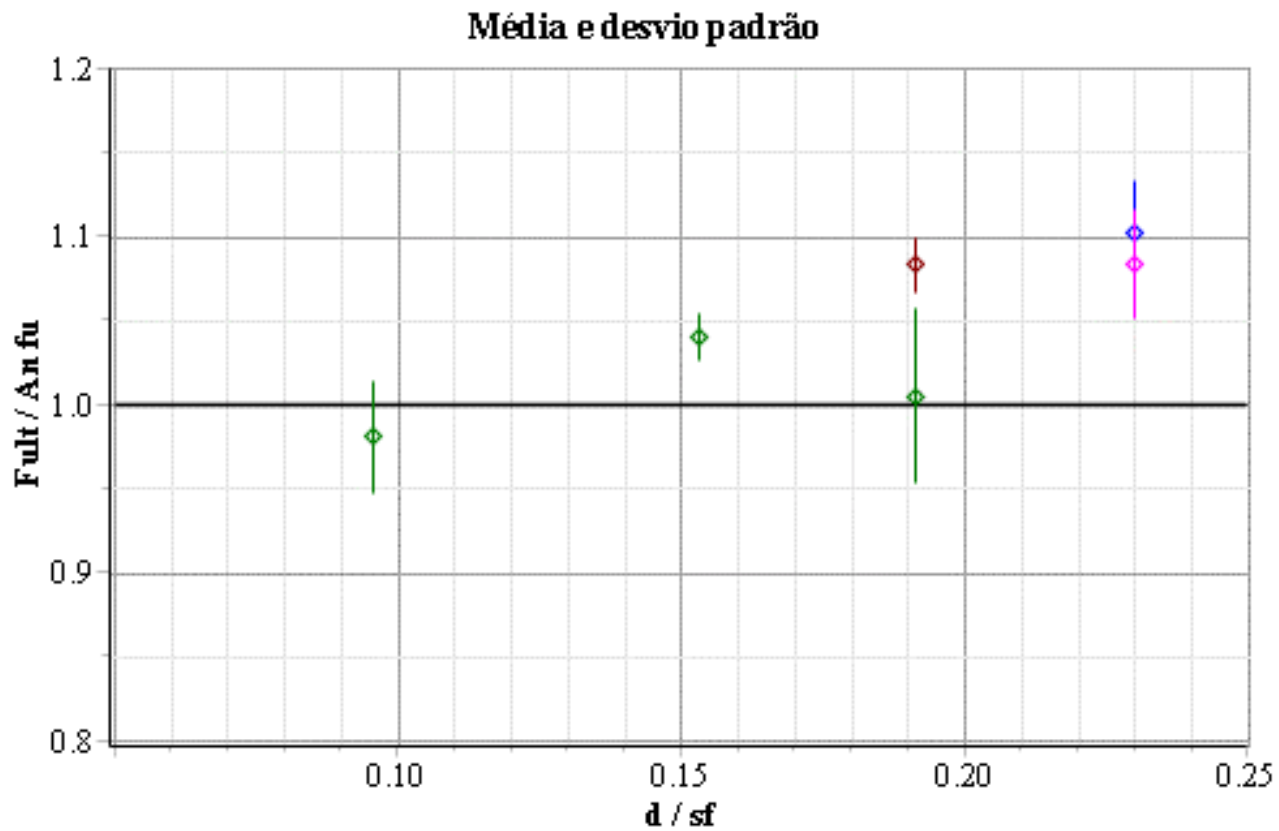

$\begin{array}{ll}+ & \text { Ch. simples corrugada } \\ + & \text { Ch. simples plana } \\ + & \text { Ch. dupla corrugada fur. coincidente } \\ + & \text { Ch. dupla corrugada fur. defasada } \\ & \text { AS/NZS 4600:2005 }\end{array}$

$\diamond \quad$ Ch. simples corrugada

- Ch. simples plana

- Ch. dupla corrugada fur. coincidente

- Ch. dupla corrugada fur. defasada AS/NZS 4600:2005

Fonte: o autor. 
O coeficiente redutor da área líquida teórico proposto pela norma AS/NZS 4600:2005 é constante e igual a 1,0 para todas as configurações de ligações parafusadas empregadas em chapas de parede de silos cilíndrico metálicos. Não há distinção, inclusive, em caso de chapa corrugada ou plana e montagem em composição simples ou dupla.

Para os testes realizados abrangendo corpos de prova com chapa corrugada e montagem em composição simples, apenas os referentes ao intervalo a) apresentaram coeficiente redutor da área líquida experimental menor do que a unidade, com valor médio de 0,98. Neste caso, o número de ensaios neste intervalo aumentou de 3 para 14, em relação à classificação pela norma americana, mas o resultado experimental se manteve o mesmo, com valor médio do coeficiente próximo à unidade. Este resultado evidencia o efeito da concentração de tensão na borda dos furos, em razão do número reduzido de parafusos por seção, ocasionando uma fratura prematura. Para as demais configurações ensaiadas obteve-se valores médios experimentais para o coeficiente de 1,04 e 1,01 para os intervalos b) e c), respectivamente.

Os resultados para os ensaios relativos a corpos de prova compostos por chapa plana com montagem em composição simples e por chapa corrugada com montagem em composição dupla foram equivalentes aos do item anterior, referente à norma americana. Para as configurações com chapas planas e montagem simples, classificadas apenas no intervalo c), conforme Figura 44, o coeficiente redutor da área líquida experimental resultou 1,09 em valor médio. Esse valor é superior às configurações equivalentes empregando chapa corrugada. Para as configurações com chapas corrugadas e montagem dupla, classificadas no intervalo d), conforme Figura 44, o coeficiente resultou sistematicamente elevado. Foram obtidos valores médios de 1,11 e 1,08 para os casos de furação coincidente e defasada, respectivamente.

O emprego da norma AS/NZS 4600:2005 no cálculo da resistência de ligações parafusadas de paredes de silos cilíndricos metálicos sujeitas a falha por ruptura da seção líquida é facilitado pelo fato do coeficiente redutor da área líquida ser unitário. Os resultados experimentais revelaram que este valor é adequado quando comparado com os valores médios obtidos experimentalmente. Em situações práticas de montagem em composição dupla há uma margem de segurança adicional, pois o coeficiente redutor da área líquida experimental para estes casos resultou sempre superior à unidade. 


\subsubsection{Ruptura da seção líquida pela norma NBR 14762:2010}

No modelo de cálculo da norma NBR 14762:2010 para a resistência de uma ligação parafusada sujeita à falha por ruptura da seção líquida, o coeficiente redutor da área líquida é definido em função do parâmetro $d_{b} / g$. Há também uma diferenciação quanto ao número de parafusos da ligação na direção paralela à solicitação, havendo maior penalização quanto menor este número, conforme Equações 38, 39, e 40.

Para dois parafusos na direção da solicitação:

$$
C_{t}=0,5+1,25 \cdot\left(\frac{d_{b}}{g}\right) \leq 1,0
$$

Para três parafusos na direção da solicitação:

$$
C_{t}=0,67+0,83 \cdot\left(\frac{d_{b}}{g}\right) \leq 1,0
$$

Para quatro ou mais parafusos na direção da solicitação:

$$
C_{t}=0,75+0,625 \cdot\left(\frac{d_{b}}{g}\right) \leq 1,0
$$

O uso desta norma previu corretamente $92 \%$ das ocorrências onde a ruína se deu por ruptura da seção líquida. A Figura 45 apresenta os resultados gráficos para o coeficiente redutor da área líquida teórico e experimental. A distribuição dos ensaios em intervalos distintos conforme o parâmetro $d_{b} / g$ é explicada na Tabela 4 .

Tabela 4 - Intervalos para ruptura da seção líquida pela norma NBR 14762:2010

\begin{tabular}{|c|c|c|c|c|c|c|}
\hline Intervalo & $N L$ & $2 y_{1}(\mathrm{~mm})$ & $y_{2}(\mathrm{~mm})$ & $g(\mathrm{~mm})$ & $d_{b}(\mathrm{~mm})$ & $d_{b} / g$ \\
\hline a) & 4 & 56,8 & 104,4 & 104,4 & 10,0 & 0,096 \\
\hline \multirow{2}{*}{$\mathrm{b})$} & 4 & $58,4^{*}$ & 52,2 & 58,4 & 8,0 & 0,137 \\
\cline { 2 - 7 } & 4 & $51,3^{*}$ & 52,2 & 52,2 & 8,0 & 0,153 \\
\hline \multirow{2}{*}{$\mathrm{c})$} & 5 & 56,8 & 52,2 & 56,8 & 10,0 & 0,176 \\
\hline & 5 & $55,8^{*}$ & 52,2 & 55,8 & 10,0 & 0,179 \\
\hline d) & 5 & 56,8 & 52,2 & 56,8 & 12,0 & 0,211 \\
\hline
\end{tabular}

*Ensaios realizados por (ESTEVES JR, 1990), em que o comprimento de corte das chapas não foi idêntico para em todos os casos. Vide Apêndice A.

Fonte: o autor.

Pela definição da norma NBR 14762:2010, o intervalo a) de ensaios abrange todas as configurações com uma ou duas cristas sem furos por seção e parafusos de diâmetro nominal 10,0 mm, conforme Figura 43a e Figura 43b. O intervalo b) compreende todos os ensaios em que foram utilizados parafusos de 8,0 mm de diâmetro. O intervalo c) engloba o restante das configurações com parafusos de diâmetro $10,0 \mathrm{~mm}$ em que há furos em todas as cristas, como 
mostrado na Figura 43c. O intervalo d) é composto por todos os corpos de prova que empregaram parafusos de 12,0 $\mathrm{mm}$ tal qual indicado na Figura $43 \mathrm{~d}$. O fato do processo de corte das chapas em (ESTEVES JR, 1990) ter causado variação de dimensões entre os corpos de prova, vide Apêndice A, resultou em valores amostrais com abscissas variáveis, conforme Figura 45a. Assim como na análise das normas americana e australiana, houve variação de parâmetros dentro de cada intervalo, tais quais espessura da chapa, resistência do aço, entre outros, que não foram considerados diretamente no coeficiente redutor da área líquida teórico, mas que têm influência na resistência última da ligação. Porém, diferentemente destas normas, o modelo teórico da NBR 14762:2010 considera o número total de parafusos no cálculo do coeficiente redutor. 
Figura 45 - Modelo da norma NBR 14762:2010 e resultados experimentais de ruptura da seção líquida com valores (a) amostrais e (b) em média e desvio padrão

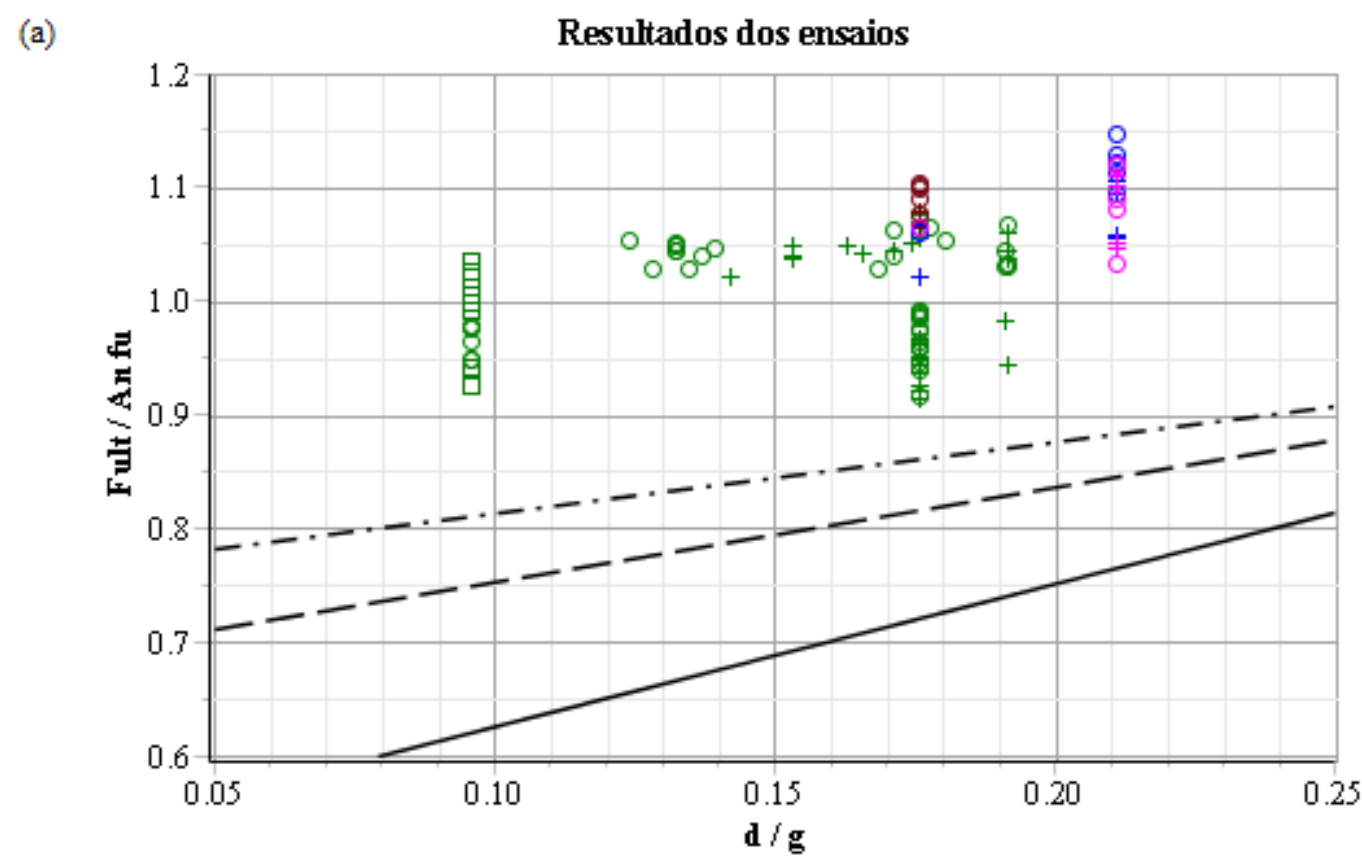

(b)

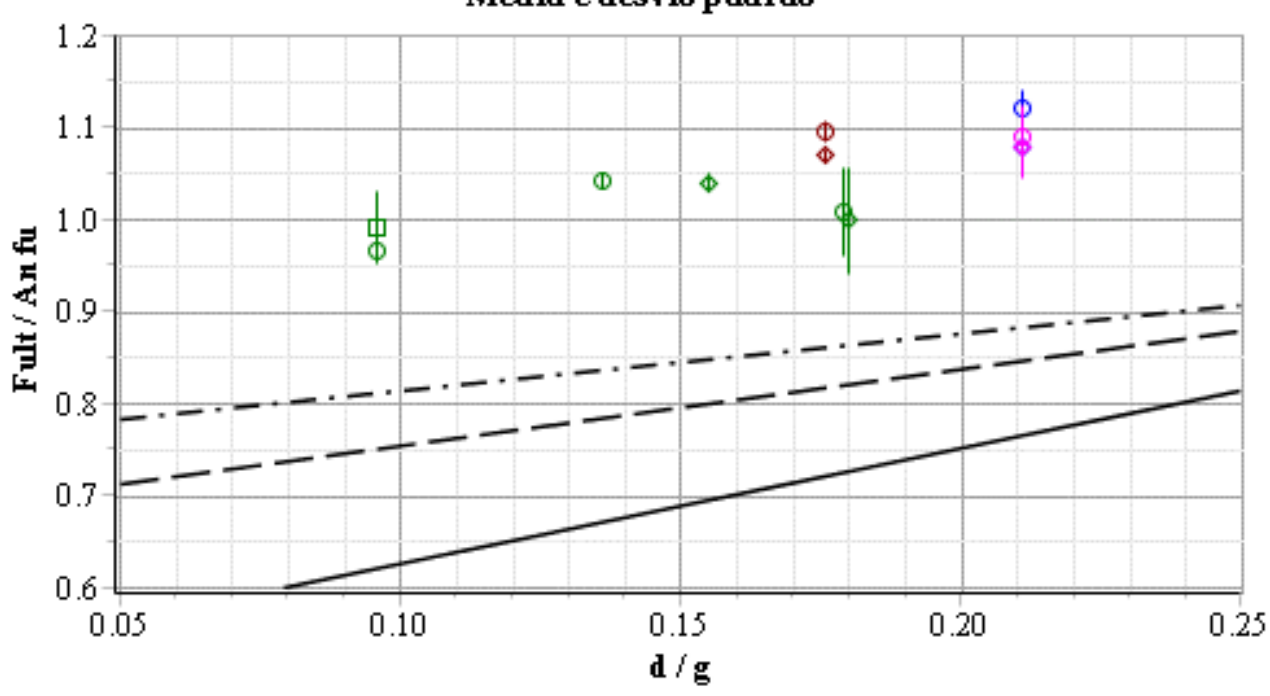

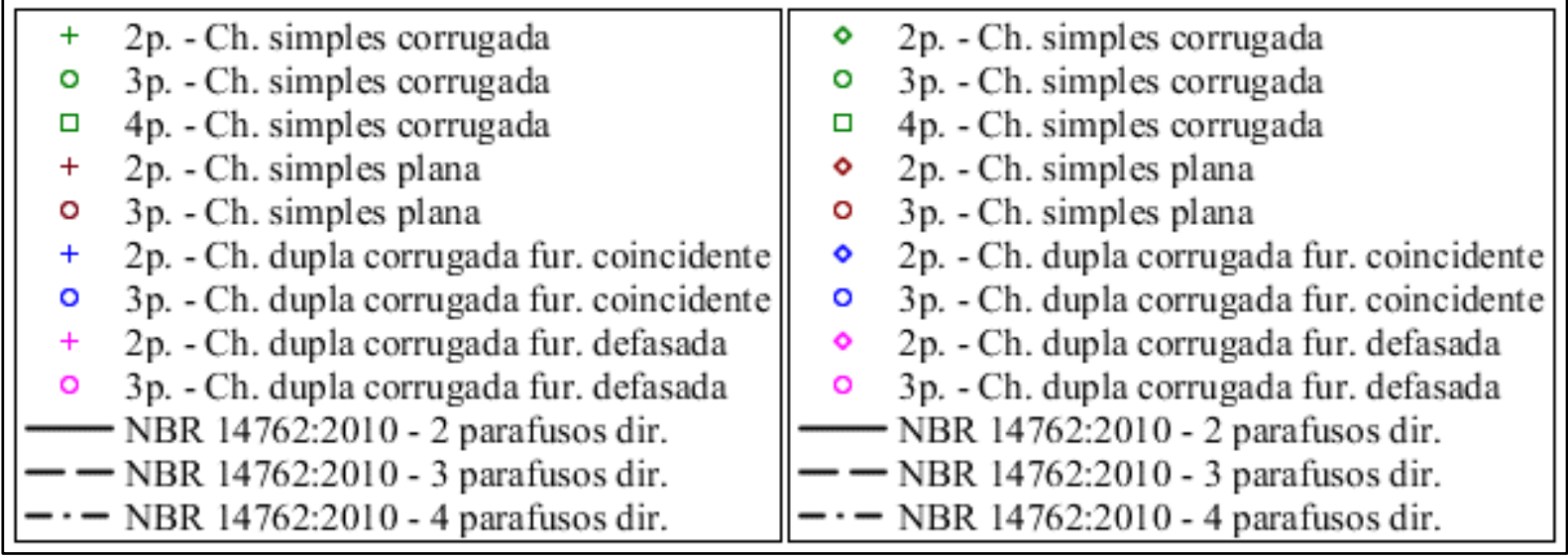

Fonte: o autor. 
O coeficiente redutor da área líquida teórico proposto pela norma NBR 14762:2010, representado pelas Equações 38, 39 e 40 possui valores compreendidos entre 0,60 e 0,90 para configurações usuais de ligações parafusadas empregadas em chapas de parede de silos cilíndricos metálicos, a depender do parâmetro adimensional $d_{b} / g$ e do número de parafusos na direção paralela à solicitação. Não há distinção em caso de chapa corrugada ou plana e montagem em composição simples ou dupla. Os resultados obtidos mostram que existe diferença e que, para todos os casos, o modelo é conservador.

Para os testes realizados abrangendo corpos de prova com chapa corrugada e montagem em composição simples, apenas os referentes ao intervalo a) apresentaram coeficiente redutor da área líquida experimental menor do que a unidade. Neste caso, houve diferença de resultado entre as configurações com 3 e 4 parafusos paralelos à solicitação, que resultaram em valores médios do coeficiente de 0,96 e 0,98, respectivamente. Para as demais configurações ensaiadas obteve-se valor médio experimental para o coeficiente de 1,04 para o intervalo b) na condição de 2 e 3 parafusos na direção paralela à solicitação e valores médios de 1,00 e 1,01 para o intervalo c) na condição de 2 e 3 parafusos na direção paralela à solicitação, respectivamente.

Os resultados para os ensaios relativos a corpos de prova compostos por chapa plana com montagem em composição simples e por chapa corrugada com montagem em composição dupla foram similares aos dos itens anteriores, referente às normas americana e australiana, com a diferença de que neste caso foi feita a distinção quanto ao número de parafusos na ligação. Para as configurações com chapas planas e montagem simples, classificadas apenas no intervalo c), conforme Figura 45, o valor médio do coeficiente redutor da área líquida experimental resultou 1,07 e 1,09 para as condições de 2 e 3 parafusos paralelos à solicitação, respectivamente. Esse valor é superior às configurações equivalentes empregando chapa corrugada. Para as configurações com chapas corrugadas e montagem dupla, classificadas no intervalo d), conforme Figura 45, o coeficiente resultou elevado em todos os casos. Para os casos de 2 parafusos paralelos à solicitação, foi obtido valor médio do coeficiente redutor da área líquida experimental de 1,08 para ambos os casos de furação coincidente e defasada. Para os casos de 3 parafusos paralelos à solicitação, o valor médio resultou em 1,13 e 1,09 para os casos de furação coincidente e defasada, respectivamente.

A aplicação da norma NBR 14762:2010 no cálculo da resistência de ligações parafusadas de paredes de silos cilíndricos metálicos sujeitas a falha por ruptura da seção líquida resulta em valores conservadores. O efeito benéfico à resistência de haver mais parafusos na direção da solicitação foi verificado experimentalmente, mas em termos práticos o ganho é 
pequeno. Os teste realizados revelaram que um coeficiente redutor da área líquida teórico unitário representa de forma mais simples e adequada os resultados experimentais obtidos, em termos de valores médios. Para os casos de montagem em composição dupla, a adoção de um coeficiente redutor da área líquida unitário resulta em uma margem adicional de segurança, pois os valores experimentais médios, nestes casos, resultaram sempre elevados.

\subsubsection{Ruptura da seção líquida pela norma EN 1993-1-3:2006}

No modelo de cálculo da norma EN 1993-1-3:2006 para a resistência de uma ligação parafusada sujeita à falha por ruptura da seção líquida, o coeficiente redutor da área líquida é definido em função do parâmetro $d_{o} / u$. Há também uma distinção quanto à razão entre o número de parafusos na seção crítica e o número total de parafusos na ligação $(r)$, havendo maior penalização quanto maior o valor de $r$, conforme Equações 41 .

$$
C_{r e d}=1+3 r \cdot\left(\frac{d_{o}}{u}-0,3\right) \leq 1,0
$$

O uso desta norma previu corretamente $100 \%$ das ocorrências onde a ruína se deu por ruptura da seção líquida. A Figura 46 apresenta os resultados gráficos para o coeficiente redutor da área líquida teórico e experimental. A distribuição dos ensaios em intervalos distintos conforme o parâmetro $d_{o} / u$ é exposta na Tabela 5 .

Tabela 5 - Intervalos para ruptura da seção líquida pela norma EN 1993-1-3:2006

\begin{tabular}{|c|c|c|c|c|c|c|}
\hline Intervalo & $N L$ & $2 y_{1}(\mathrm{~mm})$ & $y_{2}(\mathrm{~mm})$ & $u(\mathrm{~mm})$ & $d_{o}(\mathrm{~mm})$ & $d_{o} / u$ \\
\hline \multirow{3}{*}{$\mathrm{a})$} & 4 & $58,4^{*}$ & 52,2 & 52,2 & 9,5 & 0,182 \\
\cline { 2 - 7 } & 4 & 56,8 & 104,4 & 56,8 & 11,0 & 0,194 \\
\cline { 2 - 7 } & 3 & 56,8 & 104,4 & 56,8 & 11,0 & 0,194 \\
\hline $\mathrm{b})$ & 5 & 56,8 & 52,2 & 52,2 & 11,0 & 0,211 \\
\hline $\mathrm{c})$ & 4 & $51,1^{*}$ & 52,2 & 51,1 & 11,5 & 0,225 \\
\hline $\mathrm{d})$ & 5 & 56,8 & 52,2 & 52,2 & 14,0 & 0,268 \\
\hline
\end{tabular}

*Ensaios realizados por (ESTEVES JR, 1990), em que o comprimento de corte das chapas não foi idêntico para em todos os casos. Vide Apêndice A.

Fonte: o autor.

Pela definição da norma EN 1993-1-3:2006, o intervalo a) de ensaios abrange todas as configurações com uma ou duas cristas sem furos por seção e parafusos de diâmetro nominal 10,0 mm, conforme Figura 43a e Figura 43b, além das que empregaram parafuso com diâmetro nominal de $8,0 \mathrm{~mm}$. Os intervalos b) e c) compreendem os demais ensaios em que foram utilizados parafusos de 10,0 mm de diâmetro, sendo que o primeiro corresponde aos casos em que $2 y_{1}>y_{2}$, conforme Figura $43 \mathrm{c}$ e o segundo corresponde ao caso em que $y_{2}>2 y_{1}$. O 
intervalo d) é composto por todos os corpos de prova que empregaram parafusos de 12,0 $\mathrm{mm}$ tal qual indicado na Figura 43d. O fato do processo de corte das chapas em (ESTEVES JR, 1990) ter causado variação de dimensões entre os corpos de prova, vide Apêndice A, resultou em valores amostrais com abscissas variáveis, conforme Figura 46a. Semelhante à norma brasileira, houve variação de parâmetros dentro de cada intervalo, tais quais espessura da chapa, resistência do aço, entre outros, que não foram considerados diretamente no coeficiente redutor da área líquida teórico, mas que têm influência na resistência última da ligação. O número total de parafusos foi considerado no cálculo do coeficiente redutor. 
Figura 46 - Modelo da norma EN 1993-1-3:2006 e resultados experimentais de ruptura da seção líquida com valores (a) amostrais e (b) em média e desvio padrão

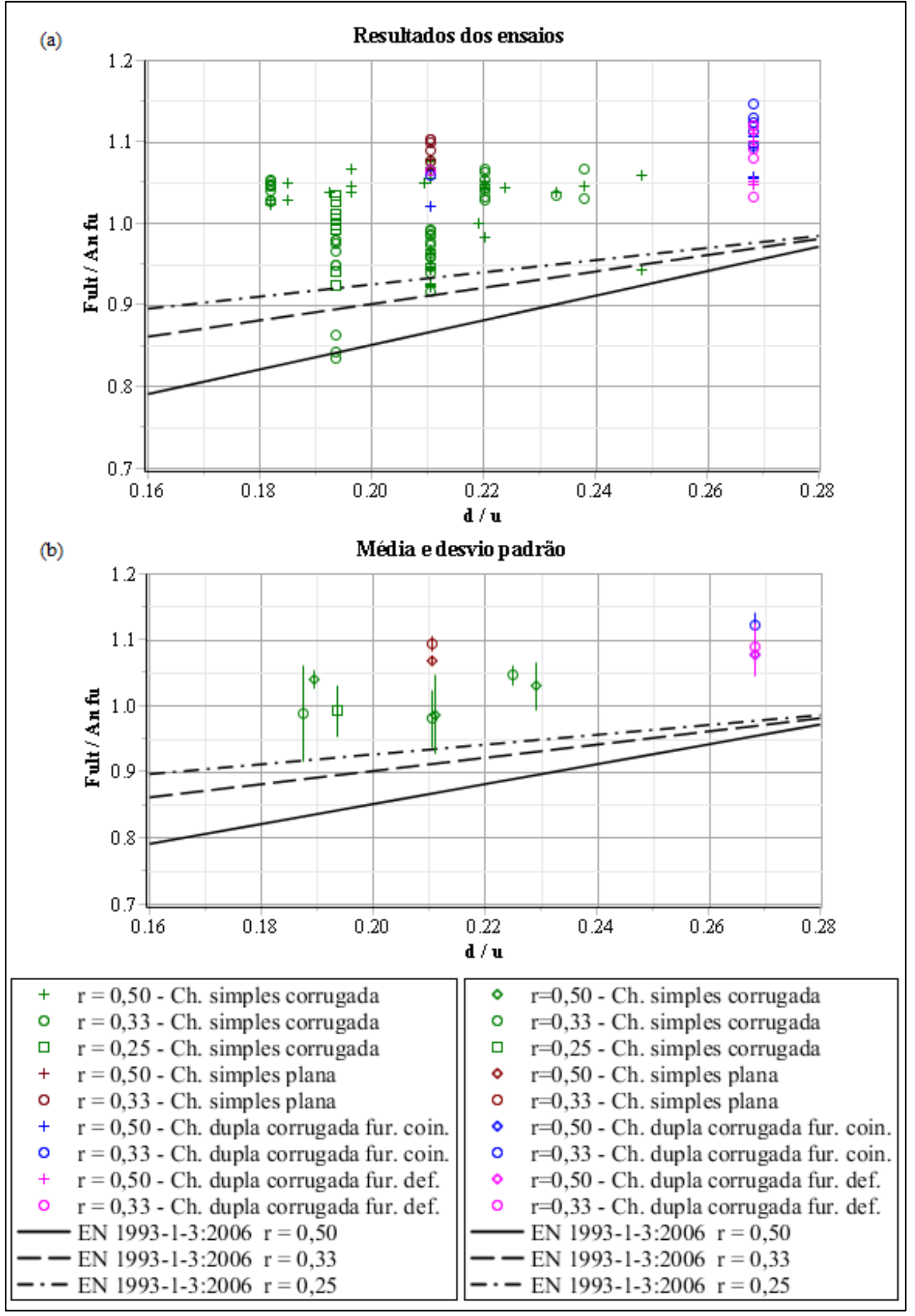

Fonte: o autor. 
O coeficiente redutor da área líquida teórico proposto pela norma EN 1993-1-3:2006, representado pela Equação 41, possui valores compreendidos entre 0,80 e 1,00 para configurações usuais de ligações parafusadas empregadas em chapas de parede de silos cilíndricos metálicos, a depender do parâmetro adimensional $d_{o} / u$ e do número relativo de parafusos na seção crítica. Não há distinção em caso de chapa corrugada ou plana e montagem em composição simples ou dupla. Os resultados obtidos mostram que existe diferença e que, para todos os casos, o modelo é conservador.

Para os testes realizados abrangendo corpos de prova com chapa corrugada e montagem em composição simples, obteve-se coeficiente redutor da área líquida experimental menor do que a unidade tanto no intervalo a) para $r=1 / 3$ e $r=1 / 4$ quanto para o intervalo b) para $r=$ $1 / 2$ e $r=1 / 3$. Nestes casos o valor médio do coeficiente foi 0,98 . Para as demais configurações ensaiadas obteve-se valor médio experimental para o coeficiente de 1,04 para o intervalo b) com $r=1 / 2$ e valores médios de 1,03 e 1,05 para o intervalo c) com $r=1 / 2$ e $r=1 / 3$, respectivamente.

Os resultados para os ensaios relativos a corpos de prova compostos por chapa plana com montagem em composição simples e por chapa corrugada com montagem em composição dupla foram similares aos do item anterior, referente à norma brasileira. Para as configurações com chapas planas e montagem simples, classificadas apenas no intervalo b), conforme Figura 46, o valor médio do coeficiente redutor da área líquida experimental resultou 1,07 e 1,09 para $r=1 / 2$ e $r=1 / 3$, respectivamente. Esse valor é superior às configurações equivalentes empregando chapa corrugada. Para as configurações com chapas corrugadas e montagem dupla, classificadas no intervalo d), conforme Figura 46, o coeficiente resultou elevado em todos os casos. Para $r=1 / 2$ foi obtido valor médio do coeficiente redutor da área líquida experimental de 1,08 para ambos os casos de furação coincidente e defasada. Para $r=1 / 3$, o valor médio resultou em 1,13 e 1,09 para os casos de furação coincidente e defasada, respectivamente.

A aplicação da norma EN 1993-1-3:2006 no cálculo da resistência de ligações parafusadas de paredes de silos cilíndricos metálicos sujeitas a falha por ruptura da seção líquida resulta em valores conservadores. Os resultados revelaram que um coeficiente redutor da área líquida teórico unitário representa de forma mais simples e adequada os resultados experimentais obtidos, e resulta em segurança adicional para os casos de montagem em composição dupla, os quais apresentaram valores médios elevados do coeficiente experimental. 


\subsection{Esmagamento da parede do furo}

A falha da ligação por esmagamento da parede do furo foi causada por pressão de contato excessiva em razão de um número reduzido de parafusos na ligação. Foram verificados grandes deslocamentos e elevada deformação na região dos furos, conforme Figura 47. Neste modo de falha, a concentração de tensão ocasionou a ruína localizada na região dos furos anteriormente à mobilização da resistência total na seção transversal crítica da chapa. A ruptura caracterizou-se pela incapacidade da ligação em suportar acréscimos de carga e aumento dos deslocamentos. Nas condições de realização dos ensaios, com controle de deslocamento do pistão, o teste permaneceu com força solicitante aproximadamente constante para níveis de carga próximos ao de ruptura até o aparecimento de fraturas na borda de furos com elevada deformação, na seção crítica. Este fenômeno foi chamado por Rogers e Hancock (2000) de rasgamento localizado e descrito como um fenômeno pós-crítico referente ao modo de falha por esmagamento da parede do furo. Foi verificado acentuado deslocamento fora do plano e ocorrência do rasgamento localizado fora da linha de furação original.

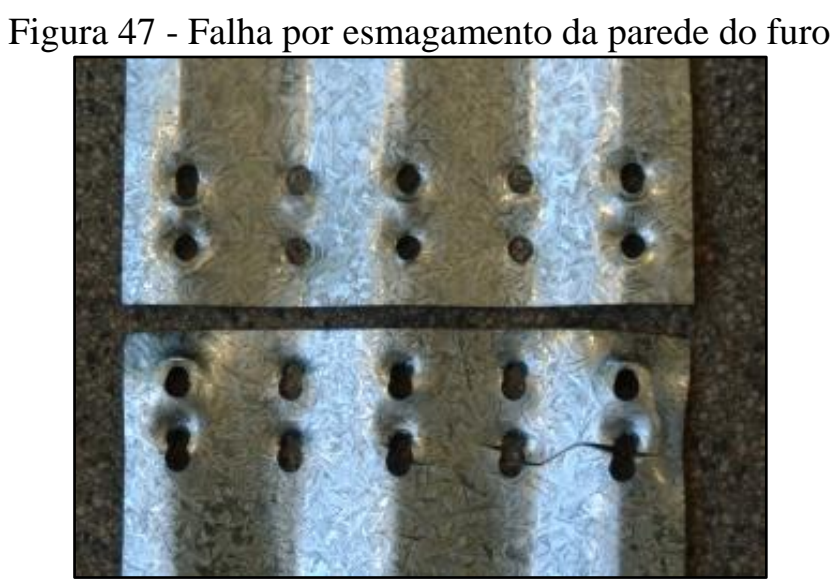

Fonte: o autor.

O modelo de cálculo da resistência da ligação parafusada sujeita a este modo de falha diverge entre as normas de dimensionamento estrutural quanto à formulação de um coeficiente referente ao esmagamento $\left(C_{\text {esm }}\right)$. O produto entre este coeficiente, a área em projeção do parafuso na chapa com direção paralela à solicitação e a tensão de ruptura do aço, multiplicado pelo número de parafusos existentes, resulta na resistência teórica da ligação, conforme Equação 42 a seguir.

$$
F_{R}=C_{e s m} d_{b} t f_{u}
$$

A formulação deste coeficiente é empírica e depende de fatores como diâmetro do parafuso, espessura da chapa, presença de arruela dupla ou simples. A análise dos corpos de 
prova que apresentaram este modo de falha foi feita em termos deste coeficiente, experimental para os testes realizados, e teórico para os modelos das normas consideradas. O coeficiente experimental foi definido como a razão $F_{u l t} / d_{b} t f_{u}$ e o teórico conforme equação do modelo. Os resultados são apresentados a seguir de forma individual para cada norma.

\subsubsection{Esmagamento da parede pela norma AISI S100-16}

No modelo de cálculo da resistência de uma ligação parafusada à falha por esmagamento da parede do furo, a norma AISI S100-16 estabelece um coeficiente teórico conforme a Equação 43 a seguir.

$$
C_{e s m}=C \cdot m_{f}
$$

Sendo:

$$
\begin{gathered}
\text { se } d_{b} / t<10 \rightarrow C=3,0 \\
\text { se } 10 \leq d_{b} / t \leq 22 \rightarrow C=4-0,1 \cdot d_{b} / t \\
\text { arruela simples } \rightarrow m_{f}=0,75 \\
\text { arruela dupla } \rightarrow m_{f}=1,00
\end{gathered}
$$

O uso desta norma previu corretamente $52 \%$ das ocorrências onde a ruína se deu por esmagamento da parede do furo. Para estes casos, a Figura 48 mostra graficamente o coeficiente teórico, como função do parâmetro $d_{b} / t$, e o coeficiente experimental, em função do mesmo parâmetro, com seus valores amostrais em a) e representados pela média e desvio padrão em b). A figura mostra também uma nova proposta de coeficiente teórico, discuta em sequência, conforme a Equação 48. 
Figura 48 - Modelo da norma AISI S100-16 e resultados experimentais de esmagamento com valores (a) amostrais e (b) em média e desvio padrão

(a)

Resultados dos ensaios

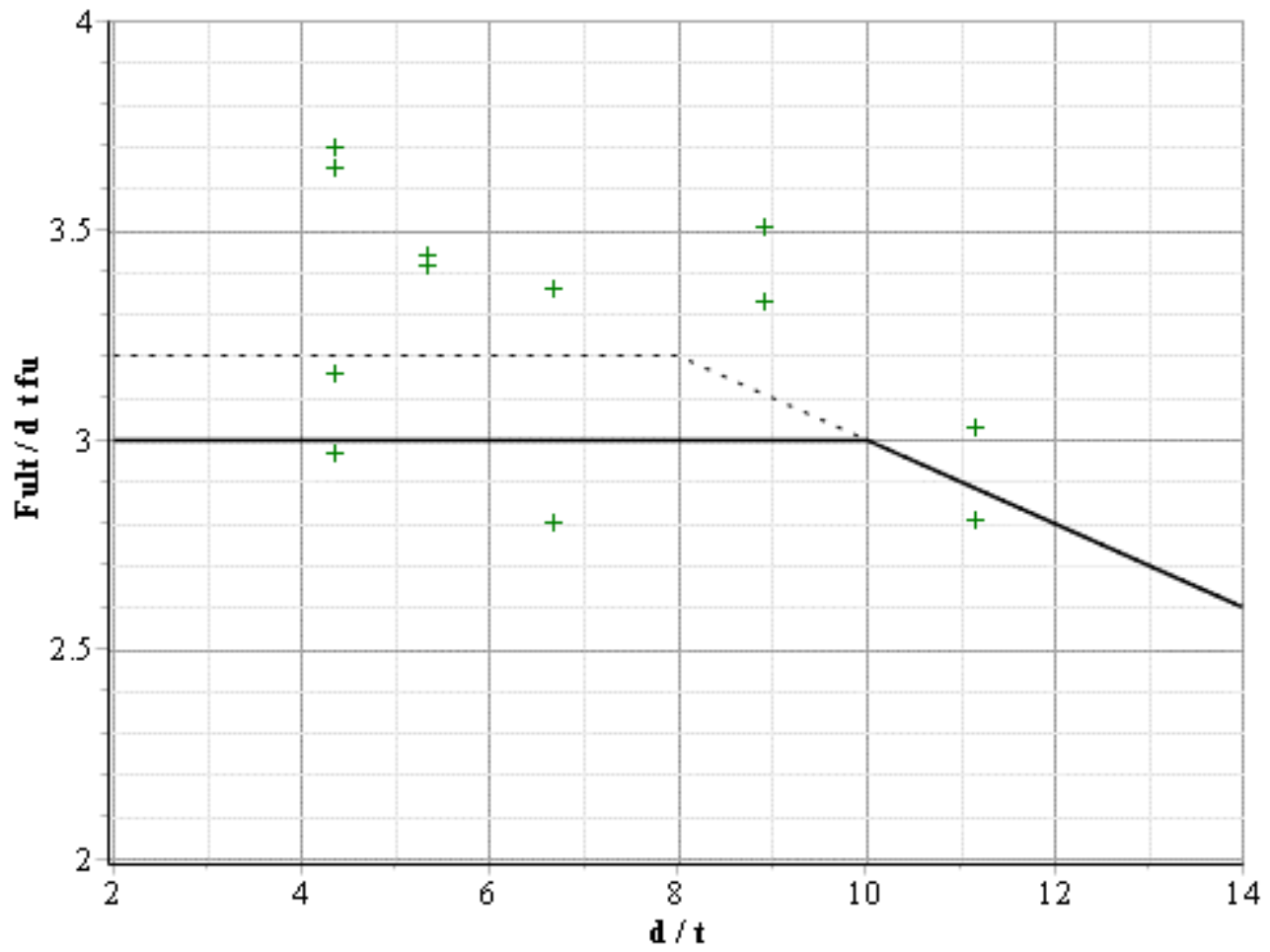

(b)

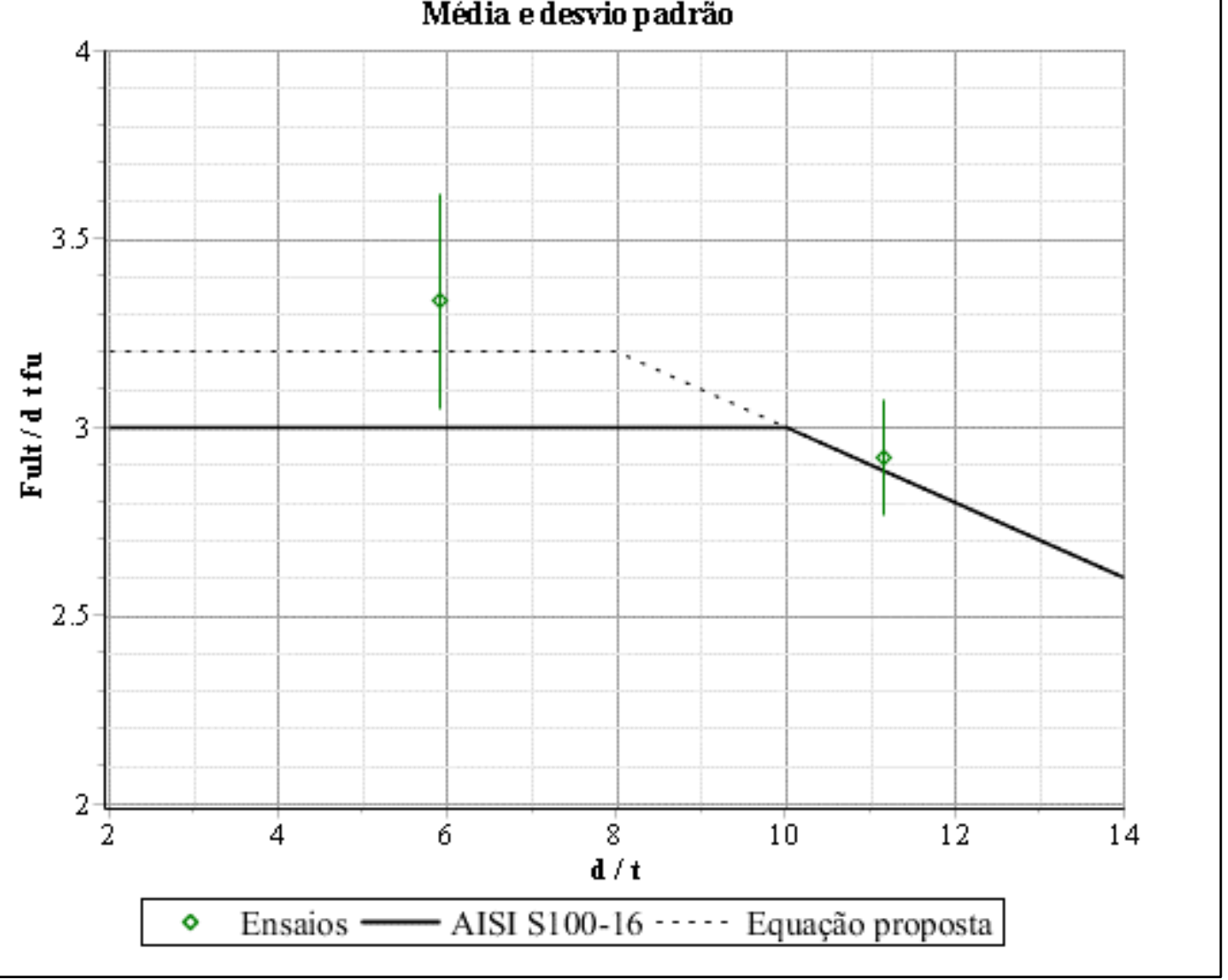

Fonte: o autor. 
Para as configurações ensaiadas, o número de falhas verificadas por esmagamento da parede do furo foi reduzido e compreende apenas casos com chapa corrugada e montagem em composição simples. Todas as situações em que a previsão da norma correspondeu ao modo de falha experimental por esmagamento da parede do furo possuíam arruela em ambos os lado da chapa. Para estes casos, o coeficiente teórico proposto pela norma AISI S100-16, representado pela Equação 43, possui valor 3,0 enquanto a espessura da chapa se mantém maior do que um décimo do diâmetro nominal do parafuso. A partir do momento em que a espessura da chapa assume valores inferiores a um décimo do diâmetro, o modelo da norma considera que há mais susceptibilidade aos efeitos de concentração de tensão e determina uma redução no valor teórico do coeficiente, de maneira linear em função de $d_{b} / t$, conforme a Equação 45 .

Os resultados para o intervalo $d_{b} / t<10$ resultaram em valor médio de 3,33 para o coeficiente experimental, superior ao valor teórico. Para o intervalo $d_{b} / t>10$, apenas dois resultados experimentais foram obtidos, com valores próximos ao teórico. Existe uma determinação quanta à análise de resultados experimentais, tanto da norma NBR 14762:2010 quanto da norma AISI S100-16, que estabelece um número mínimo de três protótipos ensaiados para a obtenção de resultados válidos. Portanto, os resultados experimentais deste intervalo não constituem um resultado formal, mas são um indicativo de que o modelo da norma parece estar adequado. Com base nestes resultados, foi proposta uma alteração na equação de resistência para o primeiro intervalo, elevando o patamar do coeficiente teórico de 3,0 para 3,2 e mantendo idêntico o segundo intervalo. Desta forma, o ponto em que passa a ocorrer redução do coeficiente teórico muda de 10 para 8 , em relação ao parâmetro $d_{b} / t$, conforme Figura 48 . A Equação 48 mostra o modelo proposto.

$$
F_{R}=\left(4-0,1 \cdot d_{b} / t\right) d_{b} t f_{u} \leq 3,2 d_{b} t f_{u}
$$

A aplicação da norma AISI S100-16 no cálculo da resistência de ligações parafusadas de paredes de silos cilíndricos metálicos sujeitas a falha por esmagamento da parede do furo resulta em valores conservadores. Foi proposto um novo modelo, representado pela Equação 48, mais próximo aos resultados experimentais obtidos, conforme Figura 48. 
No modelo de cálculo da resistência de uma ligação parafusada à falha por esmagamento da parede do furo, a norma AS/NZS 4600:2005 estabelece um coeficiente teórico idêntico ao da norma americana, a menos da nomenclatura, descrito na Equação 49 a seguir.

$$
C_{e s m}=\alpha \cdot C
$$

Sendo:

$$
\begin{gathered}
\text { se } d_{b} / t<10 \rightarrow C=3,0 \\
\text { se } 10 \leq d_{b} / t \leq 22 \rightarrow C=4-0,1 \cdot d_{b} / t \\
\text { arruela simples } \rightarrow \alpha=0,75 \\
\text { arruela dupla } \rightarrow \alpha=1,00
\end{gathered}
$$

O uso desta norma previu corretamente $87 \%$ das ocorrências onde a ruína se deu por esmagamento da parede do furo. Para estes casos, a Figura 49 mostra graficamente o coeficiente teórico, como função do parâmetro $d_{b} / t$, e o coeficiente experimental, em função do mesmo parâmetro, com seus valores amostrais em a) e representados pela média e desvio padrão em b). 
Figura 49 - Modelo da norma AISI S100-16 e resultados experimentais de esmagamento com valores (a) amostrais e (b) em média e desvio padrão

(a)

Resultados dos ensaios

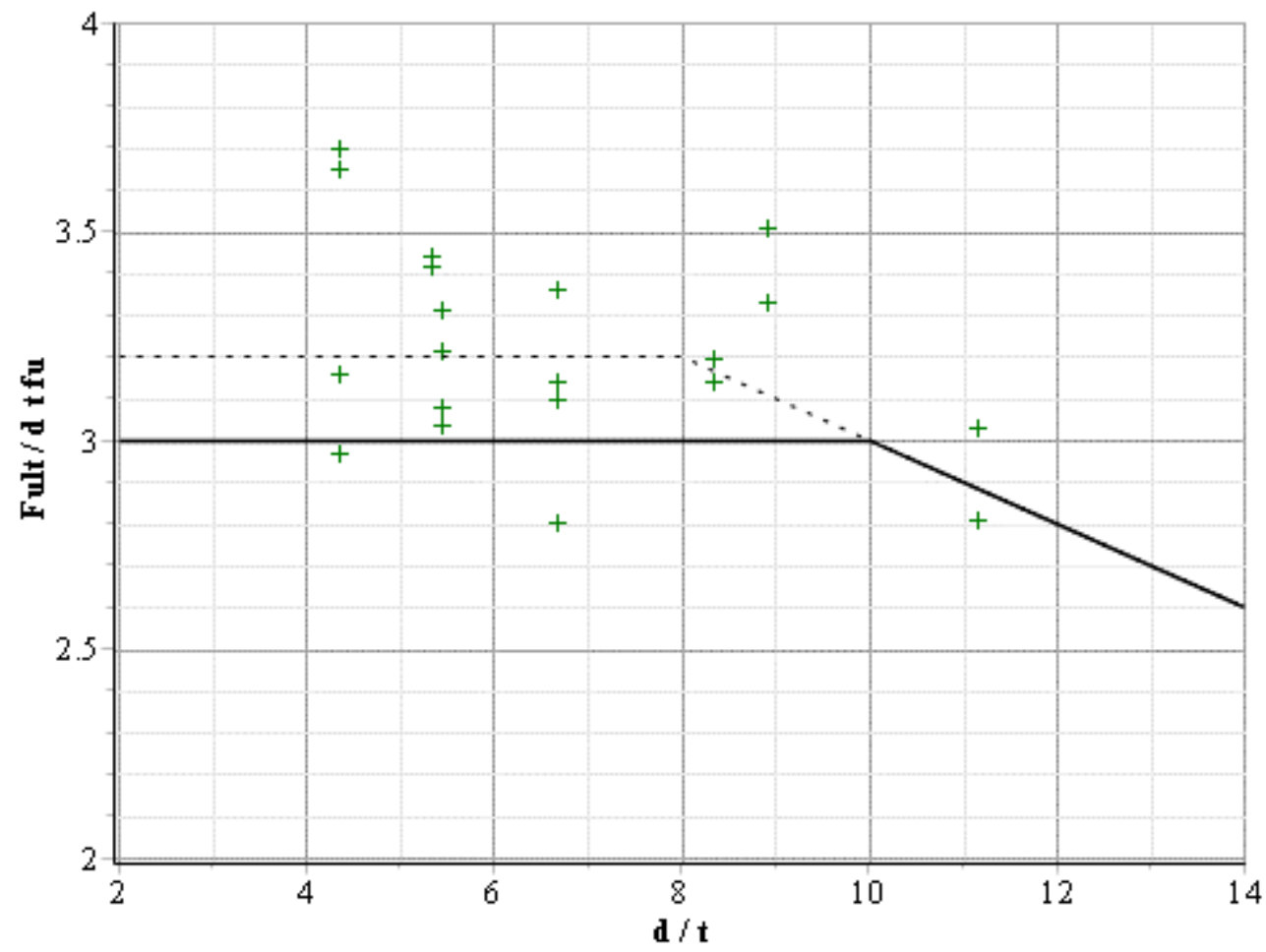

Média edesvio padrão

(b)

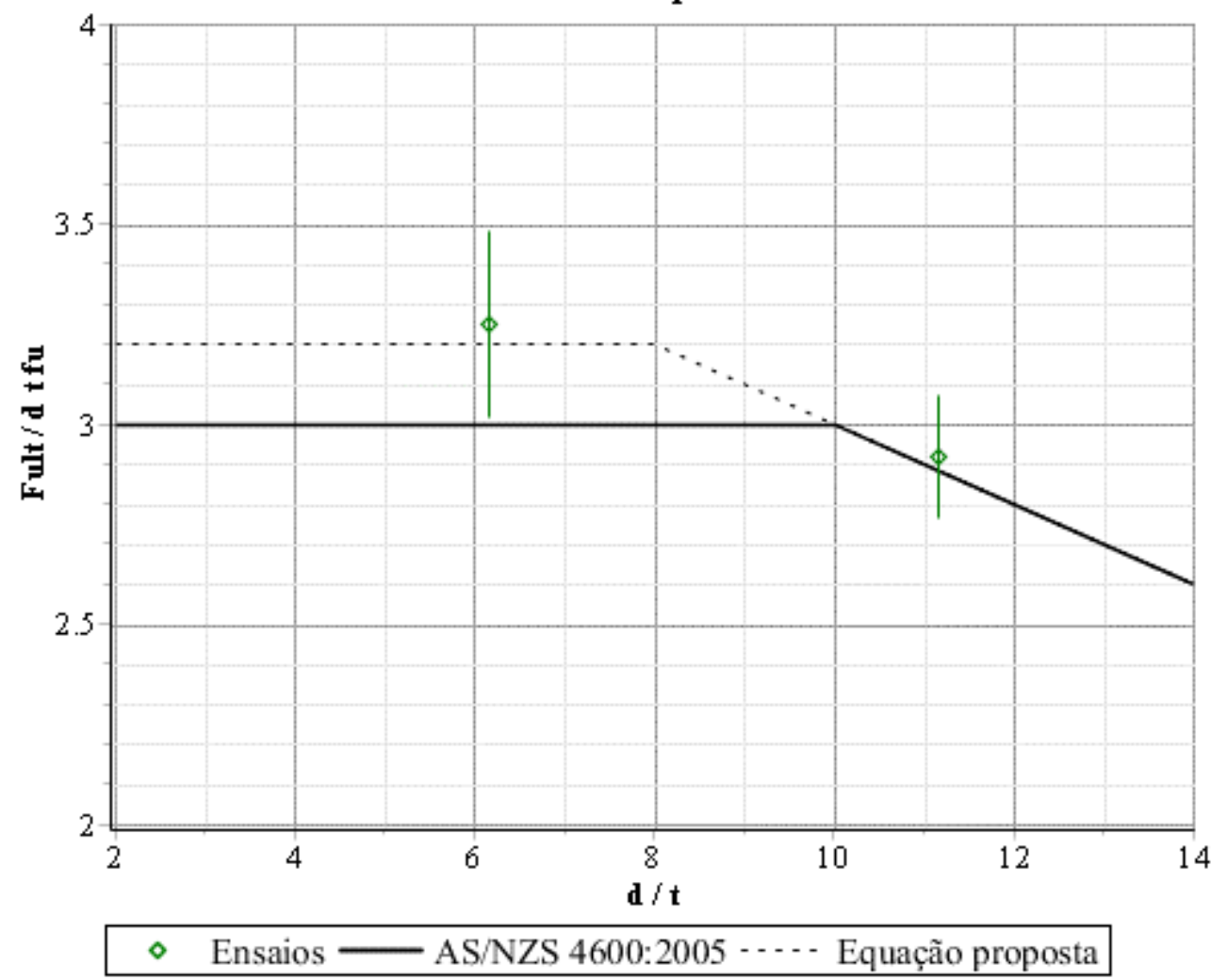

Fonte: o autor. 
Assim como no caso da norma americana, o número de falhas verificadas por esmagamento da parede do furo foi reduzido e as situações em que a previsão da norma correspondeu ao modo de falha experimental correspondem a corpos de prova com chapa corrugada, montagem em composição simples e uso de arruela dupla. Para o intervalo $d_{b} / t<$ 10 o valor médio do coeficiente experimental resultou 3,25. Este resultado é próximo, mas não idêntico, ao obtido pela norma americana pelo fato do número de ensaios analisados ter sido diferente.

A aplicação da norma AS/NZS 4600:2005 no cálculo da resistência de ligações parafusadas de paredes de silos cilíndricos metálicos sujeitas a falha por esmagamento da parede do furo resulta em valores conservadores. Foi proposto um novo modelo, representado pela Equação 48, mais próximo aos resultados experimentais obtidos, conforme Figura 49.

\subsubsection{Esmagamento da parede pela norma NBR 14762:2010}

No modelo de cálculo da resistência de uma ligação parafusada à falha por esmagamento da parede do furo, a norma NBR 14762:2010 estabelece um coeficiente teórico que é função apenas da espessura $t$ da chapa, considerando seu valor e mm, conforme Equação 54 a seguir.

$$
C_{e s m}=\alpha_{e}=0,183 \cdot t+1,53
$$

O uso desta norma previu corretamente $87 \%$ das ocorrências onde a ruína se deu por esmagamento da parede do furo. Para estes casos, a Figura 50 mostra graficamente o coeficiente teórico e o coeficiente experimental, com seus valores amostrais em a) e representados pela média e desvio padrão em b). Para compatibilizar a análise com o caso das normas americana e australiana, foi feita uma manipulação algébrica para que a expressão do coeficiente teórico resultasse em função do mesmo parâmetro $d_{b} / t$. Como a expressão original, dada pela Equação 54, é função apenas da espessura, surgiram duas curvas para o coeficiente teórico, referente aos dois diâmetros nominais de parafusos analisados, de 8,0 e 10,0 mm. Consequentemente, os valores dos coeficientes experimentais também foram subdivididos conforme o diâmetro. 
Figura 50 - Modelo da norma NBR 14762:2010 e resultados experimentais de esmagamento valores (a) amostrais e (b) em média e desvio padrão

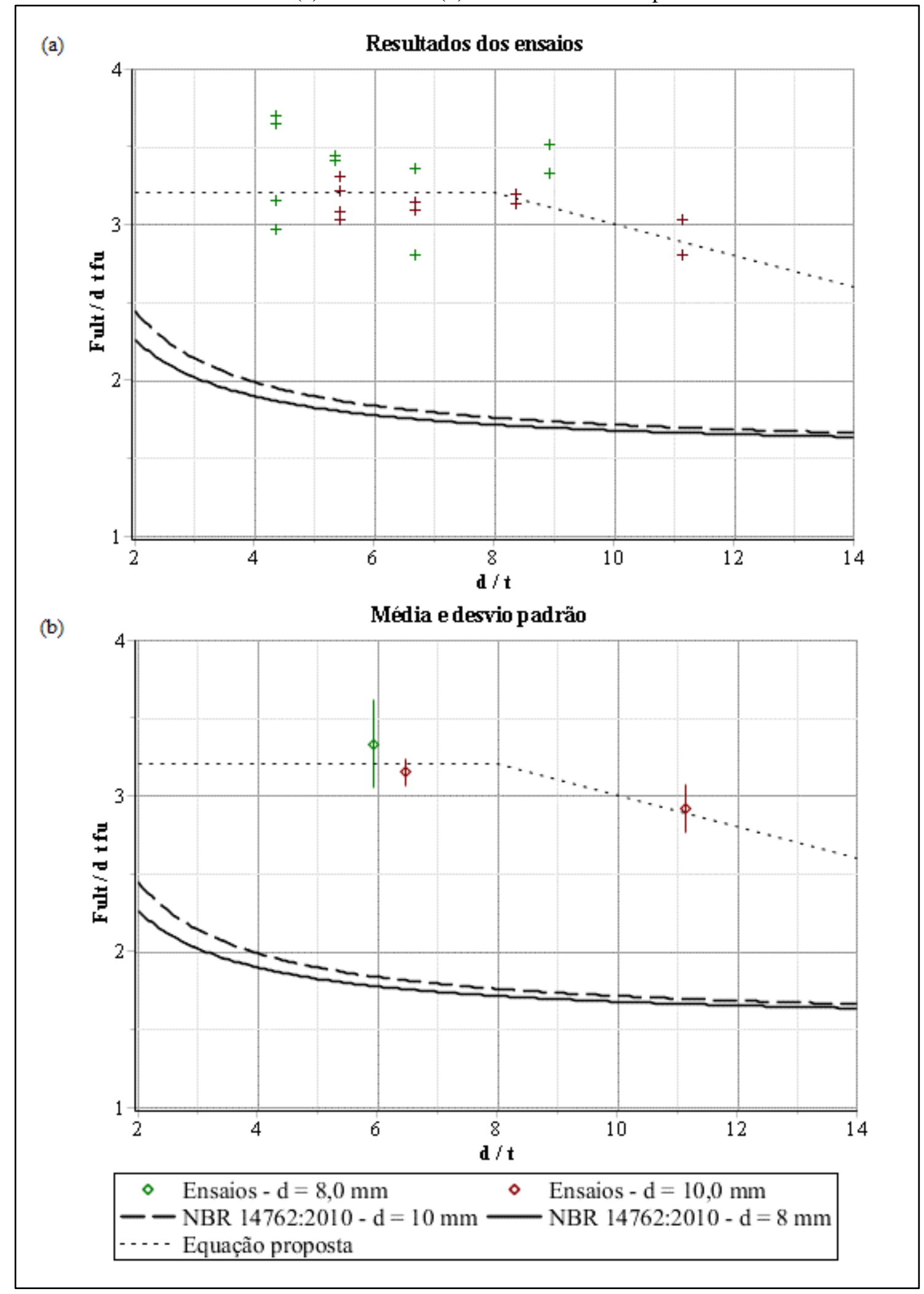

Fonte: o autor. 
O número de falhas verificadas por esmagamento da parede do furo foi reduzido e as situações em que a previsão da norma correspondeu ao modo de falha experimental abrangeram configurações de corpos de prova com chapa corrugada, montagem em composição simples e uso de arruela dupla. Para o intervalo $d_{b} / t<10$ o valor médio do coeficiente experimental resultou 3,33 e 3,15 quando empregados parafusos de diâmetro nominal 8,0 e 10,0 mm, respectivamente.

A aplicação da norma NBR 14762:2010 no cálculo da resistência de ligações parafusadas de paredes de silos cilíndricos metálicos sujeitas a falha por esmagamento da parede do furo resulta em valores bastante conservadores. Foi proposto um novo modelo, representado pela Equação 48, mais próximo aos resultados experimentais obtidos, conforme Figura 50.

\subsubsection{Esmagamento da parede pela norma EN 1993-1-3:2006}

No modelo de cálculo da resistência de uma ligação parafusada à falha por esmagamento da parede do furo, a norma EN 1993-1-3:2006 estabelece um coeficiente teórico, que é função da espessura da chapa, do diâmetro nominal do parafuso e da distância entre centro do furo e borda adjacente, na direção paralela à solicitação, com todos estes parâmetros considerados em mm. A formulação deste coeficiente é mostrada na Equação 55.

$$
C_{e s m}=2,5 \cdot \alpha_{b} \cdot k_{t}
$$

Sendo:

$$
\begin{gathered}
\alpha_{b}=\frac{e_{1}}{3 d_{b}} \leq 1,0 \\
k_{t}=\frac{0,8 \cdot t+1,5}{2,5} \leq 1,0
\end{gathered}
$$

O uso desta norma previu corretamente $70 \%$ das ocorrências onde a ruína se deu por esmagamento da parede do furo. Para estes casos, a Figura 51 mostra graficamente o coeficiente teórico e o coeficiente experimental, com seus valores amostrais em a) e representados pela média e desvio padrão em b). Para fins de representação, na Figura 51 foi adotado um valor típico de $e_{1}=31,9 \mathrm{~mm}$. A exemplo da análise anterior para a norma brasileira, também foi feita uma adequação na representação dos coeficientes teórico e experimental quanto ao 
diâmetro nominal do parafuso em questão, $8,0 \mathrm{ou} 10,0 \mathrm{~mm}$, e apresentados os resultados em função do parâmetro $d_{b} / t$.

Figura 51 - Modelo da norma EN 1993-1-3:2006 e resultados experimentais de esmagamento com valores (a) amostrais e (b) em média e desvio padrão

(a)

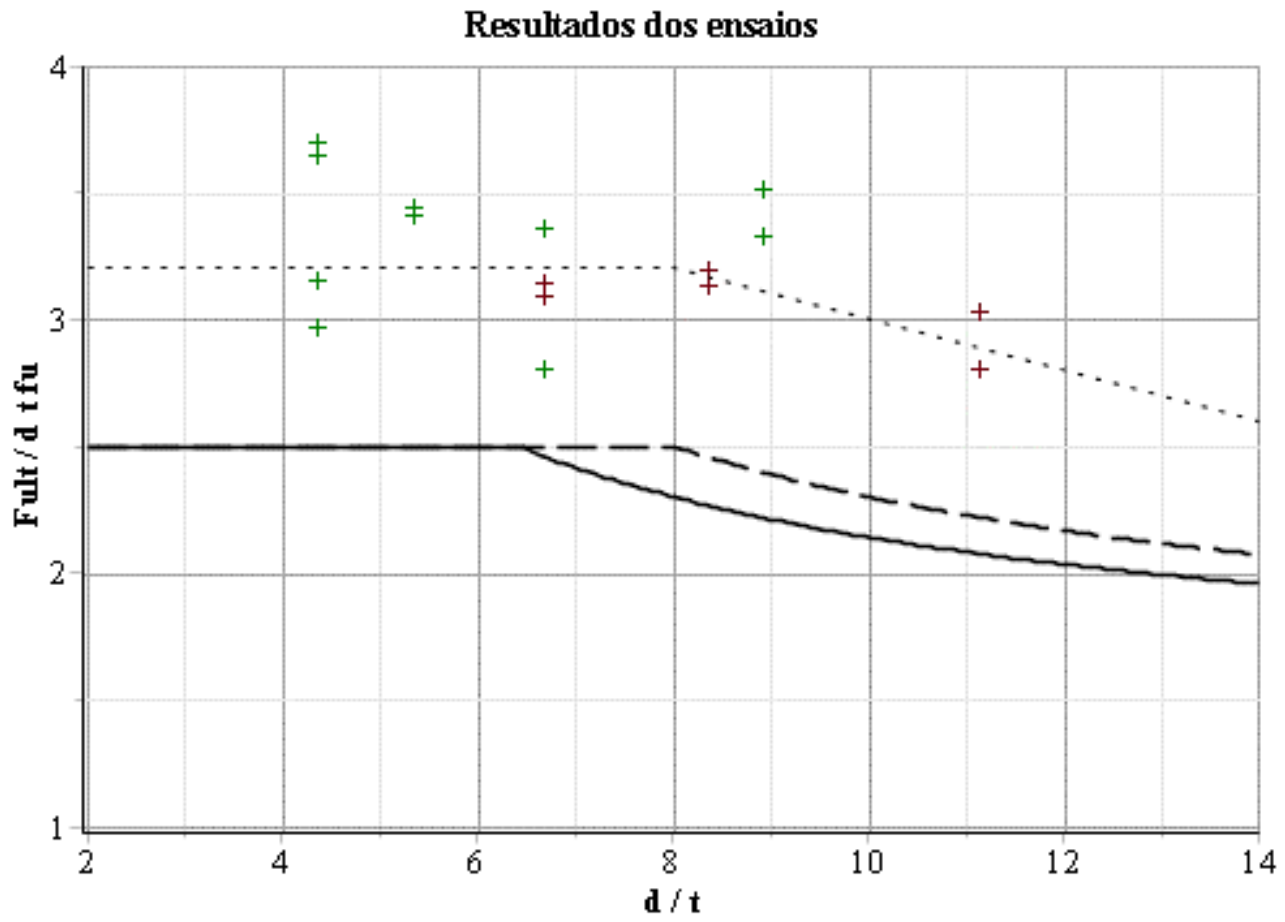

(b)

Média e desvio padrão

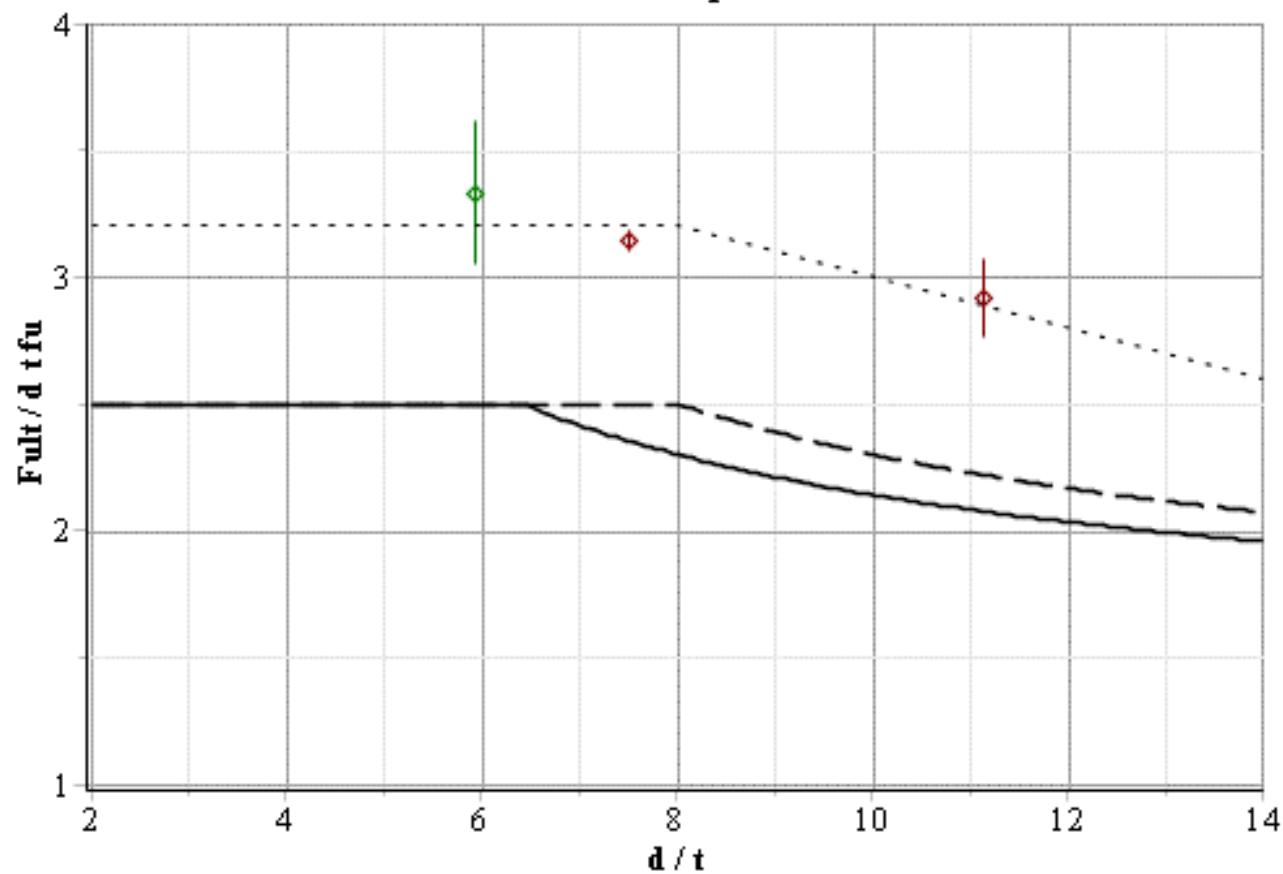

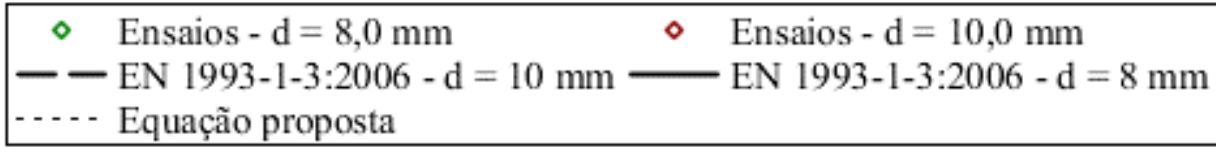

Fonte: o autor. 
O número de falhas verificadas por esmagamento da parede do furo foi reduzido e as situações em que a previsão da norma correspondeu ao modo de falha experimental abrangeram configurações de corpos de prova com chapa corrugada, montagem em composição simples e uso de arruela dupla. Para o intervalo $d_{b} / t<10$ o valor médio do coeficiente experimental resultou 3,33 e 3,14 quando empregados parafusos de diâmetro nominal 8,0 e 10,0 mm, respectivamente.

A aplicação da norma EN 1993-1-3:2006 no cálculo da resistência de ligações parafusadas de paredes de silos cilíndricos metálicos sujeitas a falha por esmagamento da parede do furo resulta em valores conservadores. Foi proposto um novo modelo, representado pela Equação 48, mais próximo aos resultados experimentais obtidos, conforme Figura 51.

\subsection{Considerações finais}

Neste item buscou-se uma investigação mais detalhada do mecanismo de resistência da ligação e da manifestação do modo de falha. Para tanto, foram analisados o registro fotográfico e os dados advindos da instrumentação utilizada nos ensaios. A influência da espessura da chapa e do número de parafusos na direção paralela à solicitação foi analisada a partir da Figura 52. O item a.1) mostra o gráfico da força solicitante de ensaio em função do deslocamento do pistão do atuador para duas configurações de ligação, com dois e três parafusos na linha paralela à solicitação, ambos em um corpo de prova com chapa de espessura nominal 0,95 mm. A Figura 52a2 e Figura 52a3 mostram, respectivamente, os corpos de prova com dois e três parafusos na linha paralela à solicitação, após a ruptura. De modo similar, os itens b), c) e d) da Figura 52 mostram as mesmas informações para configurações com chapas de espessura nominal 1,25, 1,55 e 1,95 mm, respectivamente. Dentre as situações ilustradas, os demais parâmetros não foram variados. 
Figura 52 - Análise dos ensaios em corpos de prova com chapa de espessura (a) 0,95 mm, (b) 1,25 $\mathrm{mm}$, (c) $1,55 \mathrm{~mm}$ e (d) $1,95 \mathrm{~mm}$
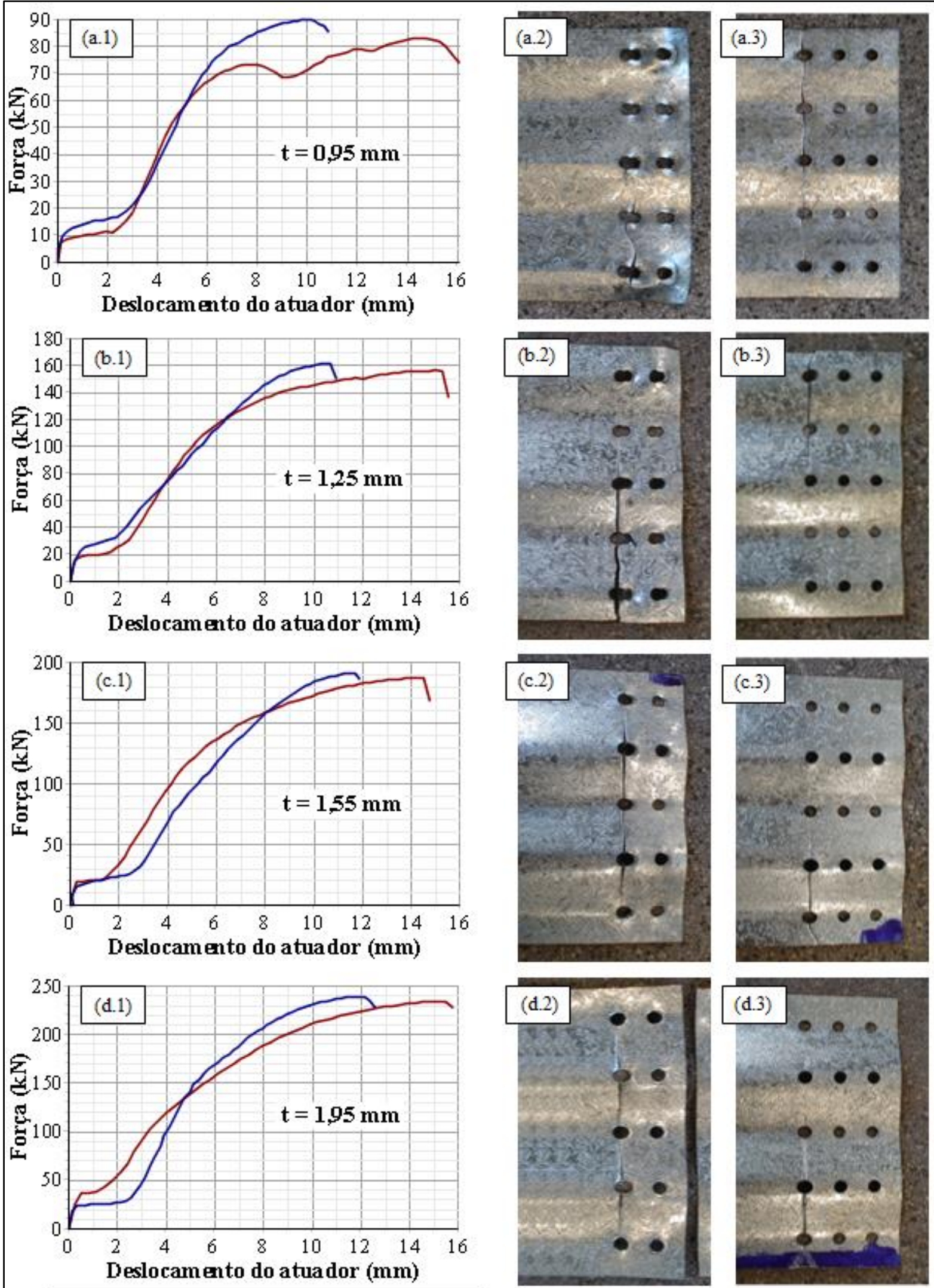

$-5 \times 2$ parafusos $-5 \times 3$ parafusos

Fonte: o autor. 
Como discutido anteriormente, os dois modos de falha a que estão mais susceptíveis as ligações parafusadas empregadas em paredes de silos cilíndricos metálicos são a ruptura da chapa na seção líquida e o esmagamento da parede do furo. Dos casos ilustrados na Figura 52, a falha por esmagamento ocorreu apenas no corpo de prova com menor espessura de chapa e número de parafusos, correspondente ao item a.2). Estes fatores ocasionaram alta concentração de tensão e, consequentemente, uma ruína local na região dos furos antes que a resistência total da chapa em sua seção transversal pudesse ser mobilizada. Um melhor aproveitamento desta ligação foi alcançado aumentando-se o número de parafusos, conforme item a.3). Esta configuração de corpo de prova possui mesma área efetiva na seção crítica, porém menor força solicitante por parafuso, de modo que a ruptura não ocorreu de forma localizada nos furos, e sim na área efetiva, após o esgotamento da capacidade resistente da seção crítica, para um valor superior de carga última experimental.

O gráfico de força por deslocamento do pistão do item a.1) mostra o comportamento de ambas as ligações durante o ensaio. A falha por esmagamento apresentou oscilação no valor de força aplicada para níveis de carga próximos ao de ruptura, na medida em que os furos progressivamente sofreram esmagamento. O ensaio finalizou com o aparecimento de um rasgamento localizado, em uma situação pós-crítica. A falha por ruptura da seção líquida caracterizou-se pela plastificação do aço na região da ligação, que apresentou crescente perda de rigidez. O ensaio finalizou com o aparecimento e propagação de uma ruptura na seção crítica.

Os corpos de prova do item b) possuíam chapa de espessura nominal 1,25 mm, de forma que ambas as configurações de ligação, com dois e três parafusos na direção da solicitação, representadas em b.2) e b.3), respectivamente, apresentaram falha por ruptura da chapa na seção líquida. O gráfico de força por deslocamento do pistão para estas duas configurações, no item b.1), mostrou que apesar de os dois corpos de prova possuírem a mesma área efetiva na seção crítica, a ligação com maior número de parafusos, e consequentemente menor concentração de tensão por furo, apresentou força última experimental levemente superior e uma deslocabilidade consideravelmente menor.

A análise dos itens c) e d) pode ser feita de forma análoga à do item b). Os resultados mostraram que, para este tipo de ligação, a influência da concentração de tensão nos furos, representada pelo número de parafusos na direção paralela à solicitação, pode ser desprezada no cálculo da resistência da ligação à falha por ruptura da seção líquida. Conforme mostrados nos itens b.1), c.1) e d.1), a diferença no valor da força última experimental é pequena, de forma que, para o dimensionamento estrutural, uma distinção no modelo teórico para contabilizar tal 
efeito implicaria em uma complicação adicional e pouco ganho prático. Contudo, atenção especial deve ser dada à deslocabilidade da ligação, pois configurações com menos parafusos apresentaram valores de deslocamento sensivelmente superiores, influenciado pela deformação dos furos, como pode ser verificado nos itens b.2), c.2) e d.2). O efeito prejudicial da concentração de tensão para a resistência da ligação só passa a ser significativo, em termos da resistência da ligação, quando efetivamente causa a mudança do modo de falha de ruptura da chapa na seção líquida para esmagamento da parede do furo, conforme mostrado no item a.1).

O efeito da furação coincidente e defasada em corpos de prova com montagem em composição dupla é mostrado na Figura 53, através do gráfico da força de ensaio pelo deslocamento do transdutor na região da ligação. O modo de falha verificado nestes ensaios foi a ruptura da chapa na seção líquida. Foram analisadas configurações com dois e três parafusos na direção paralela à solicitação, em chapas com espessura nominal simples de 1,55 e 1,95 mm, representadas em a) e b), respectivamente. Os demais parâmetros não foram variados. Os resultados para configurações com furação defasada apresentaram sempre deslocamento inferior à configuração equivalente com furação coincidente, para um mesmo nível de carga, devido ao menor valor total de folga entre furo e parafuso. A ruptura para os casos de furação defasada ocorreu para valores menores de deslocamento e força última experimental, devido à diferença de carregamentos entre as chapas. Desta maneira, a furação defasada é prejudicial à resistência da ligação, mas favorável por apresentar menor deslocabilidade. Em situações práticas de montagem em composição dupla a furação defasada é inevitável, pois as chapas são idênticas e o raio de montagem é levemente diferente. Mostrou-se anteriormente que todos os corpos de prova com chapa dupla apresentaram valores de resistência a favor da segurança, em comparação com configurações com chapa simples. Portanto, uma formulação para a resistência da ligação parafusada referente ao modo de falha por ruptura da seção líquida que não faça distinção entre o uso de chapas duplas ou simples é adequada ao caso de montagem em composição dupla e furação defasada. 
Figura 53 - Efeito da furação coincidente e defasada em corpos de prova com chapas de espessura total (a) 3,10 $\mathrm{mm}$ e (b) 3,90 $\mathrm{mm}$

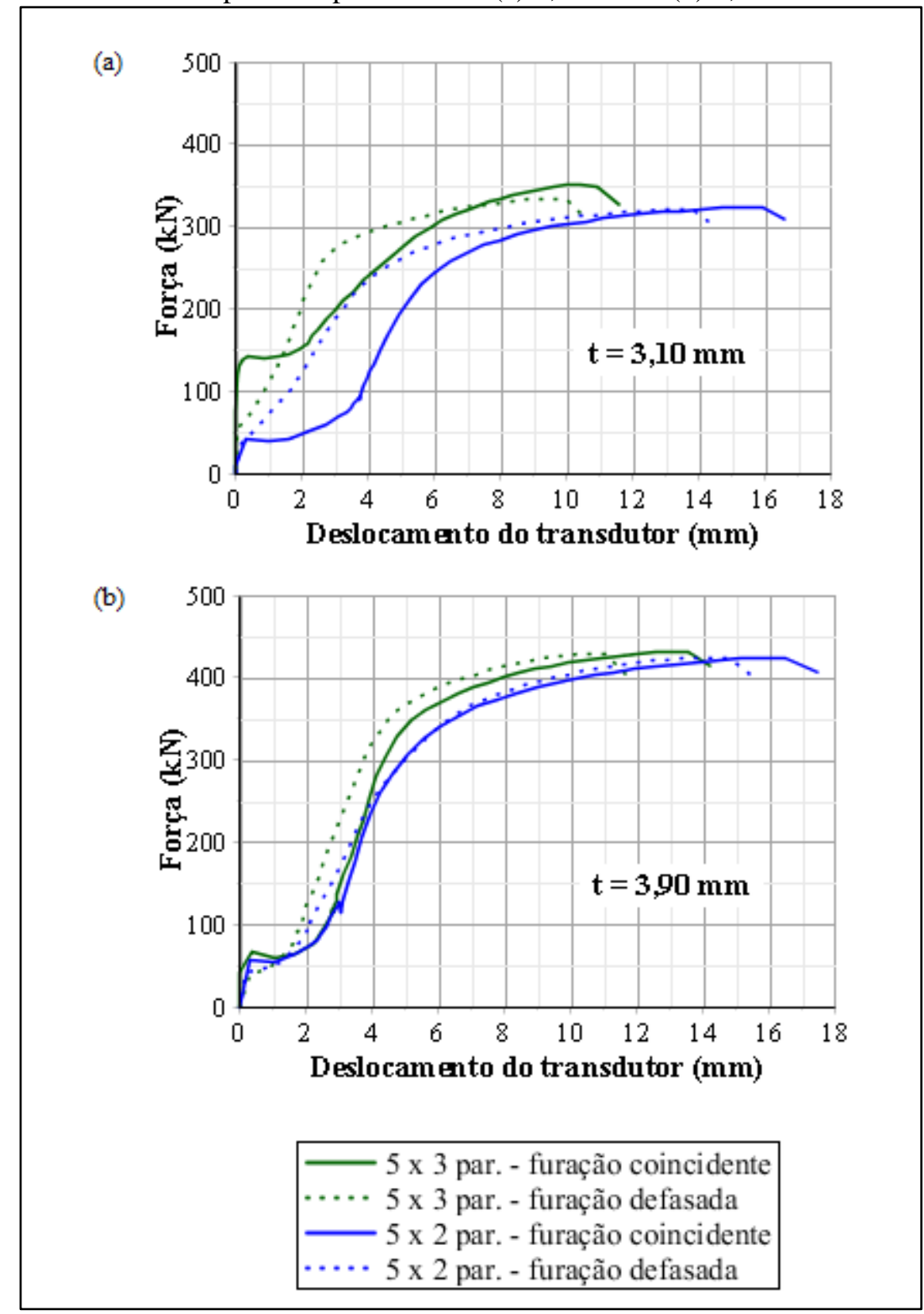

Fonte: o autor.

Com base em todos os resultados e análises deste trabalho, foram propostos modelos teóricos para a resistência de ligações parafusadas com aplicação em chapas de parede de silos cilíndricos metálicos, representados nas Equações 58 e 59, referentes aos modos de falha por ruptura da chapa na seção líquida e esmagamento da parede do furo, respectivamente.

$$
\begin{gathered}
F_{R, R S L}=A_{n} f u \\
F_{R, E S M}=\left(4-0,1 \cdot d_{b} / t\right) d_{b} t f_{u} \leq 3,2 d_{b} t f_{u}
\end{gathered}
$$




\section{CONCLUSÃO}

As ligações utilizadas em paredes de silos cilíndricos metálicos conectam chapas finas de aço, com número elevado de parafusos ao longo da extensão da ligação. Portanto, há diferenças com relação às ligações em perfis formados a frio, que apresentam menos parafusos, confinados em uma região menor. Não há, entretanto, uma diferenciação quanto a este aspecto nas normas de dimensionamento estrutural NBR 14762:2010, AISI S100-16, AS/NZS 4600:2005 e Eurocode 3. Além disso, os próprios modelos teóricos destas normas são conflitantes, evidenciando que não há um consenso sobre este assunto.

Os resultados experimentais deste trabalho mostraram que todas as normas analisadas resultaram conservadoras para a resistência dos tipos de ligação parafusada empregada nas chapas de parede de silos cilíndricos metálicos. A norma australiana AS/NZS 4600:2005 foi a que apresentou os resultados teóricos mais próximos aos experimentais. Foram propostas duas equações para o cálculo da resistência destas ligações, nos casos de falha por ruptura da chapa na seção líquida e esmagamento do aço na parede do furo.

Para a falha por ruptura da chapa na seção líquida foi proposta a Equação 58, igual ao modelo da norma australiana, sem coeficiente redutor da área líquida, em conformidade com o resultado de (ROGERS; HANCOCK, 2000). Não foi considerada uma distinção no modelo teórico para configurações de ligações com diferentes números de linhas de parafuso na direção perpendicular à solicitação, mas mesma área líquida na seção crítica, como o fazem as normas brasileira e europeia. Estas normas apresentaram resultados teóricos discrepantes dos experimentais. Os resultados obtidos mostraram que só há diferença apreciável no valor da resistência da ligação quando a pressão de contato efetivamente causa a mudança do modo de falha para esmagamento da parede do furo. Entretanto, as ligações com menos parafusos na direção paralela à solicitação resultaram em maiores deslocamentos. Os resultados experimentais para corpos de prova com chapa dupla mostraram que as configurações com furação defasada apresentaram menor resistência e deslocamento do que as configurações com furação coincidente. Em ambos os casos a resistência foi elevada em relação às configurações com chapa simples, portanto o uso da Equação 58 nestes casos está a favor da segurança. 
Para a falha por esmagamento do aço na parede dos furos em ligações com uso de duas arruelas por parafuso foi proposta a Equação 59, baseada no modelo das normas americana e australiana, que são idênticos. Esta expressão apresenta um acréscimo de resistência de 6,7\% para os casos em que a espessura da chapa é superior a um oitavo do diâmetro nominal do parafuso e mantém a formulação original para as demais situações. Os modelos das normas brasileira e europeia apresentaram resultados teóricos discrepantes dos experimentais.

Por fim, conclui-se a norma brasileira NBR 14762:2010 é conservadora no cálculo da resistência das ligações parafusadas empregadas em chapas de parede de silos cilíndricos metálicos. 


\section{REFERÊNCIAS BIBLIOGRÁFICAS}

AMERICAN IRON AND STEEL INSTITUTE. North American Specification for the Design of Cold-Formed Steel Structural Members. Washington: AISI, 2016.

ARNOLD, P. C.; ROBERTS, A. W. The Geometric Design of Storage Systems for Bulk Solids. In: Design of Steel Bins for the Storage of Bulk Solids. Sydney: University of Sydney, 1985.

ASSOCIAÇÃO BRASILEIRA DE NORMAS TÉCNICAS. NBR 14762 Dimensionamento de estruturas de aço construidas por perfis formados a frio. Rio de Janeiro: ABNT, 2010.

BROWN, C. J.; NIELSEN, J. Silos: fundamentals of theory, behaviour and design. Londres: CRC Press, 1998.

CALIL JR, C.; CHEUNG, A. B. Silos: pressões, fluxo, recomendações para o projeto e exemplos de cálculo. São Carlos: Escola de Engenharia de São Carlos - USP, 2007.

DAVIES, J. . Recent research advances in cold-formed steel structures. Journal of Constructional Steel Research, v. 55, n. 1-3, p. 267-288, 2000.

ESTEVES JR, P. Silos Metálicos de Chapas Corrugadas. Escola de Engenharia de São Carlos, Universidade de São Paulo, 1990.

EUROPEAN COMMITTEE FOR STANDARDISATION. Eurocode 3: Design of steel structures - Part 1-1: General rules and rules for buildings. Brussels: CEN, 2005a. v. 1

EUROPEAN COMMITTEE FOR STANDARDISATION. Eurocode 3: Design of steel structures - Part 1-8: Design of joints. Brussels: CEN, 2005b. v. 8

EUROPEAN COMMITTEE FOR STANDARDIZATION. Eurocode 3: Design of steel structures - Part 1-3: General rules - Supplementary rules for cold-formed members and sheeting. Brussels: CEN, 2006. v. 3

GREGORY, J. H.; THOMAS, M. M.; DUANE, S. E. Cold-formed steel structures to the AISI specification. New York: New York: Marcel Dekker, Inc, 2001.

LABOUBE, R. A.; CARRIL, J. L.; YU, W.-W. Tensile and bearing capacities of bolted connections. Rolla: Department of Civil Engineering -Center for Cold-Formed Steel 
Structures - University of Missouri, 1994.

MAIOLA, C. H. Ligações Parafusadas em Chapas Finas e Perfis de Aço Formados a Frio. São Carlos: Escola de Engenharia de São Carlos, Universidade de São Paulo, 2004.

ROGERS, C. A.; HANCOCK, G. J. Bolted Connection Tests of Thin G550 and G300 Sheet Steels. Sydney: Department of Civil Engineering - The University of Sydney, 1997.

ROGERS, C. A.; HANCOCK, G. J. Behaviour of Thin G550 Sheet Steel Bolted Connections. Fourteenth International Speciality Conference on Cold-Formed Steel Stuctures, p. 495-510, 1998.

ROGERS, C. A.; HANCOCK, G. J. Bolted connection design for sheet steels less than 1.0 mm thick. Journal of Constructional Steel Research, v. 51, n. 2, p. 123-146, 1999.

ROGERS, C. A.; HANCOCK, G. J. Failure modes of bolted-sheet-steel connections loaded in shear. Journal of Structural Engineering, v. 126, n. 2, p. 288-296, 2000.

ROTTER, J. M. Bending Theory of Shells for Bins and Silos. In: Design of Steel Bins for the Storage of Bulk Solids. Sydney: University of Sydney, 1985.

SILVA, E. L.; PIERIN, I.; SILVA, V. P. Estruturas Compostas por Perfis Formados a Frio - Dimensionamento pelo Método das Larguras Efetivas e Aplicação Conforme ABNT NBR 14762:2010 e ABNT NBR 6355:2012. Rio de Janeiro: CBCA, 2014.

STANDARDS AUSTRALIA / STANDARDS NEW ZEALAND. AS/NZS 4600 Cold-formed steel structures. Sydney: AS/NZS, 2005.

TEH, L. H.; CLEMENTS, D. D. A. Mechanisms of Block Shear Failure of Bolted Connections. Twenty-First International Specialty Conference on Cold-Formed Steel Structures, v. 138, p. 585-599, 2012.

TRAHAIR, N. S. Characteristics of Structural Form. In: Design of Steel Bins for the Storage of Bulk Solids. Sydney: University of Sydney, 1985.

WINTER, G. Tests on bolted connections in light gage steel. Journal of the Structural Division, ASCE Proceedings. Anais1956

YU, W.-W. Cold-Formed Steel Design. Third ed. New York: John Wiley \& Sons, 2000. 


\section{APÊNDICE A - Configurações dos corpos de prova}

Tabela 6 - Configurações dos ensaios de (ESTEVES JR, 1990)

\begin{tabular}{|c|c|c|c|c|c|c|c|c|c|c|c|c|c|c|c|c|c|}
\hline Corpo de prova & Ref. & $C$ & $L$ & $\begin{array}{c}t \\
(\boldsymbol{m} \boldsymbol{m})\end{array}$ & $\begin{array}{c}d_{p} \\
(\boldsymbol{m m})\end{array}$ & $\begin{array}{c}\boldsymbol{d}_{\boldsymbol{f}} \\
(\boldsymbol{m m})\end{array}$ & $\begin{array}{l}\boldsymbol{l}_{\text {chapa }} \\
(\boldsymbol{m m})\end{array}$ & $\begin{array}{c}\boldsymbol{d}_{\boldsymbol{f f p}} \\
(\boldsymbol{m m})\end{array}$ & $\begin{array}{c}\boldsymbol{d}_{\boldsymbol{b f} \boldsymbol{p}} \\
(\boldsymbol{m m})\end{array}$ & $\begin{array}{c}d_{f f l} \\
(\boldsymbol{m m})\end{array}$ & $\begin{array}{c}\boldsymbol{d}_{\boldsymbol{b f l} \boldsymbol{}} \\
(\boldsymbol{m m})\end{array}$ & $\begin{array}{c}\boldsymbol{f}_{\boldsymbol{y}} \\
(\boldsymbol{M P a} \boldsymbol{a})\end{array}$ & $\begin{array}{c}\boldsymbol{f}_{u} \\
(\boldsymbol{M P a})\end{array}$ & Tipo & Comp. & Fur. & $\begin{array}{c}\boldsymbol{F}_{\text {ult }} \\
(\boldsymbol{k N})\end{array}$ \\
\hline t096-p08-4L1C-1 & Ref. 1 & 1 & 4 & 0.90 & 8.0 & 9.5 & 205 & 52.2 & 24.2 & 30.0 & 30.0 & 323 & 375 & Corr. & Simpl. & - & 37.8 \\
\hline t096-p08-4L1C-2 & Ref. 2 & 1 & 4 & 0.90 & 8.0 & 9.5 & 205 & 52.2 & 24.2 & 30.0 & 30.0 & 323 & 375 & Corr. & Simpl. & - & 35.8 \\
\hline t126-p08-4L1C-1 & Ref. 3 & 1 & 4 & 1.20 & 8.0 & 9.5 & 200 & 52.2 & 21.7 & 30.0 & 30.0 & 295 & 366 & Corr. & Simpl. & - & 39.2 \\
\hline t126-p08-4L1C-2 & Ref. 4 & 1 & 4 & 1.20 & 8.0 & 9.5 & 210 & 52.2 & 26.7 & 30.0 & 30.0 & 295 & 366 & Corr. & Simpl. & - & 47.1 \\
\hline t156-p08-4L1C-1 & Ref. 5 & 1 & 4 & 1.50 & 8.0 & 9.5 & 201 & 52.2 & 22.2 & 30.0 & 30.0 & 274 & 360 & Corr. & Simpl. & - & 59.4 \\
\hline t156-p08-4L1C-2 & Ref. 6 & 1 & 4 & 1.50 & 8.0 & 9.5 & 208 & 52.2 & 25.7 & 30.0 & 30.0 & 274 & 360 & Corr. & Simpl. & - & 58.9 \\
\hline t190-p08-4L1C-1 & Ref. 7 & 1 & 4 & 1.84 & 8.0 & 9.5 & 207 & 52.2 & 25.2 & 30.0 & 30.0 & 297 & 375 & Corr. & Simpl. & - & 81.4 \\
\hline t190-p08-4L1C-2 & Ref. 8 & 1 & 4 & 1.84 & 8.0 & 9.5 & 209 & 52.2 & 26.2 & 30.0 & 30.0 & 297 & 375 & Corr. & Simpl. & - & 80.4 \\
\hline t190-p08-4L1C-3 & Ref. 9 & 1 & 4 & 1.84 & 8.0 & 9.5 & 206 & 52.2 & 24.7 & 30.0 & 30.0 & 363 & 447 & Corr. & Simpl. & - & 82.9 \\
\hline t190-p08-4L1C-4 & Ref. 10 & 1 & 4 & 1.84 & 8.0 & 9.5 & 203 & 52.2 & 23.2 & 30.0 & 30.0 & 363 & 447 & Corr. & Simpl. & - & 78.0 \\
\hline t096-p10-4L1C-1 & Ref. 11 & 1 & 4 & 0.90 & 10.0 & 11.5 & 204 & 52.2 & 23.7 & 30.0 & 30.0 & 323 & 375 & Corr. & Simpl. & - & 37.8 \\
\hline t096-p10-4L1C-2 & Ref. 12 & 1 & 4 & 0.90 & 10.0 & 11.5 & 208 & 52.2 & 25.7 & 30.0 & 30.0 & 323 & 375 & Corr. & Simpl. & - & 40.7 \\
\hline t126-p10-4L1C-1 & Ref. 13 & 1 & 4 & 1.20 & 10.0 & 11.5 & 207 & 52.2 & 25.2 & 30.0 & 30.0 & 295 & 366 & Corr. & Simpl. & - & 55.9 \\
\hline t126-p10-4L1C-2 & Ref. 14 & 1 & 4 & 1.20 & 10.0 & 11.5 & 208 & 52.2 & 25.7 & 30.0 & 30.0 & 295 & 366 & Corr. & Simpl. & - & 54.9 \\
\hline t156-p10-4L1C-1 & Ref. 15 & 1 & 4 & 1.50 & 10.0 & 11.5 & 205 & 52.2 & 24.2 & 30.0 & 30.0 & 274 & 360 & Corr. & Simpl. & - & 66.7 \\
\hline t156-p10-4L1C-2 & Ref. 16 & 1 & 4 & 1.50 & 10.0 & 11.5 & 203 & 52.2 & 23.2 & 30.0 & 30.0 & 274 & 360 & Corr. & Simpl. & - & 67.7 \\
\hline t190-p10-4L1C-1 & Ref. 17 & 1 & 4 & 1.84 & 10.0 & 11.5 & 211 & 52.2 & 27.2 & 30.0 & 30.0 & 297 & 375 & Corr. & Simpl. & - & 91.2 \\
\hline t190-p10-4L1C-2 & Ref. 18 & 1 & 4 & 1.84 & 10.0 & 11.5 & 205 & 52.2 & 24.2 & 30.0 & 30.0 & 297 & 375 & Corr. & Simpl. & - & 84.9 \\
\hline t190-p10-4L1C-3 & Ref. 19 & 1 & 4 & 1.84 & 10.0 & 11.5 & 210 & 52.2 & 26.7 & 30.0 & 30.0 & 363 & 447 & Corr. & Simpl. & - & 105.5 \\
\hline t190-p10-4L1C-4 & Ref. 20 & 1 & 4 & 1.84 & 10.0 & 11.5 & 210 & 52.2 & 26.7 & 30.0 & 30.0 & 363 & 447 & Corr. & Simpl. & - & 99.6 \\
\hline
\end{tabular}


Tabela 6 - Continuação

\begin{tabular}{|c|c|c|c|c|c|c|c|c|c|c|c|c|c|c|c|c|c|}
\hline Corpo de prova & Ref. & $C$ & $L$ & $\begin{array}{c}\boldsymbol{t} \\
(\boldsymbol{m} \boldsymbol{m})\end{array}$ & $\begin{array}{c}\boldsymbol{d}_{\boldsymbol{p}} \\
(\boldsymbol{m} \boldsymbol{m})\end{array}$ & $\begin{array}{c}d_{f} \\
(m m)\end{array}$ & $\begin{array}{l}\boldsymbol{l}_{\text {chapa }} \\
(\boldsymbol{m m})\end{array}$ & $\begin{array}{c}\boldsymbol{d}_{f f p} \\
(\boldsymbol{m} \boldsymbol{m})\end{array}$ & $\begin{array}{c}\boldsymbol{d}_{\boldsymbol{b f p} \boldsymbol{p}} \\
(\boldsymbol{m m})\end{array}$ & $\begin{array}{c}\boldsymbol{d}_{\boldsymbol{f} \boldsymbol{f l}} \\
(\boldsymbol{m} \boldsymbol{m})\end{array}$ & $\begin{array}{c}\boldsymbol{d}_{\boldsymbol{b f l} \boldsymbol{l}} \\
(\boldsymbol{m} \boldsymbol{m})\end{array}$ & $\begin{array}{c}\boldsymbol{f}_{\boldsymbol{y}} \\
(\boldsymbol{M P a})\end{array}$ & $\begin{array}{c}\boldsymbol{f}_{\boldsymbol{u}} \\
(\boldsymbol{M P a})\end{array}$ & Tipo & Comp. & Fur. & $\begin{array}{c}F_{\text {ult }} \\
(\boldsymbol{k N})\end{array}$ \\
\hline t096-p08-4L2C-1 & Ref. 21 & 2 & 4 & 0.90 & 8.0 & 9.5 & 205 & 52.2 & 24.2 & 30.0 & 30.0 & 323 & 375 & Corr. & Simpl. & - & 59.8 \\
\hline t096-p08-4L2C-2 & Ref. 22 & 2 & 4 & 0.90 & 8.0 & 9.5 & 200 & 52.2 & 21.7 & 30.0 & 30.0 & 323 & 375 & Corr. & Simpl. & - & 54.4 \\
\hline t126-p08-4L2C-1 & Ref. 23 & 2 & 4 & 1.20 & 8.0 & 9.5 & 208 & 52.2 & 25.7 & 30.0 & 30.0 & 295 & 366 & Corr. & Simpl. & - & 76.5 \\
\hline t126-p08-4L2C-2 & Ref. 24 & 2 & 4 & 1.20 & 8.0 & 9.5 & 205 & 52.2 & 24.2 & 30.0 & 30.0 & 295 & 366 & Corr. & Simpl. & - & 76.5 \\
\hline t156-p08-4L2C-1 & Ref. 25 & 2 & 4 & 1.50 & 8.0 & 9.5 & 202 & 52.2 & 22.7 & 30.0 & 30.0 & 274 & 360 & Corr. & Simpl. & - & 92.7 \\
\hline t156-p08-4L2C-2 & Ref. 26 & 2 & 4 & 1.50 & 8.0 & 9.5 & 208 & 52.2 & 25.7 & 30.0 & 30.0 & 274 & 360 & Corr. & Simpl. & - & 96.1 \\
\hline t190-p08-4L2C-1 & Ref. 27 & 2 & 4 & 1.84 & 8.0 & 9.5 & 213 & 52.2 & 28.2 & 30.0 & 30.0 & 297 & 375 & Corr. & Simpl. & - & 123.2 \\
\hline t190-p08-4L2C-2 & Ref. 28 & 2 & 4 & 1.84 & 8.0 & 9.5 & 221 & 52.2 & 32.2 & 30.0 & 30.0 & 297 & 375 & Corr. & Simpl. & - & 129.5 \\
\hline t190-p08-4L2C-3 & Ref. 29 & 2 & 4 & 1.84 & 8.0 & 9.5 & 206 & 52.2 & 24.7 & 30.0 & 30.0 & 363 & 447 & Corr. & Simpl. & - & 143.2 \\
\hline t190-p08-4L2C-4 & Ref. 30 & 2 & 4 & 1.84 & 8.0 & 9.5 & 205 & 52.2 & 24.2 & 30.0 & 30.0 & 363 & 447 & Corr. & Simpl. & - & 142.2 \\
\hline t096-p10-4L2C-1 & Ref. 31 & 2 & 4 & 0.90 & 10.0 & 11.5 & 203 & 52.2 & 23.2 & 30.0 & 30.0 & 323 & 375 & Corr. & Simpl. & - & 55.9 \\
\hline t096-p10-4L2C-2 & Ref. 32 & 2 & 4 & 0.90 & 10.0 & 11.5 & 215 & 52.2 & 29.2 & 30.0 & 30.0 & 323 & 375 & Corr. & Simpl. & - & 59.4 \\
\hline t126-p10-4L2C-1 & Ref. 33 & 2 & 4 & 1.20 & 10.0 & 11.5 & 217 & 52.2 & 30.2 & 30.0 & 30.0 & 295 & 366 & Corr. & Simpl. & - & 78.0 \\
\hline t126-p10-4L2C-2 & Ref. 34 & 2 & 4 & 1.20 & 10.0 & 11.5 & 208 & 52.2 & 25.7 & 30.0 & 30.0 & 295 & 366 & Corr. & Simpl. & - & 74.1 \\
\hline t156-p10-4L2C-1 & Ref. 35 & 2 & 4 & 1.50 & 10.0 & 11.5 & 218 & 52.2 & 30.7 & 30.0 & 30.0 & 274 & 360 & Corr. & Simpl. & - & 97.1 \\
\hline t156-p10-4L2C-2 & Ref. 36 & 2 & 4 & 1.50 & 10.0 & 11.5 & 214 & 52.2 & 28.7 & 30.0 & 30.0 & 274 & 360 & Corr. & Simpl. & - & 95.2 \\
\hline t190-p10-4L2C-1 & Ref. 37 & 2 & 4 & 1.84 & 10.0 & 11.5 & 203 & 52.2 & 23.2 & 30.0 & 30.0 & 297 & 375 & Corr. & Simpl. & - & 102.0 \\
\hline t190-p10-4L2C-2 & Ref. 38 & 2 & 4 & 1.84 & 10.0 & 11.5 & 209 & 52.2 & 26.2 & 30.0 & 30.0 & 297 & 375 & Corr. & Simpl. & - & 110.4 \\
\hline t190-p10-4L2C-3 & Ref. 39 & 2 & 4 & 1.84 & 10.0 & 11.5 & 206 & 52.2 & 24.7 & 30.0 & 30.0 & 363 & 447 & Corr. & Simpl. & - & 136.4 \\
\hline t190-p10-4L2C-4 & Ref. 40 & 2 & 4 & 1.84 & 10.0 & 11.5 & 205 & 52.2 & 24.2 & 30.0 & 30.0 & 363 & 447 & Corr. & Simpl. & - & 136.4 \\
\hline
\end{tabular}


Tabela 6 - Continuação

\begin{tabular}{|c|c|c|c|c|c|c|c|c|c|c|c|c|c|c|c|c|c|}
\hline Corpo de prova & Ref. & $C$ & $L$ & $\begin{array}{c}\boldsymbol{t} \\
(\boldsymbol{m} \boldsymbol{m})\end{array}$ & $\begin{array}{c}\boldsymbol{d}_{\boldsymbol{p}} \\
(\boldsymbol{m} \boldsymbol{m})\end{array}$ & $\begin{array}{c}\boldsymbol{d}_{\boldsymbol{f}} \\
(\boldsymbol{m} \boldsymbol{m})\end{array}$ & $\begin{array}{l}\boldsymbol{l}_{\text {chapa }} \\
(\boldsymbol{m m})\end{array}$ & $\begin{array}{c}\boldsymbol{d}_{\boldsymbol{f f p}} \\
(\boldsymbol{m} \boldsymbol{m})\end{array}$ & $\begin{array}{c}d_{b f p} \\
(\boldsymbol{m m})\end{array}$ & $\begin{array}{c}\boldsymbol{d}_{\boldsymbol{f} \boldsymbol{f l}} \\
(\boldsymbol{m} \boldsymbol{m})\end{array}$ & $\begin{array}{c}\boldsymbol{d}_{\boldsymbol{b} \boldsymbol{f l}} \\
(\boldsymbol{m} \boldsymbol{m})\end{array}$ & $\begin{array}{c}\boldsymbol{f}_{\boldsymbol{y}} \\
(\boldsymbol{M P a})\end{array}$ & $\begin{array}{c}\boldsymbol{f}_{u} \\
(\boldsymbol{M P a})\end{array}$ & Tipo & Comp. & Fur. & $\begin{array}{c}\boldsymbol{F}_{\text {ult }} \\
(\boldsymbol{k N})\end{array}$ \\
\hline t096-p08-4L3C-1 & Ref. 41 & 3 & 4 & 0.90 & 8.0 & 9.5 & 221 & 52.2 & 32.2 & 30.0 & 30.0 & 323 & 375 & Corr. & Simpl. & - & 64.8 \\
\hline t096-p08-4L3C-2 & Ref. 42 & 3 & 4 & 0.90 & 8.0 & 9.5 & 217 & 52.2 & 30.2 & 30.0 & 30.0 & 323 & 375 & Corr. & Simpl. & - & 63.3 \\
\hline t126-p08-4L3C-1 & Ref. 43 & 3 & 4 & 1.20 & 8.0 & 9.5 & 217 & 52.2 & 30.2 & 30.0 & 30.0 & 295 & 366 & Corr. & Simpl. & - & 81.9 \\
\hline t126-p08-4L3C-2 & Ref. 44 & 3 & 4 & 1.20 & 8.0 & 9.5 & 217 & 52.2 & 30.2 & 30.0 & 30.0 & 295 & 366 & Corr. & Simpl. & - & 81.9 \\
\hline t156-p08-4L3C-1 & Ref. 45 & 3 & 4 & 1.50 & 8.0 & 9.5 & 217 & 52.2 & 30.2 & 30.0 & 30.0 & 274 & 360 & Corr. & Simpl. & - & 101.0 \\
\hline t156-p08-4L3C-2 & Ref. 46 & 3 & 4 & 1.50 & 8.0 & 9.5 & 217 & 52.2 & 30.2 & 30.0 & 30.0 & 274 & 360 & Corr. & Simpl. & - & 101.0 \\
\hline t190-p08-4L3C-1 & Ref. 47 & 3 & 4 & 1.84 & 8.0 & 9.5 & 216 & 52.2 & 29.7 & 30.0 & 30.0 & 297 & 375 & Corr. & Simpl. & - & 126.1 \\
\hline t190-p08-4L3C-2 & Ref. 48 & 3 & 4 & 1.84 & 8.0 & 9.5 & 219 & 52.2 & 31.2 & 30.0 & 30.0 & 297 & 375 & Corr. & Simpl. & - & 128.0 \\
\hline t190-p08-4L3C-3 & Ref. 49 & 3 & 4 & 1.84 & 8.0 & 9.5 & 214 & 52.2 & 28.7 & 30.0 & 30.0 & 363 & 447 & Corr. & Simpl. & - & 151.1 \\
\hline t190-p08-4L3C-4 & Ref. 50 & 3 & 4 & 1.84 & 8.0 & 9.5 & 215 & 52.2 & 29.2 & 30.0 & 30.0 & 363 & 447 & Corr. & Simpl. & - & 151.1 \\
\hline t096-p10-4L3C-1 & Ref. 51 & 3 & 4 & 0.90 & 10.0 & 11.5 & 213 & 52.2 & 28.2 & 30.0 & 30.0 & 323 & 375 & Corr. & Simpl. & - & 59.8 \\
\hline t096-p10-4L3C-2 & Ref. 52 & 3 & 4 & 0.90 & 10.0 & 11.5 & 215 & 52.2 & 29.2 & 30.0 & 30.0 & 323 & 375 & Corr. & Simpl. & - & 60.3 \\
\hline t126-p10-4L3C-1 & Ref. 53 & 3 & 4 & 1.20 & 10.0 & 11.5 & 215 & 52.2 & 29.2 & 30.0 & 30.0 & 295 & 366 & Corr. & Simpl. & - & 77.0 \\
\hline t126-p10-4L3C-2 & Ref. 54 & 3 & 4 & 1.20 & 10.0 & 11.5 & 209 & 52.2 & 26.2 & 30.0 & 30.0 & 295 & 366 & Corr. & Simpl. & - & 74.6 \\
\hline t156-p10-4L3C-1 & Ref. 55 & 3 & 4 & 1.50 & 10.0 & 11.5 & 212 & 52.2 & 27.7 & 30.0 & 30.0 & 274 & 360 & Corr. & Simpl. & - & 94.2 \\
\hline t156-p10-4L3C-2 & Ref. 56 & 3 & 4 & 1.50 & 10.0 & 11.5 & 216 & 52.2 & 29.7 & 30.0 & 30.0 & 274 & 360 & Corr. & Simpl. & - & 94.1 \\
\hline t190-p10-4L3C-1 & Ref. 57 & 3 & 4 & 1.84 & 10.0 & 11.5 & 205 & 52.2 & 24.2 & 30.0 & 30.0 & 297 & 375 & Corr. & Simpl. & - & 112.8 \\
\hline t190-p10-4L3C-2 & Ref. 58 & 3 & 4 & 1.84 & 10.0 & 11.5 & 209 & 52.2 & 26.2 & 30.0 & 30.0 & 297 & 375 & Corr. & Simpl. & - & 115.8 \\
\hline t190-p10-4L3C-3 & Ref. 59 & 3 & 4 & 1.84 & 10.0 & 11.5 & 206 & 52.2 & 24.7 & 30.0 & 30.0 & 363 & 447 & Corr. & Simpl. & - & 135.8 \\
\hline t190-p10-4L3C-4 & Ref. 60 & 3 & 4 & 1.84 & 10.0 & 11.5 & 205 & 52.2 & 24.2 & 30.0 & 30.0 & 363 & 447 & Corr. & Simpl. & - & 139.3 \\
\hline
\end{tabular}


Tabela 7 - Configurações dos ensaios realizados no LE-EESC-USP em maio de 2015

\begin{tabular}{|c|c|c|c|c|c|c|c|c|c|c|c|c|c|c|c|c|c|}
\hline Corpo de prova & $\operatorname{Ref}$. & $C$ & $L$ & $\begin{array}{c}t \\
(\boldsymbol{m m})\end{array}$ & $\begin{array}{c}d_{p} \\
(m m)\end{array}$ & $\begin{array}{c}d_{f} \\
(\boldsymbol{m m})\end{array}$ & $\begin{array}{l}l_{\text {chapa }} \\
(\boldsymbol{m m})\end{array}$ & $\begin{array}{c}d_{f f p} \\
(\boldsymbol{m m}) \\
\end{array}$ & $\begin{array}{c}d_{b f p} \\
(\boldsymbol{m m})\end{array}$ & $\begin{array}{c}d_{f f l} \\
(\boldsymbol{m m})\end{array}$ & $\begin{array}{c}d_{b f l} \\
(m m)\end{array}$ & $\begin{array}{c}\boldsymbol{f}_{\boldsymbol{y}} \\
(\boldsymbol{M P a})\end{array}$ & $\begin{array}{c}\boldsymbol{f}_{\boldsymbol{u}} \\
(\boldsymbol{M P a})\end{array}$ & Tipo & Comp. & Fur. & $\begin{array}{c}F_{\text {ult }} \\
(\boldsymbol{k N})\end{array}$ \\
\hline t095-p10-5L2C-1 & Ref. 1 & 2 & 5 & 0.89 & 10.0 & 11.0 & 266 & 52.2 & 28.4 & 31.9 & 27.2 & 431 & 484 & Corr. & Simpl. & - & 83.9 \\
\hline t095-p10-5L2C-2 & Ref. 2 & 2 & 5 & 0.89 & 10.0 & 11.0 & 266 & 52.2 & 28.4 & 31.9 & 27.2 & 431 & 484 & Corr. & Simpl. & - & 84.8 \\
\hline t095-p10-5L2C-3 & Ref. 3 & 2 & 5 & 0.89 & 10.0 & 11.0 & 266 & 52.2 & 28.4 & 31.9 & 27.2 & 431 & 484 & Corr. & Simpl. & - & 82.8 \\
\hline t095-p10-5L3C-1 & Ref. 4 & 3 & 5 & 0.89 & 10.0 & 11.0 & 266 & 52.2 & 28.4 & 31.9 & 27.2 & 431 & 484 & Corr. & Simpl. & - & 88.1 \\
\hline t095-p10-5L3C-2 & Ref. 5 & 3 & 5 & 0.89 & 10.0 & 11.0 & 266 & 52.2 & 28.4 & 31.9 & 27.2 & 431 & 484 & Corr. & Simpl. & - & 89.8 \\
\hline t095-p10-5L3C-3 & Ref. 6 & 3 & 5 & 0.89 & 10.0 & 11.0 & 266 & 52.2 & 28.4 & 31.9 & 27.2 & 431 & 484 & Corr. & Simpl. & - & 88.4 \\
\hline t125-p10-5L2C-1 & Ref. 7 & 2 & 5 & 1.19 & 10.0 & 11.0 & 266 & 52.2 & 28.4 & 31.9 & 27.2 & 662 & 674 & Corr. & Simpl. & - & 156.0 \\
\hline t125-p10-5L2C-2 & Ref. 8 & 2 & 5 & 1.19 & 10.0 & 11.0 & 266 & 52.2 & 28.4 & 31.9 & 27.2 & 662 & 674 & Corr. & Simpl. & - & 156.2 \\
\hline t125-p10-5L2C-3 & Ref. 9 & 2 & 5 & 1.19 & 10.0 & 11.0 & 266 & 52.2 & 28.4 & 31.9 & 27.2 & 662 & 674 & Corr. & Simpl. & - & 155.4 \\
\hline t125-p10-5L3C-1 & Ref. 10 & 3 & 5 & 1.19 & 10.0 & 11.0 & 266 & 52.2 & 28.4 & 31.9 & 27.2 & 662 & 674 & Corr. & Simpl. & - & 161.5 \\
\hline t125-p10-5L3C-2 & Ref. 11 & 3 & 5 & 1.19 & 10.0 & 11.0 & 266 & 52.2 & 28.4 & 31.9 & 27.2 & 662 & 674 & Corr. & Simpl. & - & 159.6 \\
\hline t125-p10-5L3C-3 & Ref. 12 & 3 & 5 & 1.19 & 10.0 & 11.0 & 266 & 52.2 & 28.4 & 31.9 & 27.2 & 662 & 674 & Corr. & Simpl. & - & 158.6 \\
\hline t155-p10-5L2C-1 & Ref. 13 & 2 & 5 & 1.49 & 10.0 & 11.0 & 266 & 52.2 & 28.4 & 31.9 & 27.2 & 604 & 630 & Corr. & Simpl. & - & 187.2 \\
\hline t155-p10-5L2C-2 & Ref. 14 & 2 & 5 & 1.49 & 10.0 & 11.0 & 266 & 52.2 & 28.4 & 31.9 & 27.2 & 604 & 630 & Corr. & Simpl. & - & 186.5 \\
\hline t155-p10-5L2C-3 & Ref. 15 & 2 & 5 & 1.49 & 10.0 & 11.0 & 266 & 52.2 & 28.4 & 31.9 & 27.2 & 604 & 630 & Corr. & Simpl. & - & 186.4 \\
\hline t155-p10-5L3C-1 & Ref. 16 & 3 & 5 & 1.49 & 10.0 & 11.0 & 266 & 52.2 & 28.4 & 31.9 & 27.2 & 604 & 630 & Corr. & Simpl. & - & 181.1 \\
\hline t155-p10-5L3C-2 & Ref. 17 & 3 & 5 & 1.49 & 10.0 & 11.0 & 266 & 52.2 & 28.4 & 31.9 & 27.2 & 604 & 630 & Corr. & Simpl. & - & 189.7 \\
\hline t155-p10-5L3C-3 & Ref. 18 & 3 & 5 & 1.49 & 10.0 & 11.0 & 266 & 52.2 & 28.4 & 31.9 & 27.2 & 604 & 630 & Corr. & Simpl. & - & 190.4 \\
\hline t195-p10-5L2C-1 & Ref. 19 & 2 & 5 & 1.89 & 10.0 & 11.0 & 266 & 52.2 & 28.4 & 31.9 & 27.2 & 573 & 608 & Corr. & Simpl. & - & 232.6 \\
\hline t195-p10-5L2C-2 & Ref. 20 & 2 & 5 & 1.89 & 10.0 & 11.0 & 266 & 52.2 & 28.4 & 31.9 & 27.2 & 573 & 608 & Corr. & Simpl. & - & 233.9 \\
\hline t195-p10-5L2C-3 & Ref. 21 & 2 & 5 & 1.89 & 10.0 & 11.0 & 266 & 52.2 & 28.4 & 31.9 & 27.2 & 573 & 608 & Corr. & Simpl. & - & 230.0 \\
\hline t195-p10-5L3C-1 & Ref. 22 & 3 & 5 & 1.89 & 10.0 & 11.0 & 266 & 52.2 & 28.4 & 31.9 & 27.2 & 573 & 608 & Corr. & Simpl. & - & 239.5 \\
\hline t195-p10-5L3C-2 & Ref. 23 & 3 & 5 & 1.89 & 10.0 & 11.0 & 266 & 52.2 & 28.4 & 31.9 & 27.2 & 573 & 608 & Corr. & Simpl. & - & 238.1 \\
\hline t195-p10-5L3C-3 & Ref. 24 & 3 & 5 & 1.89 & 10.0 & 11.0 & 266 & 52.2 & 28.4 & 31.9 & 27.2 & 573 & 608 & Corr. & Simpl. & - & 238.8 \\
\hline
\end{tabular}


Tabela 8 - Configurações dos ensaios realizados no LE-EESC-USP em outubro de 2015 com chapas corrugadas em montagem simples

\begin{tabular}{|c|c|c|c|c|c|c|c|c|c|c|c|c|c|c|c|c|c|}
\hline Corpo de prova & $\operatorname{Ref}$ & $C$ & $L$ & $\begin{array}{c}t \\
(\boldsymbol{m m}) \\
\end{array}$ & $\begin{array}{c}\boldsymbol{d}_{\boldsymbol{p}} \\
(\boldsymbol{m m})\end{array}$ & $\begin{array}{c}\boldsymbol{d}_{\boldsymbol{f}} \\
(\boldsymbol{m m})\end{array}$ & $\begin{array}{l}l_{\text {chapa }} \\
(\boldsymbol{m m})\end{array}$ & $\begin{array}{c}d_{f f p} \\
(\boldsymbol{m m})\end{array}$ & $\begin{array}{c}d_{b f p} \\
(\boldsymbol{m m})\end{array}$ & $\begin{array}{c}d_{f f l} \\
(\boldsymbol{m m})\end{array}$ & $\begin{array}{c}d_{b f l} \\
(\boldsymbol{m m})\end{array}$ & $\begin{array}{c}\boldsymbol{f}_{\boldsymbol{y}} \\
(\boldsymbol{M P a})\end{array}$ & $\begin{array}{c}\boldsymbol{f}_{\boldsymbol{u}} \\
(\boldsymbol{M P a})\end{array}$ & Tipo & Comp. & Fur. & $\begin{array}{c}\boldsymbol{F}_{\text {ult }} \\
(\boldsymbol{k N})\end{array}$ \\
\hline t155-p10-5L3C-2 & Ref. 1 & 3 & 5 & 1.49 & 10.0 & 11.0 & 266 & 52.2 & 28.4 & 31.9 & 27.2 & 551 & 576 & Corr. & Simpl. & - & 194.1 \\
\hline t270-p10-5L3C-2 & Ref. 2 & 3 & 5 & 2.64 & 10.0 & 11.0 & 266 & 52.2 & 28.4 & 31.9 & 27.2 & 490 & 523 & Corr. & Simpl. & - & 309.8 \\
\hline t155-p10-5L2C-1 & Ref. 3 & 2 & 5 & 1.49 & 10.0 & 11.0 & 266 & 52.2 & 28.4 & 31.9 & 27.2 & 551 & 576 & Corr. & Simpl. & - & 192.3 \\
\hline t155-p10-5L2C-2 & Ref. 4 & 2 & 5 & 1.49 & 10.0 & 11.0 & 266 & 52.2 & 28.4 & 31.9 & 27.2 & 551 & 576 & Corr. & Simpl. & - & 190.3 \\
\hline t155-p10-5L2C-4 & Ref. 5 & 2 & 5 & 1.49 & 10.0 & 11.0 & 266 & 52.2 & 28.4 & 31.9 & 27.2 & 551 & 576 & Corr. & Simpl. & - & 194.2 \\
\hline t270-p10-5L2C-3 & Ref. 6 & 2 & 5 & 2.64 & 10.0 & 11.0 & 266 & 52.2 & 28.4 & 31.9 & 27.2 & 490 & 523 & Corr. & Simpl. & - & 310.9 \\
\hline t155-p10-4L4C-1 & Ref. 7 & 4 & 4 & 1.49 & 10.0 & 11.0 & 266 & 104.4 & 28.4 & 31.9 & 27.2 & 551 & 576 & Corr. & Simpl. & - & 196.3 \\
\hline t155-p10-4L4C-2 & Ref. 8 & 4 & 4 & 1.49 & 10.0 & 11.0 & 266 & 104.4 & 28.4 & 31.9 & 27.2 & 551 & 576 & Corr. & Simpl. & - & 194.7 \\
\hline t155-p10-4L4C-3 & Ref. 9 & 4 & 4 & 1.49 & 10.0 & 11.0 & 266 & 104.4 & 28.4 & 31.9 & 27.2 & 551 & 576 & Corr. & Simpl. & - & 192.1 \\
\hline t270-p10-4L4C-1 & Ref. 10 & 4 & 4 & 2.64 & 10.0 & 11.0 & 266 & 104.4 & 28.4 & 31.9 & 27.2 & 490 & 523 & Corr. & Simpl. & - & 307.8 \\
\hline t270-p10-4L4C-2 & Ref. 11 & 4 & 4 & 2.64 & 10.0 & 11.0 & 266 & 104.4 & 28.4 & 31.9 & 27.2 & 490 & 523 & Corr. & Simpl. & - & 283.1 \\
\hline t155-p10-3L4C-1 & Ref. 12 & 3 & 4 & 1.49 & 10.0 & 11.0 & 266 & 104.4 & 28.4 & 31.9 & 27.2 & 551 & 576 & Corr. & Simpl. & - & 180.0 \\
\hline t155-p10-3L4C-2 & Ref. 13 & 3 & 4 & 1.49 & 10.0 & 11.0 & 266 & 104.4 & 28.4 & 31.9 & 27.2 & 551 & 576 & Corr. & Simpl. & - & 185.1 \\
\hline t155-p10-3L4C-3 & Ref. 14 & 3 & 4 & 1.49 & 10.0 & 11.0 & 266 & 104.4 & 28.4 & 31.9 & 27.2 & 551 & 576 & Corr. & Simpl. & - & 183.2 \\
\hline t270-p10-3L4C-1 & Ref. 15 & 3 & 4 & 2.64 & 10.0 & 11.0 & 266 & 104.4 & 28.4 & 31.9 & 27.2 & 490 & 523 & Corr. & Simpl. & - & 299.5 \\
\hline t270-p10-3L4C-2 & Ref. 16 & 3 & 4 & 2.64 & 10.0 & 11.0 & 266 & 104.4 & 28.4 & 31.9 & 27.2 & 490 & 523 & Corr. & Simpl. & - & 299.5 \\
\hline t270-p10-3L4C-3 & Ref. 17 & 3 & 4 & 2.64 & 10.0 & 11.0 & 266 & 104.4 & 28.4 & 31.9 & 27.2 & 490 & 523 & Corr. & Simpl. & - & 290.2 \\
\hline t155-p10-3L4C-1 & Ref. 18 & 4 & 3 & 1.49 & 10.0 & 11.0 & 266 & 104.4 & 28.4 & 31.9 & 27.2 & 551 & 576 & Corr. & Simpl. & - & 197.7 \\
\hline t155-p10-3L4C-2 & Ref. 19 & 4 & 3 & 1.49 & 10.0 & 11.0 & 266 & 104.4 & 28.4 & 31.9 & 27.2 & 551 & 576 & Corr. & Simpl. & - & 187.6 \\
\hline t155-p10-3L4C-3 & Ref. 20 & 4 & 3 & 1.49 & 10.0 & 11.0 & 266 & 104.4 & 28.4 & 31.9 & 27.2 & 551 & 576 & Corr. & Simpl. & - & 198.8 \\
\hline t155-p10-3L3C-1 & Ref. 21 & 3 & 3 & 1.49 & 10.0 & 11.0 & 266 & 104.4 & 28.4 & 31.9 & 27.2 & 551 & 576 & Corr. & Simpl. & - & 167.9 \\
\hline t155-p10-3L3C-2 & Ref. 22 & 3 & 3 & 1.49 & 10.0 & 11.0 & 266 & 104.4 & 28.4 & 31.9 & 27.2 & 551 & 576 & Corr. & Simpl. & - & 171.9 \\
\hline t155-p10-3L3C-3 & Ref. 23 & 3 & 3 & 1.49 & 10.0 & 11.0 & 266 & 104.4 & 28.4 & 31.9 & 27.2 & 551 & 576 & Corr. & Simpl. & - & 166.3 \\
\hline
\end{tabular}


Tabela 9 - Configurações dos ensaios realizados no LE-EESC-USP em outubro de 2015 com chapas planas em montagem simples

\begin{tabular}{|c|c|c|c|c|c|c|c|c|c|c|c|c|c|c|c|c|c|}
\hline Corpo de prova & $\operatorname{Ref}$. & $C$ & $L$ & $\begin{array}{c}t \\
(\boldsymbol{m m}) \\
\end{array}$ & $\begin{array}{c}d_{p} \\
(\boldsymbol{m m})\end{array}$ & $\begin{array}{c}\boldsymbol{d}_{\boldsymbol{f}} \\
(\boldsymbol{m m})\end{array}$ & $\begin{array}{l}\boldsymbol{l}_{\text {chapa }} \\
(\mathrm{mm})\end{array}$ & $\begin{array}{c}d_{f f p} \\
(\boldsymbol{m m})\end{array}$ & $\begin{array}{c}d_{b f p} \\
(m m)\end{array}$ & $\begin{array}{c}d_{f f l} \\
(\boldsymbol{m m})\end{array}$ & $\begin{array}{c}d_{b f l} \\
(\boldsymbol{m m})\end{array}$ & $\begin{array}{c}\boldsymbol{f}_{\boldsymbol{y}} \\
(\boldsymbol{M P a})\end{array}$ & $\begin{array}{c}\boldsymbol{f}_{\boldsymbol{u}} \\
(\boldsymbol{M P a})\end{array}$ & Tipo & Comp. & Fur. & $\begin{array}{c}\boldsymbol{F}_{\text {ult }} \\
(\boldsymbol{k} \boldsymbol{N})\end{array}$ \\
\hline t155-p10-5L3C-1 & Ref. 1 & 3 & 5 & 1.49 & 10.0 & 11.0 & 266 & 52.2 & 28.4 & 31.9 & 27.2 & 551 & 576 & Plana & Simpl. & - & 198.8 \\
\hline t155-p10-5L3C-2 & Ref. 2 & 3 & 5 & 1.49 & 10.0 & 11.0 & 266 & 52.2 & 28.4 & 31.9 & 27.2 & 551 & 576 & Plana & Simpl. & - & 199.1 \\
\hline t155-p10-5L3C-3 & Ref. 3 & 3 & 5 & 1.49 & 10.0 & 11.0 & 266 & 52.2 & 28.4 & 31.9 & 27.2 & 551 & 576 & Plana & Simpl. & - & 198.2 \\
\hline t270-p10-5L3C-1 & Ref. 4 & 3 & 5 & 2.64 & 10.0 & 11.0 & 266 & 52.2 & 28.4 & 31.9 & 27.2 & 490 & 523 & Plana & Simpl. & - & 313.2 \\
\hline t270-p10-5L3C-2 & Ref. 5 & 3 & 5 & 2.64 & 10.0 & 11.0 & 266 & 52.2 & 28.4 & 31.9 & 27.2 & 490 & 523 & Plana & Simpl. & - & 317.2 \\
\hline t155-p10-5L3C-1 & Ref. 6 & 2 & 5 & 1.49 & 10.0 & 11.0 & 266 & 52.2 & 28.4 & 31.9 & 27.2 & 551 & 576 & Plana & Simpl. & - & 192.5 \\
\hline t155-p10-5L3C-2 & Ref. 7 & 2 & 5 & 1.49 & 10.0 & 11.0 & 266 & 52.2 & 28.4 & 31.9 & 27.2 & 551 & 576 & Plana & Simpl. & - & 192.1 \\
\hline t155-p10-5L3C-3 & Ref. 8 & 2 & 5 & 1.49 & 10.0 & 11.0 & 266 & 52.2 & 28.4 & 31.9 & 27.2 & 551 & 576 & Plana & Simpl. & - & 194.5 \\
\hline t270-p10-5L3C-3 & Ref. 9 & 2 & 5 & 2.64 & 10.0 & 11.0 & 266 & 52.2 & 28.4 & 31.9 & 27.2 & 490 & 523 & Plana & Simpl. & - & 309.7 \\
\hline
\end{tabular}

Tabela 10 - Configurações dos ensaios realizados no LE-EESC-USP em outubro de 2015 com chapas corrugadas em montagem dupla

\begin{tabular}{|c|c|c|c|c|c|c|c|c|c|c|c|c|c|c|c|c|c|}
\hline Corpo de prova & Ref. & $C$ & $L$ & $\begin{array}{c}\boldsymbol{t} \\
(\boldsymbol{m} \boldsymbol{m})\end{array}$ & $\begin{array}{c}d_{p} \\
(\boldsymbol{m} m)\end{array}$ & $\begin{array}{c}\boldsymbol{d}_{\boldsymbol{f}} \\
(\boldsymbol{m} \boldsymbol{m})\end{array}$ & $\begin{array}{l}\boldsymbol{l}_{\text {chapa }} \\
(\boldsymbol{m m})\end{array}$ & $\begin{array}{c}\boldsymbol{d}_{\boldsymbol{f f p}} \\
(\boldsymbol{m m})\end{array}$ & $\begin{array}{c}\boldsymbol{d}_{\boldsymbol{b f p}} \\
(\boldsymbol{m m})\end{array}$ & $\begin{array}{c}\boldsymbol{d}_{\boldsymbol{f f l}} \\
(\boldsymbol{m m})\end{array}$ & $\begin{array}{c}d_{b f l} \\
(\boldsymbol{m} m)\end{array}$ & $\begin{array}{c}\boldsymbol{f}_{\boldsymbol{y}} \\
(\boldsymbol{M P a})\end{array}$ & $\begin{array}{c}\boldsymbol{f}_{\boldsymbol{u}} \\
(\boldsymbol{M P a})\end{array}$ & Tipo & Comp. & Fur. & $\begin{array}{c}\boldsymbol{F}_{\text {ult }} \\
(\boldsymbol{k N})\end{array}$ \\
\hline t540-p12-3L5C-1 & Ref. 1 & 3 & 5 & 5.27 & 12.0 & 14.0 & 266 & 52.2 & 28.4 & 31.9 & 27.2 & 490 & 523 & Corr. & Dupla & Coinc. & 591.8 \\
\hline t540-p12-3L5C-1 & Ref. 2 & 3 & 5 & 5.27 & 12.0 & 14.0 & 266 & 52.2 & 28.4 & 31.9 & 27.2 & 490 & 523 & Corr. & Dupla & Defas. & 558.5 \\
\hline
\end{tabular}


Tabela 11 - Configurações dos ensaios realizados no LE-EESC-USP em junho de 2017 com chapas corrugadas em montagem dupla

\begin{tabular}{|c|c|c|c|c|c|c|c|c|c|c|c|c|c|c|c|c|c|}
\hline Corpo de prova & $\operatorname{Ref}$ & $C$ & $\boldsymbol{L}$ & $\begin{array}{c}t \\
(\boldsymbol{m m})\end{array}$ & $\begin{array}{c}d_{p} \\
(m m)\end{array}$ & $\begin{array}{c}d_{f} \\
(m m)\end{array}$ & $\begin{array}{l}l_{\text {chapa }} \\
(\boldsymbol{m m})\end{array}$ & $\begin{array}{c}d_{f f p} \\
(\boldsymbol{m m})\end{array}$ & $\begin{array}{c}d_{b f p} \\
(\boldsymbol{m m})\end{array}$ & $\begin{array}{c}d_{f f l} \\
(\boldsymbol{m m})\end{array}$ & $\begin{array}{c}d_{b f l} \\
(\boldsymbol{m m})\end{array}$ & $\begin{array}{c}\boldsymbol{f}_{\boldsymbol{y}} \\
(\boldsymbol{M P a})\end{array}$ & $\begin{array}{c}\boldsymbol{f}_{\boldsymbol{u}} \\
(\boldsymbol{M P a})\end{array}$ & Tipo & Comp. & Fur. & $\begin{array}{c}\boldsymbol{F}_{\text {ult }} \\
(\boldsymbol{k} \boldsymbol{N})\end{array}$ \\
\hline t310-p10-5L3C-1 & Ref. 1 & 3 & 5 & 2.97 & 10.0 & 11.0 & 266 & 52.2 & 28.4 & 31.9 & 27.2 & 447 & 526 & Corr. & Dupla & Coinc. & 349.3 \\
\hline t310-p10-5L3C-1 & Ref. 2 & 3 & 5 & 2.97 & 10.0 & 11.0 & 266 & 52.2 & 28.4 & 31.9 & 27.2 & 447 & 526 & Corr. & Dupla & Defas. & 351.0 \\
\hline t310-p10-5L2C-1 & Ref. 3 & 2 & 5 & 2.97 & 10.0 & 11.0 & 266 & 52.2 & 28.4 & 31.9 & 27.2 & 447 & 526 & Corr. & Dupla & Coinc. & 336.6 \\
\hline t310-p12-5L3C-1 & Ref. 4 & 3 & 5 & 2.97 & 12.0 & 14.0 & 266 & 52.2 & 28.4 & 31.9 & 27.2 & 447 & 526 & Corr. & Dupla & Coinc. & 351.0 \\
\hline t310-p12-5L3C-2 & Ref. 5 & 3 & 5 & 2.97 & 12.0 & 14.0 & 266 & 52.2 & 28.4 & 31.9 & 27.2 & 447 & 526 & Corr. & Dupla & Coinc. & 340.5 \\
\hline t310-p12-5L3C-1 & Ref. 6 & 3 & 5 & 2.97 & 12.0 & 14.0 & 266 & 52.2 & 28.4 & 31.9 & 27.2 & 447 & 526 & Corr. & Dupla & Defas. & 334.0 \\
\hline t310-p12-5L3C-2 & Ref. 7 & 3 & 5 & 2.97 & 12.0 & 14.0 & 266 & 52.2 & 28.4 & 31.9 & 27.2 & 447 & 526 & Corr. & Dupla & Defas. & 330.9 \\
\hline t310-p12-5L2C-1 & Ref. 8 & 2 & 5 & 2.97 & 12.0 & 14.0 & 266 & 52.2 & 28.4 & 31.9 & 27.2 & 447 & 526 & Corr. & Dupla & Coinc. & 323.1 \\
\hline t310-p12-5L2C-2 & Ref. 9 & 2 & 5 & 2.97 & 12.0 & 14.0 & 266 & 52.2 & 28.4 & 31.9 & 27.2 & 447 & 526 & Corr. & Dupla & Coinc. & 323.9 \\
\hline t310-p12-5L2C-1 & Ref. 10 & 2 & 5 & 2.97 & 12.0 & 14.0 & 266 & 52.2 & 28.4 & 31.9 & 27.2 & 447 & 526 & Corr. & Dupla & Defas. & 320.6 \\
\hline t310-p12-5L2C-2 & Ref. 11 & 2 & 5 & 2.97 & 12.0 & 14.0 & 266 & 52.2 & 28.4 & 31.9 & 27.2 & 447 & 526 & Corr. & Dupla & Defas. & 322.1 \\
\hline t390-p12-5L3C-1 & Ref. 12 & 3 & 5 & 3.77 & 12.0 & 14.0 & 266 & 52.2 & 28.4 & 31.9 & 27.2 & 421 & 518 & Corr. & Dupla & Coinc. & 432.3 \\
\hline t390-p12-5L3C-2 & Ref. 13 & 3 & 5 & 3.77 & 12.0 & 14.0 & 266 & 52.2 & 28.4 & 31.9 & 27.2 & 421 & 518 & Corr. & Dupla & Coinc. & 430.1 \\
\hline t390-p12-5L3C-1 & Ref. 14 & 3 & 5 & 3.77 & 12.0 & 14.0 & 266 & 52.2 & 28.4 & 31.9 & 27.2 & 421 & 518 & Corr. & Dupla & Defas. & 428.7 \\
\hline t390-p12-5L3C-2 & Ref. 15 & 3 & 5 & 3.77 & 12.0 & 14.0 & 266 & 52.2 & 28.4 & 31.9 & 27.2 & 421 & 518 & Corr. & Dupla & Defas. & 428.7 \\
\hline t390-p12-5L2C-1 & Ref. 16 & 2 & 5 & 3.77 & 12.0 & 14.0 & 266 & 52.2 & 28.4 & 31.9 & 27.2 & 421 & 518 & Corr. & Dupla & Coinc. & 423.6 \\
\hline t390-p12-5L2C-2 & Ref. 17 & 2 & 5 & 3.77 & 12.0 & 14.0 & 266 & 52.2 & 28.4 & 31.9 & 27.2 & 421 & 518 & Corr. & Dupla & Coinc. & 419.0 \\
\hline t390-p12-5L2C-1 & Ref. 18 & 2 & 5 & 3.77 & 12.0 & 14.0 & 266 & 52.2 & 28.4 & 31.9 & 27.2 & 421 & 518 & Corr. & Dupla & Defas. & 425.0 \\
\hline t390-p12-5L2C-2 & Ref. 19 & 2 & 5 & 3.77 & 12.0 & 14.0 & 266 & 52.2 & 28.4 & 31.9 & 27.2 & 421 & 518 & Corr. & Dupla & Defas. & 421.7 \\
\hline
\end{tabular}


APÊNDICE B - Resultados dos ensaios

Tabela 12 - Resultados experimentais dos ensaios de (ESTEVES JR, 1990)

\begin{tabular}{|c|c|c|c|c|c|c|c|c|c|c|c|c|c|c|c|c|c|c|}
\hline \multirow{3}{*}{$\begin{array}{c}\text { Ensaio } \\
\text { Ref. }\end{array}$} & \multicolumn{16}{|c|}{ Força máxima resistente por equação de norma (kN) } & \multicolumn{2}{|c|}{ Ruptura } \\
\hline & \multicolumn{4}{|c|}{ Esmagamento - ESM } & \multicolumn{4}{|c|}{ Rasgamento - RAS } & \multicolumn{4}{|c|}{ Ruptura da seção líquida - RSL } & \multicolumn{4}{|c|}{ Block shear - BLS } & \multirow{2}{*}{$\begin{array}{l}\text { Modo } \\
\text { de falha }\end{array}$} & \multirow{2}{*}{$\begin{array}{l}\text { Força } \\
(\mathrm{kN})\end{array}$} \\
\hline & AISI & AS/NZS & NBR & EN & AISI & AS/NZS & NBR & EN & AISI & AS/NZS & NBR & EN & AISI & AS/NZS & NBR & EN & & \\
\hline Ref. 1 & $32.3^{*}$ & $32.3^{*}$ & $18.2^{*}$ & $23.9^{*}$ & 40.8 & 40.4 & 40.4 & 40.4 & 51.4 & 56.2 & 21.5 & 33.5 & 53.3 & 53.5 & 53.3 & 51.6 & ESM & 37.8 \\
\hline Ref. 2 & $32.3^{*}$ & $32.3^{*}$ & $18.2^{*}$ & $23.9^{*}$ & 40.8 & 40.4 & 40.4 & 40.4 & 51.4 & 56.2 & 21.5 & 33.5 & 53.3 & 53.5 & 53.3 & 51.6 & ESM & 35.8 \\
\hline Ref. 3 & $42.1^{*}$ & $42.1^{*}$ & $24.5^{*}$ & $34.5^{*}$ & 53.1 & 52.6 & 52.6 & 52.6 & 65.0 & 71.0 & 27.2 & 46.4 & 68.9 & 68.9 & 68.9 & 66.4 & ESM & 39.2 \\
\hline Ref. 4 & $42.1^{*}$ & $42.1^{*}$ & $24.5^{*}$ & $34.5^{*}$ & 53.1 & 52.6 & 52.6 & 52.6 & 69.0 & 75.4 & 28.3 & 42.2 & 68.9 & 68.9 & 68.9 & 66.4 & ESM & 47.1 \\
\hline Ref. 5 & $51.7^{*}$ & $51.7^{*}$ & $31.1^{*}$ & $46.5^{*}$ & 65.3 & 64.7 & 64.7 & 64.7 & 80.5 & 87.8 & 33.6 & 56.3 & 83.8 & 83.8 & 83.8 & 81 & ESM & 59.4 \\
\hline Ref. 6 & $51.7^{*}$ & $51.7^{*}$ & $31.1^{*}$ & $46.5^{*}$ & 65.3 & 64.7 & 64.7 & 64.7 & 83.9 & 91.6 & 35.1 & 52.0 & 83.8 & 83.8 & 83.8 & 81 & ESM & 58.9 \\
\hline Ref. 7 & $66.1^{*}$ & $66.1^{*}$ & $41.1^{*}$ & $65.5^{*}$ & 83.5 & 82.7 & 82.7 & 82.7 & 106.6 & 116.4 & 44.6 & 67.1 & 107.9 & 107.9 & 107.9 & 104.2 & ESM & 81.4 \\
\hline Ref. 8 & $66.1^{*}$ & $66.1^{*}$ & $41.1^{*}$ & $65.5^{*}$ & 83.5 & 82.7 & 82.7 & 82.7 & 107.8 & 117.8 & 45.0 & 65.9 & 107.9 & 107.9 & 107.9 & 104.2 & ESM & 80.4 \\
\hline Ref. 9 & $78.8^{*}$ & $78.8^{*}$ & $49.0^{*}$ & $78.0^{*}$ & 99.5 & 98.5 & 98.5 & 98.5 & 126.3 & 138.0 & 52.8 & 80.9 & 129.2 & 129.2 & 129.2 & 124.7 & ESM & 82.9 \\
\hline Ref. 10 & $78.8^{*}$ & $78.8^{*}$ & $49.0^{*}$ & $78.0^{*}$ & 99.5 & 98.5 & 98.5 & 98.5 & 124.1 & 135.5 & 51.9 & 83.7 & 129.2 & 129.2 & 129.2 & 124.7 & ESM & 78.0 \\
\hline Ref. 11 & $38.8^{*}$ & $38.8^{*}$ & $22.8^{*}$ & $29.8^{*}$ & 39.2 & 40.4 & 40.4 & 40.4 & 48.9 & 53.1 & 25.4 & 39.0 & 50.9 & 51.5 & 50.9 & 49.2 & ESM & 37.8 \\
\hline Ref. 12 & $38.8^{*}$ & $38.8^{*}$ & $22.8^{*}$ & $29.8^{*}$ & 39.2 & 40.4 & 40.4 & 40.4 & 50.1 & 54.5 & 26.1 & 37.3 & 50.9 & 51.5 & 50.9 & 49.2 & ESM & 40.7 \\
\hline Ref. 13 & 52.6 & $52.6^{*}$ & $30.7^{*}$ & $43.1^{*}$ & $51.0 *$ & 52.6 & 52.6 & 52.6 & 64.8 & 70.5 & 33.8 & 49.1 & 66.2 & 66.2 & 66.2 & 63.4 & ESM & 55.9 \\
\hline Ref. 14 & 52.6 & $52.6^{*}$ & $30.7 *$ & $43.1^{*}$ & $51.0 *$ & 52.6 & 52.6 & 52.6 & 65.2 & 71.0 & 34.0 & 48.6 & 66.2 & 66.2 & 66.2 & 63.4 & ESM & 54.9 \\
\hline Ref. 15 & 64.7 & $64.7^{*}$ & $38.9 *$ & $58.2^{*}$ & $62.7^{*}$ & 64.7 & 64.7 & 64.7 & 78.8 & 85.7 & 41.0 & 61.7 & 80.6 & 80.6 & 80.6 & 77.3 & ESM & 66.7 \\
\hline Ref. 16 & 64.7 & $64.7^{*}$ & $38.9^{*}$ & $58.2^{*}$ & $62.7^{*}$ & 64.7 & 64.7 & 64.7 & 77.8 & 84.6 & 40.5 & 63.2 & 80.6 & 80.6 & 80.6 & 77.3 & ESM & 67.7 \\
\hline Ref. 17 & 82.7 & $82.7^{*}$ & $51.4^{*}$ & 81.8 & $80.2^{*}$ & 82.7 & 82.7 & 82.7 & 104.5 & 113.7 & 52.3 & $76.7^{*}$ & 103.8 & 103.8 & 103.8 & 99.4 & ESM & 91.2 \\
\hline Ref. 18 & 82.7 & $82.7^{*}$ & $51.4^{*}$ & 81.8 & $80.2^{*}$ & 82.7 & 82.7 & 82.7 & 100.7 & 109.5 & 52.4 & 78.9* & 103.8 & 103.8 & 103.8 & 99.4 & ESM & 84.9 \\
\hline Ref. 19 & 98.5 & $98.5^{*}$ & $61.3^{*}$ & 97.5 & $95.6^{*}$ & 98.5 & 98.5 & 98.5 & 123.8 & 134.7 & 63.1 & $90.8^{*}$ & 124.2 & 124.3 & 124.2 & 119.0 & ESM & 105.5 \\
\hline Ref. 20 & 98.5 & $98.5^{*}$ & $61.3^{*}$ & 97.5 & $95.6^{*}$ & 98.5 & 98.5 & 98.5 & 123.8 & 134.7 & 63.1 & $90.8^{*}$ & 124.2 & 124.3 & 124.2 & 119.0 & ESM & 99.6 \\
\hline
\end{tabular}

Fonte: $\mathrm{o}$ autor. 
Tabela 12 - Continuação

\begin{tabular}{|c|c|c|c|c|c|c|c|c|c|c|c|c|c|c|c|c|c|c|}
\hline \multirow{3}{*}{$\begin{array}{c}\text { Ensaio } \\
\text { Ref. }\end{array}$} & \multicolumn{16}{|c|}{ Força máxima resistente por equação de norma $(\mathrm{kN})$} & \multicolumn{2}{|c|}{ Ruptura } \\
\hline & \multicolumn{4}{|c|}{ Esmagamento - ESM } & \multicolumn{4}{|c|}{ Rasgamento - RAS } & \multicolumn{4}{|c|}{ Ruptura da seção líquida - RSL } & \multicolumn{4}{|c|}{ Block shear - BLS } & \multirow{2}{*}{$\begin{array}{c}\text { Modo } \\
\text { de falha }\end{array}$} & \multirow{2}{*}{$\begin{array}{c}\text { Força } \\
(\mathrm{kN})\end{array}$} \\
\hline & AISI & AS/NZS & NBR & EN & AISI & AS/NZS & NBR & EN & AISI & AS/NZS & NBR & EN & AISI & AS/NZS & NBR & EN & & \\
\hline Ref. 21 & 64.6 & 64.6 & $36.5^{*}$ & 47.7 & 73.9 & 74.3 & 74.3 & 74.3 & $51.4^{*}$ & $56.2^{*}$ & 38.8 & $44.8^{*}$ & 61.6 & 64.0 & 61.6 & 58.4 & RSL & 59.8 \\
\hline Ref. 22 & 64.6 & 64.6 & $36.5^{*}$ & 47.7 & 73.9 & 74.3 & 74.3 & 74.3 & $49.9 *$ & $54.5^{*}$ & 37.7 & $45.1^{*}$ & 61.6 & 64.0 & 61.6 & 58.4 & RSL & 54.4 \\
\hline Ref. 23 & 84.1 & 84.1 & $49.0^{*}$ & 68.9 & 96.2 & 96.8 & 96.8 & 96.8 & $68.2^{*}$ & $74.5^{*}$ & 51.5 & $58.4^{*}$ & 80.2 & 81.6 & 80.2 & 74.8 & RSL & 76.5 \\
\hline Ref. 24 & 84.1 & 84.1 & $49.0^{*}$ & 68.9 & 96.2 & 96.8 & 96.8 & 96.8 & $67.0^{*}$ & $73.2^{*}$ & 50.6 & $58.4^{*}$ & 80.2 & 81.6 & 80.2 & 74.8 & RSL & 76.5 \\
\hline Ref. 25 & 103.5 & 103.5 & 62.2 & 93.0 & 118.3 & 119.1 & 119.1 & 119.1 & $80.9 *$ & $88.4^{*}$ & $61.1^{*}$ & $72.0^{*}$ & 98.6 & 98.6 & 98.6 & 90.7 & RSL & 92.7 \\
\hline Ref. 26 & 103.5 & 103.5 & $62.2^{*}$ & 93.0 & 118.3 & 119.1 & 119.1 & 119.1 & $83.9 *$ & $91.6^{*}$ & 63.4 & $71.8^{*}$ & 98.6 & 98.6 & 98.6 & 90.7 & RSL & 96.1 \\
\hline Ref. 27 & 132.3 & 132.3 & 82.3 & 130.9 & 151.3 & 152.2 & 152.2 & 152.2 & $110.3^{*}$ & $120.6^{*}$ & $81.7^{*}$ & $94.0^{*}$ & 126.1 & 127.6 & 126.1 & 117.1 & RSL & 123.2 \\
\hline Ref. 28 & 132.3 & 132.3 & $82.3^{*}$ & 130.9 & 151.3 & 152.2 & 152.2 & 152.2 & $115.3^{*}$ & $126.1^{*}$ & 82.6 & $98.3^{*}$ & 126.1 & 127.6 & 126.1 & 117.1 & RSL & 129.5 \\
\hline Ref. 29 & 157.7 & 157.7 & 98.1 & 156.1 & 180.3 & 181.5 & 181.5 & 181.5 & $126.3^{*}$ & 138.0* & $95.4^{*}$ & $109.4^{*}$ & 150.3 & 153.2 & 150.3 & 140.5 & RSL & 143.2 \\
\hline Ref. 30 & 157.7 & 157.7 & 98.1 & 156.1 & 180.3 & 181.5 & 181.5 & 181.5 & $125.6^{*}$ & $137.1^{*}$ & $94.8^{*}$ & $109.5^{*}$ & 150.3 & 153.2 & 150.3 & 140.5 & RSL & 142.2 \\
\hline Ref. 31 & 77.6 & 77.6 & 45.6 & 59.7 & 69.0 & 73.0 & 73.0 & 73.0 & $48.6^{*}$ & $52.8^{*}$ & $39.0 *$ & $46.1^{*}$ & 58.3 & 62.0 & 58.3 & 55.4 & RSL & 55.9 \\
\hline Ref. 32 & 77.6 & 77.6 & 45.6 & 59.7 & 69.0 & 73.0 & 73.0 & 73.0 & $52.2^{*}$ & $56.8^{*}$ & $40.6^{*}$ & $47.6^{*}$ & 58.3 & 62.0 & 58.3 & 55.4 & RSL & 59.4 \\
\hline Ref. 33 & 105.1 & 105.1 & 61.3 & 86.1 & 89.9 & 95.1 & 95.1 & 95.1 & $68.8^{*}$ & $74.9 *$ & $53.0^{*}$ & $62.7^{*}$ & 76.0 & 78.9 & 76.0 & 70.9 & RSL & 78.0 \\
\hline Ref. 34 & 105.1 & 105.1 & 61.3 & 86.1 & 89.9 & 95.1 & 95.1 & 95.1 & $65.2^{*}$ & $71.0^{*}$ & $52.5^{*}$ & $59.8^{*}$ & 76.0 & 78.9 & 76.0 & 70.9 & RSL & 74.1 \\
\hline Ref. 35 & 129.3 & 129.3 & 77.8 & 116.3 & 110.6 & 116.9 & 116.9 & 116.9 & $85.1 *$ & $92.7^{*}$ & $65.2^{*}$ & $77.6^{*}$ & 93.5 & 95.4 & 93.5 & 86.1 & RSL & 97.1 \\
\hline Ref. 36 & 129.3 & 129.3 & 77.8 & 116.3 & 110.6 & 116.9 & 116.9 & 116.9 & $83.2^{*}$ & $90.5^{*}$ & $65.0^{*}$ & $75.8^{*}$ & 93.5 & 95.4 & 93.5 & 86.1 & RSL & 95.2 \\
\hline Ref. 37 & 165.3 & 165.3 & 102.8 & 163.7 & 141.4 & 149.5 & 149.5 & 149.5 & $99.5^{*}$ & $108.2^{*}$ & $80.0 *$ & $94.5^{*}$ & 119.5 & 123.4 & 119.5 & 111.1 & RSL & 102.0 \\
\hline Ref. 38 & 165.3 & 165.3 & 102.8 & 163.7 & 141.4 & 149.5 & 149.5 & 149.5 & $103.2 *$ & $112.3^{*}$ & $83.0 *$ & $94.0^{*}$ & 119.5 & 123.4 & 119.5 & 111.1 & RSL & 110.4 \\
\hline Ref. 39 & 197.1 & 197.1 & 122.6 & 195.1 & 168.5 & 178.2 & 178.2 & 178.2 & $120.8^{*}$ & $131.4^{*}$ & $97.1^{*}$ & $112.2^{*}$ & 142.4 & 148.3 & 142.4 & 133.2 & RSL & 136.4 \\
\hline Ref. 40 & 197.1 & 197.1 & 122.6 & 195.1 & 168.5 & 178.2 & 178.2 & 178.2 & $120.1 *$ & $130.6^{*}$ & $96.5^{*}$ & $112.3^{*}$ & 142.4 & 148.3 & 142.4 & 133.2 & RSL & 136.4 \\
\hline
\end{tabular}

Fonte: o autor. 
Tabela 12 - Continuação

\begin{tabular}{|c|c|c|c|c|c|c|c|c|c|c|c|c|c|c|c|c|c|c|}
\hline \multirow{3}{*}{$\begin{array}{c}\text { Ensaio } \\
\text { Ref. }\end{array}$} & \multicolumn{16}{|c|}{ Força máxima resistente por equação de norma (kN) } & \multicolumn{2}{|c|}{ Ruptura } \\
\hline & \multicolumn{4}{|c|}{ Esmagamento - ESM } & \multicolumn{4}{|c|}{ Rasgamento - RAS } & \multicolumn{4}{|c|}{ Ruptura da seção líquida - RSL } & \multicolumn{4}{|c|}{ Block shear - BLS } & \multirow{2}{*}{$\begin{array}{l}\text { Modo } \\
\text { de falha }\end{array}$} & \multirow{2}{*}{$\begin{array}{l}\text { Força } \\
(\mathrm{kN})\end{array}$} \\
\hline & AISI & AS/NZS & NBR & EN & AISI & AS/NZS & NBR & EN & AISI & AS/NZS & NBR & EN & AISI & AS/NZS & NBR & EN & & \\
\hline Ref. 41 & 96.9 & 96.9 & 54.7 & 71.6 & 107.0 & 108.3 & 108.3 & 108.3 & $56.3^{*}$ & $61.6^{*}$ & $47.6^{*}$ & $52.5^{*}$ & 69.9 & 74.4 & 69.9 & 65.3 & RSL & 64.8 \\
\hline Ref. 42 & 96.9 & 96.9 & 54.7 & 71.6 & 107.0 & 108.3 & 108.3 & 108.3 & $55.1^{*}$ & $60.2^{*}$ & $47.0 *$ & $51.4^{*}$ & 69.9 & 74.4 & 69.9 & 65.3 & RSL & 63.3 \\
\hline Ref. 43 & 126.2 & 126.2 & 73.6 & 103.4 & 139.3 & 141.1 & 141.1 & 141.1 & $1.7^{*}$ & 78.4* & $61.2^{*}$ & $66.9 *$ & 91.0 & 94.3 & 91.0 & 83.2 & SL & 81.9 \\
\hline Ref. 44 & 126.2 & 126.2 & 73.6 & 103.4 & 139.3 & 141.1 & 141.1 & 141.1 & $71.7^{*}$ & $78.4^{*}$ & $61.2^{*}$ & $66.9^{*}$ & 91.0 & 94.3 & 91.0 & 83.2 & RSL & 81.9 \\
\hline Ref. 45 & 155.2 & 155.2 & 93.3 & 139.6 & 171.4 & 173.5 & 173.5 & 173.5 & $88.2^{*}$ & $96.5^{*}$ & $75.2^{*}$ & $82.3^{*}$ & 111.9 & 113.4 & 111.9 & 100.4 & RSL & 101.0 \\
\hline Ref. 46 & 155.2 & 155.2 & 93.3 & 139.6 & 171.4 & 173.5 & 173.5 & 173.5 & $88.2^{*}$ & $96.5^{*}$ & $75.2^{*}$ & $82.3^{*}$ & 111.9 & 113.4 & 111.9 & 100.4 & RSL & 101.0 \\
\hline Ref. 47 & 198.4 & 198.4 & 123.4 & 196.4 & 219.1 & 221.8 & 221.8 & 221.8 & $112.2^{*}$ & $122.6^{*}$ & 95.9* & $104.6^{*}$ & 143.1 & 147.2 & 143.1 & 130.0 & RSL & 126.1 \\
\hline Ref. 48 & 198.4 & 198.4 & 123.4 & 196.4 & 219.1 & 221.8 & 221.8 & 221.8 & $114.0^{*}$ & $124.7^{*}$ & $96.8^{*}$ & $106.4^{*}$ & 143.1 & 147.2 & 143.1 & 130.0 & RSL & 128.0 \\
\hline Ref. 49 & 236.5 & 236.5 & 147.1 & 234.1 & 261.1 & 264.4 & 264.4 & 264.4 & $132.2^{*}$ & $144.5^{*}$ & $113.6^{*}$ & $123.3^{*}$ & 170.5 & 177.3 & 170.5 & 156.2 & RSL & 151.1 \\
\hline Ref. 50 & 236.5 & 236.5 & 147.1 & 234.1 & 261.1 & 264.4 & 264.4 & 264.4 & $133.0 *$ & $145.3^{*}$ & 113.9* & $124.0 *$ & 170.5 & 177.3 & 170.5 & 156.2 & RSL & 151.1 \\
\hline Ref. 51 & 116.5 & 116.5 & 68.4 & 89.5 & 98.9 & 105.6 & 105.6 & 105.6 & $51.6^{*}$ & $56.2^{*}$ & $45.9 *$ & $50.1^{*}$ & 65.8 & 72.4 & 65.8 & 61.6 & RSL & 59.8 \\
\hline Ref. 52 & 116.5 & 116.5 & 68.4 & 89.5 & 98.9 & 105.6 & 105.6 & 105.6 & $52.2^{*}$ & $56.8^{*}$ & $46.2^{*}$ & $50.7^{*}$ & 65.8 & 72.4 & 65.8 & 61.6 & RSL & 60.3 \\
\hline Ref. 53 & 157.7 & 157.7 & 92.0 & 129.2 & 128.8 & 137.6 & 137.6 & 137.6 & $68.0^{*}$ & $74.0 *$ & $60.1^{*}$ & $66.0 *$ & 85.7 & 91.7 & 85.7 & 78.5 & RSL & 77.0 \\
\hline Ref. 54 & 157.7 & 157.7 & 92.0 & 129.2 & 128.8 & 137.6 & 137.6 & 137.6 & $65.6^{*}$ & 71.4* & $59.2^{*}$ & $63.7^{*}$ & 85.7 & 91.7 & 85.7 & 78.5 & RSL & 74.6 \\
\hline Ref. 55 & 194.0 & 194.0 & 116.7 & 174.5 & 158.4 & 169.2 & 169.2 & 169.2 & $82.2^{*}$ & $89.5^{*}$ & 73.4* & 79.8* & 105.4 & 110.1 & 105.4 & 94.8 & RSL & 94.2 \\
\hline Ref. 56 & 194.0 & 194.0 & 116.7 & 174.5 & 158.4 & 169.2 & 169.2 & 169.2 & $84.2^{*}$ & $91.6^{*}$ & $74.2^{*}$ & $81.7^{*}$ & 105.4 & 110.1 & 105.4 & 94.8 & RSL & 94.1 \\
\hline Ref. 57 & 248.0 & 248.0 & 154.3 & 245.5 & 202.5 & 216.3 & 216.3 & 216.3 & $100.7^{*}$ & $109.5^{*}$ & $90.8^{*}$ & $99.3^{*}$ & 134.8 & 143.1 & 134.8 & 122.7 & RSL & 112.8 \\
\hline Ref. 58 & 248.0 & 248.0 & 154.3 & 245.5 & 202.5 & 216.3 & 216.3 & 216.3 & $103.2^{*}$ & $112.3^{*}$ & $93.0^{*}$ & $100.1^{*}$ & 134.8 & 143.1 & 134.8 & 122.7 & RSL & 115.8 \\
\hline Ref. 59 & 295.6 & 295.6 & 183.9 & 292.6 & 241.4 & 257.8 & 257.8 & 257.8 & $120.8^{*}$ & $131.4^{*}$ & $108.9^{*}$ & $118.6^{*}$ & 160.7 & 172.3 & 160.7 & 147.5 & RSL & 135.8 \\
\hline Ref. 60 & 295.6 & 295.6 & 183.9 & 292.6 & 241.4 & 257.8 & 257.8 & 257.8 & $120.1^{*}$ & $130.6^{*}$ & $108.2^{*}$ & $118.4^{*}$ & 160.7 & 172.3 & 160.7 & 147.5 & RSL & 139.3 \\
\hline
\end{tabular}

Fonte: o autor. 
Tabela 13 - Resultados experimentais dos ensaios realizados no LE-EESC-USP em maio de 2015

\begin{tabular}{|c|c|c|c|c|c|c|c|c|c|c|c|c|c|c|c|c|c|c|}
\hline \multirow{3}{*}{$\begin{array}{c}\text { Ensaio } \\
\text { Ref. }\end{array}$} & \multicolumn{16}{|c|}{ Força máxima resistente por equação de norma (kN) } & \multicolumn{2}{|c|}{ Ruptura } \\
\hline & \multicolumn{4}{|c|}{ Esmagamento - ESM } & \multicolumn{4}{|c|}{ Rasgamento - RAS } & \multicolumn{4}{|c|}{ Ruptura da seção líquida - RSL } & \multicolumn{4}{|c|}{ Block shear - BLS } & \multirow{2}{*}{$\begin{array}{c}\text { Modo } \\
\text { de falha }\end{array}$} & \multirow{2}{*}{$\begin{array}{c}\text { Força } \\
(\mathrm{kN})\end{array}$} \\
\hline & AISI & AS/NZS & NBR & EN & AISI & AS/NZS & NBR & EN & AISI & AS/NZS & NBR & EN & AISI & AS/NZS & NBR & EN & & \\
\hline Ref. 1 & 92.5 & 92.5 & 72.7 & 85.8 & 109.6 & 114.9 & 114.9 & 114.9 & $83.2^{*}$ & $90.6^{*}$ & $65.2^{*}$ & $75.8^{*}$ & 92.7 & 97.9 & 92.7 & 89.6 & ESM & 83.9 \\
\hline Ref. 2 & 92.5 & 92.5 & 72.7 & 85.8 & 109.6 & 114.9 & 114.9 & 114.9 & $83.2^{*}$ & $90.6^{*}$ & $65.2^{*}$ & $75.8^{*}$ & 92.7 & 97.9 & 92.7 & 89.6 & ESM & 84.8 \\
\hline Ref. 3 & 92.5 & 92.5 & 72.7 & 85.8 & 109.6 & 114.9 & 114.9 & 114.9 & $83.2^{*}$ & $90.6^{*}$ & $65.2^{*}$ & $75.8^{*}$ & 92.7 & 97.9 & 92.7 & 89.6 & ESM & 82.8 \\
\hline Ref. 4 & 138.7 & 138.7 & 109.0 & 128.8 & 163.4 & 171.6 & 171.6 & 171.6 & $83.2^{*}$ & $90.6^{*}$ & $73.9^{*}$ & $80.8^{*}$ & 103.5 & 112.5 & 103.5 & 98.8 & RSL & 88.1 \\
\hline Ref. 5 & 138.7 & 138.7 & 109.0 & 128.8 & 163.4 & 171.6 & 171.6 & 171.6 & $83.2^{*}$ & $90.6^{*}$ & $73.9^{*}$ & $80.8^{*}$ & 103.5 & 112.5 & 103.5 & 98.8 & RSL & 89.8 \\
\hline Ref. 6 & 138.7 & 138.7 & 109.0 & 128.8 & 163.4 & 171.6 & 171.6 & 171.6 & $83.2^{*}$ & $90.6^{*}$ & 73.9* & $80.8^{*}$ & 103.5 & 112.5 & 103.5 & 98.8 & RSL & 88.4 \\
\hline Ref. 7 & 180.0 & 180.0 & 139.8 & 177.4 & 204.2 & 214.2 & 214.2 & 214.2 & $155.1^{*}$ & $168.8^{*}$ & $121.5^{*}$ & $141.3^{*}$ & 172.8 & 187.6 & 172.8 & 170.5 & RSL & 156.0 \\
\hline Ref. 8 & 180.0 & 180.0 & 139.8 & 177.4 & 204.2 & 214.2 & 214.2 & 214.2 & $155.1^{*}$ & $168.8^{*}$ & $121.5^{*}$ & $141.3^{*}$ & 172.8 & 187.6 & 172.8 & 170.5 & SL & 156.2 \\
\hline Ref. 9 & 180.0 & 180.0 & 139.8 & 177.4 & 204.2 & 214.2 & 214.2 & 214.2 & $155.1^{*}$ & $168.8^{*}$ & $121.5^{*}$ & $141.3^{*}$ & 172.8 & 187.6 & 172.8 & 170.5 & RSL & 155.4 \\
\hline Ref. 10 & 270.0 & 270.0 & 209.7 & 266.0 & 304.6 & 319.8 & 319.8 & 319.8 & $155.1^{*}$ & $168.8^{*}$ & $137.8^{*}$ & $150.5^{*}$ & 192.8 & 217.7 & 192.8 & 189.5 & RSL & 161.5 \\
\hline Ref. 11 & 270.0 & 270.0 & 209.7 & 266.0 & 304.6 & 319.8 & 319.8 & 319.8 & $155.1^{*}$ & $168.8^{*}$ & $137.8^{*}$ & $150.5^{*}$ & 192.8 & 217.7 & 192.8 & 189.5 & RSL & 159.6 \\
\hline Ref. 12 & 270.0 & 270.0 & 209.7 & 266.0 & 304.6 & 319.8 & 319.8 & 319.8 & $155.1^{*}$ & $168.8^{*}$ & $137.8^{*}$ & $150.5^{*}$ & 192.8 & 217.7 & 192.8 & 189.5 & RSL & 158.6 \\
\hline Ref. 13 & 210.8 & 210.8 & 168.8 & 228.0 & 239.2 & 250.8 & 250.8 & 250.8 & $181.6^{*}$ & $197.7^{*}$ & $142.3^{*}$ & $165.5^{*}$ & 202.3 & 218.1 & 202.3 & 198.6 & RSL & 187.2 \\
\hline Ref. 14 & 210.8 & 210.8 & 168.8 & 228.0 & 239.2 & 250.8 & 250.8 & 250.8 & $181.6^{*}$ & $197.7^{*}$ & $142.3^{*}$ & $165.5^{*}$ & 202.3 & 218.1 & 202.3 & 198.6 & RSL & 186.5 \\
\hline Ref. 15 & 210.8 & 210.8 & 168.8 & 228.0 & 239.2 & 250.8 & 250.8 & 250.8 & 181.6* & $197.7^{*}$ & $142.3^{*}$ & 165.5* & 202.3 & 218.1 & 202.3 & 198.6 & RSL & 186.4 \\
\hline Ref. 16 & 316.2 & 316.2 & 253.2 & 342.0 & 356.6 & 374.5 & 374.5 & 374.5 & $181.6^{*}$ & $197.7^{*}$ & $161.3^{*}$ & $176.2^{*}$ & 225.8 & 252.5 & 225.8 & 220.3 & RSL & 181.1 \\
\hline Ref. 17 & 316.2 & 316.2 & 253.2 & 342.0 & 356.6 & 374.5 & 374.5 & 374.5 & 181.6* & $197.7^{*}$ & $161.3^{*}$ & $176.2^{*}$ & 225.8 & 252.5 & 225.8 & 220.3 & RSL & 189.7 \\
\hline Ref. 18 & 316.2 & 316.2 & 253.2 & 342.0 & 356.6 & 374.5 & 374.5 & 374.5 & $181.6^{*}$ & $197.7^{*}$ & $161.3^{*}$ & $176.2^{*}$ & 225.8 & 252.5 & 225.8 & 220.3 & RSL & 190.4 \\
\hline Ref. 19 & 258.1 & 258.1 & 215.2 & 312.5 & 292.9 & 307.2 & 307.2 & 307.2 & $222.4^{*}$ & $242.1^{*}$ & $174.3^{*}$ & $202.7^{*}$ & 247.7 & 265.8 & 247.7 & 242.3 & RSL & 232.6 \\
\hline Ref. 20 & 258.1 & 258.1 & 215.2 & 312.5 & 292.9 & 307.2 & 307.2 & 307.2 & $222.4^{*}$ & $242.1^{*}$ & $174.3^{*}$ & $202.7^{*}$ & 247.7 & 265.8 & 247.7 & 242.3 & RSL & 233.9 \\
\hline Ref. 21 & 258.1 & 258.1 & 215.2 & 312.5 & 292.9 & 307.2 & 307.2 & 307.2 & $222.4^{*}$ & $242.1^{*}$ & $174.3^{*}$ & $202.7^{*}$ & 247.7 & 265.8 & 247.7 & 242.3 & RSL & 230.0 \\
\hline Ref. 22 & 387.2 & 387.2 & 322.7 & 468.7 & 436.8 & 458.6 & 458.6 & 458.6 & $222.4^{*}$ & $242.1^{*}$ & $197.6^{*}$ & $215.8^{*}$ & 276.5 & 307.2 & 276.5 & 268.4 & RSL & 239.5 \\
\hline Ref. 23 & 387.2 & 387.2 & 322.7 & 468.7 & 436.8 & 458.6 & 458.6 & 458.6 & $222.4^{*}$ & $242.1^{*}$ & $197.6^{*}$ & $215.8^{*}$ & 276.5 & 307.2 & 276.5 & 268.4 & RSL & 238.1 \\
\hline Ref. 24 & 387.2 & 387.2 & 322.7 & 468.7 & 436.8 & 458.6 & 458.6 & 458.6 & $222.4^{*}$ & $242.1^{*}$ & $197.6^{*}$ & $215.8^{*}$ & 276.5 & 307.2 & 276.5 & 268.4 & RSL & 238.8 \\
\hline
\end{tabular}

Fonte: o autor. 
Tabela 14 - Resultados experimentais dos ensaios realizados no LE-EESC-USP em outubro de 2015 com chapas onduladas em composição simples

\begin{tabular}{|c|c|c|c|c|c|c|c|c|c|c|c|c|c|c|c|c|c|c|}
\hline \multirow{3}{*}{$\begin{array}{c}\text { Ensaio } \\
\text { Ref. }\end{array}$} & \multicolumn{16}{|c|}{ Força máxima resistente por equação de norma (kN) } & \multicolumn{2}{|c|}{ Ruptura } \\
\hline & \multicolumn{4}{|c|}{ Esmagamento - ESM } & \multicolumn{4}{|c|}{ Rasgamento - RAS } & \multicolumn{4}{|c|}{ Ruptura da seção líquida - RSL } & \multicolumn{4}{|c|}{ Block shear - BLS } & \multirow{2}{*}{$\begin{array}{c}\text { Modo } \\
\text { de falha }\end{array}$} & \multirow{2}{*}{$\begin{array}{c}\text { Força } \\
(\mathrm{kN})\end{array}$} \\
\hline & AISI & AS/NZS & NBR & EN & AISI & AS/NZS & NBR & EN & AISI & AS/NZS & NBR & EN & AISI & AS/NZS & NBR & EN & & \\
\hline Ref. 1 & 288.7 & 288.7 & 231.2 & 312.3 & 325.7 & 342.0 & 342.0 & 342.0 & 165.9* & $180.5^{*}$ & $147.3^{*}$ & 160.9* & 206.2 & 230.4 & 206.2 & 201.0 & RSL & 194.1 \\
\hline Ref. 2 & 465.6 & 465.6 & 416.5 & 675.9 & 525.2 & 551.5 & 551.5 & 551.5 & $267.5^{*}$ & 291.1* & $237.6^{*}$ & 259.5* & 332.5 & 368.3 & 332.5 & 322.0 & RSL & 309.8 \\
\hline Ref. 3 & 192.5 & 192.5 & 154.2 & 208.2 & 218.4 & 229.1 & 229.1 & 229.1 & $165.9^{*}$ & 180.5* & $130.0^{*}$ & 151.1* & 184.7 & 199.1 & 184.7 & 181.3 & RSL & 192.3 \\
\hline Ref. 4 & 192.5 & 192.5 & 154.2 & 208.2 & 218.4 & 229.1 & 229.1 & 229.1 & $165.9 *$ & $180.5^{*}$ & $130.0^{*}$ & 151.1* & 184.7 & 199.1 & 184.7 & 181.3 & RSL & 190.3 \\
\hline Ref. 5 & 192.5 & 192.5 & 154.2 & 208.2 & 218.4 & 229.1 & 229.1 & 229.1 & 165.9* & $180.5^{*}$ & $130.0^{*}$ & 151.1* & 184.7 & 199.1 & 184.7 & 181.3 & SL & 194.2 \\
\hline Ref. 6 & 310.4 & 310.4 & 277.6 & 450.6 & 352.2 & 369.4 & 369.4 & 369.4 & $267.5^{*}$ & $291.1^{*}$ & $209.6^{*}$ & $243.7^{*}$ & 297.9 & 318.9 & 297.9 & 290.9 & RSL & 310.9 \\
\hline Ref. 7 & 308.0 & 308.0 & 246.6 & 333.1 & 346.4 & 363.9 & 363.9 & 363.9 & $173.8^{*}$ & 189.9* & $153.8^{*}$ & $172.3^{*}$ & 326.4 & 360.5 & 326.4 & 319.5 & RSL & 196.3 \\
\hline Ref. 8 & 308.0 & 308.0 & 246.6 & 333.1 & 346.4 & 363.9 & 363.9 & 363.9 & $173.8^{*}$ & 189.9* & 153.8* & $172.3^{*}$ & 326.4 & 360.5 & 326.4 & 319.5 & RSL & 194.7 \\
\hline Ref. 9 & 308.0 & 308.0 & 246.6 & 333.1 & 346.4 & 363.9 & 363.9 & 363.9 & $173.8^{*}$ & 189.9* & $153.8^{*}$ & $172.3^{*}$ & 326.4 & 360.5 & 326.4 & 319.5 & RSL & 192.1 \\
\hline Ref. 10 & 496.7 & 496.7 & 444.2 & 721.0 & 558.6 & 586.9 & 586.9 & 586.9 & $280.3^{*}$ & $306.3^{*}$ & $248.0^{*}$ & $277.8^{*}$ & 526.4 & 577.0 & 526.4 & 512.4 & RSL & 307.8 \\
\hline Ref. 11 & 496.7 & 496.7 & 444.2 & 721.0 & 558.6 & 586.9 & 586.9 & 586.9 & $280.3^{*}$ & $306.3^{*}$ & $248.0^{*}$ & $277.8^{*}$ & 526.4 & 577.0 & 526.4 & 512.4 & RSL & 283.1 \\
\hline Ref. 12 & 231.0 & 231.0 & 185.0 & 249.8 & 260.5 & 273.6 & 273.6 & 273.6 & $173.8^{*}$ & 189.9* & $142.3^{*}$ & $166.4^{*}$ & 304.9 & 329.1 & 304.9 & 299.8 & RSI & 180.0 \\
\hline Ref. 13 & 231.0 & 231.0 & 185.0 & 249.8 & 260.5 & 273.6 & 273.6 & 273.6 & $173.8^{*}$ & 189.9* & $142.3^{*}$ & $166.4^{*}$ & 304.9 & 329.1 & 304.9 & 299.8 & RSL & 185.1 \\
\hline Ref. 14 & 231.0 & 231.0 & 185.0 & 249.8 & 260.5 & 273.6 & 273.6 & 273.6 & $173.8^{*}$ & 189.9* & $142.3^{*}$ & $166.4^{*}$ & 304.9 & 329.1 & 304.9 & 299.8 & RSL & 183.2 \\
\hline Ref. 15 & 372.5 & 372.5 & 333.2 & 540.7 & 420.2 & 441.2 & 441.2 & 441.2 & $280.3^{*}$ & $306.3^{*}$ & $229.6^{*}$ & 268.3* & 491.8 & 527.6 & 491.8 & 481.3 & RSL & 299.5 \\
\hline Ref. 16 & 372.5 & 372.5 & 333.2 & 540.7 & 420.2 & 441.2 & 441.2 & 441.2 & $280.3^{*}$ & $306.3^{*}$ & $229.6^{*}$ & $268.3^{*}$ & 491.8 & 527.6 & 491.8 & 481.3 & RSL & 299.5 \\
\hline Ref. 17 & 372.5 & 372.5 & 333.2 & 540.7 & 420.2 & 441.2 & 441.2 & 441.2 & $280.3^{*}$ & $306.3^{*}$ & $229.6^{*}$ & $268.3^{*}$ & 491.8 & 527.6 & 491.8 & 481.3 & RSL & 290.2 \\
\hline Ref. 18 & 231.0 & 231.0 & 185.0 & 249.8 & 259.8 & 272.9 & 272.9 & 272.9 & $181.6^{*}$ & $199.3^{*}$ & $161.4^{*}$ & $180.8^{*}$ & 246.5 & 280.5 & 246.5 & 239.6 & RSL & 197.7 \\
\hline Ref. 19 & 231.0 & 231.0 & 185.0 & 249.8 & 259.8 & 272.9 & 272.9 & 272.9 & 181.6* & 199.3* & $161.4^{*}$ & $180.8^{*}$ & 246.5 & 280.5 & 246.5 & 239.6 & RSL & 187.6 \\
\hline Ref. 20 & 231.0 & 231.0 & 185.0 & 249.8 & 259.8 & 272.9 & 272.9 & 272.9 & $181.6^{*}$ & 199.3* & $161.4^{*}$ & $180.8^{*}$ & 246.5 & 280.5 & 246.5 & 239.6 & RSL & 198.8 \\
\hline Ref. 21 & $173.2^{*}$ & $173.2^{*}$ & $138.7^{*}$ & 187.4 & 195.4 & 205.2 & 205.2 & 205.2 & 181.6 & 199.3 & 149.4 & $174.6^{*}$ & 225.0 & 249.2 & 225.0 & 219.8 & RSL & 167.9 \\
\hline Ref. 22 & $173.2^{*}$ & $173.2^{*}$ & $138.7^{*}$ & 187.4 & 195.4 & 205.2 & 205.2 & 205.2 & 181.6 & 199.3 & 149.4 & $174.6^{*}$ & 225.0 & 249.2 & 225.0 & 219.8 & RSL & 171.9 \\
\hline Ref. 23 & $173.2^{*}$ & $173.2^{*}$ & $138.7^{*}$ & 187.4 & 195.4 & 205.2 & 205.2 & 205.2 & 181.6 & 199.3 & 149.4 & $174.6^{*}$ & 225.0 & 249.2 & 225.0 & 219.8 & RSL & 166.3 \\
\hline
\end{tabular}

Fonte: $\mathrm{o}$ autor. 
Tabela 15 - Resultados experimentais dos ensaios realizados no LE-EESC-USP em outubro de 2015 com chapas planas em composição simples

\begin{tabular}{|c|c|c|c|c|c|c|c|c|c|c|c|c|c|c|c|c|c|c|}
\hline \multirow{3}{*}{$\begin{array}{c}\text { Ensaio } \\
\text { Ref. }\end{array}$} & \multicolumn{16}{|c|}{ Força máxima resistente por equação de norma $(\mathrm{kN})$} & \multicolumn{2}{|c|}{ Ruptura } \\
\hline & \multicolumn{4}{|c|}{ Esmagamento - ESM } & \multicolumn{4}{|c|}{ Rasgamento - RAS } & \multicolumn{4}{|c|}{ Ruptura da seção líquida - RSL } & \multicolumn{4}{|c|}{ Block shear - BLS } & \multirow{2}{*}{$\begin{array}{l}\text { Modo } \\
\text { de falha }\end{array}$} & \multirow{2}{*}{$\begin{array}{l}\text { Força } \\
(\mathrm{kN})\end{array}$} \\
\hline & AISI & AS/NZS & NBR & EN & AISI & AS/NZS & NBR & EN & AISI & AS/NZS & NBR & EN & AISI & AS/NZS & NBR & EN & & \\
\hline Ref. 1 & 288.7 & 288.7 & 231.2 & 312.3 & 325.7 & 342.0 & 342.0 & 342.0 & 165.9* & $180.5^{*}$ & $147.3^{*}$ & 160.9* & 206.2 & 230.4 & 206.2 & 201.0 & RSL & 198.8 \\
\hline Ref. 2 & 288.7 & 288.7 & 231.2 & 312.3 & 325.7 & 342.0 & 342.0 & 342.0 & $165.9 *$ & $180.5^{*}$ & $147.3^{*}$ & $160.9 *$ & 206.2 & 230.4 & 206.2 & 201.0 & RSL & 199.1 \\
\hline Ref. 3 & 288.7 & 288.7 & 231.2 & 312.3 & 325.7 & 342.0 & 342.0 & 342.0 & $165.9 *$ & $180.5^{*}$ & $147.3^{*}$ & $160.9 *$ & 206.2 & 230.4 & 206.2 & 201.0 & RSL & 198.2 \\
\hline Ref. 4 & 465.6 & 465.6 & 416.5 & 675.9 & 525.2 & 551.5 & 551.5 & 551.5 & $267.5^{*}$ & $291.1 *$ & $237.6^{*}$ & $259.5^{*}$ & 332.5 & 368.3 & 332.5 & 322.0 & RSL & 313.2 \\
\hline Ref. 5 & 465.6 & 465.6 & 416.5 & 675.9 & 525.2 & 551.5 & 551.5 & 551.5 & $267.5^{*}$ & $291.1^{*}$ & $237.6^{*}$ & $259.5^{*}$ & 332.5 & 368.3 & 332.5 & 322.0 & RSL & 317.2 \\
\hline Ref. 6 & 192.5 & 192.5 & 154.2 & 208.2 & 218.4 & 229.1 & 229.1 & 229.1 & $165.9 *$ & $180.5^{*}$ & $130.0^{*}$ & 151.1* & 184.7 & 199.1 & 184.7 & 181.3 & RSL & 192.5 \\
\hline Ref. 7 & 192.5 & 192.5 & 154.2 & 208.2 & 218.4 & 229.1 & 229.1 & 229.1 & 165.9* & $180.5^{*}$ & $130.0^{*}$ & 151.1* & 184.7 & 199.1 & 184.7 & 181.3 & RSL & 192.1 \\
\hline Ref. 8 & 192.5 & 192.5 & 154.2 & 208.2 & 218.4 & 229.1 & 229.1 & 229.1 & 165.9* & $180.5^{*}$ & $130.0 *$ & $151.1^{*}$ & 184.7 & 199.1 & 184.7 & 181.3 & RSL & 194.5 \\
\hline Ref. 9 & 310.4 & 310.4 & 277.6 & 450.6 & 352.2 & 369.4 & 369.4 & 369.4 & $267.5^{*}$ & $291.1^{*}$ & 209.6* & $243.7^{*}$ & 297.9 & 318.9 & 297.9 & 290.9 & RSL & 309.7 \\
\hline
\end{tabular}

Fonte: o autor.

Tabela 16 - Resultados experimentais dos ensaios realizados no LE-EESC-USP em outubro de 2015 com chapas onduladas em composição dupla

\begin{tabular}{|c|c|c|c|c|c|c|c|c|c|c|c|c|c|c|c|c|c|c|}
\hline \multirow{3}{*}{$\begin{array}{l}\text { Ensaio } \\
\text { Ref. }\end{array}$} & \multicolumn{16}{|c|}{ Força máxima resistente por equação de norma $(\mathrm{kN})$} & \multicolumn{2}{|c|}{ Ruptura } \\
\hline & \multicolumn{4}{|c|}{ Esmagamento - ESM } & \multicolumn{4}{|c|}{ Rasgamento - RAS } & \multicolumn{4}{|c|}{ Ruptura da seção líquida - RSL } & \multicolumn{4}{|c|}{ Block shear - BLS } & \multirow{2}{*}{$\begin{array}{c}\text { Modo } \\
\text { de falha }\end{array}$} & \multirow{2}{*}{$\begin{array}{c}\text { Força } \\
(\mathrm{kN})\end{array}$} \\
\hline & AISI & AS/NZS & NBR & EN & AISI & AS/NZS & NBR & EN & AISI & AS/NZS & NBR & EN & AISI & AS/NZS & NBR & EN & & \\
\hline Ref. 1 & 1117.5 & 1117.5 & 1239.1 & 2141.7 & 926.3 & 1061.7 & 1061.7 & 1061.7 & $499.0^{*}$ & $540.8^{*}$ & $457.2^{*}$ & $502.9 *$ & 607.1 & 703.5 & 607.1 & 588.6 & RSL & 591.8 \\
\hline Ref. 2 & 1117.5 & 1117.5 & 1239.1 & 2141.7 & 926.3 & 1061.7 & 1061.7 & 1061.7 & 499.0* & $540.8^{*}$ & $457.2^{*}$ & $502.9 *$ & 607.1 & 703.5 & 607.1 & 588.6 & RSL & 558.5 \\
\hline
\end{tabular}

Fonte: o autor. 
Tabela 17 - Resultados experimentais dos ensaios realizados no LE-EESC-USP em junho de 2017

\begin{tabular}{|c|c|c|c|c|c|c|c|c|c|c|c|c|c|c|c|c|c|c|}
\hline \multirow{3}{*}{$\begin{array}{c}\text { Ensaio } \\
\text { Ref. }\end{array}$} & \multicolumn{16}{|c|}{ Força máxima resistente por equação de norma $(\mathrm{kN})$} & \multicolumn{2}{|c|}{ Ruptura } \\
\hline & \multicolumn{4}{|c|}{ Esmagamento - ESM } & \multicolumn{4}{|c|}{ Rasgamento - RAS } & \multicolumn{4}{|c|}{ Ruptura da seção líquida - RSL } & \multicolumn{4}{|c|}{ Block shear - BLS } & \multirow{2}{*}{$\begin{array}{l}\text { Modo } \\
\text { de falha }\end{array}$} & \multirow{2}{*}{$\begin{array}{c}\text { Força } \\
(\mathrm{kN})\end{array}$} \\
\hline & AISI & AS/NZS & NBR & EN & AISI & AS/NZS & NBR & EN & AISI & AS/NZS & NBR & EN & AISI & AS/NZS & NBR & EN & & \\
\hline Ref. 1 & 527.7 & 527.7 & 486.4 & 823 & 595.3 & 625.0 & 625.0 & 625.0 & $303.1^{*}$ & $329.9 *$ & $269.2^{*}$ & $294.1^{*}$ & 376.9 & 402.8 & 376.9 & 355.1 & RSL & 349.3 \\
\hline Ref. 2 & 527.7 & 527.7 & 486.4 & 823 & 595.3 & 625.0 & 625.0 & 625.0 & $303.1^{*}$ & $329.9 *$ & $269.2^{*}$ & $294.1^{*}$ & 376.9 & 402.8 & 376.9 & 355.1 & RSL & 351.0 \\
\hline Ref. 3 & 351.8 & 351.8 & 324.3 & 548.7 & 399.2 & 418.6 & 418.6 & 418.6 & $303.1^{*}$ & $329.9 *$ & $237.5^{*}$ & $276.2^{*}$ & 337.6 & 351.9 & 337.6 & 323.1 & RSL & 336.6 \\
\hline Ref. 4 & 633.2 & 633.2 & 583.7 & 823 & 524.9 & 601.6 & 601.6 & 601.6 & $282.7^{*}$ & $306.5^{*}$ & $259.0^{*}$ & $284.9 *$ & 344 & 384 & 344 & 324.9 & RSL & 351.0 \\
\hline Ref. 5 & 633.2 & 633.2 & 583.7 & 823 & 524.9 & 601.6 & 601.6 & 601.6 & $282.7^{*}$ & $306.5^{*}$ & $259.0^{*}$ & $284.9 *$ & 344 & 384 & 344 & 324.9 & RSL & 340.5 \\
\hline Ref. 6 & 633.2 & 633.2 & 583.7 & 823 & 524.9 & 601.6 & 601.6 & 601.6 & $282.7^{*}$ & $306.5^{*}$ & 259.0* & $284.9 *$ & 344 & 384 & 344 & 324.9 & RSL & 334.0 \\
\hline Ref. 7 & 633.2 & 633.2 & 583.7 & 823 & 524.9 & 601.6 & 601.6 & 601.6 & $282.7 *$ & $306.5^{*}$ & 259.0* & $284.9 *$ & 344 & 384 & 344 & 324.9 & RSL & 330.9 \\
\hline Ref. 8 & 422.2 & 422.2 & 389.1 & 548.7 & 357.0 & 406.9 & 406.9 & 406.9 & $282.7^{*}$ & $306.5^{*}$ & $234.1^{*}$ & $274.2 *$ & 310.4 & 333.2 & 310.4 & 297.4 & RSL & 323.1 \\
\hline Ref. 9 & 422.2 & 422.2 & 389.1 & 548.7 & 357.0 & 406.9 & 406.9 & 406.9 & $282.7 *$ & $306.5^{*}$ & $234.1^{*}$ & $274.2^{*}$ & 310.4 & 333.2 & 310.4 & 297.4 & RSL & 323.9 \\
\hline Ref. 10 & 422.2 & 422.2 & 389.1 & 548.7 & 357.0 & 406.9 & 406.9 & 406.9 & $282.7^{*}$ & $306.5^{*}$ & $234.1^{*}$ & $274.2^{*}$ & 310.4 & 333.2 & 310.4 & 297.4 & RSL & 320.6 \\
\hline Ref. 11 & 422.2 & 422.2 & 389.1 & 548.7 & 357.0 & 406.9 & 406.9 & 406.9 & $282.7 *$ & $306.5^{*}$ & $234.1^{*}$ & $274.2 *$ & 310.4 & 333.2 & 310.4 & 297.4 & RSL & 322.1 \\
\hline Ref. 12 & 791.8 & 791.8 & 781.3 & 1198.9 & 656.3 & 752.2 & 752.2 & 752.2 & $353.5^{*}$ & $383.2^{*}$ & $323.9 *$ & $356.3^{*}$ & 430.1 & 472.3 & 430.1 & 401.6 & RSL & 432.3 \\
\hline Ref. 13 & 791.8 & 791.8 & 781.3 & 1198.9 & 656.3 & 752.2 & 752.2 & 752.2 & $353.5^{*}$ & $383.2 *$ & $323.9 *$ & $356.3^{*}$ & 430.1 & 472.3 & 430.1 & 401.6 & RSL & 430.1 \\
\hline Ref. 14 & 791.8 & 791.8 & 781.3 & 1198.9 & 656.3 & 752.2 & 752.2 & 752.2 & $353.5^{*}$ & $383.2^{*}$ & $323.9 *$ & $356.3^{*}$ & 430.1 & 472.3 & 430.1 & 401.6 & RSL & 428.7 \\
\hline Ref. 15 & 791.8 & 791.8 & 781.3 & 1198.9 & 656.3 & 752.2 & 752.2 & 752.2 & $353.5^{*}$ & $383.2^{*}$ & $323.9 *$ & $356.3^{*}$ & 430.1 & 472.3 & 430.1 & 401.6 & RSL & 428.7 \\
\hline Ref. 16 & 527.9 & 527.9 & 520.9 & 799.3 & 446.3 & 508.8 & 508.8 & 508.8 & $353.5^{*}$ & $383.2^{*}$ & $292.8^{*}$ & $342.8^{*}$ & 388.2 & 411.5 & 388.2 & 368.7 & RSL & 423.6 \\
\hline Ref. 17 & 527.9 & 527.9 & 520.9 & 799.3 & 446.3 & 508.8 & 508.8 & 508.8 & $353.5^{*}$ & $383.2 *$ & $292.8^{*}$ & $342.8^{*}$ & 388.2 & 411.5 & 388.2 & 368.7 & RSL & 419.0 \\
\hline Ref. 18 & 527.9 & 527.9 & 520.9 & 799.3 & 446.3 & 508.8 & 508.8 & 508.8 & $353.5^{*}$ & $383.2^{*}$ & $292.8^{*}$ & $342.8^{*}$ & 388.2 & 411.5 & 388.2 & 368.7 & RSL & 425.0 \\
\hline Ref. 19 & 527.9 & 527.9 & 520.9 & 799.3 & 446.3 & 508.8 & 508.8 & 508.8 & $353.5^{*}$ & $383.2^{*}$ & $292.8^{*}$ & $342.8^{*}$ & 388.2 & 411.5 & 388.2 & 368.7 & RSL & 421.7 \\
\hline
\end{tabular}

Fonte: $\mathrm{o}$ autor. 


\section{APÊNDICE C - Resultados teóricos e experimentais}

Tabela 18 - Falha por ruptura da seção líquida nos ensaios de (ESTEVES JR, 1990)

\begin{tabular}{|c|c|c|c|c|c|c|c|c|c|}
\hline \multirow{2}{*}{\multicolumn{2}{|c|}{$\begin{array}{c}\text { Resultados } \\
\text { Experimentais }\end{array}$}} & \multicolumn{8}{|c|}{ Resultados Teóricos } \\
\hline & & \multicolumn{2}{|c|}{ AISI S100-16 } & \multicolumn{2}{|c|}{$A S N Z S$ 4600: 2005} & \multicolumn{2}{|c|}{$N B R$ 14762: 2010} & \multicolumn{2}{|c|}{ EN $199313: 2006$} \\
\hline Ref. & $\frac{F_{u l t}}{A_{n} \cdot f_{u}}$ & $\begin{array}{l}\text { Modo de } \\
\text { falha }\end{array}$ & $\frac{F_{u l t}}{A_{n} \cdot f_{u}}$ & $\begin{array}{l}\text { Modo de } \\
\text { falha }\end{array}$ & $\frac{F_{u l t}}{A_{n} \cdot f_{u}}$ & $\begin{array}{l}\text { Modo de } \\
\text { falha }\end{array}$ & $\frac{F_{u l t}}{A_{n} \cdot f_{u}}$ & $\begin{array}{l}\text { Modo de } \\
\text { falha }\end{array}$ & $\frac{F_{u l t}}{A_{n} \cdot f_{u}}$ \\
\hline Ref. 21 & 1.07 & RSL & 0.92 & RSL & 1.00 & ESM & na & RSL & 0.8 \\
\hline Ref. 22 & 1.00 & RSL & 0.92 & RSL & 1.00 & ESM & na & RSL & 0.83 \\
\hline Ref. 23 & 1.03 & RSL & 0.92 & RSL & 1.00 & ESM & na & RSL & 0.78 \\
\hline Ref. 24 & 1.05 & RSL & 0.92 & RSL & 1.00 & ESM & na & RSL & 0.8 \\
\hline Ref. 25 & 1.05 & RSL & 0.92 & RSL & 1.00 & RSL & 0.69 & RSL & 0.81 \\
\hline Ref. 26 & 1.05 & RSL & 0.92 & RSL & 1.00 & ESM & na & RSL & 0.78 \\
\hline Ref. 27 & 1.02 & RSL & 0.92 & RSL & 1.00 & RSL & 0.68 & RSL & 0.78 \\
\hline Ref. 28 & 1.03 & RSL & 0.91 & RSL & 1.00 & ESM & na & RSL & 0.78 \\
\hline Ref. 29 & 1.04 & RSL & 0.92 & RSL & 1.00 & RSL & 0.69 & RSL & 0.79 \\
\hline Ref. 30 & 1.04 & RSL & 0.92 & RSL & 1.00 & RSL & 0.69 & RSL & 0.80 \\
\hline Ref. 31 & 1.06 & RSL & 0.92 & RSL & 1.00 & RSL & 0.74 & RSL & 0.87 \\
\hline Ref. 32 & 1.04 & RSL & 0.92 & RSL & 1.00 & RSL & 0.71 & RSL & 0.84 \\
\hline Ref. 33 & 1.04 & RSL & 0.92 & RSL & 1.00 & RSL & 0.71 & RSL & 0.84 \\
\hline Ref. 34 & 1.04 & RSL & 0.92 & RSL & 1.00 & RSL & 0.74 & RSL & 0.84 \\
\hline Ref. 35 & 1.05 & RSL & 0.92 & RSL & 1.00 & RSL & 0.70 & RSL & 0.84 \\
\hline Ref. 36 & 1.05 & RSL & 0.92 & RSL & 1.00 & RSL & 0.72 & RSL & 0.84 \\
\hline Ref. 37 & 0.94 & RSL & 0.92 & RSL & 1.00 & RSL & 0.74 & RSL & 0.87 \\
\hline Ref. 38 & 0.98 & RSL & 0.92 & RSL & 1.00 & RSL & 0.74 & RSL & 0.84 \\
\hline Ref. 39 & 1.04 & RSL & 0.92 & RSL & 1.00 & RSL & 0.74 & RSL & 0.85 \\
\hline Ref. 40 & 1.04 & RSL & 0.92 & RSL & 1.00 & RSL & 0.74 & RSL & 0.86 \\
\hline
\end{tabular}

Fonte: o autor. 
Tabela 18 - Continuação

\begin{tabular}{|c|c|c|c|c|c|c|c|c|c|}
\hline \multirow{2}{*}{\multicolumn{2}{|c|}{$\begin{array}{c}\text { Resultados } \\
\text { Experimentais }\end{array}$}} & \multicolumn{8}{|c|}{ Resultados Teóricos } \\
\hline & & \multicolumn{2}{|c|}{ AISI S100 - 16} & \multicolumn{2}{|c|}{$A S N Z S$ 4600: 2005} & \multicolumn{2}{|c|}{ NBR 14762: 2010} & \multicolumn{2}{|c|}{ EN $199313: 2006$} \\
\hline Ref. & $\frac{F_{u l t}}{A_{n} \cdot f_{u}}$ & $\begin{array}{c}\text { Modo de } \\
\text { falha }\end{array}$ & $\frac{F_{u l t}}{A_{n} \cdot f_{u}}$ & $\begin{array}{l}\text { Modo de } \\
\text { falha }\end{array}$ & $\frac{F_{u l t}}{A_{n} \cdot f_{u}}$ & $\begin{array}{l}\text { Modo de } \\
\text { falha }\end{array}$ & $\frac{F_{u l t}}{A_{n} \cdot f_{u}}$ & $\begin{array}{l}\text { Modo de } \\
\text { falha }\end{array}$ & $\frac{F_{u l t}}{A_{n} \cdot f_{u}}$ \\
\hline Ref. 41 & 1.05 & RSL & 0.91 & RSL & 1.00 & RSL & 0.77 & RSL & 0.85 \\
\hline Ref. 42 & 1.05 & RSL & 0.91 & RSL & 1.00 & RSL & 0.78 & RSL & 0.85 \\
\hline Ref. 43 & 1.04 & RSL & 0.91 & RSL & 1.00 & RSL & 0.78 & RSL & 0.85 \\
\hline Ref. 44 & 1.04 & RSL & 0.91 & RSL & 1.00 & RSL & 0.78 & RSL & 0.85 \\
\hline Ref. 45 & 1.05 & RSL & 0.91 & RSL & 1.00 & RSL & 0.78 & RSL & 0.85 \\
\hline Ref. 46 & 1.05 & RSL & 0.91 & RSL & 1.00 & RSL & 0.78 & RSL & 0.85 \\
\hline Ref. 47 & 1.03 & RSL & 0.91 & RSL & 1.00 & RSL & 0.78 & RSL & 0.85 \\
\hline Ref. 48 & 1.03 & RSL & 0.91 & RSL & 1.00 & RSL & 0.78 & RSL & 0.85 \\
\hline Ref. 49 & 1.05 & RSL & 0.91 & RSL & 1.00 & RSL & 0.79 & RSL & 0.85 \\
\hline Ref. 50 & 1.04 & RSL & 0.91 & RSL & 1.00 & RSL & 0.78 & RSL & 0.85 \\
\hline Ref. 51 & 1.07 & RSL & 0.92 & RSL & 1.00 & RSL & 0.82 & RSL & 0.89 \\
\hline Ref. 52 & 1.06 & RSL & 0.92 & RSL & 1.00 & RSL & 0.81 & RSL & 0.89 \\
\hline Ref. 53 & 1.04 & RSL & 0.92 & RSL & 1.00 & RSL & 0.81 & RSL & 0.89 \\
\hline Ref. 54 & 1.04 & RSL & 0.92 & RSL & 1.00 & RSL & 0.83 & RSL & 0.89 \\
\hline Ref. 55 & 1.05 & RSL & 0.92 & RSL & 1.00 & RSL & 0.82 & RSL & 0.89 \\
\hline Ref. 56 & 1.03 & RSL & 0.92 & RSL & 1.00 & RSL & 0.81 & RSL & 0.89 \\
\hline Ref. 57 & 1.03 & RSL & 0.92 & RSL & 1.00 & RSL & 0.83 & RSL & 0.91 \\
\hline Ref. 58 & 1.03 & RSL & 0.92 & RSL & 1.00 & RSL & 0.83 & RSL & 0.89 \\
\hline Ref. 59 & 1.03 & RSL & 0.92 & RSL & 1.00 & RSL & 0.83 & RSL & 0.90 \\
\hline Ref. 60 & 1.07 & RSL & 0.92 & RSL & 1.00 & RSL & 0.83 & RSL & 0.91 \\
\hline
\end{tabular}

Fonte: o autor. 
Tabela 19 - Falha por ruptura da seção líquida nos ensaios realizados no LE-EESC-USP em maio de 2015

\begin{tabular}{|c|c|c|c|c|c|c|c|c|c|}
\hline \multirow{2}{*}{\multicolumn{2}{|c|}{$\begin{array}{c}\text { Resultados } \\
\text { Experimentais }\end{array}$}} & \multicolumn{8}{|c|}{ Resultados Teóricos } \\
\hline & & \multicolumn{2}{|c|}{ AISI $S 100-16$} & \multicolumn{2}{|c|}{ AS NZS 4600: 2005} & \multicolumn{2}{|c|}{ NBR 14762: 2010} & \multicolumn{2}{|c|}{ EN $199313: 2006$} \\
\hline Ref. & $\frac{F_{u l t}}{A_{n} \cdot f_{u}}$ & $\begin{array}{c}\text { Modo de } \\
\text { falha }\end{array}$ & $\frac{F_{u l t}}{A_{n} \cdot f_{u}}$ & $\begin{array}{l}\text { Modo de } \\
\text { falha }\end{array}$ & $\frac{F_{u l t}}{A_{n} \cdot f_{u}}$ & $\begin{array}{l}\text { Modo de } \\
\text { falha }\end{array}$ & $\frac{F_{u l t}}{A_{n} \cdot f_{u}}$ & $\begin{array}{c}\text { Modo de } \\
\text { falha }\end{array}$ & $\frac{F_{u l t}}{A_{n} \cdot f_{u}}$ \\
\hline Ref. 4 & 0.97 & RSL & 0.92 & RSL & 1.00 & RSL & 0.82 & RSL & 0.89 \\
\hline Ref. 5 & 0.99 & RSL & 0.92 & RSL & 1.00 & RSL & 0.82 & RSL & 0.89 \\
\hline Ref. 6 & 0.98 & RSL & 0.92 & RSL & 1.00 & RSL & 0.82 & RSL & 0.89 \\
\hline Ref. 7 & 0.92 & RSL & 0.92 & RSL & 1.00 & RSL & 0.72 & RSL & 0.84 \\
\hline Ref. 8 & 0.93 & RSL & 0.92 & RSL & 1.00 & RSL & 0.72 & RSL & 0.84 \\
\hline Ref. 9 & 0.92 & RSL & 0.92 & RSL & 1.00 & RSL & 0.72 & RSL & 0.84 \\
\hline Ref. 10 & 0.96 & RSL & 0.92 & RSL & 1.00 & RSL & 0.82 & RSL & 0.89 \\
\hline Ref. 11 & 0.95 & RSL & 0.92 & RSL & 1.00 & RSL & 0.82 & RSL & 0.89 \\
\hline Ref. 12 & 0.94 & RSL & 0.92 & RSL & 1.00 & RSL & 0.82 & RSL & 0.89 \\
\hline Ref. 13 & 0.95 & RSL & 0.92 & RSL & 1.00 & RSL & 0.72 & RSL & 0.84 \\
\hline Ref. 14 & 0.94 & RSL & 0.92 & RSL & 1.00 & RSL & 0.72 & RSL & 0.84 \\
\hline Ref. 15 & 0.94 & RSL & 0.92 & RSL & 1.00 & RSL & 0.72 & RSL & 0.84 \\
\hline Ref. 16 & 0.92 & RSL & 0.92 & RSL & 1.00 & RSL & 0.82 & RSL & 0.89 \\
\hline Ref. 17 & 0.96 & RSL & 0.92 & RSL & 1.00 & RSL & 0.82 & RSL & 0.89 \\
\hline Ref. 18 & 0.96 & RSL & 0.92 & RSL & 1.00 & RSL & 0.82 & RSL & 0.89 \\
\hline Ref. 19 & 0.96 & RSL & 0.92 & RSL & 1.00 & RSL & 0.72 & RSL & 0.84 \\
\hline Ref. 20 & 0.97 & RSL & 0.92 & RSL & 1.00 & RSL & 0.72 & RSL & 0.84 \\
\hline Ref. 21 & 0.95 & RSL & 0.92 & RSL & 1.00 & RSL & 0.72 & RSL & 0.84 \\
\hline Ref. 22 & 0.99 & RSL & 0.92 & RSL & 1.00 & RSL & 0.82 & RSL & 0.89 \\
\hline Ref. 23 & 0.98 & RSL & 0.92 & RSL & 1.00 & RSL & 0.82 & RSL & 0.89 \\
\hline Ref. 24 & 0.99 & RSL & 0.92 & RSL & 1.00 & RSL & 0.82 & RSL & 0.89 \\
\hline
\end{tabular}

Fonte: o autor. 
Tabela 20 - Falha por ruptura da seção líquida nos ensaios realizados no LE-EESC-USP em outubro de 2015 com chapa onduladas em composição simples

\begin{tabular}{|c|c|c|c|c|c|c|c|c|c|}
\hline \multirow{2}{*}{\multicolumn{2}{|c|}{$\begin{array}{c}\text { Resultados } \\
\text { Experimentais }\end{array}$}} & \multicolumn{8}{|c|}{ Resultados Teóricos } \\
\hline & & \multicolumn{2}{|c|}{ AISI $S 100-16$} & \multicolumn{2}{|c|}{ AS NZS 4600: 2005} & \multicolumn{2}{|c|}{ NBR 14762: 2010} & \multicolumn{2}{|c|}{ EN $199313: 2006$} \\
\hline Ref. & $\frac{F_{u l t}}{A_{n} \cdot f_{u}}$ & $\begin{array}{c}\text { Modo de } \\
\text { falha }\end{array}$ & $\frac{F_{u l t}}{A_{n} \cdot f_{u}}$ & $\begin{array}{c}\text { Modo de } \\
\text { falha }\end{array}$ & $\frac{F_{u l t}}{A_{n} \cdot f_{u}}$ & $\begin{array}{c}\text { Modo de } \\
\text { falha }\end{array}$ & $\frac{F_{u l t}}{A_{n} \cdot f_{u}}$ & $\begin{array}{c}\text { Modo de } \\
\text { falha }\end{array}$ & $\frac{F_{u l t}}{A_{n} \cdot f_{u}}$ \\
\hline Ref. 1 & 1.08 & RSL & 0.92 & RSL & 1.00 & RSL & 0.82 & RSL & 0.89 \\
\hline Ref. 2 & 1.06 & RSL & 0.92 & RSL & 1.00 & RSL & 0.82 & RSL & 0.89 \\
\hline Ref. 3 & 1.07 & RSL & 0.92 & RSL & 1.00 & RSL & 0.72 & RSL & 0.84 \\
\hline Ref. 4 & 1.05 & RSL & 0.92 & RSL & 1.00 & RSL & 0.72 & RSL & 0.84 \\
\hline Ref. 5 & 1.08 & RSL & 0.92 & RSL & 1.00 & RSL & 0.72 & RSL & 0.84 \\
\hline Ref. 6 & 1.07 & RSL & 0.92 & RSL & 1.00 & RSL & 0.72 & RSL & 0.84 \\
\hline Ref. 7 & 1.03 & RSL & 0.92 & RSL & 1.00 & RSL & 0.81 & RSL & 0.91 \\
\hline Ref. 8 & 1.03 & RSL & 0.92 & RSL & 1.00 & RSL & 0.81 & RSL & 0.91 \\
\hline Ref. 9 & 1.01 & RSL & 0.92 & RSL & 1.00 & RSL & 0.81 & RSL & 0.91 \\
\hline Ref. 10 & 1.00 & RSL & 0.92 & RSL & 1.00 & RSL & 0.81 & RSL & 0.91 \\
\hline Ref. 11 & 0.92 & RSL & 0.92 & RSL & 1.00 & RSL & 0.81 & RSL & 0.91 \\
\hline Ref. 12 & 0.95 & RSL & 0.92 & RSL & 1.00 & RSL & 0.75 & RSL & 0.88 \\
\hline Ref. 13 & 0.97 & RSL & 0.92 & RSL & 1.00 & RSL & 0.75 & RSL & 0.88 \\
\hline Ref. 14 & 0.96 & RSL & 0.92 & RSL & 1.00 & RSL & 0.75 & RSL & 0.88 \\
\hline Ref. 15 & 0.98 & RSL & 0.92 & RSL & 1.00 & RSL & 0.75 & RSL & 0.88 \\
\hline Ref. 16 & 0.98 & RSL & 0.92 & RSL & 1.00 & RSL & 0.75 & RSL & 0.88 \\
\hline Ref. 17 & 0.95 & RSL & 0.92 & RSL & 1.00 & RSL & 0.75 & RSL & 0.88 \\
\hline Ref. 18 & 0.99 & RSL & 0.91 & RSL & 1.00 & RSL & 0.81 & RSL & 0.91 \\
\hline Ref. 19 & 0.94 & RSL & 0.91 & RSL & 1.00 & RSL & 0.81 & RSL & 0.91 \\
\hline Ref. 20 & 1.00 & RSL & 0.91 & RSL & 1.00 & RSL & 0.81 & RSL & 0.91 \\
\hline Ref. 21 & 0.84 & ESM & na & ESM & na & ESM & na & RSL & 0.88 \\
\hline Ref. 22 & 0.86 & ESM & na & ESM & na & ESM & na & RSL & 0.88 \\
\hline Ref. 23 & 0.83 & ESM & na & ESM & na & ESM & na & RSL & 0.88 \\
\hline
\end{tabular}

Fonte: o autor. 
Tabela 21 - Falha por ruptura da seção líquida nos ensaios realizados no LE-EESC-USP em outubro de 2015 com chapa planas em composição simples

\begin{tabular}{|c|c|c|c|c|c|c|c|c|c|}
\hline \multirow{2}{*}{\multicolumn{2}{|c|}{$\begin{array}{c}\text { Resultados } \\
\text { Experimentais }\end{array}$}} & \multicolumn{8}{|c|}{ Resultados Teóricos } \\
\hline & & \multicolumn{2}{|c|}{ AISI S100-16 } & \multicolumn{2}{|c|}{ AS NZS 4600: 2005} & \multicolumn{2}{|c|}{ NBR 14762: 2010} & \multicolumn{2}{|c|}{ EN $199313: 2006$} \\
\hline Ref. & $\frac{F_{u l t}}{A_{n} \cdot f_{u}}$ & $\begin{array}{l}\text { Modo de } \\
\text { falha }\end{array}$ & $\frac{F_{u l t}}{A_{n} \cdot f_{u}}$ & $\begin{array}{l}\text { Modo de } \\
\text { falha }\end{array}$ & $\frac{F_{u l t}}{A_{n} \cdot f_{u}}$ & $\begin{array}{l}\text { Modo de } \\
\text { falha }\end{array}$ & $\frac{F_{u l t}}{A_{n} \cdot f_{u}}$ & $\begin{array}{l}\text { Modo de } \\
\text { falha }\end{array}$ & $\frac{F_{u l t}}{A_{n} \cdot f_{u}}$ \\
\hline Ref. 1 & 1.10 & RSL & 0.92 & RSL & 1.00 & RSL & 0.82 & RSL & 0.89 \\
\hline Ref. 2 & 1.10 & RSL & 0.92 & RSL & 1.00 & RSL & 0.82 & RSL & 0.89 \\
\hline Ref. 3 & 1.10 & RSL & 0.92 & RSL & 1.00 & RSL & 0.82 & RSL & 0.89 \\
\hline Ref. 4 & 1.08 & RSL & 0.92 & RSL & 1.00 & RSL & 0.82 & RSL & 0.89 \\
\hline Ref. 5 & 1.09 & RSL & 0.92 & RSL & 1.00 & RSL & 0.82 & RSL & 0.89 \\
\hline Ref. 6 & 1.07 & RSL & 0.92 & RSL & 1.00 & RSL & 0.72 & RSL & 0.84 \\
\hline Ref. 7 & 1.06 & RSL & 0.92 & RSL & 1.00 & RSL & 0.72 & RSL & 0.84 \\
\hline Ref. 8 & 1.08 & RSL & 0.92 & RSL & 1.00 & RSL & 0.72 & RSL & 0.84 \\
\hline Ref. 9 & 1.06 & RSL & 0.92 & RSL & 1.00 & RSL & 0.72 & RSL & 0.84 \\
\hline
\end{tabular}

Fonte: $\mathrm{o}$ autor.

Tabela 22 - Falha por ruptura da seção líquida nos ensaios realizados no LE-EESC-USP em outubro de 2015 com chapa onduladas em composição dupla

\begin{tabular}{|c|c|c|c|c|c|c|c|c|c|}
\hline \multirow{2}{*}{\multicolumn{2}{|c|}{$\begin{array}{c}\text { Resultados } \\
\text { Experimentais }\end{array}$}} & \multicolumn{8}{|c|}{ Resultados Teóricos } \\
\hline & & \multicolumn{2}{|c|}{ AISI $S 100-16$} & \multicolumn{2}{|c|}{ AS NZS 4600: 2005} & \multicolumn{2}{|c|}{ NBR 14762: 2010} & \multicolumn{2}{|c|}{ EN $199313: 2006$} \\
\hline Ref. & $\frac{F_{u l t}}{A_{n} \cdot f_{u}}$ & $\begin{array}{l}\text { Modo de } \\
\text { falha }\end{array}$ & $\frac{F_{u l t}}{A_{n} \cdot f_{u}}$ & $\begin{array}{l}\text { Modo de } \\
\text { falha }\end{array}$ & $\frac{F_{u l t}}{A_{n} \cdot f_{u}}$ & $\begin{array}{l}\text { Modo de } \\
\text { falha }\end{array}$ & $\frac{F_{u l t}}{A_{n} \cdot f_{u}}$ & $\begin{array}{l}\text { Modo de } \\
\text { falha }\end{array}$ & $\frac{F_{u l t}}{A_{n} \cdot f_{u}}$ \\
\hline Ref. 1 & 1.09 & RSL & 0.92 & RSL & 1.00 & RSL & 0.85 & RSL & 0.93 \\
\hline Ref. 2 & 1.03 & RSL & 0.92 & RSL & 1.00 & RSL & 0.85 & RSL & 0.93 \\
\hline
\end{tabular}

Fonte: o autor. 
Tabela 23 - Falha por ruptura da seção líquida nos ensaios realizados no LE-EESC-USP em junho de 2017

\begin{tabular}{|c|c|c|c|c|c|c|c|c|c|}
\hline \multirow{2}{*}{\multicolumn{2}{|c|}{$\begin{array}{c}\text { Resultados } \\
\text { Experimentais }\end{array}$}} & \multicolumn{8}{|c|}{ Resultados Teóricos } \\
\hline & & \multicolumn{2}{|c|}{ AISI S100 - 16} & \multicolumn{2}{|c|}{$A S N Z S$ 4600: 2005} & \multicolumn{2}{|c|}{ NBR 14762: 2010} & \multicolumn{2}{|c|}{ EN 19931 3: 2006} \\
\hline Ref. & $\frac{F_{u l t}}{A_{n} \cdot f_{u}}$ & $\begin{array}{l}\text { Modo de } \\
\text { falha }\end{array}$ & $\frac{F_{u l t}}{A_{n} \cdot f_{u}}$ & $\begin{array}{l}\text { Modo de } \\
\text { falha }\end{array}$ & $\frac{F_{u l t}}{A_{n} \cdot f_{u}}$ & $\begin{array}{c}\text { Modo de } \\
\text { falha }\end{array}$ & $\frac{F_{u l t}}{A_{n} \cdot f_{u}}$ & $\begin{array}{c}\text { Modo de } \\
\text { falha }\end{array}$ & $\frac{F_{u l t}}{A_{n} \cdot f_{u}}$ \\
\hline Ref. 1 & 1.06 & RSL & 0.92 & RSL & 1.00 & RSL & 0.82 & RSL & 0.89 \\
\hline Ref. 2 & 1.06 & RSL & 0.92 & RSL & 1.00 & RSL & 0.82 & RSL & 0.89 \\
\hline Ref. 3 & 1.02 & RSL & 0.92 & RSL & 1.00 & RSL & 0.72 & RSL & 0.84 \\
\hline Ref. 4 & 1.15 & RSL & 0.92 & RSL & 1.00 & RSL & 0.85 & RSL & 0.93 \\
\hline Ref. 5 & 1.11 & RSL & 0.92 & RSL & 1.00 & RSL & 0.85 & RSL & 0.93 \\
\hline Ref. 6 & 1.09 & RSL & 0.92 & RSL & 1.00 & RSL & 0.85 & RSL & 0.93 \\
\hline Ref. 7 & 1.08 & RSL & 0.92 & RSL & 1.00 & RSL & 0.85 & RSL & 0.93 \\
\hline Ref. 8 & 1.05 & RSL & 0.92 & RSL & 1.00 & RSL & 0.76 & RSL & 0.89 \\
\hline Ref. 9 & 1.06 & RSL & 0.92 & RSL & 1.00 & RSL & 0.76 & RSL & 0.89 \\
\hline Ref. 10 & 1.05 & RSL & 0.92 & RSL & 1.00 & RSL & 0.76 & RSL & 0.89 \\
\hline Ref. 11 & 1.05 & RSL & 0.92 & RSL & 1.00 & RSL & 0.76 & RSL & 0.89 \\
\hline Ref. 12 & 1.13 & RSL & 0.92 & RSL & 1.00 & RSL & 0.85 & RSL & 0.93 \\
\hline Ref. 13 & 1.12 & RSL & 0.92 & RSL & 1.00 & RSL & 0.85 & RSL & 0.93 \\
\hline Ref. 14 & 1.12 & RSL & 0.92 & RSL & 1.00 & RSL & 0.85 & RSL & 0.93 \\
\hline Ref. 15 & 1.12 & RSL & 0.92 & RSL & 1.00 & RSL & 0.85 & RSL & 0.93 \\
\hline Ref. 16 & 1.11 & RSL & 0.92 & RSL & 1.00 & RSL & 0.76 & RSL & 0.89 \\
\hline Ref. 17 & 1.09 & RSL & 0.92 & RSL & 1.00 & RSL & 0.76 & RSL & 0.89 \\
\hline Ref. 18 & 1.11 & RSL & 0.92 & RSL & 1.00 & RSL & 0.76 & RSL & 0.89 \\
\hline Ref. 19 & 1.10 & RSL & 0.92 & RSL & 1.00 & RSL & 0.76 & RSL & 0.89 \\
\hline
\end{tabular}

Fonte: $\mathrm{o}$ autor. 
Tabela 24 - Falha por esmagamento nos ensaios realizados por (ESTEVES JR, 1990)

\begin{tabular}{|c|c|c|c|c|c|c|c|c|}
\hline Ensaio & AISI S1 & -16 & $A S N Z S 4$ & 0: 2005 & NBR 147 & 2010 & EN 1993 & 3:2006 \\
\hline $\operatorname{Ref}$ & $\begin{array}{c}\text { Modo de } \\
\text { falha }\end{array}$ & $\frac{F_{t e o}}{F_{\text {exp }}}$ & $\begin{array}{c}\text { Modo de } \\
\text { falha }\end{array}$ & $\frac{F_{\text {teo }}}{F_{\text {exp }}}$ & $\begin{array}{c}\text { Modo de } \\
\text { falha }\end{array}$ & $\frac{F_{t e o}}{F_{\text {exp }}}$ & $\begin{array}{c}\text { Modo de } \\
\text { falha }\end{array}$ & $\frac{F_{\text {teo }}}{F_{\text {exp }}}$ \\
\hline Ref. 1 & ESM & 1.16 & ESM & 1.16 & ESM & 2.07 & ESM & 1.58 \\
\hline Ref. 2 & ESM & 1.10 & ESM & 1.10 & ESM & 1.96 & ESM & 1.50 \\
\hline Ref. 3 & ESM & 0.93 & ESM & 0.93 & ESM & 1.60 & ESM & 1.13 \\
\hline Ref. 4 & ESM & 1.11 & ESM & 1.11 & ESM & 1.92 & ESM & 1.36 \\
\hline Ref. 5 & ESM & 1.14 & ESM & 1.14 & ESM & 1.90 & ESM & 1.27 \\
\hline Ref. 6 & ESM & 1.13 & ESM & 1.13 & ESM & 1.89 & ESM & 1.26 \\
\hline Ref. 7 & ESM & 1.23 & ESM & 1.23 & ESM & 1.97 & ESM & 1.24 \\
\hline Ref. 8 & ESM & 1.21 & ESM & 1.21 & ESM & 1.95 & ESM & 1.22 \\
\hline Ref. 9 & ESM & 1.05 & ESM & 1.05 & ESM & 1.69 & ESM & 1.06 \\
\hline Ref. 10 & ESM & 0.99 & ESM & 0.99 & ESM & 1.59 & ESM & 1.00 \\
\hline Ref. 11 & ESM & 0.97 & ESM & 0.97 & ESM & 1.65 & ESM & 1.26 \\
\hline Ref. 12 & ESM & 1.04 & ESM & 1.04 & ESM & 1.78 & ESM & 1.36 \\
\hline Ref. 13 & RAS & na & ESM & 1.06 & ESM & 1.82 & ESM & 1.29 \\
\hline Ref. 14 & RAS & na & ESM & 1.04 & ESM & 1.79 & ESM & 1.27 \\
\hline Ref. 15 & RAS & na & ESM & 1.03 & ESM & 1.71 & ESM & 1.14 \\
\hline Ref. 16 & RAS & na & ESM & 1.04 & ESM & 1.74 & ESM & 1.16 \\
\hline Ref. 17 & RAS & na & ESM & 1.10 & ESM & 1.77 & RSL & na \\
\hline Ref. 18 & RAS & na & ESM & 1.02 & ESM & 1.65 & RSL & na \\
\hline Ref. 19 & RAS & na & ESM & 1.07 & ESM & 1.72 & $\mathrm{RSL}$ & na \\
\hline Ref. 20 & RAS & na & ESM & 1.01 & ESM & 1.62 & RSL & na \\
\hline
\end{tabular}

Fonte: o autor.

Tabela 25 - Falha por esmagamento nos ensaios realizados no LE-EESC-USP em maio de 2015

\begin{tabular}{|c|c|c|c|c|c|c|c|c|}
\hline Ensaio & \multicolumn{2}{|c|}{ AISI S100-16 } & \multicolumn{2}{|c|}{ AS NZS 4600: 2005} & \multicolumn{2}{|c|}{ NBR 14762: 2010} & \multicolumn{2}{|c|}{ EN $199313: 2006$} \\
\hline Ref. & $\begin{array}{c}\text { Modo de } \\
\text { falha }\end{array}$ & $\frac{F_{\text {teo }}}{F_{\text {exp }}}$ & $\begin{array}{c}\text { Modo de } \\
\text { falha }\end{array}$ & $\frac{F_{t e o}}{F_{\text {exp }}}$ & $\begin{array}{c}\text { Modo de } \\
\text { falha }\end{array}$ & $\frac{F_{\text {teo }}}{F_{\text {exp }}}$ & $\begin{array}{c}\text { Modo de } \\
\text { falha }\end{array}$ & $\frac{F_{t e o}}{F_{\text {exp }}}$ \\
\hline Ref. 1 & RSL & na & RSL & na & RSL & na & RSL & na \\
\hline Ref. 2 & RSL & na & RSL & na & RSL & na & RSL & na \\
\hline Ref. 3 & RSL & na & RSL & na & RSL & na & RSL & na \\
\hline
\end{tabular}

Fonte: o autor. 